


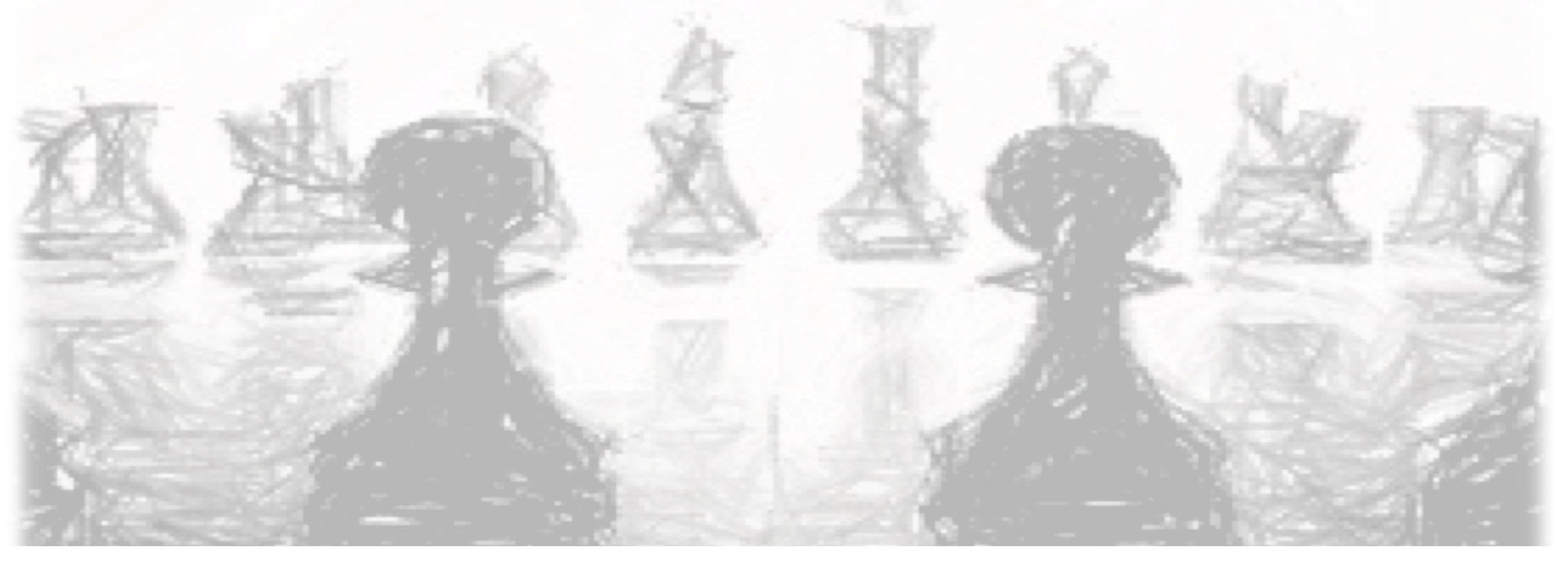




\section{Alliance Strategy}

Context, Process, and Requirements 
Dit proefschrift is goedgekeurd door de promotoren:

Prof. dr. P.C. van Fenema

Prof. dr. W.H.M. Zijm

Lay out: B.B.M. Keers

Cover design and printed by: Ministery of Defence

ISBN: 978-90-365-4458-0

DOI 10.3990/1.9789036544580

This research has been funded by TKI Dinalog, the Dutch Institute for Advanced Logistics.

(C) B.B.M. Keers, Den Helder, 2017

biancakeers@gmail.com

All rights reserved. Without limiting the rights under copyright reserved above, no part of this book may be reproduced, stored in or introduced into a retrieval system, or transmitted, in any form or by any means (electronic, mechanical or otherwise) without the written permission of both the copyright owner and the author of the book. 


\title{
Alliance Strategy Context, Process, and Requirements
}

\author{
PROEFSCHRIFT \\ ter verkrijging van de graad van doctor \\ aan de Universiteit Twente \\ op gezag van de Rector Magnificus \\ prof. dr. T.T.M. Palstra \\ volgens besluit van het College van Promoties \\ in het openbaar te verdedigen \\ op 15 december 2017 om 14:45 uur. \\ door
}

Bianca Britt Maria Keers

geboren op 31 juli 1981

te Alkmaar 
Promotiecommissie:

Voorzitter
Promotor(en)
Leden

Prof. dr. T.A.J. Toonen

Prof. dr. P.C. van Fenema

Prof. dr. W.H.M. Zijm

Prof. dr. T. Boundarouk

Prof. dr. J. van Hillegersberg

Prof. dr. P. Kenis

Prof. dr. A-P de Man

Prof. dr. J.M.L.L. Soeters
Universiteit Twente

Nederlandse Defensie Academie

Universiteit Twente

Universiteit Twente

Universiteit Twente

Universiteit van Tilburg

Vrije Universiteit Amsterdam

Universiteit van Tilburg 
To Niels, my love

To Iris, my joy 



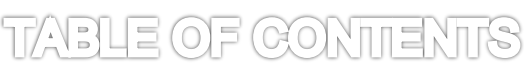

PART A: INTRODUCTION TO THE DISSERTATION

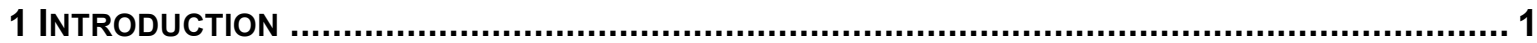

1.1 Positioning of the Research Theme ................................................................... 1

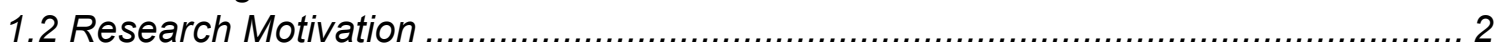

1.3 Theoretical Foundations of IOR Management .................................................... 4

1.4 Research Perspective and Objectives ........................................................... 7

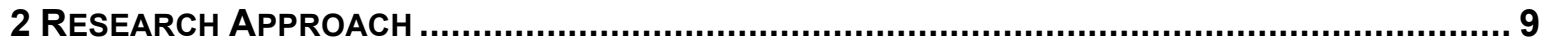

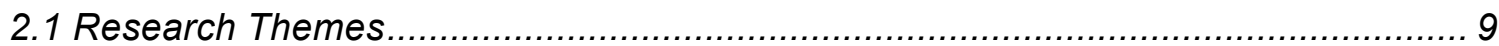

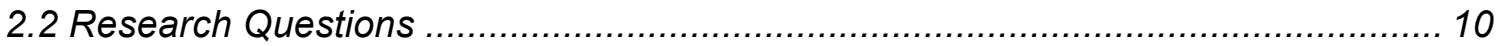

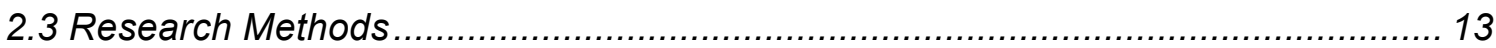

2.4 Structure of this Dissertation and Publications Included ................................... 15

PART B: PUBLICATIONS

\section{CONTEXT}

3 Inter-ORganizational Shared Services (ISS): Creating Value aCross Organizational

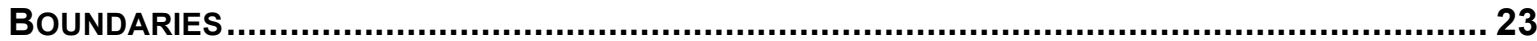

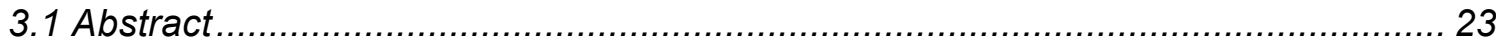

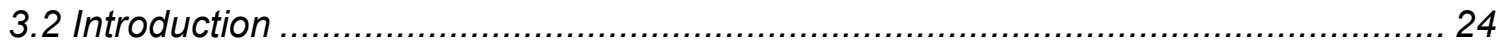

3.3 Value Creation across Organizational Boundaries: Strategic Motives and Objectives28

3.4 ISS and Value Chains: A Taxonomy............................................................... 32

3.5 Foundations for Creating Value across Organizational Boundaries ...................... 41

3.6 Future ISS Research: Three Streams of Research ...................................... 51

3.7 Conclusion: Interventions for ISS Success ................................................ 56

\section{PROCESS}

\section{Rediscovering Strategic Content in ‘Strong Process’ Research on Business}

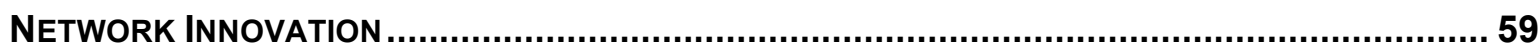

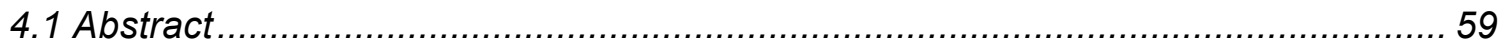

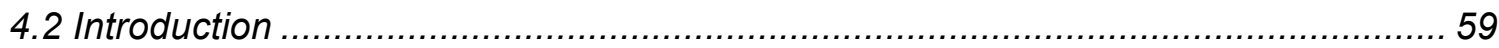

4.3 Background: Innovation and Business Networks........................................... 63

4.4 'Content' and a Strong Process View on Business Network Innovation: An Uneasy

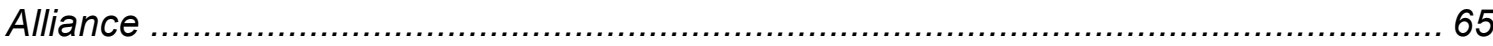

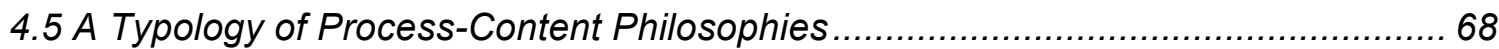

4.6 Methodological Reflection on the Four Philosophies ........................................ 77

4.7 Using the Fourth Philosophy to Study Content in Business Network Innovation ..... 81

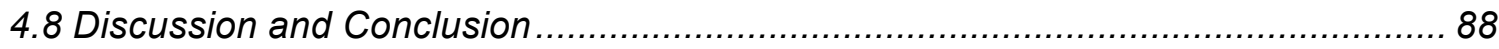

5 Inter-organizational Performance Management: A Co EvolutionaRy Model ..... 93

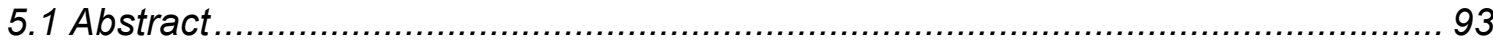

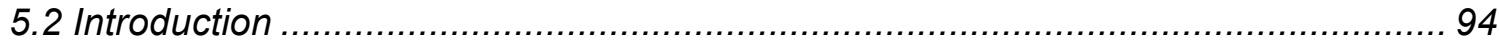

5.3 Background: Inter-organizational Cooperation and Performance Management..... 98 


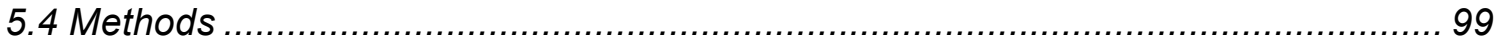

5.5 Approaches for Studying Inter-organizational Performance Management ........... 100

5.6 Structure: Value Creation Architecture and Inter-organizational Performance ...... 107

5.7 Process: Dynamic Coordination and Inter-organizational Performance

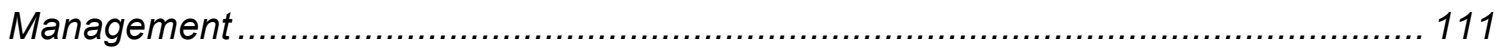

5.8 Towards a Co-Evolutionary Understanding of Inter-organizational Performance

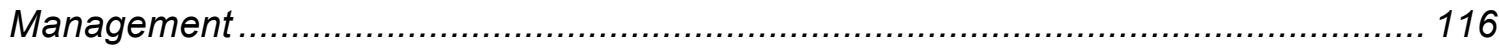

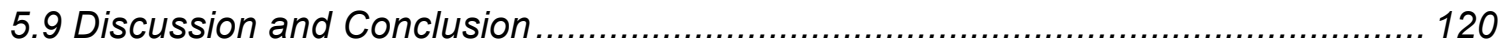

6 Towards Alliance Performance Management in Service Logistics ................... 125

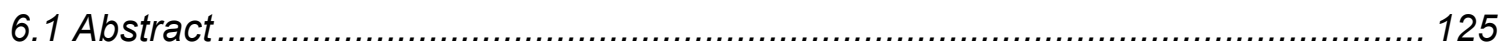

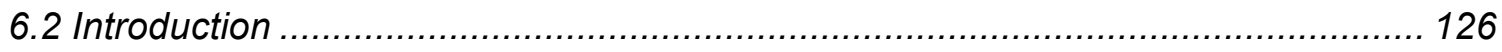

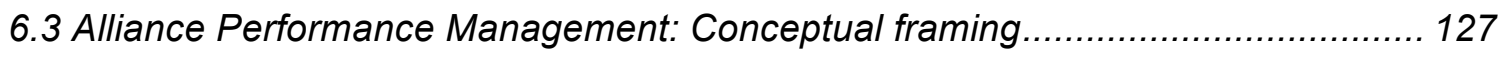

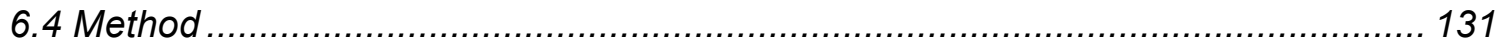

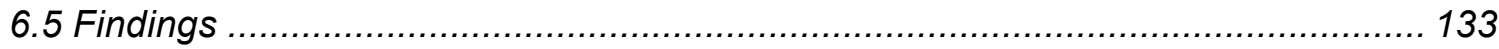

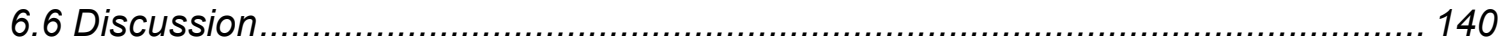

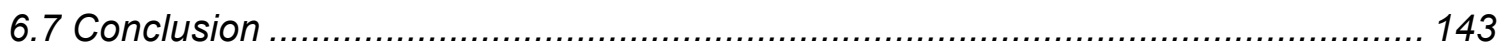

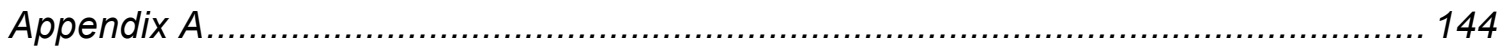

7 A narrative Perspective on Organizational Change and Alliance Formation.. 145

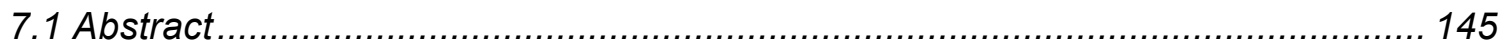

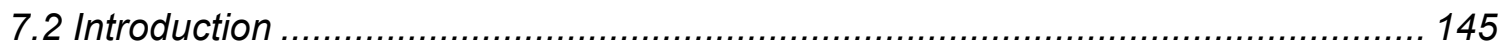

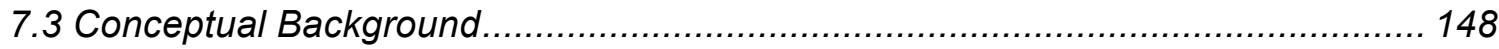

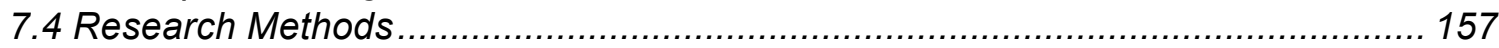

7.5 Findings: Wrestling with Organizational Change and Alliance Formation .............. 161

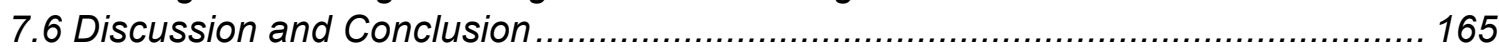

\section{REQUIREMENTS}

8 UNDERSTANDING ORgANIZATIONAL CHANGE FOR ALLIANCING .................................. 171

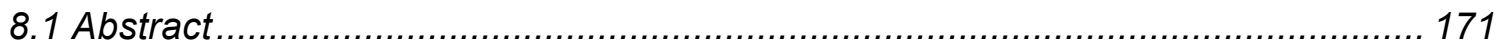

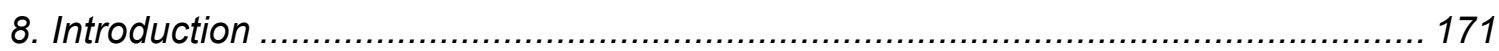

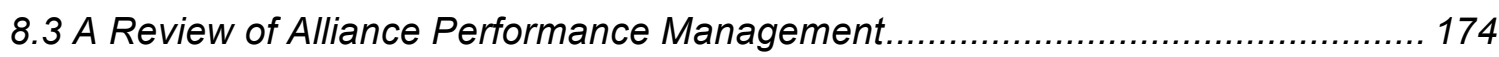

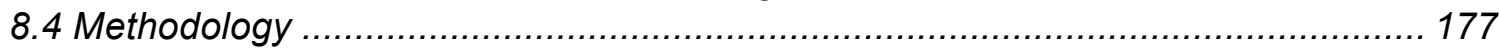

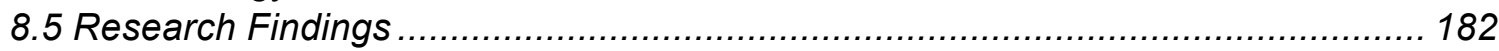

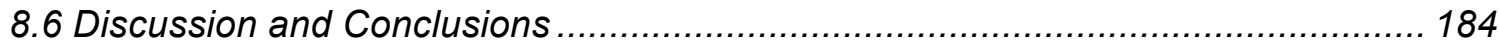

9 Risk MANAgEMENT FOR the Formation StAge OF PUBliC-PRIVATE PARTNERSHIPS.... 189

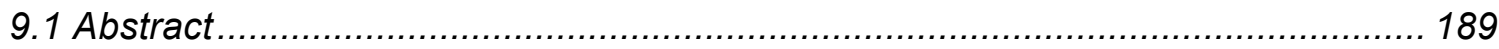

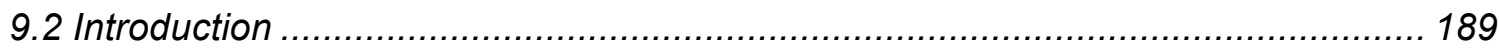

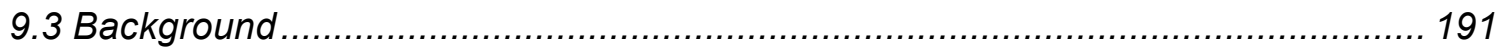

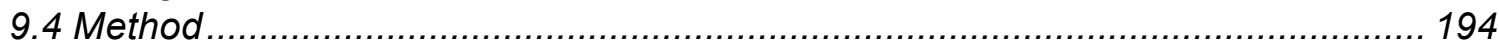

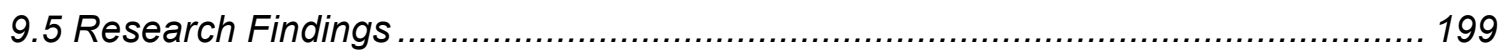

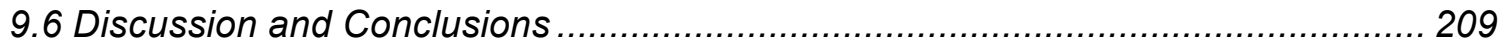


10 EMERGENCE OF INTER-ORGANIZATIONAL DATA GOVERNANCE: AN EXPLORATORY STUDY 213

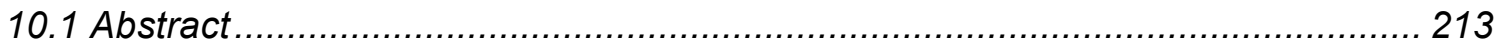

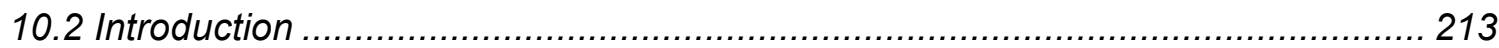

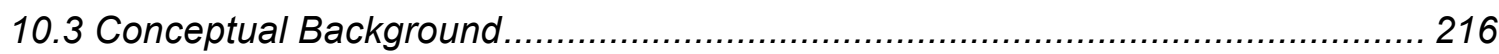

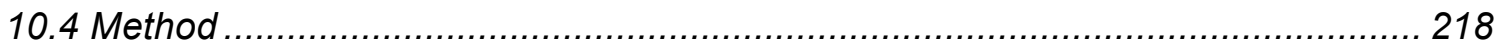

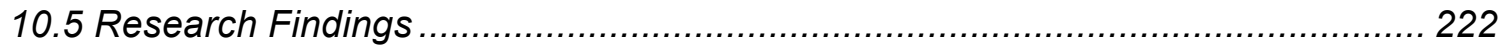

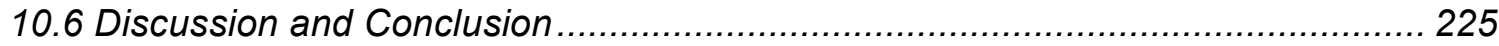

PART C: CONCLUDING REFLECTIONS AND LEADS FOR FUTURE RESEARCH

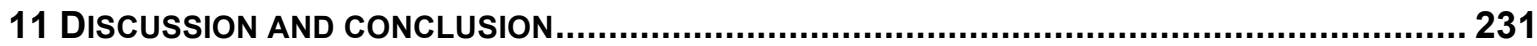

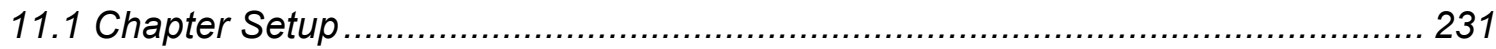

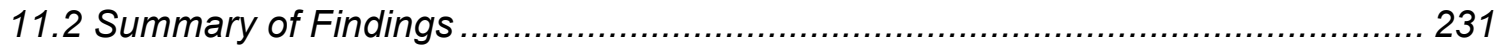

11.3 Contribution of Results to Research Objectives ........................................... 238

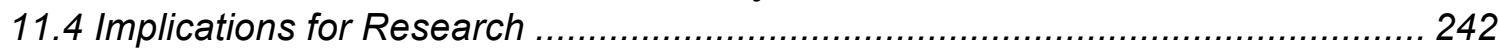

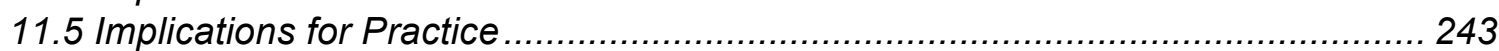

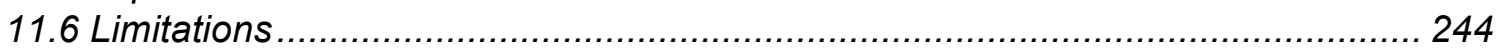

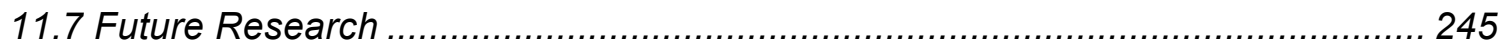

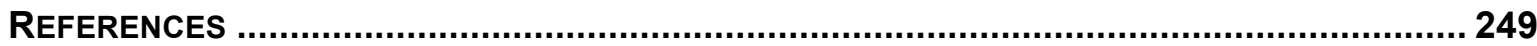

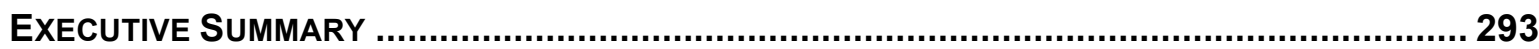

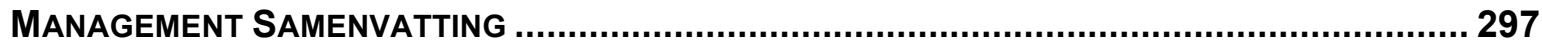

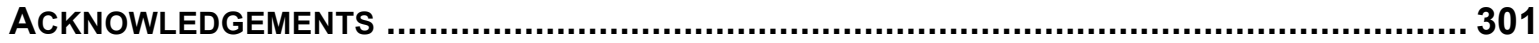

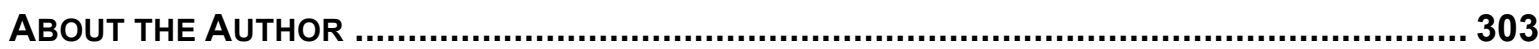




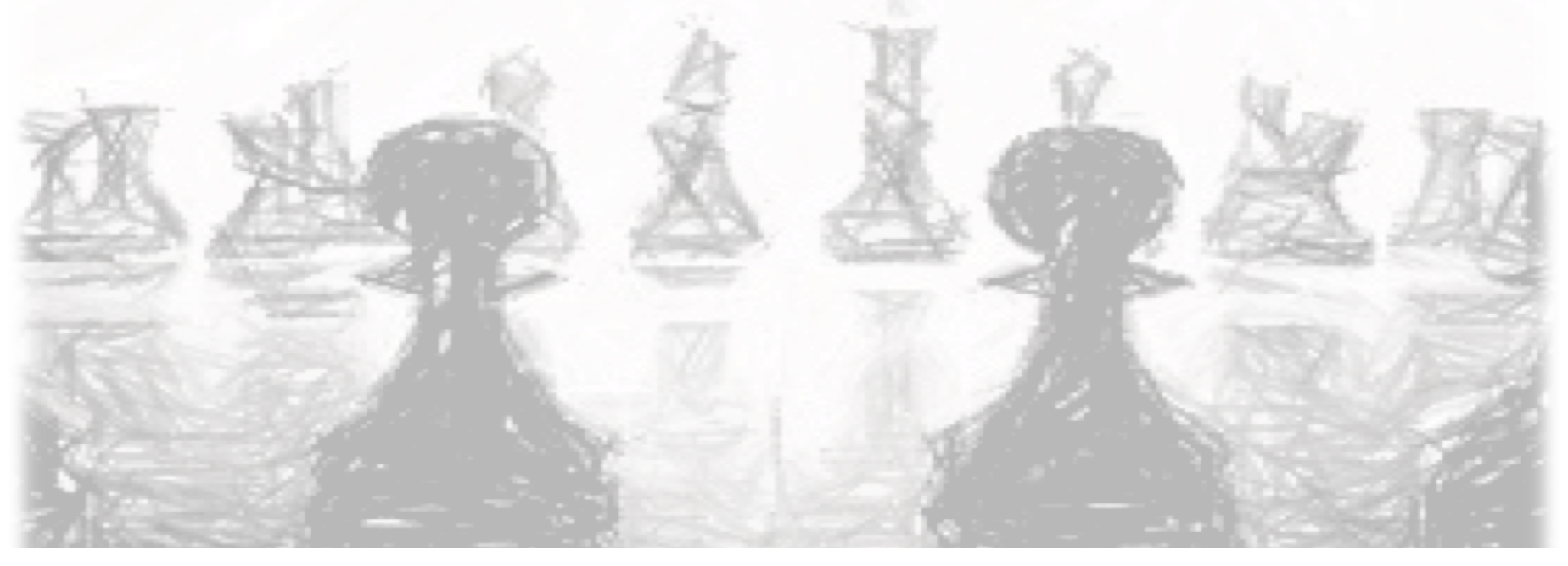


PART A: INTRODUCTION TO THE DISSERTATION

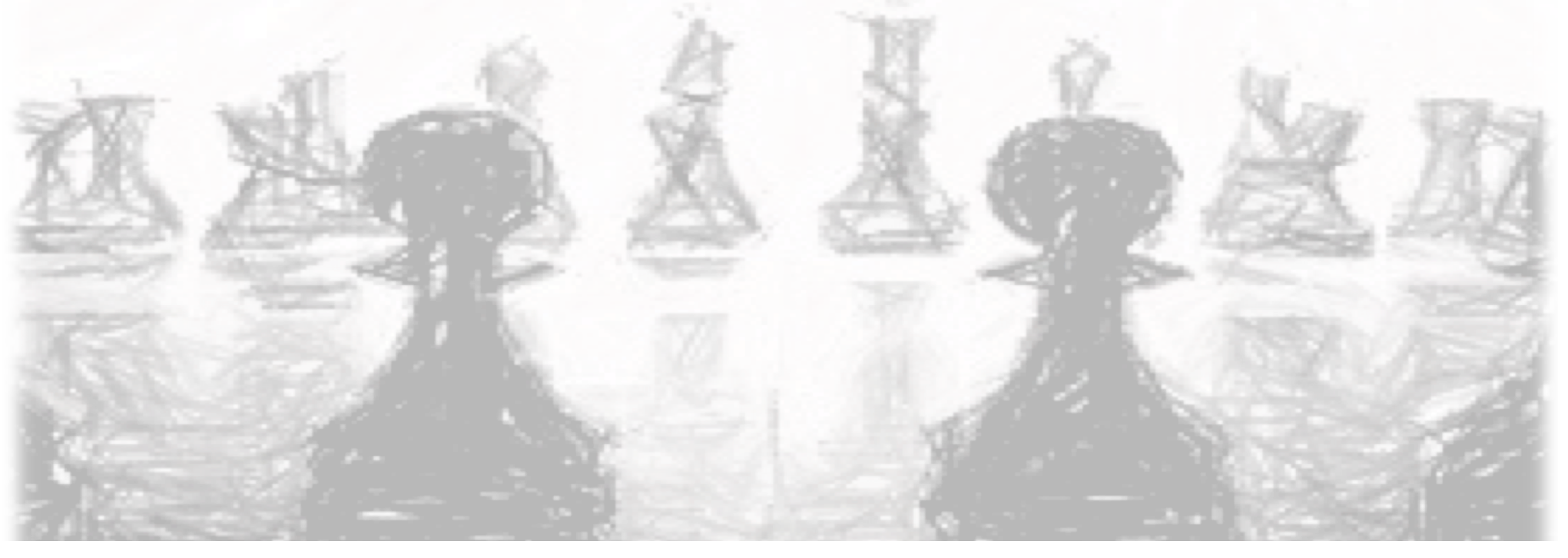





\section{INTRODUCTION}

\subsection{POSITIONING OF THE RESEARCH THEME}

Strategic alliances are voluntary cooperative arrangements between two or more firms involving exchange, sharing, or co-development of products or services (Gulati, 1998; Tjemkes et al., 1992). They can be differentiated from other forms of inter-organizational collaboration (such as transactional arrangements or joint ventures) by the long-term nature of business cooperation between autonomous organizations for the joint accomplishment of individual goals (Parke, 1993; Doz and Hamel, 1998). In the last decades the number of alliances has greatly expanded. Over time, the rationale for their development evolved from being a tactical means to access foreign markets, towards being a centre piece of business strategy to create customer value (Barringer, 2000). The reason for their strategic use today is the globalized marketplace, public savings, and the increased complexity of technological systems. These factors have expanded the competitive pressure on supply organizations running against skills and knowledge superiority (supplier effectiveness) along with economies of scale in the achievement of social or commercial objectives (Bamford et al., 2003). Despite the popularity of strategic alliances, their failure rate (estimated $>70 \%$ ) and the dynamics of their management are large (Draulans et al., 2003; Majchrzak et al., 2015). As such their performance management has been the subject of many studies within scientific disciplines such as economics, business administration, public administration, and social sciences (Anderson et al., 2015; Draulans et al., 2003; Faust et al., 2015; Walker et al., 2011). These studies provided the theoretical foundations of alliance management.

The majority of theories on alliance management explain the mechanisms and processes of inter-organizational performance management (Bititci et al., 2012; Bititci et al., 2005; Provan et al., 2007). Research findings suggest that inter-organizational commitment, trust, well-designed communication channels, cultural compatibility, and balance of power and control, are pivotal factors affecting performance (Dyer et al., 2001; Huxham, 2000; Inkpen and Curall, 2004; Kale and Singh, 2009; Mohr and Spekman, 1994). However, little is known of how various intraorganizational managerial processes, routines, tools and mechanisms - i.e. being or occurring within an organization -affect inter-organizational level performance - being or occuring between organizations - (Ireland et al., 2002).

Previous research exploring the intra-organizational level to explain the difference between organizations' alliance management success particularly underscores the importance of having alliance experience - and associated management techniques and mechanisms - to realize 
potential learning effects that might enhance an organization's alliance competence or capability. Some even assume alliance capability to be a proxy for alliance experience (Kale et al., 2002) Alliance capability refers to the organizational ability for finding, developing, and managing alliances, and is found to have a direct positive effect on the success of an alliance (Lambe et al., 2002). The notion of alliance capability is rooted in theoretical perspectives such as the competence-based view, the learning organization, absorptive capacity, and the knowledge-based theory of the firm (Sluyts et al., 2012). These perspectives approach the subject by exploring knowledge and integration issues. However, a comprehensive understanding of organizational functioning representative for its practice of alliancing is still lacking.

These arguments contributed to the dissertation's rationale to apply and combine different perspectives on strategic management - including supply chain management, organizational design and change management, performance management, risk management, and narratives management - for a coherent approach in studying organizations' alliance formation management.

We first elaborate on the scientific and managerial motivation for this dissertation. Next, we present a brief description of relevant literature on Inter-organizational Relationships, to successively explain the scientific next to the managerial rationale for and objectives of this dissertation.

\subsection{RESEARCH MOTIVATION}

The aspiration to increase understanding of alliance strategy and organization is twofold: scientific and managerial.

\subsubsection{SCIENTIFIC PERSPECTIVE}

Studies on Inter-organizational Relationships (IORs) have generated fragmented literature on the environmental interconnectedness of an organization, and its management of interorganizational relationships and exchanges that determine its survivability. Several reviews have substantially contributed to a better understanding of reasons for IOR formation and different types of IORs (Rivera-Santos, 2011). In addition, academic scholars have further developed their research in managing IORs by studying their coordination. Consequently, research has identified various management issues throughout the relationship development process as well as coordination mechanisms that can facilitate or even be decisive factors in inter-organizational 
performance (Anderson, 1995; Oliver, 1990). These include, but are not limited to, alignment of strategic incentives, partnership trust, cultural similarities, knowledge-sharing, and appropriate use of formal power (Buvik and Reve, 2002; Dyer and Hatch, 2006; Powell, 1996; Tatham, 2013). In addition, research has unfolded that successful inter-organizational performance starts within each involved organization. Captured by the concept of alliance capability, previous studies have identified that alliance management success increases by the presence of supportive infrastructural facilities for gathering, generating, institutionalizing, and dispersing alliance management knowledge (Draulans et al., 2003; Kale and Singh, 2009), and stressed the importance of experience in alliance learning (Anand and Khanna, 2000). Researchers argued that such knowledge and experience contribute to the development of interorganizational coordination mechanisms such as trust, and discovered that organizations with such a knowledge base are more successful in alliances than those without (Bamford et al., 2003). However, the question as to what it takes to build alliance capability is largely unanswered. Moreover, little is known of the intra-organizational alliance management practice (e.g. concerning barriers to alliance capability and preparations in the process towards strategy implementation), to understand why organizations continue to struggle with managing alliance performance (Dekker, 2004).

We argue that since implementing an alliance strategy involves a strategic reorientation, more explorative research is needed of the contextual characteristics underlying the alliance strategy formulation that will drive the development of the relationship, as well as functional requirements with respect to organizational transformation and development of alliance management, to understand why this impacts the inter-organizational level of performance.

\subsubsection{MANAGERIAL PERSPECTIVE}

The topic of this dissertation is studied in the course of a public-private R\&D project on Maintenance and Service Logistics for Maritime Assets (MaSelMA), in which the Royal Netherlands Navy (RNLN) participates, with the author, being a logistic officer at the RNLS, as their primary researcher. The project's aim is to improve the predictability of maintenance and service logistics demand of maritime systems, as well as the development of maintenance and logistic strategies. This is accomplished by adopting novel technological and service logistic innovations, and by improving inter-organizational collaboration between system manufacturers, 
service providers and system users (fleet owners). Supported by TKI Dinalog ${ }^{1}$, the project participants form a cross-section of the Dutch maritime maintenance industry (private as well as public organizations), a service logistics consultancy firm, and researchers from the Netherlands Defence Academy, Eindhoven University of Technology, and the University of Twente. The ambition of the project is driven by a number of challenges faced by the Dutch maritime industry. First, fleet owners are under pressure to reduce the downtime and life-cycle costs of their fleet in an attempt to improve efficiency and dependability. As such they search to optimize maintenance by switching from static to dynamic maintenance policies. This requires the sharing of system condition knowledge between asset owners and service supply organizations, and alignment of operations to effectively coordinate maintenance tasks just in time at minimum logistical costs (Brax, 2008; Samaddar et al., 2006). Second, today's integrated and unique technical systems have made it increasingly complex for one organization to develop and maintain all relevant service knowledge (Pateli, 2009). Along with the ageing of the technical workforce, Dutch maritime organizations therefore seek to group technological expertise to enhance the utilization of their manpower (Cambra-Fierro et al., 2011). Reiterating the importance of inter-organizational collaboration but also the complexity to manage, organize and regulate inter-organizational performance (Bamford et al., 2003; Hamel et al., 1989; De Man and Roijakkers, 2009), the research team launching the MaSeLMa project formulated various scientific and managerial objectives. In doing so, the focus is on improving the organizational development aimed at enabling the formation of alliances in conjunction with developing interorganizational cooperation.

Having formulated the scientific and managerial aspiration of this dissertation, we discuss what is already known in the scientific literature on developing inter-organizational cooperation.

\subsection{THEORETICAL FOUNDATIONS OF IOR MANAGEMENT}

The original cornerstone of IOR research was laid in the 1950s by the development of the general systems theory by Von Bertalanffy (Cropper, 2008). The study of inter-organizational relationship management, and especially inter-organizational relationship formation, expanded during the seventies of the preceding century, including a variety of approaches grounded in

\footnotetext{
${ }^{1}$ TKI DInalog is a national, Dutch government founded, institute that aims at advancing knowledge and practice in logistics in the broadest sense, including service logistics in the maintenance sector.
} 
several disciplines (Pittaway et al., 2004). That research led to the establishment of six theoretical paradigms, ranging from an economic towards a behavioural rationale.

IOR Paradigm 1. Transaction Cost Theory (TCT) considers inter-organizational relationships (IORs) to be governance mechanisms for economic interaction (Williamson, 1991). TCT scholars look at IOR instruments for organizing the market and price system (Hennart, 1993). Organizations need boundary-spanning activities to minimize their total production costs (Barringer and Harrison, 2000). Derived from this perspective, behavioural incentives and constraints of agents in an IOR can be explained (Hennart, 2008). For example, a strategic alliance is considered attractive to agents to exert control over a specialized activity available in the market which can not be realized with a firm's primary competencies and thereby will be difficult and costly to manage internally, but which will increase its competitive advantage. Its potential is considered subject to cost-minimizing interests and opportunistic behaviour (Nooteboom, 2006). The latter is minimized especially by institutional trust between business partners on the basis of successful business experiences and equity of business norms (Powell, 1996). TCT has been criticised for excluding strategic rationales such as learning and legitimacy (Barringer and Harrison, 2000), and for neglecting the importance of interpersonal trust. Interpersonal trust is established by corporate culture similarities, and sufficient knowledge and identification of agents (Jarvenpaa and Leidner, 1997).

IOR Paradigm 2. The Resource Based View (RBV) considers the resources and capabilities of a firm rather than their products as the primary source of competitive advantages (Wernerfelt, 1984). From a relational perspective built on the resource-based view, IORs are established to gain possession of valuable additional resources and capabilities owned by the partner. Such resources include tangible (i.e. financial, physical) and intangible (i.e. technology, reputation, culture) assets (Culpan, 2014). Strategic alliances are seen as a means for gaining access to crucial capabilities, supplementing the core competencies to increase an organization's efficiency or creation of customer value. Investments in relationship specific assets are considered a contribution to an organization's strategic advantage.

IOR Paradigm 3. Elaborating on the RBV, Resource Dependence Theory (RDT) considers the market to be an open system in which a firm is never self-sufficient and as such engages in social exchanges to obtain needed resources. The focus of the theory is externally oriented, rather than on internal resource management. It emphasizes the necessary transfer of critical resources between firms, and the organization's intention to control dependencies they enact by 
exerting their power (Pfeffer, 1978). From this theoretical perspective, a strategic alliance is initiated by a firm as an alternative to either increase its market power or to fill a resource gap. Complementary assets (such as financial resources or additional distribution channels) are gained to produce valuable, imperfectly imitable or non-substitutable products or services (Barney, 1991). A pivotal question however is whether the associated mutual dependence between partners undermines a firm's ability to create sustainable competitive advantage. In addition, RDT does not shed much light on the necessary development of organizational competences with respect to explaining alliance formation (Barringer and Harrison, 2000).

IOR Paradigm 4. Arguments derived from TCT and RDT have provided the basis for the Strategic Choice Theory (SCT). This theory argues that firms form inter-organizational alliances for a wide variety of strategic reasons, such as sharing of capital costs, creating economies of scale, entering foreign markets, acquiring local knowledge, or innovating (Almeida, 1996; Roijakkers, 2014). Subsequently, Stakeholder Theory (ST) grew out of the consideration of the strategic rationale for alliance formation (Laplume et al., 2008). It considers the organization to be in the center of a network of stakeholders, whose interests should be appropriately managed and for which the organization is the instrument to form cooperative relationships (Freeman, 2010; Jensen and Meckling, 1986). Ethical dilemmas considering the service of many stakeholders and problems that arise due to a lack of goal congruence between stakeholders and managers (agents) became important as reflected within agency theory (Bridouxet al., 2011; Eisenhardt, 1989a). ST suggests that alliances can facilitate the alignment of goals between stakeholders (Barringer and Harrison, 2000).

Touching upon describing and explaining the spatial organization of economic activity (Sheppard and Barnes, 2000), the previously mentioned perspectives induced the "relational turn" (Cropper at al., 2008: 8). It involves the enrichment with perspectives from organizational sociology, since economic processes are embedded in among other things social, cultural, and political contexts. Developed theories in the context of relationship formation that are more behaviourally oriented include Learning Theory (LT) and Institutional Theory (IT).

IOR Paradigm 5. The rationale of Learning Theory is that firms form alliances to capitalize on opportunities for learning. An example is the transfer of technical knowledge between system manufacturers and service providers to improve product quality and maintenance skills (Mowery, 1996; Prahalad and Hamel, 1990). The argument behind such a transfer is that superior knowledge can enhance an organization's strategic value (Simonin, 1997), while innovation 
evolves faster in inter-firm networks or in industry-academic collaboration than within the bureaucratic institution of the firm (Powell et al., 1996). In addition, Powell et al. (1996) conclude that a firm's central position in the network and the number of alliances it is involved in influence its innovation capability. Others distinguish exploration and exploitation rationales (i.e. the search for new sales or the increase of current efficiency) of knowledge relationships (Cohen and Levinthal, 1990). Cohen and Levinthal (1990) also stress the importance of a firm's absorptive capability. This refers to its ability to recognize, incorporate and exploit external knowledge. Specifically, absorptive capability is among other things based on a firm's interpersonal communication skills and trust, management information system, as well as training, education and experience incentives (Soekijad and Andriessen, 2003).

IOR Paradigm 6. Finally, Institutional Theory considers the environment of firms to put institutional pressure on social norms and legitimacy. Firms can obtain legitimacy by partnering with firms with a good reputation or image (Oliver, 1990). Another rationale for alliancing is the simple (un)conscious mimicking of strategies of successful organizations (DiMaggio and Powell, 1983), although it is unlikely that such a mimicking alone offers sustainable competitive advantage.

The various theories discussed offer conceptual foundations for inter-organizational cooperation, and have contributed to the evolution of approaches to alliance management: from economic towards behavioural. However, approaches are fragmented and despite the differences in theoretical perspectives the logic of their boundaries is crumbling (Cropper, 2008: 8). With the aim of engaging in more cross-boundary investigation, this dissertation approaches alliance formation from both an economic and a social behaviour and innovation oriented perspective.

\subsection{RESEARCH PERSPECTIVE AND OBJECTIVES}

Central within the research perspectives are the two core concepts that underlie IOR research: organizations and the relationships between them. IOR studies either focus on dimensions and attributes of the individual organizations involved or on their relationship. In our view, however, a comprehensive understanding of their development/progression over time can only be achieved by studying both concepts simultaneously: the macro-context in which organizations are embedded inciting alliance formation (and as such also the macro context of the alliance once established), the process through which an alliance strategy is developed - interwined with the process through which the relationship is established (i.e. the beginning of the alliance life- 
cycle), and the micro-context - refering to groups and individuals in which organizations and as such their relationship are embedded. Without descending all the way to the level of individual behaviour in organizations, the rationale behind this dissertation is to increase understanding of the intertwinement of organizational and inter-organizational performance management. More precisely, the aim is to increase the understanding of organizational conditions affecting alliance performance. Accordingly, this disseration has the following two objectives:

1. to develop IOR theory concerning the intertwinement of intra-organizational and interorganizational performance management with respect to alliance formation;

2. to identify a set of principles for organizational development aimed at the evolution of alliances. 


\section{RESEARCH APPROACH}

In the first section of this chapter, the research themes of this dissertation are discussed. In the second section, the previously discussed objectives of the dissertation are translated into eight research questions. Each research question starts with an overview of the problem, occassionally followed by a highlight of the study results. Each study fueled the formulation of the successive research question, in this way contributing to the objectives of the dissertation. The third section describes the research strategy, while the fourth section provides general information on different methods used to meet the objectives of this dissertation - of which further details are reported in the chapters of the respective studies. The final section provides an overview of the publications that make up and describe the structure of this dissertation.

\subsection{RESEARCH THEMES}

Having explained the nature of the study of IOR, and the aim and objectives of this dissertation, we now explain the three research themes structuring this book. These research themes concern:

- the context in which the alliance strategy is given consideration. It refers to the set of - continuously changing and evolving - circumstances surrounding strategy making. It includes three dimensions: the organization (representing organizational characteristics and factors,e.g. culture, demographic profile of the workforce), the industry (e.g. competitive forces, (technological) trends, life cycle), and the environmental contex (e.g. a recession) (De Wit and Meyer, 2010b). Derived from and aligned with the circumstances objectives are formulated, prioritized, and translated into targets.

- the process of developing the strategy and the collaboration (i.e. transformation of the established way of working and change of the current organizational and relationship state);

- organizational requirements for that purpose (i.e. substantive performance essentials), referring to management and control capabilities. 


\subsection{RESEARCH QUESTIONS}

\section{Context}

First, over the last twenty years, there has been an accelerating growth of organizations forming strategic alliances. Business strategic alliances are initiated by participants to get access to a subset of another organization's capabilities when developing these capabilities internally would be too expensive or would take too long. The intention is to increase individual strategic value (Kleemann and Essig, 2013, Ter Wiel, 2012), while the collaborative initiative aims at synergy hoping that the benefits obtained will exceed individual efforts (Ireland, 2002). As organizations recognize the importance of strategic alliances, there is a need to analyze which characteristics concerning the participants' context are at the root of the increased growth of alliance initiatives. This leads to the first research question.

\section{$R Q$ 1: What is the reason for the emergence of the strategic motivation to form a} (service) alliance? And how is it considered to increase value both individually and collectively?

The study results suggest that the objectives of organizations' shared service initiatives are to increase stakeholder value on the one hand - by improving the quality of its service delivery, and to reduce stakeholder cost on the other hand - by improving the utilization of its resources (costefficiency). Organizations' motivation behind it stems from facing either strategic tensions regarding the achievement of their role (e.g. regarding efficient public service offerings), or ecosystem strategic tensions (e.g. sustainable and ethically responsible production). Interorganizational shared services (ISS) may streamline supply chains when partners' business models and operations are aligned and coordinated. This implies both a vision on and development of the strategy content (e.g. on overarching supply chain concepts and business models transformation), together with development of the inter-organizational collaboration process (including e.g. shared decision-making and inter-organizational structures).

\section{Process}

Second, with respect to the development of alliances and networks, researchers increasingly adopt a strong process view to understand how such relationship evolve in co-creating value and innovation (Reypens et al., 2016). Restricting to adopting a strong process view, however, increases the risk that development of strategy content sinks into oblivion. As a consequence, research will be limited to fueling the innovative process rather than innovative outcomes, and therefore be little appealing to practitioners who expect support with the development of new 
technologies and knowledge-intense innovations. In contrast, including a content view on collaborative innovation, enables the development of new ideas in the field of business process, technology, product or service activities. As such, we wonder:

$R Q$ 2: How can content be inserted into a process view on business network innovation, without losing the power of a strong process philosophy, and how can such an effort enable research in a methodological sense?

In retrospect, regarding contextual characteristics underlying the formation of the alliance strategy, an eye must be kept on changing contexts and as such participants' interests. Hence, we argue that inter-organizational value creation is a dynamic process. Yet, literature remains silent in this area. This motivates the formulation of the third research question:

$R Q$ 3: What are the implications of the dynamic process of inter-organizational value creation for inter-organizational performance management?

The results of the study point out that the inter-organizational value creating process consists of alternating episodes of inter-organizational differentiation and integration, causing interorganizational performance management to be dynamic. Episodes of integration lead to the coordination of partners' stakeholder values. This coordination may be challenging due to the divergence between partners' values, and sometimes even impossible in case of contradictory values (Tatham, 2013). Yet, the importance of shared values - in contrast to shared objectives has received limited research attention and hence is little understood. This led to the formulation of the fourth research question:

$R Q$ 4: What role do partners' values play in ensuring participating organizations' individual and collective success?

In terms of strategic alignment, many organizations conduct also pluralistic strategizing (Jarzabkowskiet al., 2007; Smith and Lewis, 2011). One such example concerns manufacturing firms executing a service alliance stratgy to complement their traditional product offering (Neely, 2013). To increase understanding of the complexity of pluralistic strategizing, strategic management studies focusing on the intra-organizational unit of analysis explored among other things the management of strategic dualities (Birkinshaw et al., 2016), strategies for balancing intra-organizational tensions (Ansari et al., 2014), changes to organizational identity and 
knowledge (Corley and Gioia, 2004; Nag et al., 2007), and combination of diverse strategic narratives within an organization (Dalpiaz et al., 2016).

Since organizational pluralism involves dealing with multiple contexts geared towards particular offerings (Dalpiaz et al., 2016), this management complexity also applies to alliancing. Moreover, narratives are important as they set out the story of management complexity. For example, alliance narratives may emphasize the strength of the alliance and joint interests, whereas at the same time participants' narratives may characterize and legitimate a strategic movement away from allies due to e.g. contextual conflicts. Although strategic narratives are central to the maintenance of alliances (Roselle, 2010), we observe limited research on the relationship between narrartives pertaining to the alliance and its participants. To give insight into the relationship between these narratives, and the complexity of manageing it, the fith research question is as follows:

$R Q$ 5: Which factors are likely to affect differences between narratives of the alliance and its participants? And how does this influence interorganizational performance?

\section{Requirements}

Third, as regards the strategy development process with respect to changing the current organizational state, limited research attention has been devoted to exploring the consequences of implementing an alliance strategy for organizational capabilities. Organizational capabilities are described as important higher order resources, competencies or multi-level spanning capabilities. They are coordinated by business processes and managerial activities, and include valuable resources, knowledge, and skills (Helfat et al., 2003). Alliance researchers have explored drivers of an organization's ability to successfully manage alliances. Referred to as alliance capability, they explored organizational competencies (series of activities and processes) which can positively influence the alliance outcome (Sluyts et al., 2012). Their studies in particular focused on developing alliance capability by means of learning from past collaborative experience to overcome future challenges (Anand and Khanna, 2000). Since an organizational capability usually acts as a co-specialized element in the organizational system (Vesalainen and Hakala, 2014), alliance capability not only depends on organizational learning capability. Developing successful alliance management also requires leveraging organizational learning for changing management practice. Hence, the sixth research question is formulated:

$R Q$ 6: Which intra-organizational management practice should be developed in conjunction to organizational learning to enhance alliance capability? 
Since strategic requirements outline the substantive means necessary for organizational strategic performance, we argue that another important capability concerns risk management. Athough many studies examine risks associated with entering and maintaining successful IORs, few explore organizations' actual management of risks as a determinant for the succes of IORs (Elmuti and Kathawaia, 2001). However, the control of risks is an important factor to be carefully considered by organizations in the process of IOR development (Provan and Sydow, 2008). In this light, it includes identifying associated performance risks by specific formation events, identifying ownership of each risk, and analyzing whether correct controls are in place. In the absence of sufficient understanding of organizations' risk management practice within the process of IOR formation - and because of few studies on public-private alliances (Roehrich, et al. 2014: 4) - we analyze and evaluate a public organization's management of risks incidental to the formation of public-private partnership projects. The seventh research question therefore is:

$R Q$ 7: How is integrated risk management carried out with regard to alliance projects? And which governance principles should be incorporated to improve management effectiveness?

Lastly, since organizations increasingly partner to exchange a large variety of data as means to innovate and enhance customer value (Chaffey and Wood, 2005), the eighth study explores data governance within public-private partnerships. Data governance has been proposed as a concept to maximize and protect the value of information (Zhang and Dawes 2006). However, it proves to be difficult to identify necessary data, to manage the processes required to make data sufficient for inter-organizational use (accurate, timely, complete, accessible, reliable, consistent, relevant, and detailed), and to improve managers' ability to interpret the data. As such, partnership ambitions moreover include excelling in data governance (Van den Broek and Van Veenstra, 2015). Since studies on data governance, particularly in the case of public-private partnerships, are rare, the eighth research question is formulated as follows:

$R Q$ 8: How do PPPs organize their data governance and what improvements are necessary?

\subsection{RESEARCH METHODS}

In this dissertation we study alliance management through the three research themes, alternating an intra- and inter-organizational research perspective. We thereby use an inductive 
research strategy, combining systematic analysis (literature review) with qualitative empirical research. The results contribute to the breadth and depth of findings within the discipline of alliance management, and serve the development of alliance management practice.

\subsubsection{LITERATURE REVIEW}

A review of prior literature helps to understand the foundation of knowledge on an existing phenomenon. It furthermore facilitates the discovery of knowledge gaps, and thereby areas for future research and theory development (Hart, 1998). The literature review has been established with the help of conceptual papers, review papers, and empirical research papers. To identify appropriate papers we started by exploring articles of key researchers that have added to the knowledge base in the specific area of study, and often cited current studies issued by highly ranked scientific journals. Subsequently, we explored other books, articles, and theses with relevant theories, concepts and ideas referred to by these articles. In addition, we explored articles directly or indirectly referred to by other researchers at scientific conferences, and which we considered of interest. Last, we continuously monitored high-quality international scientific journals publishing in our area of interest.

\subsubsection{EMPIRICAL CASE STUDY RESEARCH}

Case studies address 'how' and 'why' questions and are especially useful to illuminate decisions or phenomena in a real-life context to improve their understanding (Yin, 2013). Single case studies are considered appropriate social science research methods in first attempts to explore management variables and deepen understanding of their relationship. Multiple (holistic) case study research is used to test or build new theory (Eisenhardt, 1989b). The challenge of case studies is to process the magnitude of data and handle the variety of evidence, while the method has been prone to concerns of validity and reliability (Gibbert et al., 2008). A clear research design regarding the collection and analysis of data is thereby helpful (Yin, 1989), and as such always developed within the dissertation's studies.

Case studies can furthermore be differentiated in being descriptive, explanatory, or explorative. In this dissertation, we particularly use explorative case studies to develop initial insights and ideas of the intertwinement of organizational development needed for an alliance strategy and alliance performance as a basis for future research. In all cases, the unit of analysis were service alliances between asset owners, maintenance and logistics service providers, and OEMs. Data was gathered by mixed methods such as surveys, workshops, minutes of meetings, and expert interviews. Data was validated by cross-source verification. Subsequently, we mostly applied post-coded content analysis as a standardized method for qualitative analysis (Bauer 
and Gaskell, 2000). Further details on the cases studied, data collection, and data analysis methods used, are reported in the respective studies.

\subsection{STRUCTURE OF THIS DISSERTATION AND PUBLICATIONS INCLUDED}

This dissertation is structured in three parts:

- Part A consists of two chapters. This first chapter introduces this research by describing the purpose, motivations, and objectives of the dissertation. The second chapter provides an overview of the research approach, by explaining the research questions along with the research strategy and methods applied. Further, the publications that make up this dissertation are introduced.

- Part B comprises eight studies reported per chapter. The studies are at various stages of external publishing (accepted, under review, revision, or preparation for submission). Each chapter starts with a cover sheet, which includes the authors and an abstract of the publication, followed by the paper in full. Table 1 provides an overview of the publications' outlet and the status of the various papers in the publishing process to date.

- Part $\mathrm{C}$ consists of one chapter. Chapter 11 summarizes and discusses findings from the publications. Thereby, it provides insight on how alliance strategy's contextual characteristics and functional requirements in terms of intra-organizational management affect inter-organizational performance management. In addition, the chapter outlines the implications for theory and practice as well as leads for future research.

References to all chapters are provided in the central reference list following Chapter 11. 
Table 1. List of publications included in the dissertation

\begin{tabular}{|c|c|c|c|c|c|c|c|}
\hline Ch. & $\mathbf{R Q}$ & Authors & Title & Type & Status & Outlet & Ranking \\
\hline 3 & 1 & $\begin{array}{l}\text { Van Fenema } \\
\text { P.C., Keers } \\
\text { B.B.M., } \\
\text { Zijm W.H.M. }\end{array}$ & $\begin{array}{l}\text { Inter- } \\
\text { organizational } \\
\text { Shared Services } \\
\text { (ISS): Creating } \\
\text { Value across } \\
\text { Organizational } \\
\text { Boundaries }\end{array}$ & $\begin{array}{l}\text { Theoretical } \\
\text { study }\end{array}$ & Published & $\begin{array}{l}\text { Book chapter: } \\
\text { Shared Services as } \\
\text { a New } \\
\text { Organizational Form } \\
\text { (Advanced Series in } \\
\text { Management, } \\
\text { Volume 13) Emerald } \\
\text { Group Publishing } \\
\text { Limited }\end{array}$ & $0.136^{*}$ \\
\hline 4 & 2 & $\begin{array}{l}\text { Van Fenema } \\
\text { P.C., Keers } \\
\text { B.B.M. }\end{array}$ & $\begin{array}{l}\text { Rediscovering } \\
\text { Strategic Content } \\
\text { in 'Strong } \\
\text { Process' } \\
\text { Research on } \\
\text { Business } \\
\text { Network } \\
\text { Innovation }\end{array}$ & $\begin{array}{l}\text { Theoretical } \\
\text { study }\end{array}$ & $\begin{array}{l}\text { Submitted } \\
\text { for } 2^{\text {nd }} \\
\text { review }\end{array}$ & $\begin{array}{l}\text { Industrial Marketing } \\
\text { Management }\end{array}$ & $1.413^{*}$ \\
\hline 5 & 3 & $\begin{array}{l}\text { Van Fenema } \\
\text { P.C., Keers } \\
\text { B.B.M. }\end{array}$ & $\begin{array}{l}\text { Inter- } \\
\text { organizational } \\
\text { Performance } \\
\text { Management: A } \\
\text { Co-Evolutionary } \\
\text { Model }\end{array}$ & $\begin{array}{l}\text { Theoretical } \\
\text { study }\end{array}$ & Accepted & $\begin{array}{l}\text { International Journal } \\
\text { of Management } \\
\text { Reviews }\end{array}$ & $2.466^{*}$ \\
\hline 6 & 4 & $\begin{array}{l}\text { Keers B.B.M., } \\
\text { Van Fenema } \\
\text { P.C. }\end{array}$ & $\begin{array}{l}\text { Alliance } \\
\text { Performance } \\
\text { Management in } \\
\text { Service Logistics }\end{array}$ & $\begin{array}{l}\text { Theoretical } \\
\text { and } \\
\text { empirical } \\
\text { study }\end{array}$ & Published & $\begin{array}{l}\text { Journal of } \\
\text { Organization Design }\end{array}$ & ** \\
\hline 7 & 5 & $\begin{array}{l}\text { Keers B.B.M., } \\
\text { Van Fenema } \\
\text { P.C., } \\
\text { Ommen N. }\end{array}$ & $\begin{array}{l}\text { Organizational } \\
\text { Change and } \\
\text { Alliance } \\
\text { Formation: A } \\
\text { Narrative } \\
\text { Perspective }\end{array}$ & $\begin{array}{l}\text { Theoretical } \\
\text { and } \\
\text { empirical } \\
\text { study }\end{array}$ & Submitted & Organization & $1.806^{*}$ \\
\hline 8 & 6 & $\begin{array}{l}\text { Keers B.B.M., } \\
\text { Van Fenema } \\
\text { P.C., } \\
\text { Zijm W.H.M. }\end{array}$ & $\begin{array}{l}\text { Understanding } \\
\text { Organizational } \\
\text { Change for } \\
\text { Alliancing }\end{array}$ & $\begin{array}{l}\text { Theoretical } \\
\text { and } \\
\text { empirical } \\
\text { study }\end{array}$ & Published & $\begin{array}{l}\text { Journal of } \\
\text { Organizational } \\
\text { Change } \\
\text { Management }\end{array}$ & $0.378^{*}$ \\
\hline 9 & 7 & $\begin{array}{l}\text { Keers B.B.M., } \\
\text { Van Fenema } \\
\text { P.C., } \\
\text { Dito S. }\end{array}$ & $\begin{array}{l}\text { Risk } \\
\text { Management for } \\
\text { the Formation } \\
\text { Stage of Public- } \\
\text { Private } \\
\text { Partnerships }\end{array}$ & $\begin{array}{l}\text { Empirical } \\
\text { study }\end{array}$ & $\begin{array}{l}\text { Submitted } \\
\text { for } 2^{\text {nd }} \\
\text { review }\end{array}$ & $\begin{array}{l}\text { International Journal } \\
\text { of Project } \\
\text { Management }\end{array}$ & $1.497^{*}$ \\
\hline 10 & 8 & $\begin{array}{l}\text { Keers B.B.M., } \\
\text { Van Fenema } \\
\text { P.C. }\end{array}$ & $\begin{array}{l}\text { Emergence of } \\
\text { Inter- } \\
\text { Organizational } \\
\text { Data } \\
\text { Governance: An } \\
\text { Exploratory } \\
\text { Study }\end{array}$ & $\begin{array}{l}\text { Empirical } \\
\text { study }\end{array}$ & $\begin{array}{l}\text { Submitted } \\
\text { for } 2^{\text {nd }} \\
\text { review }\end{array}$ & $\begin{array}{l}\text { Journal of } \\
\text { Information } \\
\text { Technology and } \\
\text { Theory Application }\end{array}$ & A-journal*** \\
\hline
\end{tabular}




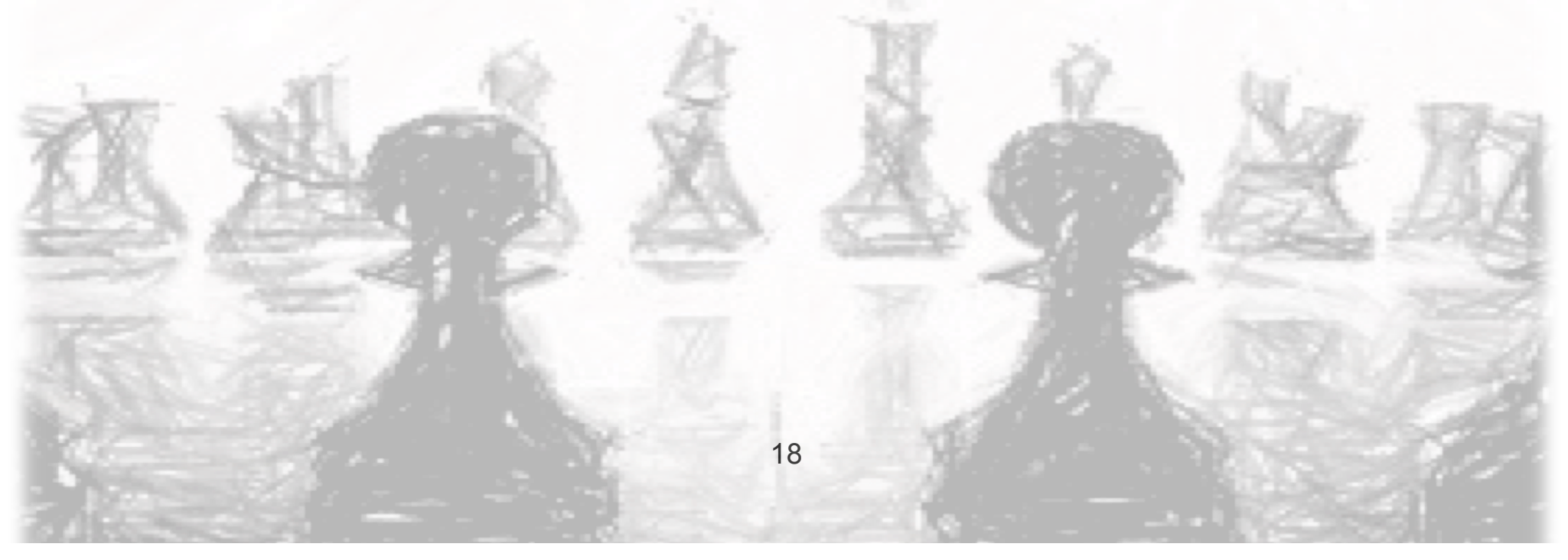


PART B: PUBLICATIONS

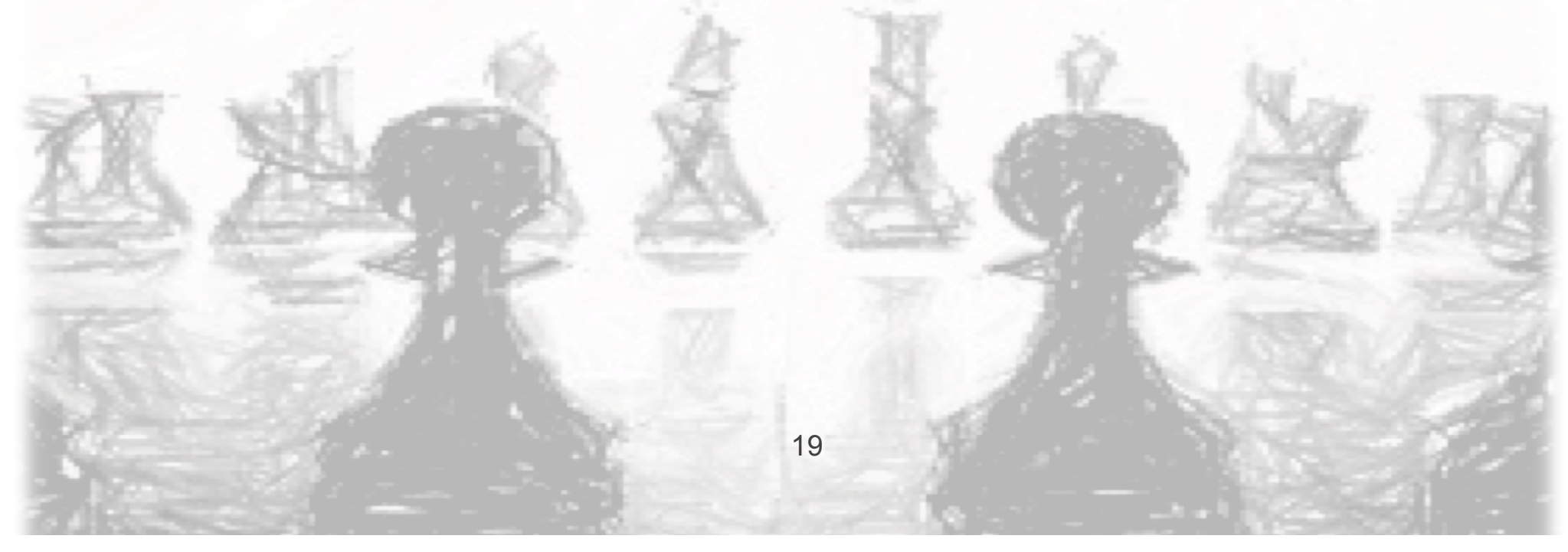


"Strategy is about making choices, trade-offs;

it's about deliberately choosing to be different"

(Michael Porter) 


\begin{tabular}{|c|c|}
\hline \multirow[t]{3}{*}{ AUTHORS } & Van Fenema P.C. \\
\hline & Keers B.B.M. \\
\hline & Zijm W.H.M. \\
\hline \multirow[t]{3}{*}{ PUBLICATION OUTLET } & Book chapter: Shared Services as a New Organizational \\
\hline & Form (Advanced Series in Management, Volume 13) \\
\hline & Emerald Group Publishing Limited \\
\hline ADDRESSES & $\begin{array}{l}\mathrm{RQ} \text { 1: What is the reason for the emergence of the } \\
\text { strategic motivation to form a (service) alliance? And how is } \\
\text { it considered to increase value both individually and } \\
\text { collectively? }\end{array}$ \\
\hline STATUS & Published \\
\hline \multirow[t]{5}{*}{ REMARK } & The publication received the Emerald award for \\
\hline & Outstanding Author Contribution in the 2015 Emerald \\
\hline & Literati Network Awards for Excellence, and is among the \\
\hline & most highly read contributions in the past year in Advanced \\
\hline & Series in Management book series. \\
\hline
\end{tabular}

\subsection{ABSTRACT}

Sharing services increasingly extends beyond intra-organizational concentration of service delivery. Organizations have started to promote cooperation across their boundaries to deal with strategic tensions in their value eco-system, moving beyond traditional outsourcing. This chapter addresses two questions geared to the challenge of inter-organizational shared services (ISS): why would organizations want to be involved in ISS? And: how can organizations use ISS to increase value both individually and collectively. The conceptual chapter reviews literature pertaining to ISS from public, commercial and non-governmental sectors. ISS is understood as a multistakeholder organizational innovation. In order to analyze ISS and conduct empirical research, we developed a taxonomy and research framework. The chapter shows how ISS can be positioned in value chains, distinguishing vertical, horizontal and hybrid ISS. It outlines ISS implications for developing business models, structures, and relationships. Success factors and barriers are presented that epitomize the dynamic interplay of organizational autonomy and inter-organizational dependence. The research framework offers conceptual ideas for 
theoretical and empirical work. Researchers involved in ISS studies may adopt strategic, strategic innovation, and organizational innovation perspectives. ISS phases are distinguished to focus innovation management - initiation, enactment, and evaluation. Furthermore, insights are provided into processes and interventions aimed at making ISS a success for participating organizations. As such, this chapter presents a cross-sectoral perspective on, and a taxonomy of ISS, as well as a research framework built on the organization and strategic management literature.

\subsection{INTRODUCTION}

Large organizations, both private and public, have invested in shared service initiatives to improve the internal use of scarce resources, increase quality, and offer new products and services (Janssen and Joha, 2008; Kamal, 2012). For instance, they have concentrated facility management, logistics, and R\&D, financial, IT and HR services in onshore, near shore, or offshore centers $^{2}$ (Howcroft and Richardson, 2012; Vlaar et al., 2008). Intra-organizational shared services imply bundling of services while delegating control to the organization's business units, i.e. not centralization (Meijerink and Bondarouk, 2013). Sharing services within an organization often proves to be a dynamic process in terms of organizational boundaries and governance. Organizations may stress their core competencies and consider services bundled in a shared service center as belonging to their core business. The shared service center, staying within organizational boundaries, may start serving other customers in addition to the parent organization ${ }^{3}$. It could outsource delivery of (parts of) its services, plugging in efforts from vendors while serving its internal customers and retaining an orchestrating role (Janssen and Joha, 2008). The center as a whole could be divested and become a business of its own (Mclvor et al., 2011). Or the center's work package and labor force could be outsourced to another vendor, possibly terminating intra-organizational responsibility for the actual delivery of services in due time (Gospel and Sako, 2010).

Complementing research paying attention to topics associated with sharing services within organizational boundaries, this chapter focuses on the inter-organizational dimension of shared services. Specifically, inter-organizational shared services (ISS) involving mutual involvement of

\footnotetext{
${ }^{2}$ Researchers refer to shared service centres (SSC), shared service organizations (SSO), e.g. (Herbert and Seal, 2012), or service-oriented enterprises (Janssen and Joha, 2008).

${ }^{3}$ See for instance engineering and maintenance services in aviation,

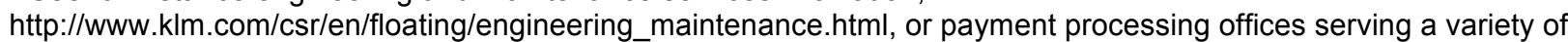
bank organizations.
} 
organizations is investigated, i.e. a relationship that goes beyond merely contracting out or subcontracting services. Mutual involvement implies more complex and often shifting roles for organizations participating in ISS as they create value in a shared manner (Porter and Kramer, 2011). It resembles Huxham's notion of organizational collaboration as ' $\ldots$ a process through which organizations exchange information, change activities, share their resources and enhance capacity for mutual benefit and a common purpose by sharing risks, rewards and responsibilities' (Huxham, 1996). Examples include collective procurement, co-creating services between vendors and their customers, and inter-organizational cooperation to deliver integrated services to common customers. Our approach excludes examples of neoclassical, hands-off contracting (outsourcing) between customers and vendors with traditional contractual organization of each organization's roles and responsibilities. In our perception, outsourcing, of for instance IT and BPO, has been around for a while and the topic has matured in terms of research. Hence, positioned in the literature on governance, this chapter does not examine market (neoclassical contracts) or intra-organizational hierarchy (internal shared service centers), but inter-organizational relationships (Bradach, 1997; Jones et al., 1997). This is also referred to as 'allying' in transaction cost economics as opposed to making or buying (Geyskens et al., 2006). Another example is constituted by Public Private Partnerships (Joha and Janssen, 2010). These relatively new relational forms of governance represent both bilateral interorganizational relationships as well as networks (Provan and Lemaire, 2012; Van de Ven, 2005). Before we proceed with the chapter's focus, we reflect on services as a concept. Services have become the backbone of advanced socio-economic systems (Grönroos, 2011b). In addition to business-to-consumer services (personal finance, medical services, entertainment, trash collection, retail etc.), business-to-business services encompass professional services such as HR, logistics, maintenance, and R\&D. Conceptually, a service is defined here as a transformational process that combines activities of value to service recipients. Service performance is intangible yet it often relies on the use of tangible products and infrastructures (Caldwell and Howard, 2010). Service encounters take place in 'serviscapes', i.e. a front stage where service recipients and providers interact, also referred to as touch points or the engagement cycle ${ }^{4}$. This front stage is connected to back stages of these stakeholders (Grove et al., 2000), encompassing people, equipment and processes for delivery (supply side) as well as customer processes (Turner and Rindova, 2012).

A common understanding is that organizations take on either a service delivery or service consumption role in vertical value chains (Shostack, 1984). This represents a traditional

\footnotetext{
${ }^{4}$ See f.i. http://thehospitalityblog.ecornell.com/customer-engagement-touchpoints/
} 
exchange-based service business model. Delivery implies designing and operationally organizing an activity system generating service elements (Oliveros et al., 2010), while consumption means that a service recipient experiences benefits from infusing its own routines with service elements ( $\mathrm{Ng}$ et al., 2012). Service quality depends on the consumer's impression of encounters with service elements provided and experienced (Parasuraman et al., 1985). For instance, a company hires an accounting firm for specific services. ISS changes this perspective on business models and associated role demarcations in service exchanges (Kamal, 2012). The word 'shared' in ISS refers to mutual involvement of distinct organization (Goes and Park, 1997). From a service perspective it could mean:

- Supply-side organizations delivering a service (e.g. integrated or comprehensive offering by diverse organizations (Kamal, 2012; Niehaves and Krause, 2010)),

- Demand-side organizations cooperating when buying and consuming the same service (e.g. collective procurement (Balcik et al., 2010)), and/or

- Organizations delivering and consuming services (e.g. shared responsibility for cocreating services and their value (Edvardsson et al., 2011; Sierra et al., 2009).

This chapter considers ISS an inter-organizational innovation. Two questions guide our study: why would organizations want to be involved in ISS? And: how can organizations ${ }^{5}$ use ISS to increase value both individually and collectively; in other words: which business model would apply and how could this be organized? In brief, value is defined as a variety of benefits organizations accumulate minus their costs (Jensen, 2010). The conceptual relationship between ISS as an innovation and value increase is represented in Figure 1.

4 We refer to organizations as stakeholders in a service eco-system, i.e. playing different roles. (Weiller and Neely, 2013) 


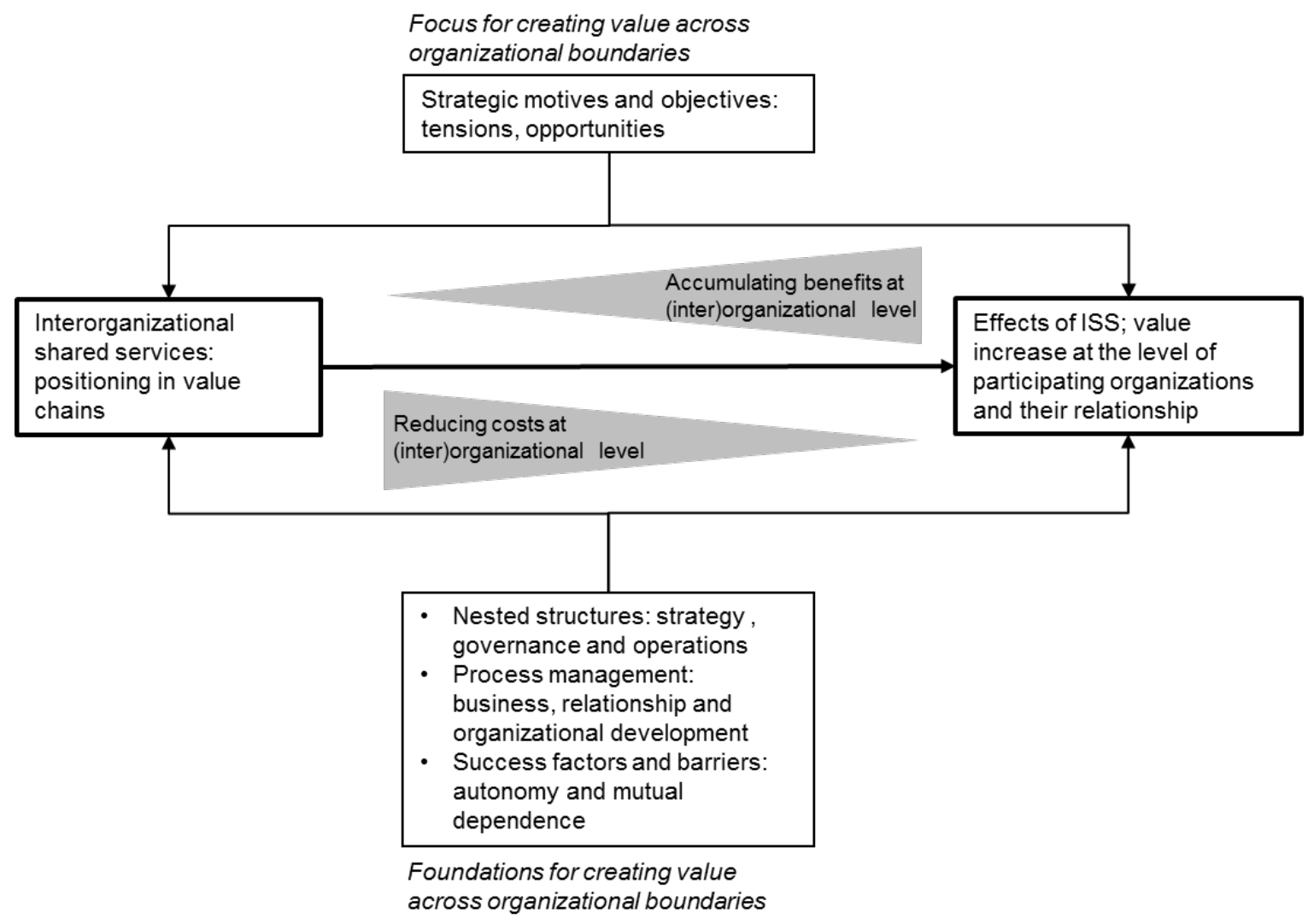

Figure 1. Focus ISS research

To give an example, suppliers of the same customer-base could combine their logistical flows or virtually combine their stocks. ISS thus improves service experienced by the customer (e.g. single point of contact instead of dealing with all suppliers separately, fewer shipments), while reducing costs for suppliers (limiting their shipments to the customer and the number of items they stock) (Cheng and Choi, 2010; Gomes and Dahab, 2010). Since ISS becomes popular in a variety of industries, this offers opportunities for synergetic insights. This chapter is built around a literature review and theory development to capture these insights; its scope is not limited to a particular industry.

Understanding the conceptual relationship between ISS and value requires insight in:

- Strategic motives and objectives for initiating ISS

- A taxonomy of ISS examples framing their position in value chains

- Structures organizations can choose to shape their relationship

- Interventions enhancing value derived from ISS

- Success factors and barriers experienced in prior ISS 
The chapter is structured accordingly, and concludes with implications and opportunities for future research.

3.3 VALUE CREATION ACROSS ORGANIZATIONAL BOUNDARIES: STRATEGIC MOTIVES AND OBJECTIVES

Value in eco-systems. Why would organizations invest in ISS? These strategic motives and objectives differ across categories of organizations (public, commercial, and NGO). In many cases, ISS is positioned at the intersection of categories of organizations. Recent work advocates a value eco-system perspective, acknowledging mutual dependence between organizations (Porter and Kramer, 2011). We start off from this perspective and elaborate on specific tensions for different categories of organizations later on. Public organizations, firms and other non-commercial organizations such as NGOs depend on support from stakeholders in their eco-system to continue operations (Weiller and Neely, 2013). Value creation has become a systemic challenge, rather than a go it alone endeavor (Jensen, 2010; Maull et al., 2012). ISS may take the form of private, public, and/or hybrid cooperation depending on the particular ecosystem organizations operate in. Within this system, organizations provide stakeholders valuable experiences while covering their expenses by the price they ask for products or services (private ISS), or by others means of funding and resourcing (public and NGO). Current research emphasizes the usefulness of organizational outcomes to others when defining value (Magala, 2009). Stakeholders in a particular context define value by the way they use products and services (Chandler and Vargo, 2011; Moore, 1995). This value-in-use notion replaces approaches focusing on the exchange value of products and services or their inherent value. In public management, value centers on the public's perception of governmental outcomes (Moore, 1995). In a commercial context value depends on what a customer can do with (features of) products and services (Grönroos, 2011b; Ng et al., 2012). What is the role of ISS? We distinguish tensions per category of organizations and at the eco-system level.

- Category-specific strategic tensions. From a strategic organizational level perspective, creating value is offset against costs. Can the organization please stakeholders with its current operations? Increasingly, inter-organizational cooperation such as ISS studied here is perceived as an opportunity to address strategic tensions specific to their category of organization. Public organizations may use ISS to better accomplish their societal role. That is, with ISS they can offer integrated services and reduce costs, e.g. combining emergency response services across municipalities. Firms can leverage the ISS concept to improve efficiency (e.g. sharing costs) or expanding markets (e.g. jointly 
setting up business in a new geographical area). NGOs may cooperate in their operational domain to extend service offerings and improve local embeddedness.

- Eco-system strategic tensions. Currently, organizations experience tensions on a strategic level when attempting to please stakeholders and sustaining operations (e.g. availability of clean water or labor force). Value chains (e.g. bioenergy chains) navigate 'between challenges and benefits of bio-energy production with simultaneous internal supply chain management and external stakeholder management needs' (Gold, 2011). Customers, for instance, demand innovative and sustainable products and services, yet global competition and substitutes erode price levels. Public organizations and other types of non-commercial organizations face shrinking budgets at multiple levels of government (Giegerich, 2012; Palm and Ramsell, 2007; Turle, 2010). Moreover, due to globalization and media, organizations have to take more stakeholders into account. Their operations are scrutinized as recent examples concerning electronics and clothing industry in South-East Asia have shown. NGOs may challenge business models and operations with negative socio-economic local impact. Tensions are defined as contradictory requirements (Smith and Lewis, 2011). At the strategic level, this means challenges - others would say: entrepreneurial opportunities (Goldsmith et al., 2010) - to sustain support (e.g. customer base erodes which requires investments) and operations (e.g. lack of affordable and capable personnel, limited resources, increasing risks, failure of complex assets, and rising costs). In construction for instance, 'there is constant pressure for the civil engineering industry to keep improving its cost efficiency. In the meantime, the industry has to operate within an increasingly stringent policy and regulatory environment, more recently driven by the growing commitment to sustainable development' (Zhang et al., 2011). An example emphasizing tensions in the sense of population needs is the bottom-of-the-pyramid movement (Collier, 2007). For instance, cooperation between Procter \& Gamble and social marketing NGO Population Services International (PSI). This project led to a product innovation geared towards the developed world - 'PUR, a sachet of powder which, mixed into a 10-litre bucket of dirty water, would make it clean and safe to drink' (Dahan et al., 2010). Considering NGOmultinational relationships in developing countries, researchers found opportunities: 'By lowering costs, reaching new groups of customers, streamlining distribution and - more broadly - by filling institutional voids through new product or service offerings, these collaborative initiatives provide bundles of social and economic value that may be very difficult to disaggregate' (Dahan et al., 2010). 
Next, we elaborate on the strategic role of ISS in creating stakeholder value on one hand, and sustaining operations and reducing stakeholder costs on the other hand.

\subsubsection{CREATING STAKEHOLDER VALUE}

First, organizations may collectively create additional value by increasing each other's business and generating positive impact in the public domain. For instance, major disasters or humanitarian crises evoke (inter)national response from businesses, governments, and other types of organizations (Quarantelli, 2007). ISS, by enhancing coherence of these efforts, could contribute to positive changes in affected communities in the sense of improved socio-economic development and security (DeConing and Friis, 2011). In developed parts of the world, ISS could activate businesses, communities and local government to improve at a collective level the strength of their socio-economic system while generating organization-level value such as enhanced public, business and consumer value (Porter and Kramer, 2011). For instance, collective use of infrastructures (Hall et al., 2013), and collectively procuring new military assets may improve national industry and result in state-of-the art technology (Rasmussen, 2011; Uiterwijk et al., 2013). Similarly, cooperation between businesses, government organizations and NGOs could result in sustainability benefits, such as new products made from recycled materials, reverse logistics, and energy independence (Gopalakrishnan et al., 2012). Moreover, organizations could share their competencies (e.g. R\&D services, market segments) to improve mutual knowledge (Gebauer et al., 2011), and to develop, produce and market products and services with innovative features and enhanced performance levels (Janssen et al., 2009; Van de Ven, 2005). These products and services may enable customers to do new things or to improve their experience. While strategic flexibility (or agility) has traditionally been defined at the organizational level, recent work points at the importance of inter-organizational innovations to create new products and services and to manufacture in a flexible manner (Oke, 2012). Upstream in value chains, ISS may fuel new ideas to suppliers to improve their products and services ( $\mathrm{Ng}$ et al., 2012).

ISS could thus improve strategic performance in the sense of adaptability at the value chain level (Wycisk et al., 2008). Conceptually, organizations combine their resources not just internally but across organizational boundaries (Galunic and Rodan, 1998; Sirmon et al., 2007). 'Strategic resources and knowledge come not only from within the organization's boundaries, but also from outside' (Lai et al., 2012: 445).' This extended Resource-Based View assumes that some organizational capabilities can be combined in a complementary manner (Caldwell and Howard, 2010; Dahan et al., 2010). For participating organizations (public or private), such combination or inter-organizational specialization allows for sustainment of capabilities they 
consider essential to (stakeholders of) their core business, while relying on other organizations for non-core activities (Brusoni, 2013; Faleg and Giovannini, 2012). For instance, in national defense programs: '(i)nstead of pursuing costly national programmes, allies can seek more costeffective solutions by pooling and sharing (P\&S) resources' (Faleg and Giovannini, 2012).

\subsubsection{SUSTAINING OPERATIONS AND REDUCING STAKEHOLDER COSTS}

Second, ISS could support sustainment of operations and reduction of stakeholders' costs. It can improve operational efficiency, risk levels and continuity (Janssen et al., 2009; Tsang, 2002). Costs (monetary expenditure, time, environmental impact/eco-footprint, and transaction costs) are incurred for categories such as personnel management, acquisition, operation and maintenance of assets, facility management, stock keeping, logistics, and procurement. Similarly, stakeholders benefiting from products and services may incur costs, e.g. transaction costs (Estep, 2012). For organizations and their stakeholders, costs diminish the value of their performances, both to the organization and their stakeholders. As Porter and Kramer claim 'companies have overlooked opportunities to meet fundamental societal needs and misunderstood how societal harms and weaknesses affect value chains' (Porter and Kramer, 2011). For example, stakeholders increasingly value environmental impact and socio-economic conditions of operations (Hall et al., 2013). From a financial point of view, organizations coinnovate with other organizations to reduce or eliminate costs. Public organizations increasingly have to follow this path since their budgets get reduced while similar or even enhanced performance is expected. Cost innovations concern reducing prices paid for resources and services (e.g. through collective procurement), standardizing spare parts to economize on stocks (Bloch, 2013), economizing on transaction costs incurred for operations (e.g. e-business), or reallocating work across organizations (Gebauer et al., 2011). Moreover, organizations can improve on total costs of ownership by considering acquisition, maintenance and use of assets on the longer term (use of e-maintenance technologies, self-healing technologies, and asset analytics (Hampapur et al., 2011)). Organizations can cooperate across their value chain to optimize their operations in terms of timing, product availability and reduction of risks (Graham et al., 2013; Yao et al., 2007). ISS may reduce smoothen supply chains (Van der Vlist, 2004) and reduce bullwhip effects: 'When an information system that allows collaborative sharing of information about the whole supply chain is introduced, the new information allows the actors to reach savings by, for example, reaching reductions in inventory. Other benefits in reducing bullwhip effect may include decrease in production overtime, increased customer satisfaction, and reduced lead times' (Björk et al., 2012). Organizations can improve performance by sharing back-office services and service delivery (Arya, 2011; Niehaves and Krause, 2010), or bundle 
incoming or outgoing logistical flows to reduce environmental impact and monetary costs. And finally, organizations may share assets, pool stocks and co-organize maintenance services to improve economies of scale, uptime, safety, and capacity use (Karsten and Basten, 2014; Van Horenbeek et al., 2013). Inter-organizational cooperation could enable proactive and life-cycle based approaches to maintenance which reduce overall costs over time (Van der Lei et al., 2012).

In short, these two aspects of inter-organizational value creation exemplify possible operationalization of network (i.e. inter-organizational) effectiveness. Researchers consider network effectiveness in relation to organizational effectiveness, noting the risk of unequal distribution of value: 'what may be a positive outcome for the network as a whole (e.g., improving innovation, economic activity, or community well-being) may prove detrimental to one or more individual network members, as when innovations are implemented by some firms but not others, making the innovators more competitive relative to others in the network' (Provan et al., 2007). Ideally speaking, ISS could increase value for all stakeholders involved: 'enlarging the pie' of a particular business market, or improving the performance of public networks (Joha and Janssen, 2010). Public organizations may share back office services to reduce costs and empower their service delivery. Next, we provide a taxonomy of ISS positioned in value chains; this offers a more precise understanding of how ISS could increase value.

\subsection{ISS AND VALUE CHAINS: A TAXONOMY}

The increasing variety of ISS examples calls for an analytical framework to understand more specifically why organizations start off ISS initiatives, and how they use ISS to increase value for themselves and collectively. We use the notion of value chains for this purpose. Value chains refer to processes of transforming inputs into outputs (Stabell and Fjeldstad, 1998); they demarcate value-generating activities within and across organizational boundaries (Ehret and Wirtz, 2010; Van Fenema and Beeres, 2010). Along the value chain, organizations add value with their business model and operations consisting of primary and support activities. Figure 2 depicts two value chains each consisting of 3 organizations, moving from top (upstream) to bottom (downstream). We distinguish three categories of ISS. First, examples that concern vertical relationships within a single value chain (as mentioned in the introduction, we are interested in mutual involvement, not neo-classical outsourcing). Second, ISS between organizations operating in their own value chains (with or without vertical impact). And finally, hybrid ISS that encompasses both horizontal and vertical cooperation. Next, we elaborate on 
specific examples of ISS across the three categories and point at challenges that we elaborate on in later sections.
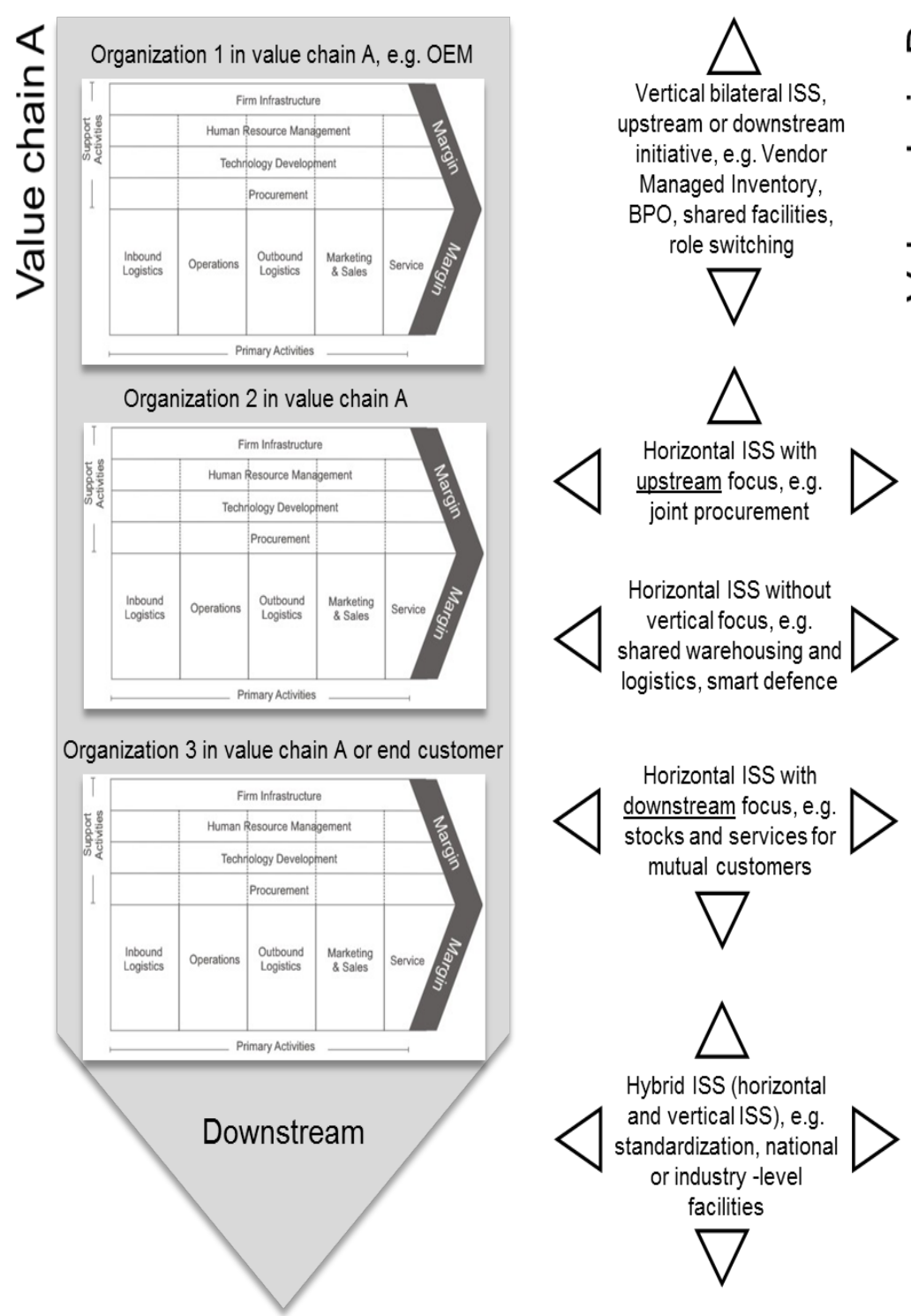

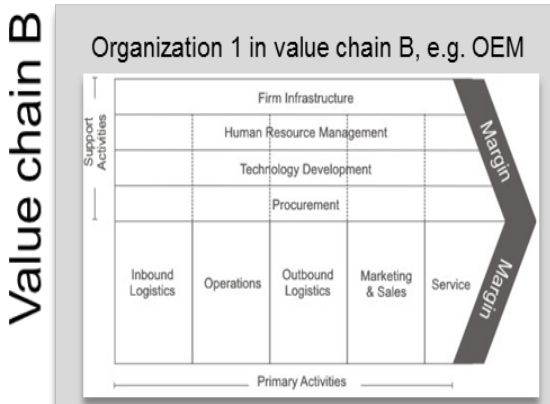

Organization 2 in value chain B

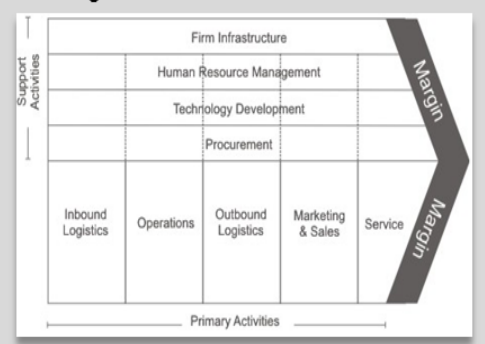

Organization 3 in value chain B or end customer

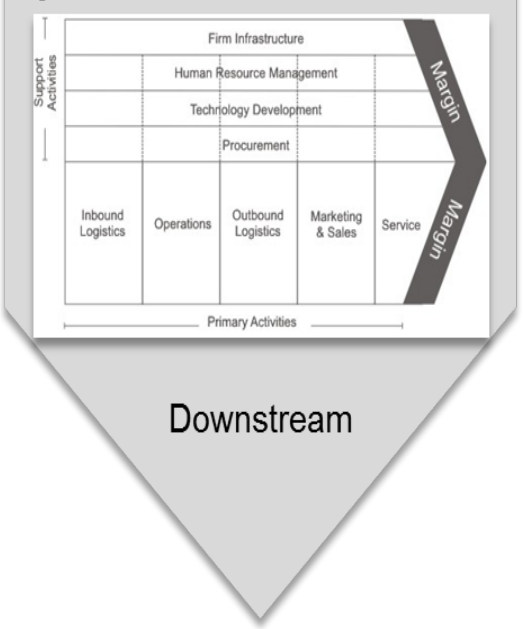

Figure 2. A taxonomy of ISS and value chains 


\subsubsection{VERTICAL ISS}

Vertical ISS re-organizes services and their associated business processes and resources in supplier-customer relationships ${ }^{6}$. Demarcation and arrangement of supplier-customer responsibilities shift (Sierra et al., 2009), resulting in renewed attention for specialization across the value chain (Johnston and Lawrence, 1991). This specialization and awareness of value chain partner's potential contributions lead to new dependencies and coordination patterns, for instance programs for engaging customers or citizens in service design and delivery (Messinger, 2013). Literature on business-to-business marketing argues that suppliers should orient their operations towards their customers' value creating activities (Grönroos, 2011b), more recently referred to as co-creation (Maull et al., 2012). New technologies such as virtual reality and social media enable close contact with customers, and increasingly customized and bundled offerings (Edvardsson et al., 2005). From a logistics perspective, suppliers gain intimate knowledge of customer operations and they use knowledge of local markets. This allows suppliers (e.g. service providers) to tailor and contextualize their services. Activities can be dynamically divided between suppliers and customers to make the best use of capabilities and resources (Gebauer et al., 2011; Rollins et al., 2011). They may take over some of their customers' business processes (Vendor Managed Inventory; Collaborative Planning, Forecasting and Replenishment (CPFR); Vendor Stocking (Bloch, 2013)), or some echelons (levels) of maintenance (Sherbrooke, 2004; Tsang, 2002). Suppliers and customer can ex ante synchronize their ordering-delivery cycles to optimize supplier operations (Van der Vlist, 2004; Van Fenema and Koeiman, 2003). Suppliers may transform their product offering into services (Performance Based Contracting), thus concentrating on the (potential) functionality a product provides instead of on the product itself. Supplier services thus become part of customer operations. Conversely, customer resources and services could empower a supplier's operations. For instance, when maintaining major assets, a supplier depends on access to and use of customer facilities and services. ISS may involve dyadic relationships, or cover an entire value chain (Jayaram et al., 2010). Examples of the latter include standardization, supply chain redesign, and sustainability initiatives (Porter and Kramer, 2011). Public-Private Partnerships could be considered a heterogeneous example of vertical ISS. Private companies may design, build, finance, maintain and/or operate infrastructures and facilities for public customers (Brinkerhoff and Brinkerhoff,

\footnotetext{
${ }^{6}$ We remain focused on mutual involvement of vertically linked organizations; this excludes shared service centres that are completely outsourced (Janssen and Joha, 2008). It could involve partial ownership, also referred to as partial vertical integration (Pishchulov et al., 2012).
} 
2011). 'The idea is that the private sector can provide the services in a more cost-efficient way, including financing' (Joha and Janssen, 2010).

Why would vertical ISS add value? Value chains become more predictable, reliable, and proactive (Van Horenbeek et al., 2013); this may enhance value chain adaptability, and capacity use while reducing costs and risks (Shirodkar and Kempf, 2006). Advantages work both sides. For instance, in the dredging business, '(i)n case this data (from the customer - authors) is shared with IHC (supplier - authors), it is able to give advice on pending failures and the need for parts. It also helps IHC to keep track of the regions the ships move to in order to adapt their part stocking decisions in the depots in these regions' (Dekker et al., 2013). In addition to such exploitation enhancement strategies (Raisch et al., 2009), from an exploration point of view, vertical ISS could foster product and service innovations and accelerate time to market (Busquets, 2010; Oke, 2012). From a customer perspective, suppliers can take care of operations that typically are non-core to the customer's operations. This concentrates managerial attention towards activities supporting the customer organization's business model (Penrose, 1959). Customers, retaining an orchestrating role for ISS activities, receive functions ('solutions') rather than products. They can focus on what suppliers' products could do for them in terms of their own value creating processes (Grönroos, 2011b). To this end, suppliers are granted room for innovations as long as functions are guaranteed. Suppliers extend their offering and develop closer relationships. For VMI this win-win has been described as follows: 'The customer benefits from higher product availability and lower inventory costs. The supplier benefits from lower overall costs (especially through reduction of the "bullwhip" effect), marketplace differentiation, and increased customer retention and sales due to the value-added services it provides' (Tatikonda et al., 2005). A supplier can execute activities at lower costs, especially when these represent its core business (e.g. Rolls Roys' engines). Vertical ISS thus could foster innovation and increase the 'size of the pie' of (segments of) the value chain (Priem and Swink, 2007). Yet for vertical ISS to work, drivers of innovation, distribution of value, and costs for customers and suppliers are a concern. These call for ex ante concepts and boundary conditions that sufficiently align interests ( $\mathrm{Ng}$ et al., 2012; Tatham, 2013; Yadav et al., 2003). Suppliers may experience cost increase when customers deviate from these ex ante agreements, or their operations call for substantial investments in new expertise. Customers, on the other hand, may incur costs for enabling suppliers to do their job and controlling them. They may get nervous from depending on supplier commitment and delivery quality. Suppliers may be tempted to put their least valuable resources on the contract to optimize their margin. Moreover, 
customers may experience inflexibility and lock-in when suppliers take over operations, accumulate expertise and become more difficult to replace.

\subsubsection{HORIZONTAL ISS}

With horizontal ISS organizations that are part of distinct value chains cooperate. This distinction could refer to merely different organizations being part of similar value chains (coopetition (Richardson, 1998; Rod and Spinler, 2011)), to geographical areas (e.g. public organizations from different jurisdictions, water companies from different countries or public transportation companies operating similar assets in adjacent regions (Karsten and Basten, 2014)), or to value chain work content (local firefighting organizations and police sharing facilities). Conversely, reasons for horizontal cooperation could stem from similarity of value chain content across geographical areas or proximity advantages (Richardson, 1998). We distinguish horizontal ISS without up- or downstream impact, versus ISS where this impact is at the core of what organizations seek to achieve collectively.

- Horizontal ISS without vertical focus concerns mutual involvement in primary or support activities. It encompasses common ownership, utilization and maintenance of resources. For instance US Army Materiel Command and US Marine Corps Logistics Command seek cooperation in terms of stocking, depot maintenance and in-theater services: 'Our collective goal in supporting the joint warfighter calls for us to establish more interoperable capabilities' (USArmy, 2013). International military and other organizations have collectively operated Kandahar airport in Afghanistan (Soeters and Tresch, 2010). European countries share a pool of military strategic transportation assets. Organizations exchange (expensive) spares and share information to enjoy better economies of capacity use (e.g. shared warehousing, shared databases). Some may merge and collocate parts of their back offices or primary business processes to economize on costs. For instance, national government's Ministries increasingly share services; locally, emergency management or health care organizations operating in adjacent regions do the same (Arya, 2011; Niehaves and Krause, 2010; Palm and Ramsell, 2007). Another example would be international cooperation of the military for training purposes or in crisis areas, or cooperation between the military and NGOs (Rietjens et al., 2013). And finally, organizations can initiate inter-organizational programs for mutual learning (e.g. users of the same assets) and link their complementary R\&D units (Feller et al., 2013). An example would be NATO Centers of Excellence serving NATO members. Over time, with sustained cooperation programs, organizations may setup shared facilities 
(Niehaves and Krause, 2010) or specialize, thereby increasing mutual dependence (Faleg and Giovannini, 2012).

- Horizontal ISS with upstream focus aims at combining demand of organizations for similar products and services. Such shared (also referred to as joint) procurement projects strengthen their position vis-à-vis suppliers. This may lead to lower prices, lower transaction costs, more innovative products, and better services quality. In short, this form of ISS translates into better service to internal customers. Suppliers could be pushed to improve their performance. Examples include national or local government, NGOs (Balcik et al., 2010), and businesses combining their procurement. Internationally, smart defense programs at NATO and $\mathrm{EU}^{7}$ combine or even mutually adjust their demand for military assets: 'Mart Laar, defense minister of Estonia, ... contends that the future for European defense lies with shared procurement and pooling resources. Recently, Estonia and Finland bought 12 Thales-Raytheon radar systems, which meant that Estonia effectively got two radars for the price of one' (Fidler and MacDonald, 2011). The value of horizontal ISS with upstream focus depends on similarity of required products, services, and functions across organizations (Uiterwijk et al., 2013); their willingness to invest in horizontal coordination; opportunities to lower internal costs; limited internal capacity to handle procurement processes (Janssen et al., 2009; Murray and Rentell, 2008); and limited conflicting interests within horizontal relationship (e.g. not serving the same customers downstream). Public organizations, including hospitals and emergency services, often participate in networks and tend to meet these criteria. Contrary to retailers experiencing commercial tension for instance (Comez et al., 2012), they do not compete for instance in their respective 'markets'. Costs for cooperation tend to increase the more assets and services appear complex and require customization (Uiterwijk et al., 2013). And second, vertically, organizations depend on opportunities to obtain better deals (f.i. 'more bang for the buck' (Fidler and MacDonald, 2011), more advanced products (Uiterwijk et al., 2013), or shorter lead times (Ghaderi and Dullaert, 2012)) when negotiating with suppliers.

- Horizontal ISS with downstream focus concerns cooperation between public and/or private organizations to better serve their customers and lower costs. For instance, NGOs and multinationals cooperate in developing markets: 'Doctors Without Borders' extensive on-the-ground networks in developing countries make it a reliable, efficient and

\footnotetext{
${ }^{7}$ See for instance http://www.eda.europa.eu/.
} 
trustworthy partner for pharmaceutical companies for distributing medications in such environments. New products targeted for developing markets are often distributed as a bundle with an array of complementary services - such as technical assistance, service and financing - that are critical to the success of the venture. Providing this product/service bundle on the ground can be a shared responsibility between the firms and NGOs' (Dahan et al., 2010). In emergency and crisis response, organizations combine their services to effectively address threats (van Opdorp, 2005) ${ }^{8}$. In the public domain, local government improves their service offering (Janssen et al., 2009). In the private domain, companies share stocks physically or virtually, exchange expertise, and they coordinate their services for mutual customers. Examples of these services include maintenance, warehousing, and logistics. Horizontally, organizations can draw on competencies that complement or reinforce each other. Moreover, they can improve capacity use and reduce costs, for instance when sharing transportation from plants to warehouses or retailers. Since this type of ISS concerns customers, commercial tensions may rise in case of private sector ISS delivering similar products or services.

Organization A, partnering for horizontal ISS, may provide services to organization B's customers (f.i. delivering spare parts from organization A's site). Organization A's initial customers may benchmark performances from organization $B$ and reconsider choices thereby hurting organization A's market. The value of horizontal ISS with downstream impact comes from increasing customer value experience (e.g. offering complete solutions $^{9}$, product/ service extension, customization, ensuring flexible delivery from a horizontal network of suppliers, offering multi-site access to services (Estep, 2012)), improving market access, while better allocating and economizing business processes horizontally.

Horizontal ISS may lead to more value when it reduces strategic tensions, while evoking limited levels of new tensions. 'Smart Defence can ... help nations meet two challenges they face today: how to get more security for the limited resources they devote to defence, and how to invest enough to prepare for the future' (Rasmussen, 2011). More generally speaking, horizontal ISS can provide new benefits (inter-organizational learning, new services, and power) and reduce costs (transactions, prices).

\footnotetext{
${ }^{8}$ NATO uses the concept 'connected forces' (Schaub Jr and Breitenbauch, 2012), and earlier Network Centric Operations or Warfare (Wilson, 2007).

${ }^{9}$ See f.i. http://www.cambridgeservicealliance.org/news/106/61/Successfully-Making-the-Shift-to-Services---ServiceWeek-2013-Write-Up.htmIFirefoxHTML\%5CShell\%5COpen\%5CCommand
} 


\subsubsection{HYBRID ISS (MIXTURE OF HORIZONTAL AND VERTICAL ISS)}

Finally, we refer to hybrid ISS when categorization as either vertical or horizontal cannot be made. Often, this involves a heterogeneous network of organizations, such as universities, public organizations and businesses (Zhang et al., 2011). Organizations cooperate in a relational setting where they take on different roles, as in 'team' interdependence (Grandori, 1997b; Van de Ven et al., 1976). Having identified overlapping interests, they engage in a complex network of stakeholders. Different types of hybrid ISS seem to emerge.

First, organizations could have interests associated with a particular geographical domain or transportation infrastructure, such as a site (retail center or industrial zone), a city (neighborhood), a region, or a transportation infrastructure (rail, water, and road). Increasingly, the role of clusters is recognized, i.e. "...geographic concentrations of firms, related businesses, suppliers, service providers, and logistical infrastructure in a particular field-such as IT in Silicon Valley, cut flowers in Kenya, and diamond cutting in Surat, India" (Porter and Kramer, 2011). Stakeholders co-invest in improving value for themselves and collectively, enhancing socio-economic activities within and beyond the geographical domain. Infrastructures such as roads and bridges (Zhang et al., 2011), sea and airports continue to be developed. Through sometimes PPP (Joha and Janssen, 2010), organizations invest in their technical-economic potential and environmental performance to better serve public, private and societal stakeholders (De Martino et al., 2013; Hall et al., 2013; Pestana et al., 2012). The Silicon valley technical-economic success has led to new concepts such as 'maintenance valley', cluster policy, and campuses that are experimented across the globe (Hospers et al., 2009). Other examples include redevelopment of office spaces, e-commerce hubs, development of regional economic clusters (LBS, 2012), or multi-stakeholder involvement for innovative tourism: 'a supportive environment is conducive to growth and expansion of niche tourism' (Carlisle et al., 2013). Local government (and NGOs in developing countries) tend to play a facilitating role as they encourage socio-economic development and sustainability within the geographical domain and promote external networking.

Second, some vital global-local value chains (food, forest, water, energy, and transportation) and critical societal processes (health care, education) warrant hybrid ISS. Scarcity and tensions tend to increase due to economic growth and scarce resources. Globalization of food chains requires hybrid ISS due to demand-supply mismatches (e.g. excess fishing (Berghöfer et al., 2008)). New agricultural development and new initiatives for sustainability engage multiple stakeholders (Devaux et al., 2011). Public institutions (at both a national and international level) and multinationals usually take the lead to improve network value creation (Gopalakrishnan et al., 2012). Similarly, combating piracy and securing or innovating energy supply chains 
encourage stakeholder cooperation, often with different perspectives and interests (Gold, 2011). In the area of health care and education, stakeholders develop new network level concepts and technologies to improve standardization and quality (Matlay, 2011); sharing technologies and implementing innovations such as telecare may offer service delivery advantages while reducing costs (Barlow et al., 2006; Estep, 2012).

Third, hybrid ISS are formed to serve collective interests in security, humanitarian crisis response and emergency management. Over the past decades, international civilian-military operations have rallied military from multiple countries, international agencies, NGOs and businesses (De Coning and Friis, 2011). They have addressed short term needs due to natural disasters, and worked with local stakeholders to improve socio-economic development in fragile states (Voorhoeve, 2010). To counter new risks in the cyber domain national governments have initiated task forces and centers that merge public, military and private expertise (Van Fenema and Soeters, 2012). Moreover, organizations share information to counter fraud, e.g. banks, insurance companies, and police. They cooperate to secure borders, such as the European Frontex organization ${ }^{10}$. A final example is community policing; police organizations cooperate with stakeholders such as businesses and social organizations to improve security and socioeconomic stability (Morabito, 2010).

Fourth, hybrid ISS concerns service logistics, supply chains, and asset-centric networks due to pressure to improve economic and environmental performance (Gopalakrishnan et al., 2012). Companies are developing and implementing collaborative concepts that horizontally and vertically span value chains (Mason et al., 2007), such as 4C (Cross Chain Control Centers, or Cross Chain Coordination Centers). These concepts seek to coordinate stocks, optimize business processes and services, and they bundle logistics across multiple organizations (Graham et al., 2013) across even competing organizations (Franklin and Spinler, 2011). Suppliers with the same downstream customer may ship to a shared Consumer Goods Consolidation Center (CGCC) and contract the same logistics service provider. High value assets in aviation, space, offshore, and the military bring together universities, businesses, and governments. They collectively develop (Berends et al., 2011), use (Faleg and Giovannini, 2012), and maintain assets based on innovative expertise and IT (e.g. prognostics) (Candell et al., 2009). Horizontal relationships (between asset users) interrelate with vertical upstream relationships (Bloch, 2013). Moreover, third parties may get involved with complementary services: 'As there is a trend (e.g. in the aviation industry) towards outsourcing the MRO (Maintenance, Repair and Overhaul) operations, pooling will move more into a vendor or third-

\footnotetext{
${ }^{10}$ See http://frontex.europa.eu/
} 
party model where a neutral independent company or pooling provider (at the first echelon) will offer component pooling options to companies (at the second echelon)' (Wong et al., 2007). Another ISS example would be the new production and service logistics network for the Joint Strike Fighter which involves governmental organizations at national and regional levels, in addition to educational institutes and international or national companies. Asset-related roles may switch or be extended. For instance organizations using and maintaining assets may share their expertise with other users. Multiple asset users may share their information horizontally and vertically (upstream). Stakeholders thus better utilize expertise and capacity; they increase flexibility at the network level, while potentially lowering costs and risks.

To conclude, these forms of hybrid ISS may overlap and coincide, for instance a regional UK government organization writes on supporting agricultural supply chains: ' $\ldots$ there are not only potential cost savings, but also environmental benefits from using shared facilities for produce going to the same retailers, or using shared transport to deliver linked products such as food and flowers' (LBS, 2012). Hence, they combine the first, second and fourth type. Hybrid ISS refers to innovation networks and collaborative commerce and communities (Bøllingtoft et al., 2012); these broaden the scope of organizations involved, and they provide room for new value adding roles (Boudreau and Lakhani, 2009; Busquets, 2010). Stakeholders increasingly recognize the importance of their eco-systems from both a sustainability and technology innovation point of view (Porter and Kramer, 2011; Van de Ven, 2005; Weiller and Neely, 2013). For instance, 'innovation by semiconductor makers must overcome technological and commercial hurdles to provide lower cost chips with more features ... Chipmakers are "critically dependent" on the industry's ecosystem to create value in their offerings' (Wharton, 2013). Across value chains, they strive for standardization and value enhancement, e.g. sustainability certification and branding (McDermot, 2011). Value creation in hybrid ISS appears less straightforward compared to vertical or horizontal ISS. Networks tend to be very heterogeneous and objectives vague and at times grand. Stakeholders may agree on common objectives. Yet operationalizing these often takes considerable time and effort, and meets with resistance. Innovation tends to be incremental and long term. Overcoming these constraints depends on the felt urgency to act as a network, or the feasibility of creating new benefits.

\subsection{FOUNDATIONS FOR CREATING VALUE ACROSS ORGANIZATIONAL BOUNDARIES}

In conjunction with ISS focus and value chain positioning, organizations shape the foundations of their cooperation. They interrelate various aspects of their own processes, suggesting a multilevel (Markand and Truffer, 2008) or nested perspective (Perlow et al., 2004). We elaborate 
such a perspective on foundations in three ways: nested structures, process management, and success factors and barriers.

\subsubsection{NESTED STRUCTURES: STRATEGY, GOVERNANCE, AND OPERATIONS}

Structures refer to patterns of organizational practices (Perlow et al., 2004), they reflect the interplay of human understanding and action. Structures are represented or shaped using overarching concepts (e.g. the very idea of 'shared services' (Herbert and Seal, 2012)), and description or prescription of structural elements (Pentland and Feldman, 2008). These structural elements result from choices on applicable dimensions, e.g. a centralized or decentralized style of decision making (DeSanctis and Poole, 1994). A concept can be understood by its philosophy (also referred to as 'spirit' (DeSanctis and Poole, 1994)) and structural elements. An example of the latter: 'The three components of smart defence are prioritisation (aligning national capability priorities more closely with NATO's capability goals), cooperation (pooling of military capability among Allies to generate economies of scale and improve inter-operability) and specialisation' (Giegerich, 2012). Concepts emerge from and influence practice. Their role can be evaluated, i.e. the extent to which they play a role in enhancing value creation (Figure 1).

As a source of structure, concepts play a key role in ISS. Organizations involved in ISS draw on generic concepts that get interpreted, adjusted and applied in a particular context (Woywood, 2002). Examples of a few concepts applicable to ISS include Vendor Managed Inventory (Tatikonda et al., 2005), supply chain synchronization (Van der Vlist, 2004), new logistics service providers concepts (Mason et al., 2007), or the Comprehensive Approach (Moelker, 2014). Such concepts concern multiple stakeholders; they move beyond organizational level innovation. By considering ISS, organizations choose from and combine concepts available in international discourses (Wong et al., 2007). These concepts concern strategy, governance and operations.

First, in a strategic sense, organizations reconsider their business model when getting involved with ISS. A business model, commonly defined at the organizational level, articulates by which value propositions an organization will serve which stakeholders, and which operations are associated with value propositions and stakeholders (Weiller and Neely, 2013). Business models change (Cinquini et al., 2013), e.g. an organization shifting from a luxury airline model towards a low cost model, or from good dominant logic towards service dominant logic ( $\mathrm{Ng}$ et al., 2012); this obviously requires internal adjustment (Bacharach et al., 1996). ISS asks organizations to think about the extent to which their current business models match or maybe compete (Weiller and Neely, 2013). As earlier elaborated upon, ISS offers organizations new 
strategic motives and objectives to deal with tensions and opportunities (see also Figure 1). Depending on the positioning of ISS in value chains (Figure 2), organizations may need to adjust their business models, and negotiate which organization is making which adjustments (Dahan et al., 2010). In fact, ISS demand business models at the value chain level, i.e. how the value chain and its constituents will relate and create value (Weiller and Neely, 2013). Organizations have developed strategic logistics concepts ('solutions') containing features that reinforce business models of multiple organizations (Gebauer et al., 2011). As they collectively develop business scenarios, they need to balance collective 'win-wins' and their own interests and prospects. That is, on the one hand business models ought to be 'flexible enough to accommodate shared service arrangements', while on the other hand 'every established individual business is unique and operates based on its autonomously defined aim and objectives' (Kamal, 2012). Business models from one particular organization, even those aimed at ISS, cannot prevail in interorganizational relationships. More applied, strategic structures refer to high-level choices with respect to specialization and service design across organizations (Brusoni, 2013). This involves topics such as which organization becomes responsible for which service modules (Janssen and Joha, 2008) or level of maintenance (Van Horenbeek et al., 2013; Wong et al., 2007).

Second, governance structures embed ISS in organizational and institutional structures. They express strategic focus and structures in contracts, and enable cooperation and control. Xu and Beamon (2006), using the term coordination mechanism, distinguish resource sharing structure, level of control, risk and reward sharing, and decision style (Xu and Beamon, 2006). This chapter's focus on ISS excludes neoclassical outsourcing. Forms of ISS mentioned in the earlier introduced taxonomy are of relational type. They often rely on contracts or high level agreements such as a Memorandum of Understanding (Uiterwijk et al., 2013). These define how ISS fits in legal regulations (in particular when public organizations are involved (Brinkerhoff and Brinkerhoff, 2011)). Moreover, contracts explicate commitments in the sense of funding (Giegerich, 2012), mutual obligations and rights (e.g. intellectual property, disclosure policies) (Turle, 2010), and performance measurement (Keebler and Plank, 2009). This is especially the case when ISS concerns operational, 'exploitative' processes such as participating in the European Air Transport Command. Another example would be maintenance and inventory policies when sharing spare parts stocks (Larsen et al., 2012). 'The financial details for being able to use and replace co-owned spares should be well defined in advance as part of the shared ownership pool. Vendor stocking arrangements place the vendor under contractual obligation to have certain machines or parts available on very short notice. In return, the potential user of these parts or machines accepts the contractual obligation to purchase vendor- 
stocked assets at a predefined premium cost' (Bloch, 2013). Contracts may contain service level agreements and Key Performance Indicators (Howcroft and Richardson, 2012), risk sharing agreements (Inderfurth and Clemens, 2012), and stipulations for calculating and sharing revenues and costs (Karsten and Basten, 2014). Valuing mutual performances tend to prove a daunting challenge; for instance what is the value of VMI for a supplier and how does this value benefit the customer? Moreover, cost sharing is challenging, requiring insight in organizationallevel costs and investments in the ISS (Wong et al., 2007). Frequently, especially with large numbers of ISS participants or an innovative ('explorative') orientation, contracts remain fairly incomplete (Hart, 1991). They resemble agreements befitting a relational form of governance (Jones et al., 1997). Governance structures also regulate who participates, how organizations make decisions (Berghöfer et al., 2008), what policies they apply, and how mutual relationships and power are kept in balance. Taken from research on service dominant logic (SDL), researchers state: 'However in SDL, no one economic actor owns the value network. Therefore, this issue includes considerations of: what power sources will be the most effective in value networks; what is the responsibility of the customer; and what or who dictates who enters and leaves the value network?' (Maull et al., 2012). Moreover, strategic control of ISS operations introduces a governance challenge. For instance, hybrid ISS in crisis response has led to network level concepts for command and control (Bigley and Roberts, 2001; Boersma et al., 2012). ISS governance may be a shared responsibility, or assigned to a lead organization (e.g. territorial responsibility in humanitarian operations) or a dedicated organization such as the US Federal Emergency Management Agency (Provan and Kenis, 2008). Research on regional healthcare ISS suggests: 'The move from decentralisation to centralisation (or vice versa) is often an attempt for the system to become more effective and efficient. There is a tendency to centralise if and when it is recognised that there are not enough economies of scale or the size of the Health District presents critical mass issues to enable efficiencies to be achieved. Similarly decentralisation occurs when the span of responsibility appears to be too large to manage the business of delivering healthcare' (Arya, 2011).

Third, to generate value, ISS connects existing operations of participating organizations and may introduce new ones. Operational structures thus encompass organizational design initiatives to define roles, procedures and infrastructures (Janssen et al., 2009). These structures operationalize strategic and governance concepts; structural elements of strategic concepts can be compared with patterns of 'on the ground' activities (Moelker, 2014). Structures at the operational level involve planning methods and workflow (re)design to optimize business processes and associated roles. Moreover, IT is a ubiquitous conceptual (e.g. business process 
modeling) and technical infrastructure (Graham et al., 2013). While organizations have invested in enterprise architectures to enhance consistency of IT investments (Ross et al., 2006), recent work extends this thinking to inter-organizational cooperation (Janssen et al., 2010). Organizations may have to standardize their operations, product data, and technical infrastructures in order to share information (Candell et al., 2009; Lia et al., 2006) ${ }^{11}$. They connect their ERP systems or introduce new technologies such as RFID (LBS, 2012). Other examples of technologies include Service Oriented Architectures (SOA) to support 'business process synchronization' of virtual organizations (Danesh et al., 2013). In crisis response, 'new information technology (IT) infrastructures or systems have been introduced ... in order to facilitate shared situational awareness' (Boersma et al., 2012); these infrastructures enact socalled Netcentric Working concepts of inter-organizational cooperation. In some cases, ISS organizations introduce new physical facilities to support their connected operations, e.g. collocated control rooms with crisis response. They may have to take local transportation, warehousing and legal infrastructures into account (Gebauer et al., 2011), especially in case ISS is located in developing countries (Dahan et al., 2010) or concerns offshore/off-road or mobile serviscapes.

\subsubsection{PROCESS MANAGEMENT: BUSINESS, RELATIONSHIP AND ORGANIZATIONAL DEVELOPMENT}

This chapter deals with ISS that involve mutual involvement and relational governance. This form of shared services differs from intra-organizational shared services and also from neoclassical outsourcing contracts where suppliers take over IT or business processes from the customer. The inter-organizational and relational character of ISS influences, as can be expected, process management. In our understanding of process management it involves management of stakeholders involved in ISS, and program-based management of the sequential phases of an ISS lifespan. Process management in ISS concerns three dimensions: business, relationship, and organizational development (Table 1).

\footnotetext{
${ }^{11}$ For instance, NATO and its partner nations have invested in standardization of technologies and operational processes.
} 
Stakeholder management

\begin{tabular}{|c|c|c|c|}
\hline & Initiation > & $\begin{array}{c}\text { Managing phases: } \\
\text { Setup and operations }\end{array}$ & Adjustment, closure \\
\hline Business development & $\begin{array}{l}\text { - } \quad \text { ISS business } \\
\text { case } \\
\text { development }\end{array}$ & $\begin{array}{ll}-\quad & \text { Organizational } \\
& \text { business model } \\
-\quad & \text { Inter- } \\
& \text { organizational } \\
\text { business model }\end{array}$ & $\begin{array}{l}\text { Business model } \\
\text { adjustment, or } \\
\text { return to } \\
\text { autonomous } \\
\text { business model }\end{array}$ \\
\hline Relationship development & $\begin{array}{l}\text { Emerging core } \\
\text { network: } \\
\text { contacts at } \\
\text { higher } \\
\text { management } \\
\text { levels }\end{array}$ & $\begin{array}{ll} & \text { Broadening intra- } \\
\text { organizational } \\
\text { involvement } \\
\text { Inter-team } \\
\text { contacts }\end{array}$ & $\begin{array}{ll}\text { - } & \text { Continuity or } \\
\text { closure }\end{array}$ \\
\hline $\begin{array}{l}\text { Organizational } \\
\text { development }\end{array}$ & $\begin{array}{ll}\text { Exploring inter- } \\
\text { organizational } \\
\text { opportunities }\end{array}$ & $\begin{array}{ll} & \text { Intra- } \\
& \text { organizational } \\
& \text { adjustments } \\
\text { - } & \text { Inter- } \\
\text { organizational } \\
\text { projects, mutual } \\
\text { learning }\end{array}$ & $\begin{array}{l}\text { Reconsidering } \\
\text { organizational } \\
\text { adjustments, } \\
\text { possibly closing } \\
\text { inter- } \\
\text { organizational ISS } \\
\text { cooperation }\end{array}$ \\
\hline
\end{tabular}

Business development. Organizations participating in ISS work according to a particular business model. They have positioned themselves in their industry's value chains. ISS challenges organizations to reflect on how they deliver, create and explore value (IMP, 2013). Specifically, such business development calls for awareness of current business models and operational concepts participants use, as well as generic conceptual trends (e.g. VMI, control towers, supply chain ERP, or smart defense). Operational concepts may apply to their primary or supportive value creating activities such as their business, IT and logistics (Porter, 1998). Organizations can choose from various concepts for these value creating activities. Once chosen, these concepts are to be aligned across primary and supportive activities (Tallon, 2012). With ISS, participants develop business cases for new operational concepts (Janssen et al., 2009). They translate generic concepts (f.i. the very idea of shared services) into ones that are useful to them. 'The translation process considered people and policy aspects and transformed the general management idea of shared services into a specific configuration reflecting the organization's individual conditions' (Ulbrich, 2010). Such a concept-centric process affects their business model and relationships with ISS partners. In an example of vertical ISS, a European manufacturing company redefined its logistics concept parameters (e.g. roles and responsibilities) in cooperation with Asian partner organizations (Gebauer et al., 2011). In a hybrid example, organizations selected promising academic and technological innovations 
to pursue (Bakker et al., 2011). Organizations, taking generic concepts into account, thus develop new concepts for their own business and relationships with value chain partners. Together, they dynamically craft their business models (Demil and Lecocq, 2010). These models have been defined as 'a conceptual framework that expresses the underlying economic logic and system that proves how a business can deliver value to customers at an appropriate cost and make money' (Van Horenbeek et al., 2012). While ISS offers new opportunities, autonomous functioning of organizations and value delivery remains paramount (Dahan et al., 2010). Hence, organizations are expected to develop inter-organizational concepts as negotiated structures that relate to their own business models in a coherent and synergetic manner. With ISS relating to participating organizations' business models, and business models are likely to differ between organizations ${ }^{12}$, organizations face a strategic alignment challenge. Building new concepts serves strategic value improvements, and yields concept-elements that change operations (Gebauer et al., 2011). In fact, organizational operations become strategically embedded in a dual manner: participating organizations' own business model and their ISS cooperation. While promising new strategic opportunities, this duality - which echoes the individual-collective dimension in our guiding questions - adds to the complexity of operations management.

Relationship development. To individuals at participating organizations, ISS represents a challenge to simultaneously innovate and develop new interpersonal relationships. Focusing on relationship development, individuals may have already worked together before. Yet the ISS network is likely to introduce new themes and to engage people who have not worked together before (Uiterwijk et al., 2013). New personal network structures emerge in conjunction with the business-content of work. Researchers increasingly point at the role of trust in interorganizational relationships. Trust implies that individuals allow for mutual vulnerability, risk, and positive expectations (Edelenbos and Klijn, 2007). Studies also show that vulnerability of relationships makes inter-organizational innovation challenging (Berends et al., 2011). Relationships interplay with inter-organizational power. They may not last due to factors such as a lack of personal chemistry or limited perceived mutual interests. Moreover, within partner organizations people may move on to new roles or leave their organization. Relationship development evolves as a dynamic process. It also benefits from deliberate interventions such as group meetings, especially when individuals work at different sites (Kumar et al., 2009). Over time, individuals can develop a shared language, set of concepts, and style of communication.

${ }^{12}$ Depending on their position in the value chain and the ISS configuration adopted. 
Organizational development. ISS innovations depend on professionals with different backgrounds, e.g. legal, business, IT, finance, and procurement. Within participating organizations, multidisciplinary teams are to be formed to handle external contacts and interface with those responsible for internal business processes. Internal understanding of ISS and commitment are to be encouraged. Changes to business processes are likely across internal value chains, for instance the way organizations order products and services, how they produce, and how they deliver products and services (see organizational-level value chains in Figure 2). ISS impacts internal business processes that may have operated in a fragmented manner. Between organizations, ISS requires development and use of coordination mechanisms such as liaisons, teams, meetings and procedures (Gittell and Weiss, 2004). These mechanisms keep partners informed and support dynamic management of stakeholders (Uiterwijk et al., 2013). For both intra- and inter-organizational cooperation, awareness of external dimensions is likely to increase. Such an extended awareness is pivotal for managing stakeholders expectations (Ancona and Bresman, 2007), and for developing and translating concepts between communities (Carlile, 2004; Levina and Vaast, 2005).

To sum up, process management integrates these three dimensions, encompassing (1) the management of stakeholders involved in ISS and (2) phases of the ISS lifespan. (1) The number of stakeholders, their involvement and influence may vary over time (De Vries, 2012).

Stakeholder interests have to be dynamically monitored and managed to deliver them value (EIGohary et al., 2006; Johansson, 2008). Moreover, as a cooperative effort, their roles, direct partners, in and contributions to ISS need attention (Janssen et al., 2007). This value stems from generating innovations that match their demands (Hall et al., 2013). In addition, for broader ISS legitimacy, it may be useful to keep external stakeholders updated (Messinger, 2013). (2) Managing phases is a process that interacts with stakeholder management and organizational contexts (Barlow et al., 2006). Several parameters of phase-based management are to be defined, such as how fast the project progresses, who gets involved in the project, how the project is structured, and how radical the innovations are that stakeholders strive for. It is a formal and informal process. On the formal side, ISS requires project plans with implementation plans, milestones, contracts and financial agreements (Faleg and Giovannini, 2012; Zhang et al., 2011). Moreover, formal methods can be used for simulating, developing and experimenting with ISS scenarios (Janssen et al., 2009; Voinov and Bousquet, 1010). Informally, representatives of participating organizations cooperate on a personal basis, in conjunction with their intra-organizational responsibilities and networks. Between organizations, representatives 
are to develop mutual understanding as well as shared insights in the potential and application of ISS concepts (Barlow et al., 2006).

\subsubsection{SUCCESS FACTORS AND BARRIERS: AUTONOMY VERSUS MUTUAL DEPENDENCE}

Finally, researchers have reported numerous success factors and barriers when studying various forms of ISS. These echo challenges of balancing processes within organizations participating in ISS (autonomy) and between them (mutual dependence). Organizations are drawn to ISS to achieve strategic objectives and reduce strategic tensions (Oliver, 1990; Smith and Lewis, 2011). An example is smart defense. While this concept addresses austerity and capability challenges at the level of NATO, this innovation itself introduces new challenges and possibly tensions (Faleg and Giovannini, 2012). First, organizational logics (their way of thinking and working) and interests may diverge (Dahan et al., 2010). Even without mutual adaptation ISS could be possible. Yet the dynamics of cooperation may move ISS in a direction that offers limited value to one of the participants. For instance, multinationals' 'partnerships with NGOs may sometimes open a path to escalating (and potentially unrealistic) demands for firms to upgrade their commitment to social development' (Dahan et al., 2010).

Second, ISS partners face dynamics of who to include, and how to deal with organizations that join or those leaving (Busquets, 2010). Moreover, within ISS, questions can be raised - in particular in ISS with large numbers of participants - such as how to engage participants (Zhang et al., 2011) and how to manage inter-organizational dynamics (Berghöfer et al., 2008). While increasingly 'innovation is a collective process which increasingly depends on the formation of collaborations and alliances' (De Martino et al., 2013), selecting and building actual ISS relationships are delicate processes. Some ISS remain limited to bilateral horizontal or vertical cooperation. Others involve industry-wide participants, such as multi-stakeholder coalitions (MSC) in agri-food, defined as 'a long-term partnership involving multiple participants from two or more categories of stakeholders (government, business, societal organizations, and knowledge institutions) with the objective of jointly defining and reaching sustainability objectives' (Peterson, 2013). Moreover, ISS may be subject to external influence and have societal impact (Gold, 2011). Organizations may join such hybrid ISS purely based on their activities. In other cases, ISS organizations could be selective in allowing others to join or stay. In order for ISS to increase value for participants, expectations and joint interests are to be strategically managed over time: which innovation projects get initiated, invested in, and 
terminated? (Bakker et al., 2011; Berends et al., 2011). This could turn out to be a complex, sensitive and at times political process (Hall et al., 2013; Lorell, 1980; Uiterwijk et al., 2013).

Third, organizations open up their 'black box' to ISS cooperation processes ('white boxing'13). Providing access to information and knowledge underpins generative processes of innovation (Rollins et al., 2011; Tsoukas, 2009). Information visibility and transparency increase (Wang and Wei, 2007), supply chains are optimized (Björk et al., 2012), and new knowledge networks and solutions are developed (Gebauer et al., 2011; Majchrzak et al., 2007). Yet this open and relational approach could be naïvely oriented towards collective ISS advantages. Opening up organizations also raises new questions such as: how much is enough, which boundaries should be defined, who invests in information and knowledge infrastructures? And: how valuable are our resources to another organization and vice versa? These questions correlate with the extent to which organizations have worked together before and how tacit (specifiable) certain knowledge is. The more knowledge is tacit and evolving, the harder inter-organizational control becomes (Loebbecke et al., 2000). Organizations may feel this tension in particular when their businesses overlap, for instance in horizontal ISS (Doz, 1996; Hamel et al., 1989). ISS participants may hold divergent value perceptions and set different priorities (Arya, 2011). They may experience intra-organizational constraints when ISS impacts how professionals work. For instance, a partner organization may take over service delivery and use facilities in exchange for other types of resources.

Fourth, from a strategic perspective, interdependence between ISS organizations increases (Pfeffer and Salancik, 1978); this may exacerbate negative emotions and change the role of trust. With respect to smart defence for instance, 'if nations specialize in some areas but withdraw from others, the accompanying increase in mutual dependency will give rise to fears of abandonment and entrapment' (Giegerich, 2012). ISS organizations may encounter new challenges when dealing with their own stakeholders. For instance, nations participating in smart defense have to interface with their national political arena. ISS thus involves a network of participants' stakeholders, demanding attention for ISS-external control and communication. Conversely, depending on the ISS environment and level of uncertainty, ISS organizations need to consider how decision making and governance at the ISS level is organized in relation to external stakeholders (Van Bortel, 2009). To what extent do they formalize contractual obligations and governance procedures (Arya, 2011), and/or do they rely on trust (De Martino et

\footnotetext{
${ }^{13}$ A term coined by Tim Grant, Netherlands Defence Academy.
} 
al., 2013; Edelenbos and Klijn, 2007)? Compared with neoclassical outsourcing relationships based on exchange and market mechanisms, ISS' dependence on shared ownership and relational governance may prove more difficult to control (Maull et al., 2012). 'Actors face competing challenges in negotiating between institutional demands of their parent organization and the joint project (Agterberg et al., 2010). There is no clear division of labor or shared means of addressing these boundaries, requiring actors to negotiate what it is that they are doing within and across practices' (EGOS, 2013).

Finally, ISS alters revenues, benefits, costs allocation and financial performance (Bhaskaran and Krishnan, 2009; Janssen et al., 2009; Wong et al., 2007). For instance, bundling transportation or sharing spares on one hand reduces direct costs, yet it may also incur new costs for coordination and extending capacity. ISS partners may have limited insight in their performance (Keebler and Plank, 2009). Moreover, they may set boundaries to the extent to which they share their own performance information, especially when commercial interests are at stake (Forslund, 2012) and incentives work in different directions (Yadav et al., 2003). Yet especially with horizontal and vertical ISS, organizations develop contracts and tools for calculating changes to revenues and costs (Inderfurth and Clemens, 2012; Karsten and Basten, 2014). This may lead to changes to ISS business processes (e.g. when to order) and rules for distributing benefits and investments. Original business case calculations and financial policies may need adjustment once the dynamics of ISS come into play. 'It is likely that not all strategic intents can be accomplished and that certain strategic intents can only be accomplished at the expense of others. Therefore, it is recommended to compare the strategic intents with the accomplished benefits' (Joha and Janssen, 2010). This is likely to remain an informal process of negotiations.

\subsection{FUTURE ISS RESEARCH: THREE STREAMS OF RESEARCH}

Two questions have guided this chapter: a strategic question (why organizations would want to invest in ISS), and a strategic organization question (how to organize for new cooperative business models). Our literature review and theory development can be summarized in an ISS research framework along these questions (Figure 3). The framework considers organizational and inter-organizational value creation across three phases of ISS (initiation, enactment, and evaluation). 


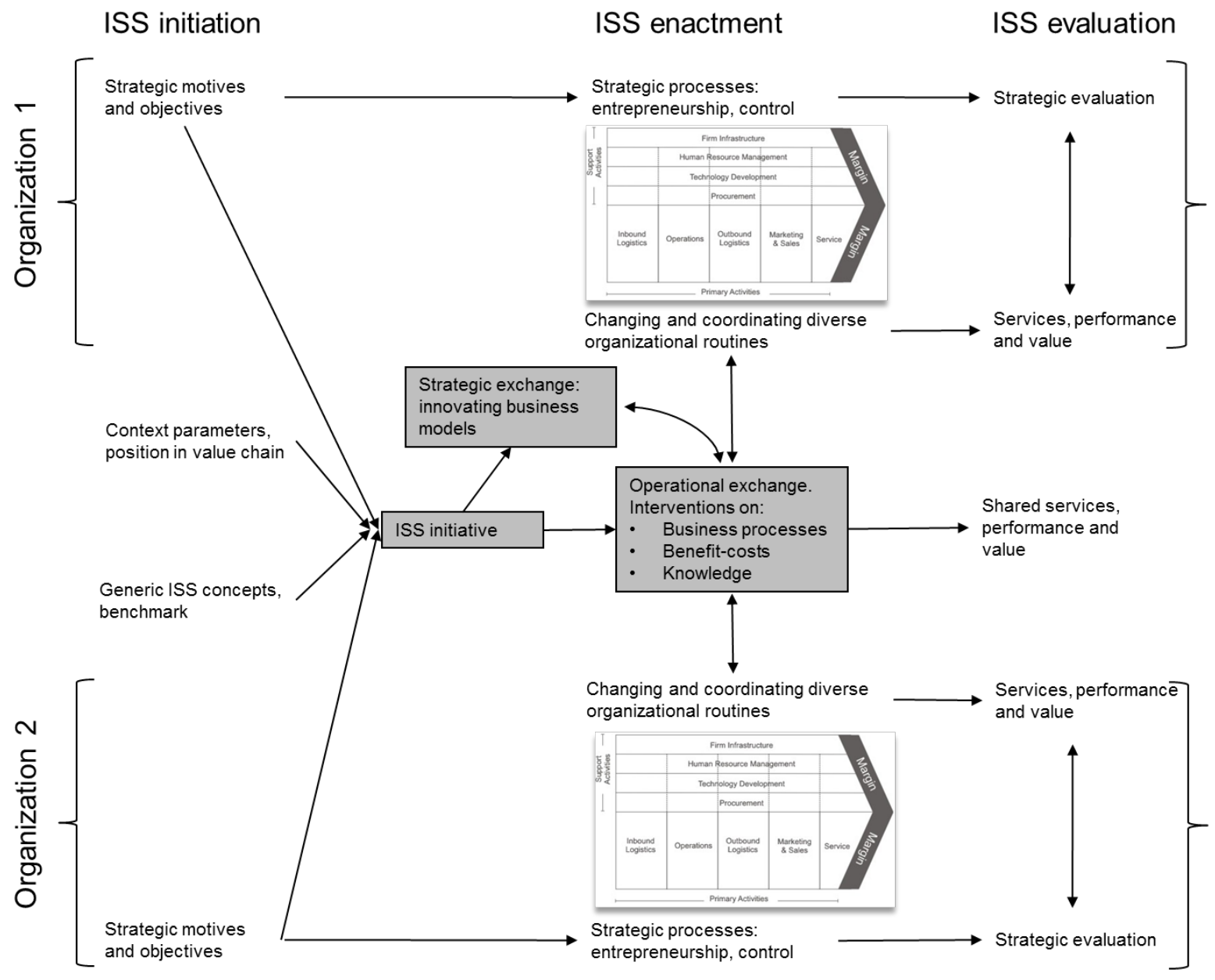

Figure 3. ISS research framework

Research on ISS has only a recent history. It complements scholarly work on intraorganizational shared services and inter-organizational outsourcing. Thus far, most attention has been devoted to the ISS initiation phase, i.e. strategic and objectives, context, and generic properties of ISS concepts (Figure 3). Studies on initial experiences have led to insights in interorganizational value creation, governance modes, relationships, and challenges of interpersonal cooperation across organizational boundaries. ISS is increasingly understood as an example of multidimensional innovation, combining innovation content (business model and business process concepts), process (actors, relationships), and context (Crossan and Apaydin, 2010). Moreover, it extends organizational level innovation such as implementing LEAN concepts or technologies such as ERP systems. New research streams on inter-organizational/ network innovation challenges researchers to build understandings of innovation as a dynamic 
multistakeholder process. Actors representing different organizations make sense of their interests and opportunities for cooperation (Berends et al., 2011; Carlisle et al., 2013; Hall et al., 2013). We presume future research will move on to ISS enactment and evaluation phases. Moreover, we encourage researchers to draw on and contribute to three streams of research each pertaining to particular dimensions of the two guiding questions.

First, literature on inter-organizational value creation is concerned with value dimensions of interorganizational relationships (Grönroos, 2011b). While value creation has been understood as a fairly static process of developing an organizational business model, recent work emphasizes the dynamic and innovative nature of business models. Since value takes on an ephemeral quality (Magala, 2009), business models become less useful as reified concepts. They are reframed as evolving, intersubjective constructions for substantiating paths of innovation in search for new value (Chesbrough et al., 2013; Demil and Lecocq, 2010; Merli, 2013). ISS research will elaborate on inter-organizational conjunctions of these paths of innovation, building on the context and background (e.g. public versus private) of stakeholders and their organizations (Dahan et al., 2010; Gold, 2011; Yaziji and Doh, 2009). Tensions and opportunities characterizing ISS in practice call for research that strives for dialectic processes to create new realities within and between organizations (Tsoukas, 2009). Examples of reframing inter-organizational exchanges must be expanded, e.g. shift from transactive to relational exchanges (Gutek et al.,1999), from supply chains to demand chains (Jüttner et al., 2006), from product to service logics ( $\mathrm{Ng}$ et al., 2012), and from purchasing to supply chain management (Priem and Swink, 2007). Such strategic reframing implies new ways of thinking about content and its relationship to strategic processes (De Wit and Meyer, 2010b).

Second, literature on strategic innovation offers a backdrop for rethinking (inter)organizational management of resources and capabilities. The Resource-Based View (RBV) is a strategic management theory that theorizes on the absorption and combination of unique resources. Recently, this thinking on organizational capabilities has been extended to inter-organizational relationships (Lai et al., 2012: 445). This earlier mentioned Extended Resource-Based View (ERBV) enables new insights on the use of unique organizational resources across organizations, i.e. network-level value creation and innovation (Busquets, 2010). Similarly, Priem and Swink (2007) note that 'R-A (resource advantage) theory may also be more useful to SCM if it is applied to value creation by the entire value system rather than to value capture by a specific firm. Considering the complete value system brings to the fore opportunities for value co-creation by suppliers and buyers up and down the value system, which thereby highlights the potential of cooperative efforts like user innovation'. An entrepreneurial approach following this 
line of thought stretches beyond organizational innovation. It calls as its counterpart for research on inter-organizational governance and control (Dekker and Van den Abbeele, 2010; Marcum et al., 2012; Uiterwijk et al., 2013). Which structures have organizations in place to govern ISS? How do they communicate amongst each other? To what extent do they share information and knowledge? Questions like these probe for mechanisms that can structure the process of realizing ISS benefits even if organizational interests overlap only to a limited extent (Gnyawali and Park, 2011; Wang and Wei, 2007).

A third and final research stream concerns routines, services and performance. Increasingly, researchers open the 'black box' of how organizations structure, bundle, and leverage resources for value creation (Sirmon et al., 2007). This approach represents micro-RBV theorizing which complements extended RBV we just discussed. Other theories also provide insight in the internal operations of organizations, for instance literature on routines (Pentland and Feldman, 2005) and knowledge cycles (Nonaka, 1994). Like RBV, these literatures could be extended to inter-organizational cooperation. That is, routines have become increasingly infused with external elements due to sourcing and internationalization of value chains (Turner and Rindova, 2012). And concentration on organizational core competencies results in knowledge cycles crossing organizational boundaries (Gupta and Polonsky, 2013; Rollins et al., 2011). Micro-level theorizing and inter-organizational cooperation will provide fruitful opportunities for further ISS research. Given the importance of knowledge for ISS, we briefly elaborate on knowledge cycles as an example (Figure 4). 


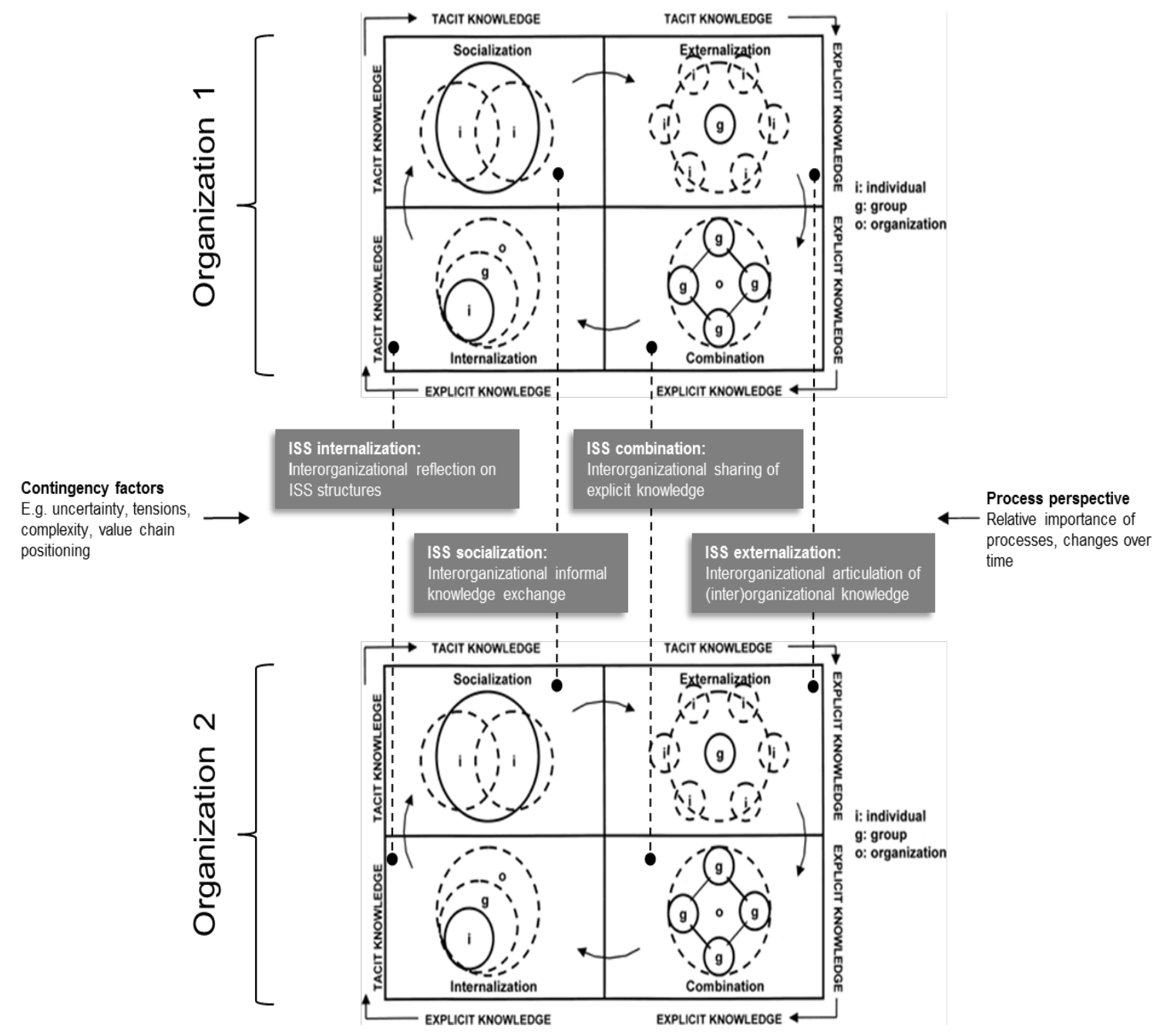

Figure 4. ISS: inter-organizational routines and services (adapted from (Armbrecht Jr. et al., 2001; I. Nonaka, 1994))

Knowledge cycles have been understood as processes for exchanging, internalizing and using expertise (Carlile and Rebentisch, 2003). Nonaka (1994) emphasizes the explicit (articulated) and tacit (implicit) nature of knowledge, abstracting from the particular content and context of knowledge. At individual, group and organizational levels, organizations engage in processes of socialization, externalization, combination, and internalization. Organizations engaging in ISS projects connect their knowledge cycles with those of the ISS partner. For instance, a supplier learns from a customer's operations to provide better or new services (Gebauer et al., 2011). For ISS researchers specific domains warrant attention. They may explore inter-organizational knowledge cycles in the area of strategic framing (business model adjustment), service and performance (re)definition, organization of business processes, benefits and costs (e.g. fair share), and Information Systems (connecting organizational systems, role of third party systems). We envision research based on both contingency theorizing (which factors influence 
the role of the four knowledge cycles processes between organizations), as well as processbased research (how do these processes change over time) (Mohr, 1982). For instance, in some cases organizations may prefer to cooperate in an informal manner when competitive tensions are low and complexity is high. In other cases, elaborate contractual stipulations are required to safeguard organizations' interests.

\subsection{CONCLUSION: INTERVENTIONS FOR ISS SUCCESS}

In this concluding section we reflect on interventions aimed at implementing ISS and making it successful. On one hand, ISS represents a concept for innovating inter-organizational cooperation, e.g. (Kumar and Van Hillegersberg, 2008). On the other hand, seemingly readymade concepts for innovation need to be unpacked, both during their development and organizational implementation stages. Their success depends on interventions that engage professionals working in organizations. Organizational change is effectuated when these professionals rethink the way they organize and do business. Interventions concern both organizational and inter-organizational processes. Their specific content and measure of success depends on organizations and their position in value chains: 'The specific type of network-level outcome considered is not, however, defined by us but depends on the particular constituency assessing the functioning of the network ... This implies that we do not consider a certain outcome a priori as the correct one because each presents a potentially valid point of view' (Provan et al., 2007). At a generic level, interventions can be studied and tried out. As a

primary philosophy, we suggest a social, exploratory approach to ISS implementation advocated by (action research) academics and consultants (James et al., 2011; Pentland and Feldman, 2008). Interventions build on subjective and bounded understandings of actors in a social context as well as actors' interactions. These social processes are focused on ISS and managed to ensure commitment and commonality of understandings, both within and between organizations. In addition, rational intervention methods have a place. Design science research proposes a method for understanding field problems and mechanisms that link interventions with outcomes (Denyer et al., 2008). Interventions are designed by means of a creative process with the potential of achieving desirable outcomes (Jelinek et al., 2008). The impact of intervention can be evaluated, leading to possible adjustment to the ISS implementation process. While interventions tend to be interpreted as operational challenges, we stress a complementary strategic dimension (see also Figure 4). Due to the often delicate nature of ISS, the role of strategic interventions and strategic aspects of operational interventions need managerial attention throughout the ISS process. 


\section{PROCESS}

"Strategy is the pattern in a stream of decisions"

(Henry Mintzberg) 


\title{
4 REDISCOVERING STRATEGIC CONTENT IN 'STRONG PROCESS' RESEARCH ON BUSINESS NETWORK INNOVATION
}

\author{
AUTHORS Van Fenema P.C. \\ Keers B.B.M. \\ PUBLICATION OUTLET Industrial Marketing Management \\ ADDRESSES RQ 2: How can content be inserted into a process view on \\ business network innovation, without losing the power of a \\ strong process philosophy, and how can such an effort \\ enable research in a methodological sense? \\ STATUS \\ Under $2^{\text {nd }}$ review
}

\subsection{ABSTRACT}

A strong process view on business networks takes 'becoming' as a starting point for understanding business networks and innovation. This view tends to leave the role of strategic content implicit and underdeveloped. Yet, embracing content from a process angle is important to obtain insight in the role of strategic intent and value transformation. A philosophical architecture for addressing this gap is currently lacking. In the context of business network innovation, this paper seeks to explore how content can remain theoretically relevant and how it can be inserted in a strong process view underpinning industrial marketing research. This conceptual paper makes a distinction between content-centric, process-content coevolution, and process-centric philosophies. These are mutually exclusive and fail to cater to the gap introduced. A fourth strategy is introduced that adopts the process-centric view as a foundation but reaches uses pragmatism and encapsulation to reach out to content research. The paper offers methodological considerations for empirical research and applies the resulting approach to industrial marketing. It concludes with implications for research in industrial marketing.

\subsection{INTRODUCTION}

The organization of value creation increasingly relies on business networks (Andersen and Medlin, 2016; Möller and Svahn, 2003) and innovation enacted by these networks. Researchers have defined networks as 'companies and relationships between them', noting the difficulty of 
demarcating network boundaries (Ford et al., 2002). Innovation in networks takes the form of business process improvement (De Martino, 2013), development of network relationships (Reypens et al., 2016), and collective product-service delivery (Tax, 2013).

Networks form a complex and constantly changing fabric of interactions amongst firms at the organizational and micro level (Bobbink et al., 2016; Storbacka et al., 2016). According to the Interactive Business Marketing approach, actors in a network are influenced by and exert influence on their counterparts in the network (Håkansson and Lundgren, 2006). To capture the ephemeral, non-stable nature of business networks, researchers increasingly adopt an endogenous change perspective (Lorenzen, 2005). They rely on post-processual (Chia and MacKay, 2007), strong change (Andersen and Medlin, 2016), or strong process views to understand how business networks dynamically evolve. This approach offers a new platform compared to firm-centric theorizing or outside-in theorizing on competitive advantage. It essentially departs from a dualist organizational boundary ontology which separates what is inside the organization from what is outside in the environment (as if the organization would metaphorically speaking resemble a physical house).

The shift towards a strong process view represents a major change in theorizing on business networks. 'Weak process sees the world as made of things and views process as a change in entities, while strong process views the world as a process in which things are reifications of processes and in a constant state of becoming' (Halinen et al., 2012). According to the latter view, business networks 'exist' in the sense of multiple intersecting practices (Holttinen, 2014). The network of relationships is '... continually changing without equilibrium and so there is a constant need to build and re-build managerial understanding of the network' (Andersen and Medlin, 2016: 11). Metaphorically speaking, the emphasis shifts from the house towards the complex, networked lives of its users who are constantly moving in or out, in person or electronically. Studies have shown processual accounts of for instance network conflicts, deal making, and learning (Berends et al., 2011; Gibb, 2016; Jarvenpaa and Majchrzak, 2016; Olsen and Håkansson, 2017).

The emerging tradition of a strong process view on business network innovation runs the risk, however, of ignoring, forgetting, or ambiguously relating to the strategic content dimension. Content would then merely represent description of what people do rather than underpinning the actual research. Researchers working within the process tradition have included content in their work, e.g. technology, products, market devices, and resources in a broad sense (Callon et al., 2007; Håkansson and Lundgren, 2006). Lacking, however, is attention to strategic content, i.e. business strategy which may drive inter-organizational cooperation. Recent work elaborates on 
inter-organizational content in the sense of 'deals' (Olsen and Håkansson, 2017), yet mostly at the project rather than strategic level.

Content could be defined in a broad sense as interrelated, unique characteristics of an object. In industrial marketing and organization science, content could include what organizations want to do (their business strategy) (Ketchen Jr and McDaniel Jr, 1996), values people consider important (Gehman et al., 2013), knowledge (Venkitachalam and Willmott, 2015), what people think and communicate about (Werner and Cornelissen, 2014), patterns of activities (Pentland et al., 2012), properties of products and services (Kuijken et al., 2017), and structural properties of how people organize (Malhotra et al., 2001). Since we are interested in the relationship between process and content for business network innovation, we focus on a narrow, strategic conception of content which encompasses business strategy (Ketchen Jr et al., 1996) at the network level, i.e. which objectives business networks strive to materialize (Kraimer, 1997), and value transformation enacted by business network processes which could render this strategy successful. Strategic content in this paper is interpreted in the sense of, first, a consensual achievement ${ }^{14}$ that is considered useful to organizations involved and that provides temporary or longer-term stability. And second, content refers to (inter)organizational value creation: what matters to organizations and how this can be realized. With respect to the 'what': it can be represented as formal statements or the fabric of organization members' ideas. With respect to the 'how': value transformation such as e-commerce (Amit and Zott, 2001) takes the form of business concepts, models, and value propositions which materialize a strategy and become operationally translated into products and services.

This demarcation of content leads a pivotal question: how can innovation change value transformation to better cater to network objectives? Rooted in the strong process tradition, our paper focuses on innovation pertaining to the strategy of organizations constituting a business network, and their organization-centric and interlinked value transformation. Our unit of analysis is business networks consisting of multiple organizations (Mena et al., 2013; Provan et al., 2007). This network level has also been called the meso level (Akaka et al., 2013; Tax, 2013), positioned between the macro institutional realm and the micro realm of operational productservice interactions.

Lack of attention to the content dimension makes it more difficult for process researchers to communicate with, first, researchers working in traditions that put content centre stage, such as engineers working on business process innovations and tools; strategists and marketers studying business strategies and business models (Kuijken et al., 2017; Martins et al., 2015);

\footnotetext{
${ }^{14}$ We thank one of the reviewers for highlighting this aspect of content.
} 
and innovation management scholars interested in content in the sense of 'outcomes' of innovation (Crossan and Apaydin, 2010). Second, practitioners tend to expect and work on concepts that propel their organization forward in the technology- and knowledge-based economy (Leydesdorff and Ivanova, 2016; Rai and Tang, 2014). Forgetting the content dimension also implies an incomplete methodology for exploring knowledge-intense problems (Perkmann, 2011) and effectiveness of business network innovation (Kohl et al., 2015). Process research does pay attention to content when focusing for instance on subjective constructing and interrelating images (Abrahamsen et al., 2016; Håkansson and Waluszewski, 2016). Yet content in the sense of the strategic logic of work and value creation could retreat to the periphery of research efforts. The content of images is more than a representation of how a network functions; it offers access to increasingly complex and rapidly developing knowledge of how value is created now and in the future. Industrial marketing concerns products and services that become increasingly technology-intense and complex (Caldwell and Howard, 2014; Yoo et al., 2012). Organizations partner to develop solutions for complex societal and sectoral challenges (Ranga and Etzkowitz, 2013). Hence, community-based or open innovation (Garud et al., 2013; Öberg, 2016) has been proposed to combine expertise. Subsequently, cooperation between organizations requires boundary spanning (Vauterin et al., 2012) around particular content themes and topics (Bechky, 2003; Vlaar et al., 2008).

In short, while picturing as a process draws attention, process research also needs to pay attention to the content of business network innovation to sustain its relevance. Insight in managing knowledge-intense interactions aimed at new content development and enactment is currently lacking. Hence, to complement process-based insights in cooperation, attention for content dynamics would enable researchers and managers to develop understanding of how knowledge-intense practices change. The gap between strong process and content-based research seems presently difficult to resolve. In fact, a philosophical architecture for addressing this gap is currently lacking. Strategic research on business network innovation needs a philosophical reflection and a foundation for theorizing and empirical research - in addition to methodological problematizing on case studies and other process methods. The objective of this conceptual paper is to explore how strategic content can be inserted in a strong process view on business network innovation, without losing the explanatory power of a strong process philosophy. Moreover, it seeks to understand how research on business network innovation can be strengthened in a methodological sense.

We make the following steps to accomplish this objective. We distinguish three research philosophies considering process and content. Working in the strong process tradition, these philosophies are synthesized using pragmatism and 'encapsulation'. We then examine how we 
can use this approach in a methodological sense for examining business network innovation. We thus seek to enrich the process view by theorizing on the role of content. This reinforces current work on business networks processes with an approach for obtaining insight in content evolution without losing the strong process foundation. Our philosophical and methodological considerations will help researchers answer research questions such as: Why do business network innovations with particular content features (such as servitization, digitalization) emerge? How do these business network innovations interrelate with ongoing business practices? And why are some innovations successful and others not? The paper concludes with implications for research and directions for future research.

\subsection{BACKGROUND: INNOVATION AND BUSINESS NETWORKS}

A strong process view implies that business networks are understood as being in constant flux. From this angle, participants co-construct innovations in the sense of networked interaction, knowledge exchange and learning to do things differently (Knight, 2002; Möller and Rajala, 2007; Waluszewski and Håkansson, 2007). Innovation reinforces the notion of a 'constant state of becoming' (Halinen et al., 2012). It enables '... the creation of substantial new value for customers and the firm by creatively changing one or more dimensions of the business system' (Birkinshaw et al., 2011: 29). We concur with this definition and apply it to business networks as a research context. Business network innovation seeks to find ways to obtain more benefits and or lower costs from their resources (Dyer and Singh, 1998; Van Fenema et al., 2014). Scholars distinguish social-relational and technological process innovation (De Martino, 2013; Håkansson and Snehota, 1995; Saji and Ellingstad, 2016). The former concern the development and implementation of new managerial practices, processes or structures (Birkinshaw et al., 2008), while the latter examines the role of new technology in organizations and organizational fields (Greve and Seidel, 2015).

\subsubsection{BUSINESS NETWORK INNOVATION: LEVELS AND PROCESS-CONTENT DIMENSIONS}

In industrial marketing, innovation is associated with platforms for value creation ranging from macro to micro: networks (Matthyssens et al., 2006), business models (Simmons et al., 2013) and product-service offerings (Eisingerich et al., 2009). Two features deserve more attention for studying business network innovation: multilevel approaches and process-content dimensions. Multilevel approach. Researchers increasingly frame innovation as a multilevel phenomenon (Berends et al., 2011; Van Dijk et al., 2011). Instead of merely looking at interfirm network 
structures, innovation in networks has been understood as interfacing of organizational and technological resources across organizational boundaries (Bygballe et al., 2014). Since networks involve organizational and network (inter-organizational) levels (Provan et al., 2007), network innovation can follow this distinction. First, organizational innovation often refers to enhancement of coordinated capabilities a firm uses to compete (Grant, 1996). Dynamic capabilities reflect the organization's ability to integrate, build, and reconfigure internal and external competencies to cope with rapidly changing environments (Agarwal and Selen, 2009; Kohlbacher, 2013). While such strategic management studies tend to develop generalized approaches to organizational innovation processes, other research has examined how innovation actually evolves across hierarchical levels (Burgelman, 1996; Whittington, 2006). Second, the locus of innovation has shifted from the firm, team or individual towards the interorganizational network in which a firm is embedded (Pittaway, 2004). The network is considered playing a pivotal role in helping organizations to acquire the resources and information needed to become more responsive to external demands. Organizations form cooperative relationships as they relate their own development with partners' development (Håkansson and Eriksson, 1993). Inter-organizational innovation has been pursued to realize complementary resource combinations (Kale et al., 2002). Internally within the network, a successful inter-organizational relationship could have a positive impact in the sense of offering access to new expertise value which may accelerates innovation processes (Gnyawali and Park, 2011; Lewin et al., 2011). External to the network, towards the partners' markets and stakeholders beyond their primary network, combining products and services could underpin new value propositions (Ye et al., 2012). Research is emerging that relates industrial marketing theory with (open) innovation (Öberg, 2016). This could further strengthen a multilevel approach to business network innovation. Combining organizational innovation studies with research on inter-organizational dyadic and network relationships enhances insight in the process of how smaller innovations lead to network-level innovations and vice versa. A multilevel approach can shape process research on business network innovation: processes at different levels and across levels can offer insight in how the network evolves.

Process and content. Innovation research predominantly adopts a process approach though seldom a strong process view. For instance, research explores factors that influence the development of stages through which relationships may proceed (Gulati, 1998). Often, innovation processes are considered instrumental steps to be managed for accomplishing an organization's or network's agenda. Content is then considered an outcome of innovation, for instance a new business model or technology (Crossan and Apaydin, 2010). Researchers tend to look for processes - bridging the inner and the outside aspects of an organization - that can 
be abstracted and externally generalized for research and practice. For instance, research has provided insight in generic processes of absorption (Lewin et al., 2011), routine development (Dionysiou and Tsoukas, 2013), service management processes (Grönroos, 2011b; Lusch et al., 2010), and learning capability (Gibb, 2016).

These examples of innovation research could be framed by the discussion on weak versus strong process research. We seek to extend this discussion to the role of content. So far scholars tend to mention the content of innovation only on the sideline. Content, as earlier defined at the strategic level, concerns the creation and exploitation of a new idea in relation to the content of current organizational activities. New ideas are for instance related to a new process, technology, product, or service and generated by people's knowledge (Pittaway, 2004). We argue that innovation as a process of generating and exploiting new ideas encompasses process and content. Yet refined insight in content, a philosophical foundation for combining process and content, and methodological insights for studying and co-shaping process and content are lacking. The next sections contribute to addressing these gaps.

\section{4 'CONTENT' AND A STRONG PROCESS VIEW ON BUSINESS NETWORK INNOVATION: AN UNEASY ALLIANCE}

\subsubsection{A GENERIC VIEW ON CONTENT}

What role could content play in process-based research on business network innovation? First, different philosophical stances with respect to content can be adopted. Content can be understood in a reified sense, as 'something' - for instance a business strategy, a value proposition or knowledge. Given the dynamics of business networks and organizations, researchers increasingly advocate an alternative view on content that acknowledges its ephemeral, 'under construction' nature (Alvesson, 1998; Ballantyne et al., 2011). They use verbs instead of nouns, like business modelling (Baden-Fuller and Mangematin, 2015), aligning business and technology (Chan and Reich, 2011) or knowing and practicing (Geiger, 2009). These verbs reflect a different ontological positioning that puts human agency centre stage (Garud and Karnøe, 2003). A second foundational aspect is the knowledge-intense nature of content. This applies to people creating and being appealed to by content, as well as products and services as artifacts resulting from multiple specialized knowledge flows. Content can be associated with fostering generation of new knowledge (Tsoukas, 2009), like an entrepreneur starting with a new product idea. This triggers knowledge processes to develop, make and market the product. Likewise, consumers need to understand what the product is about, how they could use it, and what new affordances the product entails (Holttinen, 2014; Yoo et al., 
2012). A third and final foundational element concerns the composite and relational nature of content. It consists of elements (features such as activity steps, resources) that can be combined into narratives (Pentland and Feldman, 2007). Research on technology in organizations posits that features of technology and organizations could clash and get adapted (DeSanctis and Poole, 1994). Narratives emanating from such relational processes can be analysed and articulated, for instance how people respond to (features of) a new technology. Narratives expressing content are not stable from a strong process or practice-based angle (Orlikowski, 2000). They can be deconstructed, reshaped, and related to alternative narratives (Frandsen et al., 2016). Moreover, people do not act in a closed system content-wise. They learn from others and pick up ideas developed and tried elsewhere (Aaltio-Marjosola, 1994). Content thus is a consensual achievement ${ }^{15}$, representing a dynamic and open order. Its coherence is transient due to ongoing adaptation processes (DeSanctis and Poole, 1994). Content evolves in changing patterns within and across organizations (Håkansson and Snehota, 1989; Lewin et al., 2011). While ordering of content is necessary for value, 'value in use' changes in a context-dependent manner (Chandler and Vargo, 2011; Holttinen, 2014), and hence the role of order as well. This applies especially to business networks consisting of multiple organizations, with less opportunity to settle on for instance a particular content narrative (Lowe et al., 2016; Uiterwijk et al., 2013). In addition to the generic view on content presented so far, we proceed with distinguishing different types of content of importance to value creation.

\subsubsection{TYPES OF CONTENT IN BUSINESS NETWORKS}

While our paper concentrates on strategic content, the first type, we include organized activity and technology content to offer a richer background of content in business networks. This way, we link strategic content to the micro-level phenomenon of value creation (Akaka et al., 2013). Strategic content refer to the interests and ideas that network value creation consists of (Alvesson, 1998; Keen and Williams, 2013). As mentioned, it encompasses strategic interest (what organizations in a business network want to achieve) and value transformation (models for effectuating this intent). Such content is nested (Perlow et al., 2004) in the sense of industrylevel interests and ideas and organizational or micro-level interests and ideas. Content changes over time, sometimes in a radical sense when the 'recipe' of an industry changes (Matthyssens et al., 2006; J.-C. Spender, 1989). Examples include the increasing impact of sustainability

\footnotetext{
${ }^{15}$ We thank one of the reviewers for highlighting this aspect of content.
} 
(Gopalakrishnan et al., 2012), the transition from goods-dominant to service-dominant value creation (Grönroos, 2011a; Lusch and Vargo, 2006), the emergence of digital value creation (Henfridsson and Bygstad, 2013; Yoo et al., 2010), or the transition towards hub-and-spoke airline operations (Greve and Seidel, 2015). These macro trends interact with actual changes in organizations and networks.

Strategic content is relational. It encompasses interaction between demand (what customers value) and supply (offerings). Demand content has been studied by looking at customer preferences and how customers create value in their own context (Holttinen, 2014). Supply content concerns business models defined as '... a concise representation of how an interrelated set of decision variables ... are addressed to create sustainable competitive advantage in defined markets' (Morris et al., 2005: 727). Business models are networked to produce value for end customers (Heikkilä et al., 2014; Nenonen and Storbacka, 2010). Interaction of demand and supply can be conceptualized as value practices that translate expectations into offerings, and enable experience and adjustment of these offerings (Gehman et al., 2013; Grönroos, 2011b).

Organized activity content concerns how partners in a business network organize their activities at network and organizational levels. At the organizational level, content represents ideas for structuring how activities are coordinated, for instance in a centralized or decentralized mode, or the idea of shared services (Herbert and Seal, 2012). At the network level, governance concepts have been proposed that offer alternative modes for linking organizations (Jones et al., 1997; Provan and Kenis, 2008), including public-private partnerships (Brinkerhoff and Brinkerhoff, 2011), and triple helix cooperation (Leydesdorff and Ivanova, 2016). These concepts may not express strategic content but they concern how organizations relate.

Technology content includes products, services and solutions that in conjunction undergird networked value creation (Busquets, 2010). Technology content has been dissected as consisting of features, core ideas, and layers (DeSanctis and Poole, 1994; Griffith, 1999; Yoo et al., 2012). Technology is constructed during development and enactment in organizations and networks. Recent work emphasizes the socio-material nature of technology and affordances (Leonardi, 2013b). While early research on technology and its use concentrated on organizations and teams, increasingly, technology (development) is considered at the network level (Calia et al., 2007; Håkansson and Lundgren, 2006). This introduces new challenges such as governing complex and heterogeneous technologies (Holmström and Stadler, 2001). So far, a more refined understanding of content in business networks has been explored. Yet how does content relate to process research? 
There have been several ways to study content in research on business network innovation.

First, content can be studied as a topic by itself. For instance, researchers have introduced new models for understanding servitization and digitization of value chains (Barrett et al., 2015; Vendrell-Herrero et al., 2017). Process and time hardly play a role in this approach. Second, interplay over time of network processes and content could offer a valid research design: network actors shape and reshape value propositions (Canhoto et al., 2016; Holttinen, 2014). Metaphorically, content could be interpreted as a product that gets designed and assembled. And third, research could consider content an outcome and examine network actors' journey towards this final 'destination' (Crossan and Apaydin, 2010).

While these three research patterns introduce some process elements, content remains a somewhat mystified and difficult to grasp concept. A strong process view shifts towards an ontology that puts interhuman and inter-organizational interaction centerstage (Håkansson and Ford, 2002; Halinen et al., 2012). It rejects a reified notion of content in accordance with a longstanding tradition of practice-based theorizing on technology (Orlikowski, 2000). Adopting a strong process view, researchers could study content evolution, yet this depends very much on their preferences and research context. Content is not an obvious phenomenon to be embedded in strong process research and underpin theorizing. The shift in technology research to sociomateriality compensates for this problem (Leonardi, 2013b), yet a similar shift does not seem to be useful for studying strategic content in industrial marketing. Strategic content concerns intent and value transformation rather than materiality. How can strategic content play a role in strong process research? Before answering this question, we reflect in more depth on forms of process-content research.

\subsection{A TYPOLOGY OF PROCESS-CONTENT PHILOSOPHIES}

To make progress on the inclusion of content in strong process research on business network innovation, we develop a philosophical typology of process and content research. Typologies clarify emerging structure of a research field (Doty and Glick, 1994). Review studies in the area of innovation studies (Crossan and Apaydin, 2010) and business models (Foss and Saebi, 2017) have supported development of typologies. As far as we know, a similar review in the area in business network innovation does not yet exist. The typology introduced here offers a first step; the objective of this paper is to rediscover content in strong process research, rather than to provide a review. 
Theorizing on the interplay of process and content requires a starting point of thinking, a philosophy. While research philosophies are commonly perceived as excluding each other, this does not imply that awareness of different options is no longer important. Literature shows different philosophies that separate research communities pursue. For instance, knowledge management researchers contrast studies that assume knowledge is 'something', existing on its own and being transferable, with studies emphasizing humans as knowing and interacting actors (Bechky, 2003). This contrasting implies that holding on to these two philosophies simultaneously does not make sense. Likewise, researchers contrast process and variance theorizing, with the former focusing on evolving reality and the latter on causal relationships between variables (Mohr, 1982; Van de Ven, 2005).

Since philosophy represents a foundation of research traditions, it is important to reflect on possible philosophies, and to provide clarity as a researcher on the philosophy adhered to. Reverting to process-content philosophies, researchers express an unease with the current condition of the field. Confusion pertains to the relationship between process and content, with research communities tending to stick to their research tradition. In a philosophical and methodological sense, an organizing framework is lacking (Elter, 2009) to understand how content plays a role in research on business network innovation. To develop such as framework we consider four philosophies. We focus on philosophies of theorizing on content, rather than content of value creation and innovation itself.

\subsubsection{CONTENT-CENTRIC PHILOSOPHY}

First, in a content-centric philosophy, content is assumed to be palpable, demarcated, and it exists independent of processes leading to or making use of content. Content is pervasive, complex and layered: it includes specific features (possibly a material existence) and an underpinning idea, or body of thought (DeSanctis and Poole, 1994). Empirically, people can be asked about their mental model of how value is created and how a network works (Abrahamsen et al., 2016). 'A' model would emerge from such research. Adjustment of content (often between multiple types of content) takes centre stage (DeSanctis and Poole, 1994), especially in the context of innovation (Leonard, 1988). In this first philosophy, the process by which content gets combined and changed receives less attention or serves merely as a hermeneutic instrument for eliciting patterns (Pentland and Feldman, 2007) and meaning (Schreier, 2015). Content consists of elements that together become meaningful in a cross-sectional manner, e.g. the logic of a business model or value proposition (Levina and Ross, 2003; Martins et al., 2015). Content could be understood as a dynamic phenomenon, e.g. elements of a customer journey (Tax, 2013). The distinction of elements that together form a pattern - one could metaphorically 
imagine a swarm - implies that researchers focus on consistency, coherence or narrative patterns across these elements (Ibarra and Barbulescu, 2010; Pentland and Feldman, 2007; Weller, 2012).

For business network innovation, a content-centric philosophy can be related to strategic content: it refers in a business sense to co-creation of products, services, value propositions and business models (Nenonen and Storbacka, 2010; Van Fenema et al., 2014), increasingly relying on advanced technologies (Amit and Zott, 2001; Bharadwaj et al., 2013; Yoo et al., 2010). Aimed at business model classification (Foss and Saebi, 2017), most work concentrates on organizational level strategic content such as business models (Amit and Zott, 2001), business strategy (Bharadwaj et al., 2013), and value propositions (Levina and Ross, 2003). Content of network value creation tends to be quite generic and sparse. It can be found in research on industry recipes (Rosa et al., 1999; Spender, 1989), public-private cooperation (Klijn, 2010), interlinked business models (Bankvall et al., 2017; Nenonen and Storbacka, 2010), smart business networks (Van Heck and Vervest, 2007) and visionary theorizing on for instance shared value creation (Porter and Kramer, 2011).

For theorizing on business network innovation, a content-centric philosophy would concentrate on innovation content that impacts the two dimensions of strategic content: intent and value transformation. On one hand, innovation impacts the content of what networked organizations want to accomplish on their own and collectively (Oliver, 1990). And on the other hand, content of what they know and do themselves (Kogut and Zander, 1996) and content of interorganizational contracts (Berends et al., 2011) matter as expressions of networked value transformation. The content of business network innovation enables new ways of serving demand, exploit opportunities and commercialize technologies (Keen and Williams, 2013). It could include improvement-oriented concepts such as Just In Time management (Kannan and Tan, 2005), service dominant logic (Lusch and Vargo, 2006), technology with strategic impact such as analytics (Trkman et al., 2010), and the instrumental importance of cooperation (Keers and Van Fenema, 2015). According to a content-centric philosophy, innovative content can replace old content because it assumes a new coherent set of features. Outcomes of network innovation thus stem from changing content that becomes re-reified, e.g. a new business model (Crossan and Apaydin, 2010). Such an innovation outcome consists of altering key features or combining content in novel ways. Content-centric theorizing offers important insights in the conceptual logic of value creation, including categorization (which network business models can be distinguished) and variance explanation (why does a particular network business model (no longer) work). Yet reification poses new challenges as it can 'stifle' (Lane et al., 2006) research. The actual process through which content effectuates innovation and value creation remains 
unclear (Sminia and De Rond, 2003). Explanation of the effectiveness of business network innovation is lacking.

\subsubsection{PROCESS-CONTENT CO-EVOLUTION}

Second, starting in strategic management, a philosophy has been developed that considers strategy content and process as two related yet distinct phenomenon (Barnett and Carroll, 1995; Miller et al., 1988; Pettigrew, 1992). Process obtained a new spot compared with the previous philosophy. '... (S)trategy content emerges through implementation and, hence, is inimically entwined with the processes that produced it' (Le and Jarzabkowski, 2014). This view offers an intuitively legitimate way to extend content-centric research (De Wit and Meyer, 2010) and adopt a longitudinal perspective. Content is understood as part of an emerging pattern of translating '... intentions of executives ... into genuine organizational change' (A. M. Pettigrew, 1987) as cited in (Sminia and De Rond, 2003: 1330). The second philosophy stresses the role of context and integrates strategy development and implementation (A. M. Pettigrew, 1992). It embraces a situated structuration view on content (Orlikowski and Robey, 1991). Research in this line of thinking, e.g. technology structuration, acknowledges content (referred to as structures) as well as process as interactive objects of study. Structures depend on and shape human agency (Barley, 1990; Giddens, 1979; Martins et al., 2015). Content and process (interaction) may explain performance (Ketchen Jr et al., 1996); they co-shape a specific phenomenon such as diversity awareness and competence, and thereby explain outcomes (Avery and Thomas, 2004).

Industrial marketing. In industrial marketing, innovation can be understood as human-centric processes effectuating changes to business models and value propositions (Simmons et al., 2013). With some exceptions (Bankvall et al., 2017), most of this work remains at the organizational level. Process seems instrumental to achieving better content, and could be interpreted as 'how things actually went' (performative view (Garud et al., 2014)), or as prescriptive steps in a design process (Franca et al., 2017). Process stands for (micro) human interactions and cognitions (e.g. learning, decision making), yet virtually without reference to what these processes are about (Elter, 2009).

Renewal. Several attempts have been made to renew the second philosophy, enriching theorizing on the relationship between process and content. Some propose integrative concepts such as events and issue streams in which process and content come together (Langley, 1999). Others use process and content as explanatory variables between the context and structure of an organization (Miller et al., 1988). Content has also been used to analytically distinguish 
processes, differentiating between for instance strategic (abstract content) versus specific issues emanating from ongoing organizational experience.

Co-evolution. In business networks, the second philosophy extends the first one with an equal role for process theorizing. Hence, innovation involves according to the second philosophy not only how content elements interrelate and change, but also the processes by which this occurs. The second philosophy originally emerged from structuration theory in sociology, yet currently it tends to be somewhat implicit with respect to its intellectual foundations. It seems that a coevolutionary notion drives this theorizing: on one hand, conceptual constructs are assumed to exist on their own, while on the other hand they are related, change and influence each other. In biological co-evolutionary theory trait changes of individuals from different populations are examined (Janzen, 1980), in an organization and marketing science, 'the environment' and 'the organization' take centre stage in co-evolutionary theory (Djelic and Ainamo, 1999).

Research streams. In various streams of literature reasoning on the relationship between process and content returns. For instance, strategic management scholars argue that dynamic strategy processes (or more recently referred to as practices) alter the content of organizational strategy (De Wit and Meyer, 2010). Content remains a static and reified 'thing'. The way process draws upon and alters content remains ill understood, with different literatures making some progress. 'Knowledge' in knowledge management literature connects process and content because knowledge as a concept is used for looking at processes (e.g. transfer, combination) as well as content (what knowledge is about). Commonly, the content side of knowledge does not play a major theoretical role in the argumentation, as scholars are interested in how knowledge management may lead to beneficial outcomes (Andersson et al., 2015; Rothenberg, 2003). Similarly, research on social networks and knowledge theorize on the impact of a particular interaction pattern (ties) on knowledge innovation (Kang et al., 2007). Some research on organizational change pays attention to process, content and context, including skills regulating their interrelationships (Pettigrew, 1985). For instance, skilled executive can 'mobilize' the organization's context to legitimize process and content pertaining to strategic change. Finally, literature on routines proposes an iterative model of ostensive and performative aspects of routines. Performances - what people do - draw on ostensive (structural) features of a routine, and change these features, especially when people encounter tensions between service expectations and delivery (Feldman, 2000).

Business network innovation. How does the second philosophy approach business network innovation? The attention for both process and content opens opportunities for theorizing on network and organization level processes and content. For instance, the phenomenon that organizations (suppliers and customers) shift from a product to a service based business model 
(Ng et al., 2012) can be understood on one hand as a content topic of study: what does this new content entail, and how does it relate to earlier content? On the other hand, the process part of this philosophy focuses on change over time, that is, how organizations learn about and develop a new concept, and how they implement and adjust it. A co-evolutionary approach would argue that achieving beneficial outcomes of business network innovation depends on synergy between process and content in a particular context (A. Pettigrew, 1985). Similarly, researchers have explored how dissonance between an organization's strategy and operations triggers processes to reduce tensions (Bacharach et al., 1996). The strength of the second philosophy is the pairing of process and content tied to events, issues, or outputs (Langley, 1999; Murray, 2002). At the network level, organizations engage in a joint trajectory that offers opportunities for this pairing. They reflect on the content of their operations and business relationship (for instance a productbased exchange); from a process angle, they collectively start innovating to insert new concepts (e.g. service-based working). This will be represented in process (who talks to whom when) and content elements (what they talk about). Such process and content trajectories would have to be synchronized to enable process and content development. Beneficial outcomes would result from changing content of organizational and network processes in accordance with expectations emanating from participating organizations' context.

Concerns. The co-evolutionary approach extends content-centric thinking and has an intuitive legitimacy to it. Yet it obscures the philosophical problem and 'deadening' effect (King, 2004) of dualism. By according separate existence to two phenomenon, interaction between them remains problematic (Robinson, 2016). In fact, similar unease was well expressed back in 1994 by a set of questions formulated at the end of a strategic management conference. These could be considered reflection on weak process theorizing and the beginnings of a strong process view:

- 'Are there strategies?

- How do industries evolve?

- How is organizational competence generated and sustained?'

(Rumelt et al., 1994) as cited in (Sminia and De Rond, 2003: 1336)

\subsubsection{PROCESS-CENTRIC PHILOSOPHY}

The third philosophy emphasizes the construction of reality as a process of ongoing interactions (Håkansson and Waluszewski, 2013). This philosophy is rooted in a constructivist ontology, representing a 'strong' view on process or change (Tsoukas, 2005). We concur with this strong view, implying that networks are not so much understood as structures or relationships, but intersecting practices that dynamically evolve (Holttinen, 2014). We therefore do not consider 
here theories on processes which reflect a weak process view; these theories aim at a specific type of causal explanation or they inform practitioners with prescriptive ideas (Dyer et al., 2001; Sarkar et al., 2009; Sirmon et al., 2007). Rather, taking human agency as a starting point, we are interested in what people think and do when participating in - and thereby constructing business networks. Building on a monist philosophy tradition, separation of organization and environment is rejected; as they interact, people make sense of the world (Weick, 1982). Process research - using verbs - highlights organizations' agency, e.g. concepting, acting, experiencing (Sminia and De Rond, 2003) and distinguishes various discourses (Mantere and Vaara, 2008).

Business network innovation. In business networks, ongoing picturing of who does what is important (Abrahamsen et al., 2016), rather than examining 'a picture' that emerges at some stage. Similarly, network strategizing has been explored to understand how organizations position themselves vis-à-vis other organizations and reconsider possible use of their resources (Gadde et al., 2003). Innovation draws on interfirm interactions that change organizations' views, build their relationships, and enable use of resources in new settings (Anderson et al., 1994; Håkansson and Ford, 2002; Van de Ven, 2005). We are specifically interested in the dynamic role of content in value creation and innovation from a strong process view, resonating with literature that advocates 'dismantling' the process-content dichotomy (Johnson et al., 2003). Despite the pros of such an endeavour, content should not be ignored ${ }^{16}$ in strong process research, being an 'inherent and indissoluble part of ongoing processes' (Johnson et al., 2003). The adjectives 'inherent' and 'indissoluble' need further theorizing. Process research seeks explanation based on 'becoming-realism' (Chia, 1996). If reality is believed not to exist on its own but to consist of evolving processes (Chia, 1995), what role would content play in it? Content and business network processes. Process-centric research at the network level often focuses on interactions (Blaschke et al., 2012), and the pivotal role of agency (Gulati and Srivastava, 2014) and time (Halinen et al., 2012). Networks are discursive constructions in which participants construct meaning (Lowe et al., 2016), 'network pictures' and network strategies (Abrahamsen et al., 2016; Vaara et al., 2004). Research in industrial marketing tends to study buyer-supplier relationships as a default form of networking. It theorizes on the relationship between interaction and the dynamic evolution of the buyer's value in use (Grönroos, 2011b). Content implicitly features in this perspective in the sense of enabling a supplier's awareness of buyer needs, translation thereof in products, services, and solutions - and ultimately buyer

\footnotetext{
${ }^{16}$ For a similar concern, see research on Information Systems (Orlikowski \& lacono, 2001), leading to socio-material theorizing (Leonardi, 2013a).
} 
experience. Buyer preferences evolve and practices associated with the buyer's value creation dynamically intersect with supplier practices (Holttinen, 2014). Content permeates the processes of network participants: value propositions offer an example of co-constructed and enacted content reflecting co-creation value with different roles and interdependencies (Ballantyne et al., 2011; Frow et al., 2014).

Research streams. Industrial marketers' research on interaction, value in use, and service dominant logic (Grönroos, 2011b) relates to organization science studies on relational value creation (Dyer and Singh, 1998), episodes of network cooperation (Berends et al., 2011), network and societal level discourses on legitimacy of change (Vaara et al., 2006), tensions (Van Fenema and Loebbecke, 2014), and network learning (Gibb, 2016). Moreover, scholars working on the edge of industrial marketing and organization science have acknowledged the embeddedness of network interaction in organizational processes (Håkansson, 2016). After all, individuals representing organizations participating in a network need to anchor network cooperation within their own organization. Network cooperation also entails work transformation, for instance a customer making a supplier's offering useful in his own organization (Chandler and Vargo, 2011; Holttinen, 2014). Across these research streams, content seems to play a role in network processes but it remains unclear how.

The three philosophies introduced so far explore content and process, and relate these to innovation. They offer pieces of the puzzle without providing combined explanatory power. The first content philosophy introduces strategic logic on competitive advantage or legitimacy, yet without being explicit about the process by which these results are achieved (Sminia and De Rond, 2003). The second co-evolutionary perspective expands content and enables a dynamic perspective (Crossan and Apaydin, 2010); it suffers though from a problematic dualist ontology of separating process and content. Rejecting this dualism, the third philosophy proposes a strong process view, radically opting for a constructivist ontology. In that case, researchers seem to refrain from content, or they struggle with including content in their theorizing.

\subsubsection{PRAGMATISM AND CONTENT ENCAPSULATION}

The three philosophies elaborated in this section cannot be hold on to simultaneously (Bechky, 2003; J.-C. Spender, 1996; J. C. Spender, 1998). The first philosophy assumes content exists as an entity, while the third philosophy takes a constructivist, process-dominant stance with content on the background. The second philosophy considers process and content equal objects of study, while the first and third philosophy do not accept this dichotomy. Given our research approach and objective, we propose to use the third philosophy to build a strong process framework that can be related to the other two. This is captured in our fourth philosophy. 
Ignoring the first two philosophies would isolate the third philosophy: for many researchers and practitioners involved in business network innovation, content is at the core of their work. Merely talking about processes would imply communicating at a different wave length and possibly imply a disconnect from work practices. A philosophical foundation is required that does not accept the process-content dichotomy as a starting point, yet offers more of an opening to content than the strong process ontology per se. In addition, theorizing on reinserting content needs attention. We address these challenges next by introducing pragmatism and encapsulation.

Pragmatism. First, we propose pragmatism as a foundation for a philosophy that can deal with content within a strong process tradition. Pragmatism takes what is useful for a collective as a starting point and puts reflective thinking centre stage. A problematic situation is reflected upon by describing its constituting elements and relationships among these elements (Smith, 1978). Moreover, the position of stakeholders in relation to each other is clarified (James, 1907).

Pragmatism offers a number of steps for enacting collective inquiry: 'a felt difficulty, its location and definition, suggestion of possible solution, development by reasoning of the bearings of the solution, further observation and experiment leading its acceptance or rejection, that is the conclusion of belief or disbelief' (Dewey, 1982 (1910): 72) as cited in (Metcalfe, 2014: 3). Conception is not considered an absolute belief (thus rejecting ideal-type business concepts), but its effectiveness depends on its relation to humans' rich experiences. Dichotomy between 'theoretical beliefs' and 'practical deliberations', or 'experiences' and 'sense data' are rejected (Hookway, 2013). Pragmatism considers experience, conception and action in an integrated fashion, and explores effectiveness of problem solving embedded in relationships (Farjoun et al., 2015). It rejects absolute truths (e.g. prescriptions for novel business strategies), and is very sensitive to context and time: what works in one place may not work in another place, and what works at one moment may not work at another moment.

Encapsulation. Second, building on this foundation, content needs to be reinserted. A foundation of strong process and pragmatism suggests that content is evolving and hopefully (becoming) 'useful'. To this end, we propose content encapsulation. This offers a more explicit approach to dealing with content in a strong process tradition than strategies earlier proposed (e.g. 'live and let live' (Orlikowski and Baroudi, 1991), integration (Lee, 1991) or re-theorizing (Firat et al., 1996). Encapsulation reflects an unequivocal choice that propels consistent research, yet without ignoring the benefits of alternative philosophies.

Combining pragmatism and encapsulation provides a method for reinserting content in process research. Throughout Dewey's steps, content could be approached in a cross-sectional manner, i.e. considering for each step which role content plays in the sense of strategic intent and value 
transformation mode. Cross-sectional research on content could take the form of an analysis of content features (including its complex architecture, components, and effectiveness). This echoes research in search of generic business strategies (Bharadwaj et al., 2013), value propositions (Levina and Ross, 2003), and business models (Amit and Zott, 2001) aligned with operations (Chan et al., 1997). Alternatively, research could also be structured to examine evolution of content in the sense of possible changes of strategic intent or value transformation mode. Studies could focus on the dynamic analysis of content evolution playing a role in realizing strategic intent (Pettigrew, 1992) and thereby solving strategic problems. In the past, research has shown cases of drifting where a practice starts to deviate from its original innovation objectives (Holmström and Stadler, 2001), and cases of business initiative failure (Sminia, 2003). The cross-sectional mode of considering content resembles and connects with the first philosophy, while the dynamic content mode invites a stance as advocated in the second process-content philosophy.

Monist foundation. The third philosophy represented the enduring strong process research stance which is monist in nature. As an extension, the fourth philosophy, adding pragmatism and content encapsulation, can accommodate dualistic process-content research and even monist content-centric research ${ }^{17}$. Leaving the strong process foundation intact, researchers may consider reification (Halinen et al., 2012). That is, the fourth philosophy allows for sub-studies that seek to leverage the opportunities of the two alternative philosophies while safeguarding foundational consistency of research ontology and epistemology. How could this philosophy be operationalized for empirical research? The next section investigates opportunities for conducting empirical research on business network innovation based on a foundation of strong process theorizing, pragmatism, and content encapsulation.

\subsection{METHODOLOGICAL REFLECTION ON THE FOUR PHILOSOPHIES}

Business network innovation is complex and urgent (Reypens et al., 2016). Organizations need to change the myriad of collective activities that lead to network-level creation of new ideas (Vaara and Whittington, 2012). In industrial marketing, researchers have varied the scope and methodology of studying business networks. In addition to content-centric deterministic views on business models, more attention is paid to the process of changing strategic content, understanding evolving inter-organizational relationships, and embedding change (Holttinen,

\footnotetext{
${ }^{17}$ The authors are grateful to a strategic management colleague for highlighting this aspect.
} 
2014; Merli, 2013; Simmons et al., 2013). Researchers in adjacent fields have repeatedly called for more practice-based research and interactive research methods (Crossan and Apaydin, 2010; Van Aken, 2004). Especially for network research, these have led to methodologies such as collaborative management research (Canterino et al., 2016), aimed at building understanding, developing interventions, and enacting and evaluating these interventions (James et al., 2011).

Phase-based research. In a methodological sense, empirical research is understood as a process consisting of interactive phases. Following common approaches to action and collaborative management research, business network innovation commences with understanding what participants want, which value tensions they experience, and which opportunities they find of interest for their business. Moreover, network research that focuses on the 'understanding' phase is interested in describing and explaining what happened (Berends et al., 2011). Then, organizations develop interventions, possibly engaging new partners in the network. These interventions involve both process and content dimensions, for instance a plan to implement new logistics concepts (De Martino, 2013). A design-oriented approach has been advocated to develop interventions consisting of new tools, concepts, and implementation steps (Russell et al., 2015). This phase activates knowledge aimed at changing network practices. And finally, interventions are further developed into actions which are evaluated (Kapucu and Garayev, 2012). Iterations of phases ensure ongoing innovation of the business network. Philosophical reflection. The empirical phases require reflection on content and process across the four philosophies earlier introduced (Figure 1). 


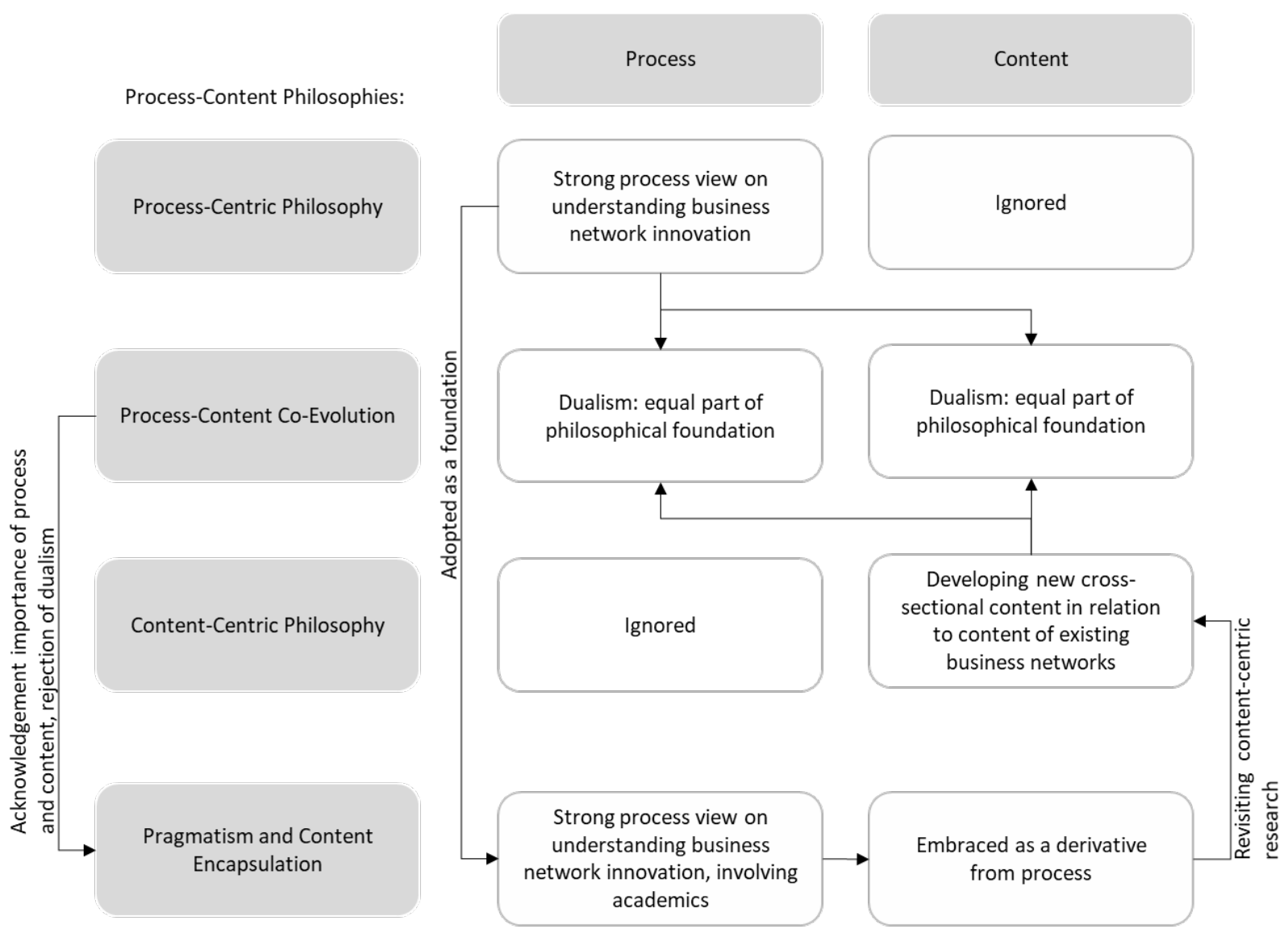

Figure 1 Content and process philosophies for research on business network innovation

Starting from the top, the process-centric philosophy could represent empirical phases and underpin the pragmatism and encapsulation philosophy. It mostly ignores, however, strategic content. Process-content co-evolution embraces content yet builds on a problematic dualistic foundation. Given its attention to interaction between content and process, it is frequently used to examine how content gets changed over time (Simmons et al., 2013). A content-centric philosophy tends to emphasize the properties of current and possible strategies and explanatory theorizing on what makes these effective (Amit and Zott, 2001; Bharadwaj et al., 2013). Its reification of content as a cross-sectional phenomenon is useful to think through content architecture for value creation and effectiveness thereof. Content research ignores the process of implementing strategies and the logical process by which a particular strategy would yield competitive advantage or legitimacy (Sminia, 2003, 2015).

Our fourth philosophy is founded on a strong process view: participants engage in a processcentric mode of reflective agency. Pragmatism and content encapsulation grant a new role for content without a dualistic base. The role of content shifts from descriptive-explanatory theory 
development towards understanding of a network's challenges and associated journey. The fourth philosophy enables development of improvement-oriented theory (which interventions will work under which conditions (Denyer et al., 2008)) and implementation (how do results relate to the context and original challenges) (Cederlund, 2015).

As we zoom in on the fourth philosophy, a set of principles is needed to operationalize this philosophy for research on business network innovation. This extends the generic empirical methodology phases earlier mentioned. Research is a layered process that starts with a philosophy and provides instruments for conducting research (Davison et al., 2004; McNiff, 2003; Myers and Klein, 2011). These instruments take the form of making research traditions explicit and suggesting specific steps or questions (Leonardi, 2017; Myers and Klein, 2011; Wynn and Williams, 2012). Building on a strong process philosophy and pragmatism's transactional epistemology ${ }^{18}$ (Biesta, 2010), our approach proposes pragmatism and encapsulation as a complementary foundation for research that can take content into account. Such a research approach is rooted in practice, in our case industrial marketing, rather than studying this practice at arm's length. Researchers adopting a pragmatist stance are:

'... encouraged to:

(i) reject "spectator" theories of knowledge that "[deprive] reason in man of an active and creative office" (Dewey, 1939: 60);

(ii) observe the "ends" of action are, "in empirical fact" ends-in-view or "projections of possible consequences," and are not the consequences themselves; and

(iii) recognize that end states "actually reached" are in effect tests of the validity of those projections ("tests of valuations previously made").

The result ... thereby generates a framework that leaves space in the analysis for creative action without, however, rendering its agents as somehow "free-floating." (Whitford and Zirpoli, 2014).

Students of industrial marketing thus closely identify with managers and entrepreneurs, rather than striving for a 'copy theory of truth' (Hookway, 2013). This implies a major ontological and epistemological shift for the traditional role of an academic researcher. In the next section, we operationalize our methodology following the steps for structuring reasoning as advocated in pragmatism (Dewey, 1910).

18 ،... the transactional view implies that all we can know concerns relationships between actions and consequences that have occurred in the past ... A transactional epistemology allows us to make warranted assertions about what has worked in the past but not about what will work in the future ... It can make, in Dewey's words, our action and problem solving more intelligent' (Biesta, 2010: 495-496). 


\subsection{USING THE FOURTH PHILOSOPHY TO STUDY CONTENT IN BUSINESS NETWORK INNOVATION}

We can now elaborate on the steps proposed in pragmatist research (Dewey, 1910: 72) as cited in (Metcalfe, 2014: 3) from the standpoint of developing industrial marketing research on business network innovation. For each step, after a brief introduction, the role of pragmatism as well as encapsulation of strategic content are examined.

\subsubsection{STEP 'A FELT DIFFICULTY'}

Step - a felt difficulty in industrial marketing refers to a business model that is no longer working well (including its value proposition, product-service configurations), or inter-organizational innovation that does not come to fruition. We focus in this paper on the latter. A felt difficulty could also refer to a new way of working that is proposed or tried out elsewhere but not yet in a particular business network. For instance, servitization may not yet resonate with the way of working in a specific local industry.

Pragmatism - a pragmatist researcher identifies with this felt difficulty without preconceiving the nature of the problem and possible solutions. With an open mindset, organization members' practical, emotional and cognitive experience of their 'dwelling place' (Basbøll, 2012) is explored. The experience of 'difficulty' can be deconstructed: which organizations and organization members have which experiences, and how are these related? To provide a micro level example, some people get frustrated when garbage collection trucks do not pick up their trash at the same day and within the same time slot (Turner and Rindova, 2012). Narratives of felt difficulty can be constructed that weave elements of felt difficulty into common stories (Pentland and Feldman, 2007). Researchers can bracket the first step in a pragmatist study by describing narratives. The experienced difficulty is likely to imply contradictory relationships between narratives or their elements, for instance between a network's value chain sustainability performance and changing customer expectations.

Encapsulation - the felt difficulty can be interpreted against network organizations' strategic intent and current value transformation processes. In the garbage collection example, preference structures could be explored as well as reasons why the garbage collection company varies its operations and does not want to cater to some customers' expectations (Turner and Rindova, 2012). Given the strong process foundation, evolution over time of the difficulty, strategic intent and value transformation can be brought to the fore. Within this approach, a cross-sectional analysis of content could be useful, in particular when a network seems to deploy stable structures (Benson, 1975). However, the content of strategic intent and value 
transformation is not taken as a given. They emerge from stories, artefacts and actions and may prove ambiguous (Abdallah and Langley, 2013) and unstable (Mair, 1999).

\subsubsection{STEP 'LOCATION AND DEFINITION OF THE FELT DIFFICULTY’}

Step - the second step zooms in on the felt difficulty with the researcher trying to locate and define what is going on. It represents almost a medical process of diagnosing. In complex business networks, this presents a major challenge compared with the often fairly simple examples used by pragmatist researchers. Difficulty also encompasses opportunities that extend current value transformation (Keen and Williams, 2013). This steps translates for business network innovation into operationalized questions such as: How is value contextually (not well) constructed, how could it be constructed (Priem, 2007)? Which organizations and members are involved, where can research boundaries be drawn? And how can the difficulty be understood when it involves (im)material or socio-material experiences in relation to expectations in the network?

Pragmatism - organizations' meaning and role stem from ongoing interaction with network partners (Håkansson and Snehota, 1989). Hence, the location and definition of a felt difficulty can be traced back to patterns of interaction. Researchers can examine what type of network has been formed (horizontal, vertical or hybrid (Van Fenema et al., 2014)), and how the current network and its difficulty can be characterized on the continuum stability versus radical change (Möller and Rajala, 2007). For instance, in a stable network, disruption of routine business processes may characterize the difficulty, while in a radically innovating network problems of innovation processes prevail. The location and definition could also be framed from an extranetwork perspective, considering interaction with environmental actors (Benson, 1975). Research on business network innovation requires attention to demarcating the empirical domain based on for instance the nature of value creation, geographical network environment, and the impact of the felt difficulty. A wide net will be casted when a global value chain suffers major sustainability issues in contrast to for instance a regional business network. Encapsulation - the location and definition of the business network's felt difficulty requires an interactive process of exploring and developing consensus. Different views can be elicited which could for instance point at customers' problems with a particular value proposition (Holttinen, 2014). Such an approach needs to be related to strategic content applicable to the situation. In a generic sense, researchers argue for a reified notion of value creation, proposing 'realities' of value creation (Keen and Williams, 2013) or generic strategic models (Porter, 1998). Encapsulated in a process view, these could be developed and considered helpful as constructed 'devices' (Bacharach, 1989; Callon et al., 2007). In a situation-specific sense, 
content such as a deal governing services between organizations (Olsen and Håkansson, 2017; Sandin, 2015) can offer a backdrop for understanding the location and definition of the felt difficulty.

\subsubsection{STEP 'SUGGESTION OF POSSIBLE SOLUTION'}

Step - studying a possible solution adds the dimension of the artificial to the setting (Simon, 1996). In this stage, solutions consist of vague ideas of how the difficulty could be addressed. In industrial marketing, solution would eventually refer to a supplier's offering of integrated products and services (Sandin, 2015). Here, the structural demand of the customer to which such as solution caters is not the starting point, but addressing the ad hoc 'felt difficulty'. Pragmatism starts with experience. It should be remarked that the notion of a solution ${ }^{19}$ is problematic for strong process research. Rather, researchers should concentrate on organization members' thinking and knowing in the context of addressing a felt difficulty. As we will show, encapsulation can allow a researcher to capture 'a solution' which might be expressed in for instance a policy document or PowerPoint slide set (Kaplan, 2011b). This could include cross-sectional snapshots, as well as analysis over time of how interrelated content elements understood 'a solution' evolve.

Pragmatism - starting with the felt difficulty pertaining to strategic intent and value transformation, a developmental process concerning a problem solving solution is initiated. That is, a process view on business model innovation (Foss and Saebi, 2017) is conceived involving multiple organizations. Researchers examine how value transformation of a business network starts to interact with problem solving process. The previous step provides insight in the location and definition of the difficulty. With this step, solutions are conceived that involve initial ideas of interventions (such as a shift from good dominant logic towards service dominant logic (VendrellHerrero et al., 2017)), as well as triggering mechanisms that enable desirable outcomes (Van Aken, 2005). Pragmatism concerns the process of coming up with a useful solution that may alter the use of resources, positioning of the firm and nature of inter-organizational relationships. This process depends on interactions in social networks to develop ideas across the network's participating organizations (Davis, 2010; Kijkuit and Van den Ende, 2010). Defined in relation to strategic intent and value transformation, 'useful' concerns in business networks the solution's impact on the meaningfulness of what organizations do and the role they play (Håkansson and Snehota, 1989).

\footnotetext{
19 'Solution' is used in accordance with pragmatism, it should not to be confused with product-service solutions in industrial marketing.
} 
Encapsulation - for this step, the suggested solution is inserted as a new form of strategic content. The core innovative idea supposedly changes the value transformation process and thereby the extent to which strategic interests are served. During this step, content of the solution is ephemeral and immature. The interaction between innovative content (often technology) and organizations has been studied in Information Systems literature. Organization members relate features of the innovative technology and the organization (DeSanctis and Poole, 1994; Griffith, 1999). The 'possible' solution - such as a modified or new value proposition - implies that content features are emerging. Encapsulation means that the various forms of content can be examined in isolation; moreover, content of the solution and ongoing value transformation can be compared in a cross-sectional or dynamic fashion. Positive impact of a solution (i.e. new content) on the felt difficulty can be analysed in a conceptual and possibly quantitative-explanatory manner. As a default, however, the researcher views value transformation and innovative problem solving as ongoing processes.

\subsubsection{STEP 'DEVELOPMENT BY REASONING OF THE BEARINGS OF THE SOLUTION'}

Step - while the steps advocated by Dewey (1982) may seem like a regular problem cycle, he was aiming at understanding knowledge inquiry. Research and practical action go hand in hand on path towards a solution for a felt difficulty.

'For Dewey ... a key feature of this process is that the observation of results yields tentative new expectations for future transactions, not a firm conclusion about the world ... While Dewey's emphasis on felt difficulties, actions, and transactions tightly connected his pragmatism to practical action, he recognized that researchers seek to acquire knowledge apart from their own practical felt difficulties. Researchers seek out situations where the connections between action and consequences are not yet known, with the aim of advancing the acquisition of knowledge that can be shared with others' (Floden, 2009: 491-492).

The step elaborated here then picks up on the suggested solution and explores why it would work. The reasoning implies that researchers play a prominent role. For industrial marketing, strategic content developers - e.g. strategists, business model developers, alliance managers would participate in the process of thinking through the usefulness of the suggested solution. Pragmatism - understanding the bearings of a solution challenges researchers and practitioners to develop an understanding of why a solution would work. The situated nature of value creation implies that the bearings of a solution must be related to strategic intent of network partners and interconnected value transformation (Canhoto et al., 2016). This includes insight in changes to relationships, use of knowledge and resource/technology combination across the network 
(Håkansson and Ford, 2002). As an example, a proposed shift towards performance-based solutions need to be thought through in terms of matching with the customer's needs, effective financial models, and providers' business processes and willingness to accept more risk (Mahon, 2007).

Encapsulation - strategic content in this step refers to the reasoning behind business network innovation. Content-centric research becomes highly relevant. Strategic content research theorizes on environmental analysis, strategic intent, and business strategies for value transformation. Innovation alters the 'value narrative', 'value engine' and business practices (Keen and Williams, 2013). This organization-level approach to strategic logic can be extended to the network. Strategic economic theory proposes models for complementary resource management and synergy in networks (Tantalo and Priem, 2016; Van Fenema et al., 2014). These reap benefits such as improved economies of scale, mutual opportunities, or resource reallocation and economizing (e.g. reducing stocks) which could be theoretically tested in terms of explanatory power. Yet these strategic economic models remain a-contextual and aprocessual. As an encapsulated effort, context and process must be taken care of by embedding content results in a pragmatist, strong process approach. For instance, a new model for vertical value chain cooperation can be discussed and its assumptions validated.

\subsubsection{STEP 'FURTHER OBSERVATION AND EXPERIMENT'}

Step - rejecting foundationalist empiricism, pragmatism keeps engaging the context in which a difficulty is felt to ensure usefulness of a solution. '... observation of results yields tentative new expectations for future transactions, not a firm conclusion about the world' (Floden, 2009: 491). This step thus resonates with processual industrial marketing research which acknowledges the ongoing in-context process of value creation innovation (Canhoto et al., 2016; Holttinen, 2014). Pragmatism - business networks' organizations experience ambiguity that can be processual engaged with but not resolved (Abdallah and Langley, 2013; Möller and Rajala, 2007). Innovation may change their business models and require new enactment loops and adaptive tactical sensemaking (Laszczuk et al., 2017). Thus, this step encourages researchers and practitioners to relate their problem solving process with going business as they need to '...embed knowledge into a business world full of already activated and interdependent solutions' (Waluszewski and Håkansson, 2007). Observing initial response is vital in a pragmatist mode to advance theorizing and to validate the solution that has been substantially developed over the previous steps. Over time, experimenting would engage different stakeholders in the ecosystem experiencing the 'felt difficulty' (Reypens et al., 2016). Network 
participants can develop and test prototypes in conjunction with problem definition as they pursue technology and business innovations (Biemans, 1995).

Encapsulation - during this step, strategic content has matured and researchers can study its stand-alone qualities using descriptions such as elaborate rationale, and business and implementation plans. Pragmatism pushes researchers and practitioners to validate their solutions, even though these have been thought through in detail. The solution has become more complex and complete, with overarching ideas, and a concept architecture and components. Yet the relationships between the solution's structure and the problem context keeps requiring attention. Success of a solution cannot be taken for granted. Communicating the solution's complexity to members of networked organizations is a challenge, but it seems important to relate the solution to the going business complexity of '.. . already activated and interdependent solutions' (Waluszewski and Håkansson, 2007). In fact, researchers point at the intricacies of interdependent business models (Bankvall et al., 2017; Sydow et al., 2015). Solutions thus interact with the complex 'landscape' in which they supposedly play a positive role. It is likely that they will undergo major change: in addition to communicating ('implementation' or 'roll-out') a solution to the network, conversely, encapsulation invites isolated analysis and redevelopment of a solution's content in response to feedback. This includes reflection on a solution's generic conceptual backdrop and applicability.

\subsubsection{STEP 'ACCEPTANCE OR REJECTION, THAT IS THE CONCLUSION OF BELIEF OR DISBELIEF'}

Step - the final step challenges actors to conclude the (initial) cycle of dealing with a felt difficulty. Originally in pragmatism this step is oriented towards knowledge. Actors need to dichotomously evaluate the solution in the light of the problem: is it acceptable or should it be rejected? According to pragmatism, solutions or ideas ' ... become true just in so far as they help us to get into satisfactory relation with other parts of our experience' (Lawlor, 2006: 326). Deciding on belief does not imply a finite answer, but articulates a felt position that can fuel additional debate. In this paper, the final step does not refer to the development of knowledge per se, but to the belief of cooperating organizations in a proposed solution for innovating network value creation.

Pragmatism - if organizations can agree on the qualification of belief or disbelief with respect to a solution, this provides temporary closure and stability in the network (Benson, 1975). The temporary of stability nature matches pragmatism. In fact, researchers and practitioners are urged to avoid a dominant logic or a fixed belief on how a network creates value (Rosa et al., 1999). The well-developed nature of a solution and its initial effectiveness may lure organizations into believing that their new mode of value transformation has staying power. 
Sensitivity to signals of a new felt difficulty should keep organizations on their toes. The final step could also involve rejection which demands the network's organizations to revert to earlier steps.

Encapsulation - the steps have produced a solution with sufficient qualities and potential to elicit an acceptance or rejection decision. (Dis)belief brackets the solution as novel strategic content that can(not) resolve the felt difficulty. For instance, in order to sustain competitive advantage, a novel low-cost business model for an airline is proposed to replace the older one that was built on differentiation (Bacharach et al., 1996). During this step, encapsulation has moved to a final dichotomous, stage-gating decision. This can be analysed in a cross-sectional fashion. It would require criteria for deciding whether the developed knowledge will lead to the 'desired end' (Morgan, 2007). That is, to what extent does the solution match the felt (strategic intent and value transformation) difficulty and proves meaningful in this sense for the network's organizations (Håkansson and Snehota, 1989)? The acceptance-rejection decision could benefit from non-processual research that aims for explanation or evaluation. These insights need to be reinserted in research on the ongoing network (innovation) processes. For instance, an accepted solution could become institutionalized over time.

Our paper's second objective can be addressed by now. Research on business network innovation can benefit from awareness of different philosophies. We proposed and elaborated on a fourth philosophy that combines strong process, pragmatism, and encapsulated content. The steps proposed in pragmatism can guide researchers through their research process. After this philosophical groundwork, method specifics need attention. Research quality depends on common criteria for qualitative research such as immersion in the context, completeness of the data, consistency and validity (Henneberg and Mouzas, 2008). Since a network can proceed through the steps multiple times, data can be coded by cycle and step. Cycles could be distinguished based on major episodes (Blaschke et al., 2012).

Encapsulation represents subprocesses and partial results which must be additionally legitimized by applicable empirical methods and logics (e.g. mathematical simulations). We emphasize that encapsulation represents a process of isolating content-related questions in an a-processual manner and feeding back results of such an effort into the strong processual research effort. Reporting research in an academic common paper format is likely to put the felt difficulty centre stage in accordance with pragmatism. Encapsulated research could be presented as appendices to a process study, or as stand-alone work. Research based on the strong process view and pragmatism initiates a storyline allowing the reader to follow a 
network's quest to deal with a felt difficulty over time. Core themes can be distilled from this storyline and contribute to theory development on business network innovation.

\subsection{DISCUSSION AND CONCLUSION}

Industrial marketing research on business networks has embraced a strong process view to understand evolving interaction patterns, deals, relationships and resource combination (Håkansson and Snehota, 1989; Halinen et al., 2012; Holttinen, 2014; Olsen and Håkansson, 2017). This emerging tradition equips researchers with an exciting new repertoire for studying how networks innovate, and why these innovations succeed or fail. A concern that has also been aired with respect to a similar movement in strategic management, is that strategic content does not seem to play a substantial role (Sminia and De Rond, 2003). Such content seems to be pushed back to the backstage, as micro content of interpersonal communications. Strategic content's complexity and impact remain undertheorized. This study proposes a fourth philosophy that complements content-centric, co-evolutionary and process-centric philosophies. Content is not separate from processes (De Wit and Meyer, 2010) or merely an outcome of processes (Crossan and Apaydin, 2010), but ontologically and inseparably part of processes. Firmly rooted in strong process theorizing, it builds on pragmatism and content encapsulation to overcome process-content dualism and marginalization of content. Pragmatist steps for dealing with a felt difficulty structure a proposed method for business network innovation research.

\subsubsection{IMPLICATIONS FOR RESEARCH}

Results from this conceptual paper have three implications for industrial marketing research on business network innovation.

Industrial marketing research philosophy. Our work encourages researchers to examine the philosophical foundation of their work. Articulating a research position in this sense facilitates debate within and across categories of business network innovation research. Monist or dualist ontologies need to be justified to avoid separate research communities with internally taken for granted assumptions yet little in common. A similar shift can be noted in fields other than industrial marketing such as international relations (Jackson, 2008), information management (Myers and Klein, 2011) and education (Liu and Matthews, 2005). Monist philosophy could be further refined and expanded to better understand the dynamics of functionalism or 'usefulness' in industrial marketing. This offers new opportunities for business network innovation research. For instance, research projects on changing network business models could include parallel trajectories focusing on content-centric problems. We advocate a strong process view but this 
should not discourage researchers starting from other philosophical foundations. A common thread across research with different philosophical stances could be legitimacy and effectiveness of business network innovation, and how organizations experience and deal with network controversies. Considering different philosophies could imply overcoming the taken for granted entanglement of themes and philosophies. That is, process studies tending towards human agency topics (e.g. communication, leadership, power), and content studies focusing on quantitative and strategic-economic conceptual challenges. Putting a felt difficulty centre stage could lead to process research on models emanating from content research, and cross-sectional content research on topics usually approached from a process angle.

Structuring process-content research. Increasingly, business networks change how they create value as organizations engage with trends such as servitization and digitization (VendrellHerrero et al., 2017) and sustainability (Mylan, 2015). Starting with the 'felt difficulty' notion driving pragmatist research, scholars can examine why business models and networks fail or lag. Moreover, a felt difficulty could concern resource and routine affordances (Van Dijk et al., 2011), strategic options (Keen and Williams, 2013), and a business model's value potential in a network (Gans and Ryall, 2017). Images of future value creation (social cognition in networks (Abrahamsen et al., 2016)) and optimization of network value creation (quantitative cognition (Gans and Ryall, 2017)) can be interrelated, starting from the same felt difficulty and the potentiality of developing solutions. Research embracing 'the possible' or 'the desirable' can be critically examined against actual business network practices. The steps can guide this process since a felt difficulty starts in the context of a current practice's strategic intent, value transformation and experiences. Over the course of the steps, researchers can develop insights in how potentiality translates into differently enacted business models (Simmons et al., 2013) and business network innovation (Reypens et al., 2016). Finally, value creation in business networks increasingly tends to be interpreted in a broader sense, to include non-economic dimensions such as ethics and local impact (Porter and Kramer, 2011). A pragmatist researcher can study how direct and indirect network stakeholders experience these extensions of value creation definitions, and how they may act in a more synergetic manner (Tantalo and Priem, 2016). This includes examination of network orchestration (Dhanaraj and Parkhe, 2006), changing power configurations (Zirpoli et al., 2013) and moving back and forth between macro and micro levels of analysis (Akaka et al., 2013).

Methods. Our work challenges industrial marketing researchers to reflect on their research philosophy. After all, '... it is important to create theory-method package "fit." This goes beyond ensuring that a study's methods are internally consistent to encompass the relationships among methods and the research question one is asking and theoretical contribution(s) one intends to 
make' (Gehman et al., Forthcoming). Pragmatism can be interpreted as a 'withness' style of conducting process research (Shotter, 2006). Other philosophies may advocate a more distant, a-contextual research stance. When 'withness' is considered a default mode to address a felt difficulty, researchers may complement their work with research that keeps more distance to the network's practice for analytical and operational purposes. For instance, conceptual work or explanatory quantitative research may explore partial problems in depth, without investing much effort in engaging with network actors. This encapsulated research can be reinserted in the main pragmatist conversation of the researcher with the network. It seems likely that more than one researcher would be involved in research following the fourth philosophy. Moreover, depending on the felt difficulty and solution elements, these researchers would need to include experts from various industrial marketing subdisciplines and possibly related fields such as strategic management, operations research, and supply chain management.

\subsubsection{LIMITATIONS AND FUTURE RESEARCH}

Our study provides some pointers for researchers developing their studies in business network innovation. Yet, reflecting on this work, several limitations could be noted. Our study adopted a narrow strategic definition of content, i.e. intent and value transformation. Since innovation involves changes to the various types of content, future research could examine the relationship with action patterns, knowledge, and resources and inter-organizational governance. It could link up with organization and technology innovation literatures to examine how content domains 'are becoming' in relation to evolving strategic content.

Our emphasis on philosophy has left little room for stability-change as a longstanding network theme (Benson, 1975). In fact, a blind spot of our strong process view may be the acknowledgement and conceptualization of network stability and network dynamics (Moller and Wilson, 2006). Future research along the lines of our philosophy could retheorize on meanings of stability in relation to how organizations manage their (power) position in a network (Håkansson and Ford, 2002).

Pragmatism that builds on a strong process view seems to assume a common positive attitude

of co-developing knowledge and solving problems, as well as actors with an unequivocal internal structure. Network researchers, however, may need to study why organizations leave (Berends et al., 2011; Busquets, 2010), or how organizations struggling with a variety of internal strategic logics (Besharov and Smith, 2014). Researchers could challenge assumptions underpinning pragmatism and construct new ones to study situations of fierce competition, opportunism and conflict (Håkansson and Waluszewski, 2002). Common ways of doing business in value chains may be disrupted with organizations struggling to reconnect their interest to interests of their 
partners or the network at large (Ford et al., 2002). Intra-organizational complexity - rather than a presumed unequivocal internal structure - calls for deconstructing the notion of felt difficulty, and developing theories on its implications for business network innovation. For instance, some organization units may not applaud or engage actively in network-level change (Caldwell and Howard, 2014; Mahon, 2007). Finally, the steps may draw researchers towards tactical level network studies. However, strategic network performance or effectiveness (Provan and Kenis, 2008) could be reconceptualised to better understand drivers of network value creation.

\subsubsection{CONCLUSION}

A strong process view understands business networks as ongoing practices rather than a usually stable network of relationships and value creation modes. This important theoretical step has not yet been matched in the way content is studied. Researchers struggle with content in relation to process in a philosophical and methodological sense. The conceptual work presented here explores philosophical stances on process and content, distinguishing three categories: content-centric, process-content evolution, and process-centric. The latter stance is adopted here and further operationalized using pragmatism. Then, encapsulation is proposed to improve embedding of content-based research. Steps introduced in pragmatist studies are elaborated for research on business network innovation. Research adopting the fourth philosophy can accommodate studies building on the currently used philosophies as long as its foundational assumptions are ultimately adhered to. Implications for research involve philosophical reflection, opportunities for developing new research approaches for conducting business network innovation research, and methodological reflection. 


\section{INTER-ORGANIZATIONAL PERFORMANCE MANAGEMENT: A CO EVOLUTIONARY MODEL}

$\begin{array}{ll}\text { AUTHORS } & \text { Van Fenema P.C. } \\ & \text { Keers B.B.M } \\ \text { PUBLICATION OUTLET } & \text { International Journal of Management Reviews } \\ \text { ADDRESSES } & \text { RQ 3: What are the implications of the dynamic process of } \\ & \text { inter-organizational value creation for inter-organizational } \\ & \text { performance management? } \\ \text { STATUS } & \text { Accepted }\end{array}$

\subsection{ABSTRACT}

Making inter-organizational cooperation successful proves a daunting task. While current approaches to inter-organizational performance management highlight why inter-organizational cooperation matters and which phases are required, it remains silent on the dynamics of interorganizational performance management. That is, how can performance management evolve with and contribute to inter-organizational cooperation. The purpose of this paper is to increase understanding of inter-organizational performance management. To this end, it develops a structure and process foundation of inter-organizational value creation, and it provides a model that shows how processes of organizational and inter-organizational performance management co-evolve.

The study starts with providing insight in differences between organizational and interorganizational performance management. It then presents five approaches pertaining to performance in inter-organizational cooperation. The paper distinguishes strategic-economic, performance management, supply chain management, organizational and marketing approaches. These approaches are related from a structure and process angle and used to develop a co-evolutionary model of inter-organizational performance management. The resulting conceptualization has implications for research on new modes of complex and heterogeneous inter-organizational value creation. The paper elaborates on these implications, pointing to new directions for future performance management research. 
The research field of performance management has rapidly evolved, and it increasingly impacts current thinking and acting in organizations (Bititci et al., 2012). Scholars and practitioners have expanded the scope of performance management to include multiple externally-oriented dimensions (e.g. sustainability, stakeholder management), thus preparing organizations for an effective and responsible role in their direct and indirect business context (Gopalakrishnan et al., 2012; Weiller and Neely, 2013). We use value creation literature to flesh out how organizations can materialize multiple objectives (Jensen, 2010) and carve out their complex role in value chains (Ketchen and Hult, 2007). In our globally connected world, the creation of sustainable stakeholder value is no longer contributed to a single organization ( $\mathrm{Li}, 2014)$ or even basic buyer-supplier relationships. Instead, organizations have become aware of their position in value networks. To share R\&D costs for instance, they can play with the cooperative-versuscompetitive nature of their horizontal relationship with competitors (Hamel et al., 1989). Vertically, value co-creation has been advocated to improve interaction, value experience, customized outcomes and adaptation in relationships with upstream or downstream partners (Prahalad and Ramaswamy, 2004). Relationship become more reciprocal as firms utilize customer competence and networks to fine-tune their offering and enhance customer experience (Prahalad and Ramaswamy, 2000). Digitization further accelerates this development, e.g. analytics and social media (Vendrell-Herrero et al., 2016; Nylén and Holmström, 2015).

Moreover, cooperation has become more heterogeneous with firms extending their interaction with public and not-for-profit partners (Shinn, 2002; Dahan et al., 2010). Cooperation concerns a trust-based process of transforming input into output (Smith et al., 1995), with varying levels of joint action (Bensaou, 1997). Inter-organizational cooperation has intensified in a connected economy and it involves diverse and sometimes new forms such as ad hoc projects, extended enterprises, alliances, joint ventures and (digital) networks (Bobbink et al., 2016; Tjemkes et al., 2012; Jones and Lichtenstein, 2008; Nylén and Holmström, 2015). The relationships underpinning such cooperation have been defined as 'relatively enduring transactions, flows, and linkages that occur among or between organizations and one or more organizations in its environment' (Oliver, 1990: 241). Cooperation across organizational boundaries promises opportunities for a novel combination of resources and innovation (Pittaway, 2004; Frow et al., 2015), as well as efficiency improvements, e.g. cost reduction by optimizing interfirm production flows (Möller and Rajala, 2007). Other researchers have warned for risks associated with cooperation across organizational boundaries beyond common transactions. Benefits may be limited, knowledge could leak and strategic positions could be harmed (Jiang et al., 2013; Hamel 
et al., 1989). Cooperation tends to be a rocky road, comprising win-win and conflict episodes (Hamel et al., 1989; Berends et al., 2011). Performance improvement from cooperation is in fact neither guaranteed nor is the process through which it could be achieved well understood. First, success of for instance alliances and networks appears challenging and these relationships become more short-lived (Majchrzak et al., 2015; Madhok et al., 2015). Collective outcomes are jeopardized when organizations start to over-emphasize their self-interests or interests diverge. Moreover, sharing resources with a partner can be risky when organizations have a complex relationship that blends cooperation and competition (Loebbecke et al., 2016). And with value creating relationships changing from unidirectional buyer-seller exchange towards bidirectional and multisided networking (Storbacka et al., 2016; Muzellec et al., 2015), 'who does, receives and deserves what' can become daunting a performance management question.

Second, the shift in research attention from organizational to inter-organizational value creation invites new theorizing on performance management, also referred to as inter-organizational or network effectiveness (Provan and Kenis, 2008). Inter-organizational performance represents outcomes of cooperative value creation that are desirable to those involved in the partnership. For instance, university-industry alliances yielding 'direct outcomes (and) indirect outcomes ... matching ... the project's initial objectives' (Perkmann, 2011: 205). Defining inter-organizational performance proves challenging since it depends on the situatedness and complexity of mutual agreements. Researchers propose for instance: 'satisfaction with the knowledge accumulated from participating in the collaborative agreement; the extent to which the alliance created new opportunities for the firm; and the degree to which the alliance satisfied the partnering firm's initial objectives' (Zollo et al., 2002: 706). Management of such performance requires a 'process of using inter-organizational systems to collaboratively measuring performance of collaborative enterprise processes and using the measurement to enable decision-makers to proactively and strategically manage the collaborative enterprise itself' (Busi and Bititci, 2006: 11).

These seems to be a gap between research suggesting on one hand that inter-organizational cooperation benefits organizations (Oliver, 1990), while on the other hand noting that actual cooperation proves unpredictable and challenging (Berends et al., 2011; Mahon, 2007). Performance management could bridge this gap since it includes the full cycle of objective setting, measurement, evaluation and action. Our review of organizational and interorganizational performance management revealed that achievement of inter-organizational objectives in relation to organizational performance requires more research. This would extend performance management models as well as complement research on why and how interorganizational cooperation could be shaped. Inter-organizational performance and cooperation 
are tightly connected: cooperation results in outcomes that are evaluated by each organization in terms of performance. This paper answers calls to address the gap in current literature in the area of inter-organizational performance management. Scholars distinguish two levels: organizational and inter-organizational, and they call for new insights in the mechanisms and processes of inter-organizational performance management (Provan et al., 2007; Bititci et al., 2005; Bititci et al., 2012). As mentioned, inter-organizational performance management cannot be studied in isolation. People externally representing their organization also have an internal brokering role. Inter-organizational performance management should be dovetailed with organizational performance management to offer organizations instruments to pursue their own interests in relation to counterparts (Kivleniece and Quelin, 2012; Lepak et al., 2007; Van Fenema et al., 2014).

We can now define inter-organizational performance management as structures and processes that (1) represent and inform organization-level performance management, (2) define objectives shared by cooperating organizations, (3) orient actual value creation towards achievements of these objectives. We emphasize the embeddedness of this process in organizations and their organization-level performance management.

While current approaches to inter-organizational performance management highlight why interorganizational cooperation matters, which phases are required (Dyer and Nobeoka, 2000) and how inter-organizational governance could be setup (Jones et al., 1997; Wareham et al., 2014), it remains mostly silent on the process of developing inter-organizational performance management and in particular its dynamic nature and synergy effects (beyond the primary objectives of partners' cooperation). Performance management is not only a set of interrelated processes (Neely et al., 2002). It evolves over time as expectations of these processes change and inter-organizational relationships change. This suggests a process-based approach to theorizing (Ring and Van de Ven, 1994). For instance, while performance management during the early phase of cooperation aims at negotiating agreement of what organizations want to achieve and the likelihood of achieving desired results - it needs to evolve towards a set of instruments for measuring actual value creation and signalling performance problems or opportunities for innovation. The dynamic aspect is particularly important because of the continuously changing business environment and the need for improving performance. ${ }^{20}$ As such, this conceptual paper seeks to contribute to this exciting and timely challenge, based on a review of inter-organizational cooperation and performance management literature. We reflect on this issue. Specifically, the purpose of this review paper is to offer academics and

\footnotetext{
${ }^{20}$ We thank one of the reviewers for highlighting the relevance of a dynamic perspective.
} 
practitioners a model for managing inter-organizational performance, that provides insight in the process of inter-organizational value creation and how its dynamic evolution can be understood and managed. We focus on performance management in general, not one of its specific elements. The model we seek to develop does not represent a theory in the sense of offering a validated explanation of a phenomenon as common in the natural sciences. We offer a conceptual model as a contribution, which is theoretical in the sense of 'a linguistic device used to organize a complex empirical world' (Bacharach, 1989: 496) as cited in (Walker et al., 2015: 1183). ${ }^{21}$ We seek to better understand the complex empirical world of inter-organizational performance management and develop a co-evolutionary model. For inter-organizational performance management, complexity stems in part from the interplay of organizational and inter-organizational processes. Our co-evolutionary model helps to gain understanding of this complexity which may help academics as well as enable practitioners responsible for developing inter-organizational cooperation of relevance to their own organization.

As further elaborated in the methods section, an inductive research process started off with queries aimed at understanding differences between organizational and inter-organizational performance management. Key authors in the field and conference contributions were identified; highly cited research was looked up using academic, conference, and publishers' databases. Then, literatures on inter-organizational cooperation - searched and analysed with a focus on inter-organizational performance management - were explored, building on the previous phase. This broad scan - with pros and cons as brought forward in related work (Bititci et al., 2012) resulted in five approaches to performance management. Next, our study on inter-organizational performance management literature revealed the multidisciplinary yet incoherent nature of this domain of study. Without more coherence across these literatures, conceptual progress would be difficult and slow. Hence, inspired by the approaches we found, we elaborate on the structure and process of inter-organizational performance management to develop a co-evolutionary model. The paper concludes with implications for research and practice, paying attention to new modes of complex and heterogeneous value creation involving multiple organizations.

\footnotetext{
${ }^{21}$ We thank one of the reviewers for highlighting differences between a theory and a model.
} 
5.3 BACKGROUND: INTER-ORGANIZATIONAL COOPERATION AND PERFORMANCE MANAGEMENT

This section offers the backdrop of theorizing on inter-organizational performance management. Organizational value creation is reinterpreted at the inter-organizational level, thereby introducing inter-organizational cooperation. Theorizing on this topic has shifted from an idealized mode towards acknowledgements of the multidimensional and emerging nature of cooperation. This motivates our subsequent literature review and synthesis process.

Inter-organizational cooperation increasingly offers advantages for organizations to achieve their strategic objectives without relying on neo-classical market transactions (Gulati et al., 2012; Van Fenema et al., 2014). Examples include alliances and sourcing relationships (Feller et al.; 2013, Bastl et al., 2012). Reverting to the organizational level, traditionally value has been defined as 'the amount buyers are willing to pay for what a firm provides them. Value is measured by total revenue ... A firm is profitable if the value it commands exceeds the costs involved in creating the product' (Porter, 1985: 38). Current research has acknowledged and criticized the narrow economic paradigm underpinning value creation literature. This implies that extra-economic dimensions of value creation are taken into account such as the socio-ecological environment, and value networks are defined more broadly to include global-local relationships and multiple stakeholders (Reypens et al., 2016; Sedláček, 2011; Whiteman and Cooper, 2011; Porter and Kramer, 2011).

Between organizations, value creation could be achieved when organizations take advantage of economies of scale (Oliver, 1990). Research on 'value nets' for instance emphasize the benefits of combining resources. '...(A) set of specific activities (are) carried out by the actors constituting the net ... these activities are based on the resource constellation controlled by the actors' (Möller and Rajala, 2007: 898). Inter-organizational cooperation moves beyond transactionbased exchanges between organizations. Transaction Cost Economics has extended the notion of markets with the concept of neoclassical or relational contracting (Williamson, 1996). Recent work elaborates on alliances and interaction-based value creation (Edvardsson et al., 2011; Gulati et al. 2012).

Several approaches have been proposed to understand how inter-organizational cooperation could get started and start performing. These initial idealized phases include for instance strategic assessment and decision-making. During this phase, topics such as the role of ex ante relationships between organizations and partner selection are considered important (Dyer et al., 2001; Segers, 2015; Mukherjee et al., 2013). A second phase consists of partnership configuration and contracting to achieve agreement on what organizations want to achieve and which roles each organization will play. Third, management of ongoing inter-organizational 
operations represents a next step, as well as adaptation and evaluation of performance depending on the partners and their business contexts.

While these phases offer some structure for thinking through inter-organizational cooperation, real-life development of inter-organizational cooperation hardly fits this idealized pattern, including frequent failures (Berends et al., 2011). Moreover, performance associated with (progression of) phases remains ill understood. Literature has repeatedly reported on alliances that fail, get stalled or follow non-linear trajectories (Van Fenema and Loebbecke, 2014; Berends et al., 2011; Doz, 1996). So, while strategic formation of inter-organizational cooperation and its idealized phases has received ample attention, the actual processes of collaborating across organizational boundaries (Majchrzak et al., 2015; Pitsis et al., 2004) and delivering performance (Bititci et al., 2012) appear challenging. In fact, contrary to Transaction Cost Economics theorizing, transactions with low volume and high specificity and complexity are increasingly organized across organizational boundaries (Caldwell and Howard, 2014; Ghoshal and Moran, 1996). Risks is shifted upstream the value chain, and organizations face major difficulty to define performance ex ante (Kleemann and Essig, 2013). Hence, inter-organizational performance management is increasingly drawing attention in the performance management as well as broader management science community. In the next section, we present results from our query on approaches to inter-organizational performance management.

\subsection{METHODS}

Our study started with a clear focus on inter-organizational performance management in conjunction with a deliberately open mind-set. That is, our research and education experiences led us to believe that across many literatures scholars have been working on this topic. Yet reaching out across disciplinary boundaries was lacking except for some 'bilateral' linkages such as marketing-logistics (Lusch et al., 2010), or organization theory and logistics (Ketchen and Hult, 2007). We demarcated our work to management or business sciences in a broad sense. This includes general management and functional domains such as logistics and marketing. Our boundary crossing view implied limited depth for each disciplinary domain and a focus on key papers and authors.

As is well-known in empirical research, we adopted an inductive approach which represents a transformational process from specific cases (in our study conceptual approaches across disciplines) to general 'laws' (Kovács and Spens, 2005). We used a snowballing rather than systematic literature review strategy to identify with an open mind-set the 'specific cases'. So our model development process started with open queries using (using AND in queries) 
combinations of 'performance' with words like inter(-)organizational, inter-organizational cooperation, inter-organizational relationships, alliances and so forth (Pilbeam et al., 2012). Common formal and informal databases were used for scholarly work such as World of Science, EBSCO, as well as Google Scholar, Research Gate. The resulting papers were checked for bearing relevance to the organization level and organizational performance management, using words like organization or firm. Due to the massive number of papers, we could usually not read the papers in detail. Depending on their relevance, we scanned the papers for core models and relied on intra-document queries aimed at performance management. Inductive research involves a hermeneutical process in which the transformation mentioned is achieved, i.e. from specific cases to more generic understandings. Such a transformation processes tends to stabilize over time; our review led to the five approaches. Once we had identified these, we looked for specific papers within these approaches using again combinations of performance management and words to describe inter-organizational cooperation. A limited set of papers and a few key authors emerged that serve as the foundation of this paper. These authors have a long-term agenda and publication record pertaining to inter-organizational performance management. We looked specifically at the work of these authors and their co-author network using Google Scholar. For instance, in organization science Keith Provan is an expert in interorganizational performance, with an emphasis on governance (Provan and Milward, 1995; Provan and Kenis, 2008; Provan and Lemaire, 2012); in performance management Umit Bititci has been exploring the inter-organizational dimension of organizational performance (Martinez and Bititci, 2006; Bititci et al., 2012; Bititci et al., 2005).

\subsection{APPROACHES FOR STUDYING INTER-ORGANIZATIONAL PERFORMANCE MANAGEMENT}

Theorizing on the relationship between inter-organizational cooperation and performance has evolved in different communities. This has resulted in a variety of models (Bititci et al., 2012) that must be interrelated to make conceptual and empirical progress in inter-organizational performance management (Franco-Santos et al., 2012). Our query resulted in the identification of five approaches (Figure 1). We elaborate on these approaches next. 


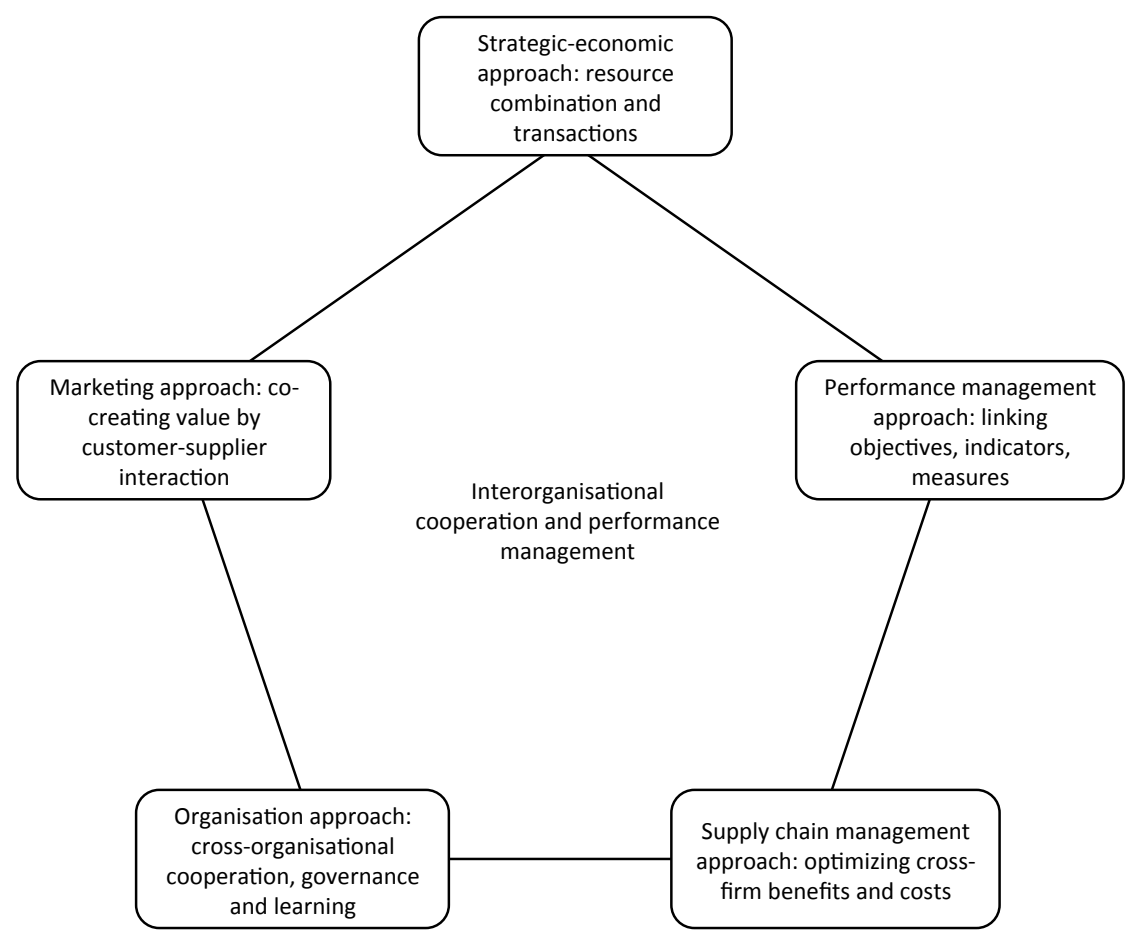

Figure 1. Approaches to inter-organizational cooperation and performance management

\subsubsection{STRATEGIC-ECONOMIC APPROACH}

First, strategic-economic research takes the firm as a starting point and contrasts it with the market. ${ }^{22}$ Complex, low frequency transactions should be organized within a firm's boundaries, while the market offers a platform for transactions that do not run the risk of opportunistic behaviour (Geyskens et al., 2006, Williamson and Ouchi, 1981). Firms can engage in a third form of governance - relationship or alliance - when this offers advantages that exceed the risks of opportunism (Parkhe, 1993; Dyer and Singh, 1998). Economic theorizing has been extended to include additional factors influencing effective governance such as 'behavioural uncertainty, human and process asset specificity and contractual governance' (Vandaele et al., 2007). Moreover, firms should concentrate on unique resources that offer a sustainable advantage (Wernerfelt, 1984), invest in (renewal of) their capabilities to compete (Jacobides and Winter, 2005) and manage their dependence on resources (Pfeffer and Salancik, 1978). Firms manage

\footnotetext{
${ }^{22}$ Following one of the reviewers, we acknowledge differences between premises of economic and strategic management theorizing. The former assumes a rather abstracted rational decision making process on value, while the latter encompasses various approaches that (increasingly) stick more closely to human agency, e.g. strategy-aspractice views. In this paper, we have to ignore these nuances since our objective is to provide an overview of approaches towards inter-organizational performance management.
} 
these resources through multiple processes to create value (Sirmon et al., 2007). The ResourceBased View and related theorizing on capabilities and resource dependencies has been extended to inter-organizational relationships. Scholars acknowledge the meta-organizational advantages of combining unique organizational resources (Combs and Ketchen, 1999; Arya and Lin, 2007; Caldwell and Howard, 2010) or creating distinct patterns of resources which are by themselves not unique (Eden and Ackermann, 2000). Firms' patterns of networking may offer a new base for economic advantage (Gulati et al., 2000). They could even cooperate and compete simultaneously or sequentially (Gnyawali and Park, 2011), and develop meta-organizational capabilities for 'elevated service offerings' (Agarwal and Selen, 2009). In particular, interorganizational cooperation can offer access to complementary knowledge resources (Reid et al., 2001). This extends research looking inside an organization's black box of value creation (Sirmon et al., 2007). External stakeholders engage in these resource processes rather than remaining on the fringe of organizational value creation as customers, suppliers, or employees (Kang et al., 2007).

Strategic-economic research embraces ideas on value creation and appropriation; that is, what do firms contribute and receive when cooperating (Kivleniece and Quelin, 2012; Lepak et al., 2007). Crossing organizational boundaries entails risks and requires new alliance capabilities (Gulati, 1999). Strategic-economic research is concerned with organizational positioning in value chains and long term advantage. While cooperation has been lauded for reinforcing an organization's strategic position, strategic risks have been acknowledged as well. For instance, controlling for knowledge leakage and opportunism also characterizes strategic-economic research on inter-organizational cooperation and performance management (Möller and Rajala, 2007; Van Fenema and Loebbecke, 2014). A partner may absorb resources and undermine their unique qualities (Wernerfelt, 1984), or cooperation may lead to disintermediation and power shifts in markets (Kumar and Van Dissel, 1996; Inkpen and Beamish, 1997). The strategiceconomic approach tends to assume rational and monolithically organizational decision making. It offers limited insights in performance outcomes and human agency.

\subsubsection{PERFORMANCE MANAGEMENT APPROACH}

Second, performance management has its roots in understanding and improving the performance of a single organization. A rich body of research has developed methods to make stakeholder expectations explicit, and link these to strategies, processes and capabilities (Neely et al., 2002; Neely et al., 2001). A rational, performance-oriented style of reasoning has emerged that has been inspired by cybernetics (Espejo et al., 1996). This approach seeks to ensure the instrumental, coordinated relevance of the various activities an organization enacts. 
Starting point tends to be the strategic level, but some authors elaborate on more micro level performance control, e.g. business process management, or they link strategic and micro performance (Solaimani and Bouwman, 2012). Powerful notions such as the organizational success map challenges management and organization members to think through desirable end-results and supportive intermediate outcomes and processes (Kaplan and Norton, 1996; Neely and Adams, 2003).

Performance management in this cybernetic sense has been extended to include multiple dimensions of performance and stakeholders involved, e.g. the Balanced Scorecard (Kaplan and Norton 1996). Research on various forms of sustainability broadens the foundations of value creation (Epstein and Roy, 2001). Moreover, inter-organizational cooperation shifts the unit of analysis from a single organization towards managing multiple organizations (Kaplan et al., 2010). Often, this occurs in conjunction with a broadened view on performance, e.g. organizations getting mutually involved in complex value creation for multiple stakeholders (Porter and Kramer, 2011; Reypens et al., 2016). Shifting the analytical aggregation level has important implications for performance management. No longer are elements of performance management residing in the confines of an organizational hierarchy. Scholars call for network performance evaluation concepts while acknowledging organizations' hesitation to invest in such efforts (Bititci et al., 2012). '(...) performance of an organization or individual will be judged by the network/community they belong to, according to their contribution, where factors such as trust, relationship and ingenuity will become important dimensions of performance evaluation' (Bititci et al., 2012: 314). Inter-organizational cooperation entails lateral relationships in which objectives, measures and performance management processes need to be developed and negotiated (Bobbink et al., 2016). Organizations bring in their own success maps which must be interrelated. Their internal performance-generating logic does not easily map to their partner's success maps; partial synergies and conflicts are likely to emerge (Keers and Van Fenema, 2015). Researchers propose dynamic models to develop inter-organizational performance management systems, taking various properties of cooperation and organizations that are involved into account (Ukko et al., 2015). The dynamic and innovative nature of current interorganizational relationships makes changes to performance management likely (Sols et al., 2012), for instance when an initial performance-based contract configuration does not seem to work well over time (Mahon, 2007). In short, a dynamic, processual approach seems to emerge to address the challenges of inter-organizational performance management. So far, the mechanics of this processual performance management approach remain unclear. Moreover, the relationship between performance and (inter)organizational processes tends be conceptualized without much detail. 


\subsubsection{SUPPLY CHAIN MANAGEMENT APPROACH}

Third, supply chain management extends organization-level logistics. Supply chains link multiple firms between input and output markets at an aggregated level of analysis (Jayaram et al., 2010; Christopher, 2011). The field of supply chain management has developed foundational insights in supply chains as an object of study, e.g. physical and support aspects, and fuzzy horizon of visibility (Van Liere and Koppius, 2007; Carter et al., 2015). It predominantly builds on a reductionist paradigm, focusing on tangible, observable dimensions of work processes (Nonaka, 2000) and outcomes. This paradigm abstracts from real-life organizational and (inter)personal processes. Concepts commonly used include service levels (e.g. waiting time), monetary value of services, and costs (e.g. transportation or stocks) (Franco-Santos et al., 2012). A reductionist perspective has its pros and cons. On the positive side, it allows for supply chain decision making tools based on Operations Research for optimization geared towards particular networklevel objectives (Humair and Willems, 2006), e.g. achieving the lowest network-level costs for a particular service level (Tsadikovich et al., 2016). Researchers offer powerful frameworks for pinpointing relevant performance indicators and they offer associated operationalization (Beamon and Balcik, 2008). Moreover, researchers (re)design new instruments, models and concepts for performance management or supply chain innovation (Harland et al., 2004). On the negative side, results of performance management research based on supply chain management needs to be re-contextualized to counteract the reductionist paradigm. Supply chain management research seems to assume availability and cross-organization sharing of data which in practice is likely to meet resistance (Lia et al., 2006; Loebbecke et al., 2016). Two directions are starting to enrich a reductionist supply chain management approach. On one hand, a linear one-to-one-to-one structure of a supply chain is considered no longer adequate for conceptualizing networked value creation. Notions such as value networks, circular value creation and multi-sided platforms offer new strands of research. On the other hand, recontextualization concerns both the organizational level (e.g. internal support for interorganizational alignment of operational processes) and inter-organizational and institutional levels (e.g. power and interest aspects of inter-organizational relationships) (Forslund, 2012). Specifically, innovations for supply chain performance improvement - e.g. Vendor Managed Inventory - require insight in the knowledge and social process of developing and implementing new concepts - given a particular set of actual practices (Tatikonda et al., 2005; De Martino, 2013; Paton and McLaughlin, 2008). Hence, emerging research on supply chain performance management inserts organization science, e.g. use of contingency and governance theorizing to 
determine how to achieve desirables outcomes such as viability, control, coordination and performance (Wilding, 2012).

\subsubsection{ORGANIZATION APPROACH}

Fourth, organization theory - this field traditionally builds on contingency approaches, relating the use of structures to variables such as uncertainty and task interdependence (Van de Ven and Delbecq, 1974). Extended to inter-organizational cooperation, contingency theory has led to studies on decision making on forms of inter-organizational and network governance. For instance, the number of organizations, their relationships (including (dis)intermediation, goal consensus and exchange task properties matter for selecting a mode of governance (Jones et al., 1997; Grandori, 1997; Provan and Milward, 1995; Provan and Kenis, 2008; Rossignoli and Ricciardi, 2014). In addition, contingency-style theorists examine the relationship between network structure (firm size, relationships) and outcomes (Provan et al., 2007).

In addition and more recently, process theorizing has gained ground which considers organizational change (Gioia and Thomas, 1996) and the evolving nature of what people in organizations do (Langley et al., 2013; Tsoukas and Chia 2002). Process theorists emphasize human agency, and hence the role of inter-organizational sensemaking, innovation, trust and learning (Batt, 2004; Gibb, 2016; Hamel, 1991). Interpersonal relationships stretch across organizational boundaries, constituting network social capital (Huggins, 2010). How do contingency and process theorizing relate to performance management? To organization scholars, inter-organizational performance management concerns effectiveness and outcome achievement (Provan and Milward, 1995); this has a role in contingency approaches in the sense of: better fit means better performance. Process theorizing, on the other hand, tend to concentrate on what happens in and between organizations, rather than the performance effects thereof. Sometimes they relate processes such as network learning to outcome achievement (Knight, 2002): 'The literature shows evidence of the effects of relational orientation promoting organizational learning, which influences innovation, supply chain effectiveness, and performance' (Agarwal and Selen, 2009: 433). The mechanisms of translating organizational processes into performance remain unknown. That is, one of the concerns with an organization approach is a superficial conceptualization of performance and value creation. 


\subsubsection{MARKETING APPROACH}

Fifth, marketing - scholars in marketing have broadened and contextualized the framing of value creation to encompass interactions among buyers and sellers in networks (Chandler and Vargo, 2011; Prahalad and Ramaswamy, 2004). Customer value depends on what a customer firm can do with a product or service ('value in use') (Grönroos, 2011; Grönroos, 1984). This implies a shift from a product or good logic towards a service logic, i.e. servitization ( $\mathrm{Ng}$ et al., 2012; Vargo and Lusch, 2008; Bititci et al., 2012). Value propositions are interactively shaped, experienced and adjusted (Ballantyne et al., 2011; Martinez and Bititci, 2006). Organizations engage with their customers through a myriad of intricately related processes over time (Minkiewicz et al., 2016). Taking value co-creation as a starting point, business models of firms and their practices are interactively connected (Holttinen, 2014; Heikkilä et al., 2014) and (re)designed (Nenonen and Storbacka, 2010; Frow et al., 2015). Relationships among firms in a network are believed to promote interaction, mutual orientation and thereby value (Kothandaraman and Wilson, 2001; Grönroos, 2015). Firms and networks need to learn to renew their offerings to remain relevant (Lusch et al., 2010). Taking a cognitive marketing turn at the network level, recent work explores how network actors make sense of their partners and the value creating network (Mattsson et al., 2015). Earlier research found that interaction between organizations promotes collective meaning, goal consensus (Van de Ven and Walker, 1984) and efficiency and innovativeness (Håkansson and Waluszewski, 2013). In short, performance thus depends on a dynamic and inter-firm processes of value co-construction. A concern that can be raised with the marketing approach is the limited attention paid towards the costs of interaction, the economics of value exchange and organizational processes required for interaction. A normative stance seems to underpin interactive marketing models which in some cases could be undesirable from a customer perspective, for instance in case of commodities or a high suppliers-to-buyers ratio.

To conclude this section, five approaches can be distinguished based on scholarly work relevant for understanding inter-organizational cooperation and performance management. Researchers increasingly (urge to) explore performance management and inter-organizational cooperation (Bititci et al., 2012). They have started to cross disciplinary boundaries. Mostly, authors combine two approaches. For instance, our view of performance management is enriched by adopting concepts from marketing (Bobbink et al., 2016), or marketing concepts are applied to supply chain management (Lusch et al., 2010). Others extend performance management by looking at organization science to arrive at a more complete understanding of effectiveness (Mandell and Keast, 2008). Yet a framework for systematically integrating all five categories is lacking. We elaborate on structure (value architecture) and process (dynamic coordination) dimensions of 
such a framework in the next two sections. These dimensions underpin a co-evolutionary model of inter-organizational performance management.

\subsection{STRUCTURE: VALUE CREATION ARCHITECTURE AND INTER-ORGANIZATIONAL PERFORMANCE}

\subsubsection{VALUE CREATION ARCHITECTURE}

To understand the performance of inter-organizational cooperation in an integrated fashion, we turn to models of value creation architecture. This domain consists of research that seeks to understand the coherent set of practices of value creation using the metaphorical notion of 'architecture'. The word puts the practices that yield value centre stage (Holttinen, 2014; Gehman et al., 2013). It is used here in a non-technical sense, e.g. not as platform or software architecture (Tiwana et al., 2010). In terms of unit of analysis, literature in this domain focuses on single organizations and inter-organizational exchange (Ngo and O'Cass, 2010). Value creation encompasses innovation as a sub-process that can enhance outcomes (Fjeldstad et al., 2012). Early research on value creation architecture includes work on Human Resource practices. Researchers assert that practices such as work structure, staffing, appraisal and reward, and training and development contribute to organizational learning and eventually value creation (Kang et al., 2007). Similarly, Sirmon, adopting a Resource-Based View, explains value by distinguishing resource management practices, such as structuring the resource portfolio, building resources to build capabilities, and leveraging capabilities (Sirmon et al., 2007). Research on firm-customer dyads adopted two questions as a starting point: "what constitutes value", and "how do firms create value for customers?" (Ngo and O'Cass, 2010). These questions lead to essential components of value creation organized around the 'strategic space of value creation processes' (tied to the first question) and the 'capability space of value creation processes' (tied to the second question). Ngo and O'Cass (2010) develop a model that explains offered and perceived value from resource-based capabilities. Building on a relational interorganizational models within the strategic-economic school of thought (Dyer, 2000; Dyer and Singh, 1998), Grover and Kohli (2012) propose four components, determinants or layers of value creation: an asset layer, i.e. relationship specific assets, a knowledge-sharing layer, a complementary resources and capabilities layer and an effective governance layer. Across the layers cross-effects can be distinguished, e.g. 'having an effective governance capability can incentivize learning and knowledge sharing, leading to greater investments in specialized assets, and co-creation of new capabilities' (Grover and Kohli, 2012). Layers may foster a 
'virtuous cycle' of value creation. Keen and Williams define a firm's value architecture as 'its blueprint for resource management that meet today's demands and adapt to tomorrow's uncertainties' (Keen and Williams, 2013). They propose various disruptive forces that enlarge the choice space of firms (e.g. deregulation, technology development and modularity), with value being considered a function of the choice space. A value architecture deals with these forces and utilizes the choice space advantageously. It combines three factors: value narrative - a plan (also called business model) to generate value, value engine (operational capabilities), and opportunity platform (business practices for investing in and managing resources, respond to value generating opportunities). Value creation is constantly in motion due to the disruptive forces and firms' responses. Research on value management for projects proposes three questions (Gillier et al., 2015): What is the value to be managed? How is the value to be managed? And for whom is the value to be managed? In short, strategic opportunities, expectations and evaluation ('what' of value creation) are related to the 'how' of actual value delivery. We can now synthesize literature on value creation architecture geared towards interorganizational cooperation and performance management. Value creation architecture is detached from the organizational unit of analysis and dissected in key processes that span multiple organizations.

\subsubsection{INTER-ORGANIZATIONAL VALUE MANAGEMENT: THREE PROCESSES}

We propose a synthesis of the previous discussion, proposing three processes constituting value architecture for inter-organizational cooperation: Value Management Processes, Governance Processes and Business Capability Processes. The first and third processes reflect the core questions "what constitutes value", and "how do firms create value for customers?" (Ngo and O'Cass, 2010). The second process connects these two. Governance translates expected value into operational actions (business capability processes). Conversely, it measures enacted performance and related it back to value management (for instance comparing service delivery with service level agreements). The layers mentioned (asset, knowledge-sharing and complementary resources and capabilities (Grover and Kohli, 2012)) are tied to the third process, the governance layer to governance processes. Keen and Williams' (2013) value narrative is linked to the first process, value engine refers to operational capabilities (third process), while opportunity platform related to the second process. We link the three processes back to value creation architecture literature and the five approaches to interorganizational performance earlier brought to the fore.

Value Management Processes. The first process combines researchers' notions of value creation (Kang et al., 2007), the 'strategic space of value creation processes' (Ngo and O'Cass, 
2010), the choice space of firms i.e. value narrative of business model (Keen and Williams, 2013), and the questions 'what value is to be managed' and 'for whom is the value to be managed' (Gillier et al., 2015). The value creation process consists of strategic value proposition management (what organizations need from whom, or what they intend to achieve for whom), value packaging (ideas for specific products or services they want to include in the exchange process), and - commonly after operational value creation processes - the experience and evaluation of value delivery (how actual value creation is achieved). Following recent research (Gehman et al., 2013), the actual operational delivery of value (utilizing resources, capabilities) should be distinguished from and is not included in value management processes. Value management, as a sub-process in a value creation architecture, concerns normative processes (Gehman et al., 2013), aimed at defining and evaluating what matters to an organization, not the operational actions such as a supplier conducting maintenance on a buyer's machine.

Reframing this example from a value management angle could imply that organizations attach value to for instance availability of machines, cost levels, workforce requirements and environmental impact ( $\mathrm{Ng}$ et al., 2012; Van der Lei et al., 2012).

We now reflect on the five approaches in relation to value management processes. First, these processes echo strategic-economic studies linking (organizational or inter-organizational) resources and capabilities to value creation, as well as theory on transaction costs as a form of governance. Concerning performance management, value management processes reflect the organizational objectives (beginning of performance management cycle) and the concluding experience and evaluation of performance. Value management processes can be used as a lens to study how multiple organizations define desirable performance (Bobbink et al., 2016), and why they might not be satisfied with outcomes of their relationship (Mahon, 2007). Supply chain management offers an explicit articulation of performance expectations that express the content of value management processes. Organization science pays limited attention to the specifics of value management processes. Finally, marketing's strong focus on value in use and buyer-supplier interaction reflects the importance of value management processes, Governance Processes. The second process encompasses the effective governance layer (Grover and Kohli, 2012) and opportunity platform (Keen and Williams, 2013). Governance such as transaction infrastructure provides a platform for value creation (Tiwana et al., 2010). We now reflect on the five approaches in relation to governance processes. Strategic-economic research explains the use of governance modes (e.g. contract or relationship) based on contingency factors such as uncertainty, transaction volume and uncertainty. While this approach links governance to resources and capabilities, it remains virtually silent on governance in relation to specific outcomes and value processes. Performance management, focused on organizations, 
assumes performance management systems can be translated into effective organizational governance. Less insight has been generated into inter-organizational governance and performance management. Supply chain management offers ideas on service levels and outcome performance indicators, and some research translates these notions into contractual governance. Organization theory elaborates extensively on governance forms, including formal and informal governance mechanisms (contingency theorizing) and processual insights, e.g. inter-organizational contracting and learning. Marketing, finally, stresses relational views on governance in relation to value creation, yet without elaborating details of this governance mode and governance alternatives to relationships.

Business Capability Processes. Finally, the third process concerns operational practices (Kang et al., 2007), capability space (Ngo and O'Cass, 2010), asset, knowledge and resource layers (Grover and Kohli, 2012), value engine or operational capabilities (Keen and Williams, 2013), and the question 'How is the value to be managed' in the sense of how to operationally deliver on value promises (Gillier et al., 2015). Business capability processes operationally enact expectations emanating from the value management and governance processes; they rely on resources and technology development (Vanhaverbeke and Cloodt, 2006). Organizations codefine and co-organize products and services as well as business processes enabling these outputs (Frow et al., 2015; Möller and Rajala, 2007). We now reflect on the five approaches in relation to business capability processes. Strategic-economic research extensively conceptualizes resource (combination) and capabilities as a source of value creation at the organizational and inter-organizational level. Performance management considers this topic instrumental when conceptualizing for instance an organization's success map. At the interorganizational level, this approach has limited insights to offer thus far. Supply chain management considers resources in terms of a commonly quantified understanding of capacity constraints and costs; it remains silent on capabilities. Organization science tends to consider tasks and human functioning and collaboration, rather than resources and capabilities. Our notion of business capability processes can be enriched by this awareness of what 'real' people do in organizations. Conversely, performance implications receive limited detailed attention in organization science. Finally, marketing considers products and services geared towards value processes. It virtually ignores resources; capabilities receive some attention.

In accordance with value creation architecture, the processes we have distinguished are mutually interdependent; they have cross-effects (Grover and Kohli, 2012). Value Management Processes translate into Governance Processes, for instance when codifying expectations (Gehman et al., 2013). They depend on these for evaluating actual value creation, e.g. comparing experience of actual value creation with agreed upon service levels. Governance 
Processes, operationalizing and stipulating mutual expectations, shape Business Capability Processes. The latter limit or enable Value Management Processes, for instance when contextual constraints prevent successful operational delivery. And finally, Value Management Processes connect to Business Capability Processes when organizations experience the value delivered by means of actions, (im)material resources, products or services. While value architecture provides insight in the structural dimensions of inter-organizational performance management, the process dimension needs further attention (Hall and Tolbert, 2005). Our model of inter-organizational performance management requires insight in coordination processes to deal with the dynamics of inter-organizational cooperation. This will provide a dynamic rather than cross-sectional perspective on value creation architecture. Specifically, we are interested in a dynamic view on coordination since inter-organizational cooperation represents an ephemeral, transitive phenomenon.

5.7 PROCESS: DYNAMIC COORDINATION AND INTER-ORGANIZATIONAL PERFORMANCE MANAGEMENT

Inter-organizational cooperation involves ambiguity with respect to process (Thomson and Perry, 2006) and outcomes (Provan et al., 2007). As each organizations operates in its own evolving environment, the collective risk is likely to be substantial and multifaceted (Dekker, 2004). In addition to cooperation, organizations need to pay attention to dynamic coordination (Gulati et al., 2012; Gulati and Singh, 1998), a more pragmatic process of synchronizing actions (Schakel et al., 2016; Jarzabkowski et al., 2011). Scholars studying how organizations deal with this ambiguity have developed coordination rhetorical coordination theory (Jarzabkowski and Sillince, 2007). Rhetoric is the evolving process of connecting two or more parties; they both protect their own identity (differentiation ${ }^{23}$ ) and seek convergence when interacting with counterparts (integration) (Sillince et al., 2012; Sillince, 2005). The paradoxical tension of autonomy and collectiveness has permeated inter-organizational cooperation theorizing (Galaskiewicz, 1985; Thomson and Perry, 2006; Ring and Van de Ven, 1992), and becomes palpable with for instance coopetition (Gnyawali and Park, 2011; Van Fenema and Loebbecke,

\footnotetext{
${ }^{23}$ Differentiation and integration originate in literature on the relationship between organizations and their environment Lawrence, P.R. and Lorsch, J.W. (1967). Organization and Environment: Managing Differentiation and Integration Boston, MA: Harvard University Press. Differentiation builds on the notion of horizontal task differentiation in organizations, acknowledging managers' different time frames, interpersonal orientation, and goal orientation. Integration refers to collaboration for dealing effectively with these differences.
} 
2014). Organizations' mutual actions and reactions can reflect differentiation and integration simultaneously (Bednarek et al., 2016).

Interdependence of actors or actions and autonomy drive coordination efforts (Van de Ven et al., 1976; Jarzabkowski et al., 2011). While traditionally coordination theory addressed the management of interdependence at the operational level (Faraj and Sproull, 2000; Crowston, 1997), it currently offers a more dynamic and strategic approach that acknowledges and includes differentiation (Jarzabkowski et al., 2011; Sillince, 2005). We now consider this rhetoricbased theory in the context of inter-organizational cooperation and performance management.

- Differentiation, on one hand, involves two specific processes highlighting the diversity of - in our case - cooperating organizations: emphasizing context and switching perspectives (Sillince, 2005). The former process compares and possibly contrasts organizations, and puts them in their own unique context; the latter process positions, relates, and comments on different views much like in a debate. Differentiation enlarges the playing field by using comparison (Sillince, 2006) and relativisation (Sillince, 2005). This befits an exploratory and flexibility-promoting mode of inter-organizational cooperation.

- Integration, on the other hand, refers to processes of creating consistency and purpose (Sillince, 2005). The former process aims for creating shared meaning, cross-references, and a common story, logic and structure to coherently connect diverse organizations; while the latter process fosters social cohesion by prescribing a common vision, purpose and trajectory for collective achievement. Integration fuses different organizations, enacting a simplifying and rallying meta-narrative of cooperation that attempts to reduce dissonance (Sillince, 2005; Bacharach et al. 1996).

\subsubsection{INTER-ORGANIZATIONAL PERFORMANCE MANAGEMENT: THE DYNAMIC NATURE OF VALUE CREATION}

We combine models of value creation architecture and coordination to develop a dynamic model of inter-organizational performance management (Table 1). Starting point for our model is the evolving nature of inter-organizational cooperation, performance management and interorganizational outcomes. Current research moves beyond the notion of stylized cooperation processes (Dyer et al., 2001): it acknowledges the complexity and ambiguity of shaping, organizing and managing an inter-organizational relationship (Pitsis et al., 2004). Performance management develops in conjunction with inter-organizational cooperation. For instance, when starting an alliance, definition of performance indicators and contractual stipulation of service 
levels are still immature and tacit. Over time, as relationships grow, organizations can define more precisely what they want and how this can be achieved (Heimeriks et al., 2014; Madhok et al., 2015). Research on inter-organizational cooperation distinguishes episodes - rather than stylized phases - depending on major events and transitions, i.e. studying what actually happened (Berends et al., 2011; Gibb, 2016).

While differentiation and integration develop conjointly, we distinguish episodes in which either differentiation or integration take centre stage. Between these episodes, transition occurs depending on organizations' response to an episode. We depict transitions as opportunity spaces after a differentiation or integration episode. The episode following a transition may include continuation of differentiation or integration, or a shift from one process to the other one. For illustrative purposes, Table 1 depicts transitions as shifting from differentiation to integration (left to right, over time).

Table 1. Structure and process: value creation architecture and dynamic coordination

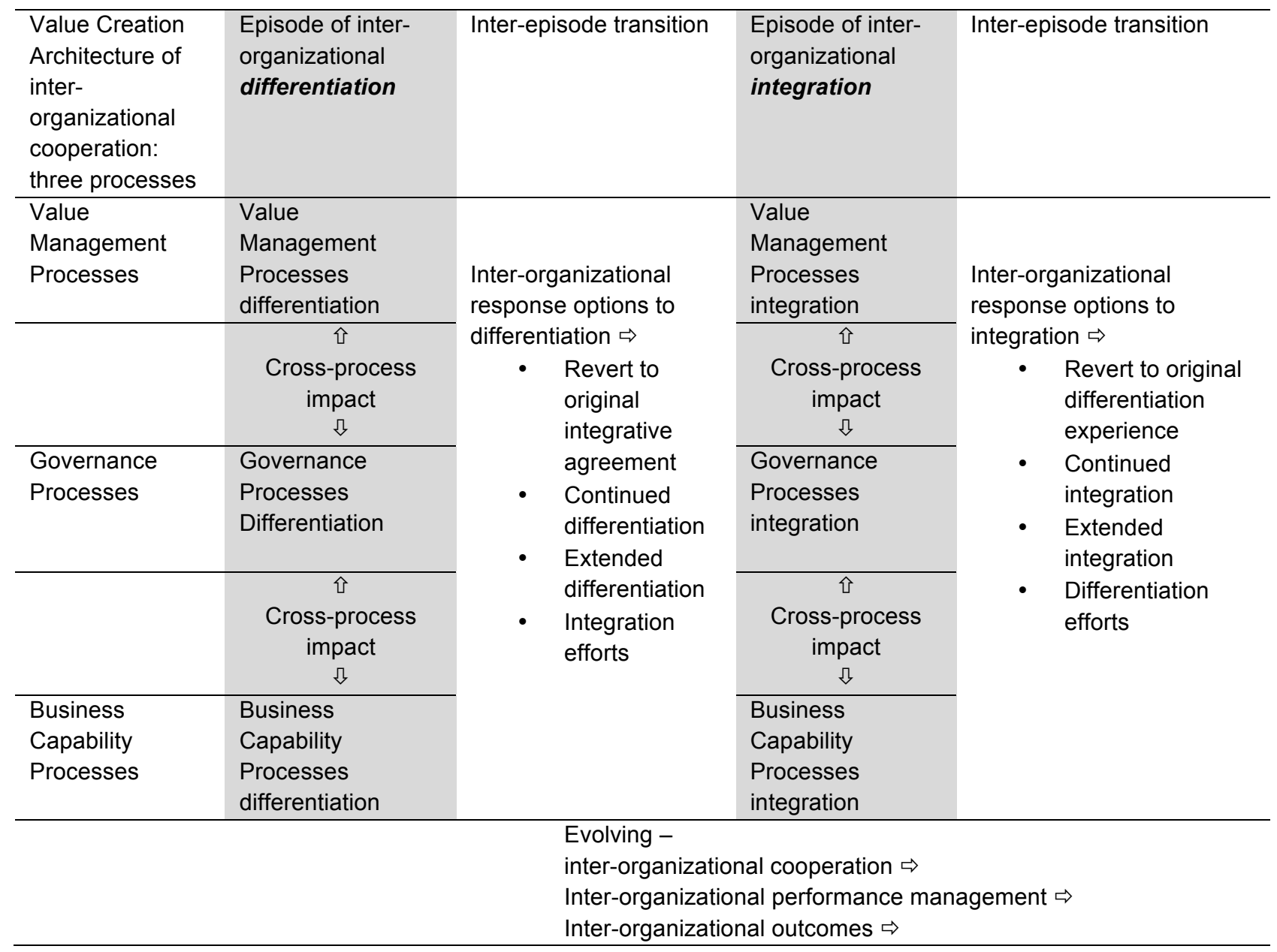


Episode of inter-organizational differentiation. Differentiation can be initially applied to the three processes of value creation architecture. It implies that value management processes across organizations diverge. Organizations may need to adapt their business model to deal with market dynamics (Bacharach et al., 1996). This disrupts the inter-organizational relationship, calling for increased interaction to make sense of changes (Sillince, 2005) and oscillate between prior and current understandings (Weick, 1995). Differentiation of governance processes has been examined in extant research on inter-organizational networks, where interpersonal relationships across organizations and contractual arrangements appear constantly in flux (Berends et al., 2011; Lumineau et al., 2011; Faems et al., 2008). Differentiation of business capability processes refers to interoperability problems across organizations, due to idiosyncratic routines and technologies (Andersson, 2015).

Differentiation also implies effects across the processes of value creation architecture, representing new opportunities or constraints (Grover and Kohli, 2012). On one hand, during a differentiation episode discrepancies between initial understandings and actual events can become a topic for debate among participants. For instance, business capability processes may not deliver in accordance with governance processes, leading to value tension (Mahon, 2007). On the other hand, potential innovations and shifting preferences may challenge the status quo of inter-organizational cooperation, performance management and outcomes. New technologies could offer partners opportunities to enhance their value creation and reduce costs (Möller and Rajala, 2007). A supplier wants for instance to shift towards a servitization relationships which changes all three processes (Bastl et al., 2012).

Inter-organizational response options to differentiation. Organizations can respond to a differentiation episode in different ways. Paradox management literature suggests a dialectical process of sticking to contradictory positions or seeking a new equilibrium of understanding and integration (Smith and Lewis, 2011). In the context of inter-organizational performance management, response options include reverting to an original integrative agreement. This may however not prove a viable strategy when organizations and their environments change and the agreement proves inflexible. Continued differentiation runs the risk of a widening gap between organizations. Extended differentiation implies that organizations seek to understand and interrelate their differences in accordance with the rhetorical strategies earlier mentioned. And integration efforts seek to counter differentiation by looking for common meaning and purpose. According to paradox theory, this could lead to a new equilibrium (Smith and Lewis, 2011), for instance exploring new opportunities for creating 'win-win' situations (Van Fenema et al., 2014; Oliver, 1990). 
Episode of inter-organizational integration. During an integration episode, partners seek to find common ground. This could concern the start-up phase of cooperation, but also intermediate efforts to develop common understandings and negotiate exchange conditions. Depending on the value chain relationship (e.g. a buyer-seller or triadic relationship, or horizontal cooperation), integration of value management processes results in common concepts for value propositions, products, services or innovations (De Martino, 2013). Governance process integration 'captures' organizations' exchange relationship in contractual terms, including interfirm organization of responsibilities, risks and incentives (von Deimling et al., 2013). Integration of business capability processes links organizational infrastructures and routines, enabling sharing of operational data and expertise.

Integration across the three processes is the foundation of value creation architecture in an ostensive sense (designing how organizations want cooperation to yield desirable outcomes) and a performative sense (what actually happens within and across organizational boundaries $)^{24}$. It can be accomplished and experienced by translating value expectations into governance and business capability processes (Gehman et al., 2013), and conversely, checking governance-consistency of business capability processes (e.g. does a supplier meet service level agreements?), and value impact of governance and business capability processes (Keen and Williams, 2013). The logic across the three processes requires coherence and buy-in from partners. For instance, do buyer and supplier agree on the extent to which they apply servitization and transfer risks? This depends on each organization's perspective on value management (what the buyer and supplier each want), contract design (servitization contracts that include performance measures, incentives, fine structure), and arrangements for business capability processes (who does what across organizations) ( $\mathrm{Ng}$ et al., 2012).

Inter-organizational response options to integration. Building on paradox theory (Smith and Lewis, 2011), response options to an integration episode mirror those of differentiation response. Integration may estrange organizations from their differences, so they can feel the urge to revert to their own idiosyncrasies. They could pursue integration as an ongoing process that must be continued, or even extend it when both consider this beneficial. And finally, building on integration achieved, they can explore new opportunities for differentiation such as seeking new market positions or developing new technologies. This may follow concerns of lock-in, and may include discontinuation of the relationship.

\footnotetext{
${ }^{24}$ This distinction was introduced in literature on routines Feldman, M.S. and Pentland, B.T. (2003). Reconceptualizing Organizational Routines as a Source of Flexibility and Change. Administrative Science Quarterly, 48, 94-118.
} 
The concepts differentiation and integration acknowledge the built-in tension between organizational autonomy and collective interests. This process view complements the structural value architecture earlier introduced. To better understand the extent to which interorganizational performance management proves effective over time, a co-evolutionary understanding is required. This will conceptually relate partners' internal performance management and the way they approach performance management collectively.

\subsection{TOWARDS A CO-EVOLUTIONARY UNDERSTANDING OF INTER-ORGANIZATIONAL PERFORMANCE MANAGEMENT}

While inter-organizational performance management represents a demarcated domain of research, linking it to organizational performance management is important. Organizations increasingly function as an open system, fostering bridges between their internal and external context (Franco-Santos et al., 2012). Ultimately, regardless of an organization's cooperative relationship, primary stakeholders of the organization expect an organization to take its responsibility for developing and successfully executing its own strategy (Neely and Adams, 2003). So how can organizational performance management of each partner be related to interorganizational performance management in a dynamic manner? These two phenomena 'exist' on their own: they represent separate domains of study: organizational versus interorganizational performance management. Yet they need to be understood in mutual dependence. Hence, a co-evolutionary perspective can be useful which acknowledges that organizations (micro) change in conjunction with their environment (macro) ${ }^{25}$ (Volberda and Lewin, 2003; Cantwell et al., 2010). To start with, similar elements of macro and micro performance processes can be related as this example of a multiunit firm shows (Figure 2). Each element of the goal-achievement cycles (solid arrows) has macro and micro instantiations that are linked (see dotted lines).

${ }^{25}$ We use macro for inter-organizational level and micro for organizational level. 


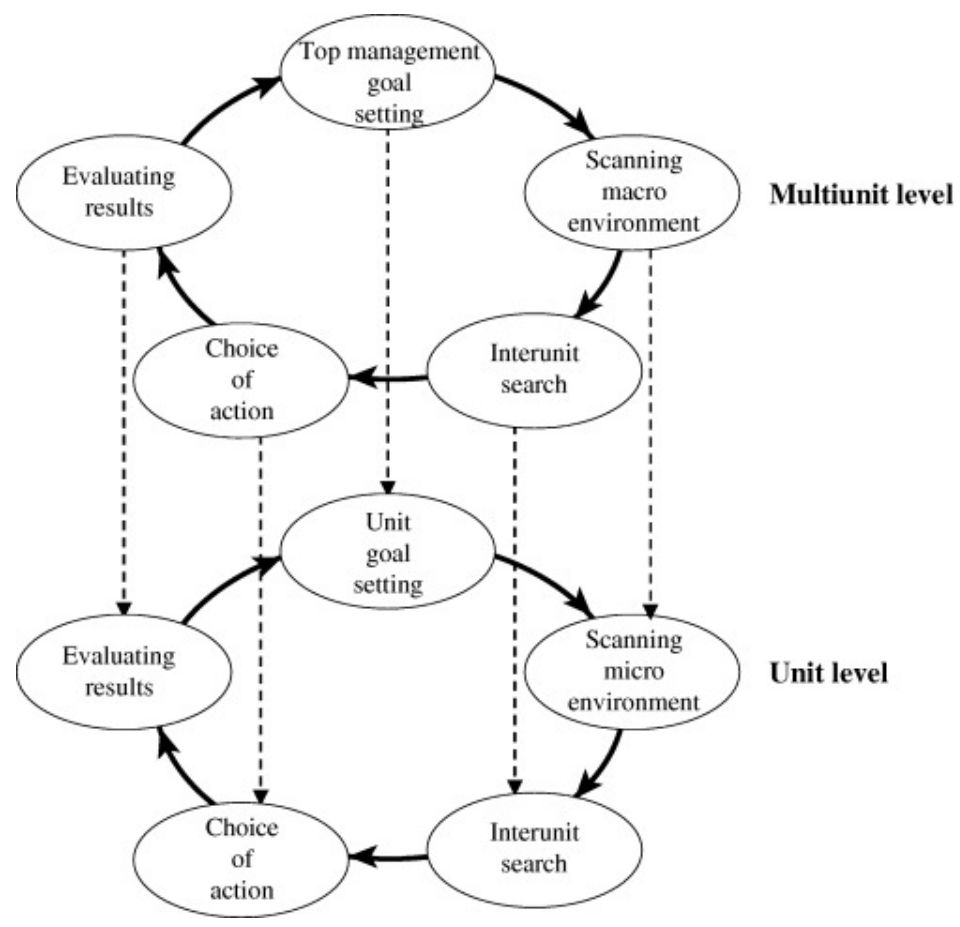

Figure 2. Macro-micro co-evolutionary processes (Volberda and Lewin, 2003)

To relate macro-micro processes and their elements, we propose three mechanisms that influence the effectiveness of inter-organizational performance management in conjunction with its organizational level counterpart (Figure 3). First, organizations need to make sense of their own performance management in relation to inter-organizational cooperation (Keers and Van Fenema, 2015). This concerns the strategic logic of cooperation. How can organizations fit interorganizational cooperation in their own 'pyramidal' (Chenhall and Langfield-Smith, 2007) performance management structure? Most organizations are likely to develop a variety of relationships with downstream customers, upstream suppliers, horizontal partners and other organizations that (are supposed to) matter to their primary strategy (Möller and Rajala, 2007). Recent work suggests that sensemaking in networks consists of 'individual sensemaking' (how do managers build network pictures) and 'sensemaking and the relationship with networking' (managerial actions to position their organizations in a network) (Henneberg et al., 2010). Organizations need to invest in interactions and artefacts to dynamically improve their understanding of their organization and its embeddedness in and co-shaping of interorganizational relationships. Effectiveness of inter-organizational performance management is likely to depend on balancing inclusion of organization members in inter-organizational relationships (Draulans et al., 2003), and balancing differentiation and integration (seeking congruence) at both levels and between these levels (Henneberg et al., 2010; Golant et al., 
2015). Conversely, intra-organizational sensemaking requires inclusion of boundary spanners working with the partner organization.

Second, modelling represents a mechanism for synchronizing organizational and interorganizational business models, metrics and measurement systems (Bobbink et al., 2016). Which performance matters to which organization and how are these business logics related in a conceptual and operational sense? Macro and micro modelling processes need to establish a baseline of expectation alignment and coordinated action. This could rely on for instance system dynamics, value mapping, business process modelling and IT configuration management. Organizational interests overlap only in part, so organizations need to establish sufficient clarity of their expectations and inputs to the relationship and to operationalize these. This helps to shape and align actions with and across organizations and to deliver for instance seamless 'customer journeys'. Effectiveness of inter-organizational performance management depends on modelling at macro and micro levels focused on organizational and inter-organizational value creation. These investments need to avoid lock-in across partners and escalation of system integration efforts. And third, dynamic value management entails evaluation, adjustment, and innovation, for instance monitoring whether contractual stipulations are executed well, or adjusting them when they prove no longer relevant. Organizations need to frequently examine their own benefits and costs associated with their external relationships, as well as aggregate (relationship level) benefits and costs - the value creation-capturing discussion (Kivleniece and Quelin, 2012; Lepak et al., 2007). With the increasingly reciprocal nature of cooperation (Reypens et al., 2016), organizations seek to manage their engagement intelligently within their own boundaries as well as externally (Storbacka et al., 2016; Lewin et al., 2011). Effectiveness for this third mechanism depends on the accuracy of insight in actions and how these evolve over time, macro and micro level reflection, openness to discuss how the relationship is working and interventions when needed.

Figure 3 visualizes the reasoning presented so far. Co-evolutionary mechanisms are positioned at he the intersection of organizational and inter-organizational performance management. For organizational performance management, we use the common framework of Neely and Adams (2003) focused on organizational success. Inter-organizational performance management has been succinctly conceptualized as a combination of structure and process, building on value architecture and dynamic coordination. Moreover, various types of inter-organizational cooperation can be distinguished that characterize how organizations jointly create value over time, e.g. relational (trust-based), transactional (market-based) and hybrid forms that contain elements of both (Nooteboom et al., 1997). These forms influence inter-organizational performance management and the co-evolutionary mechanisms. 


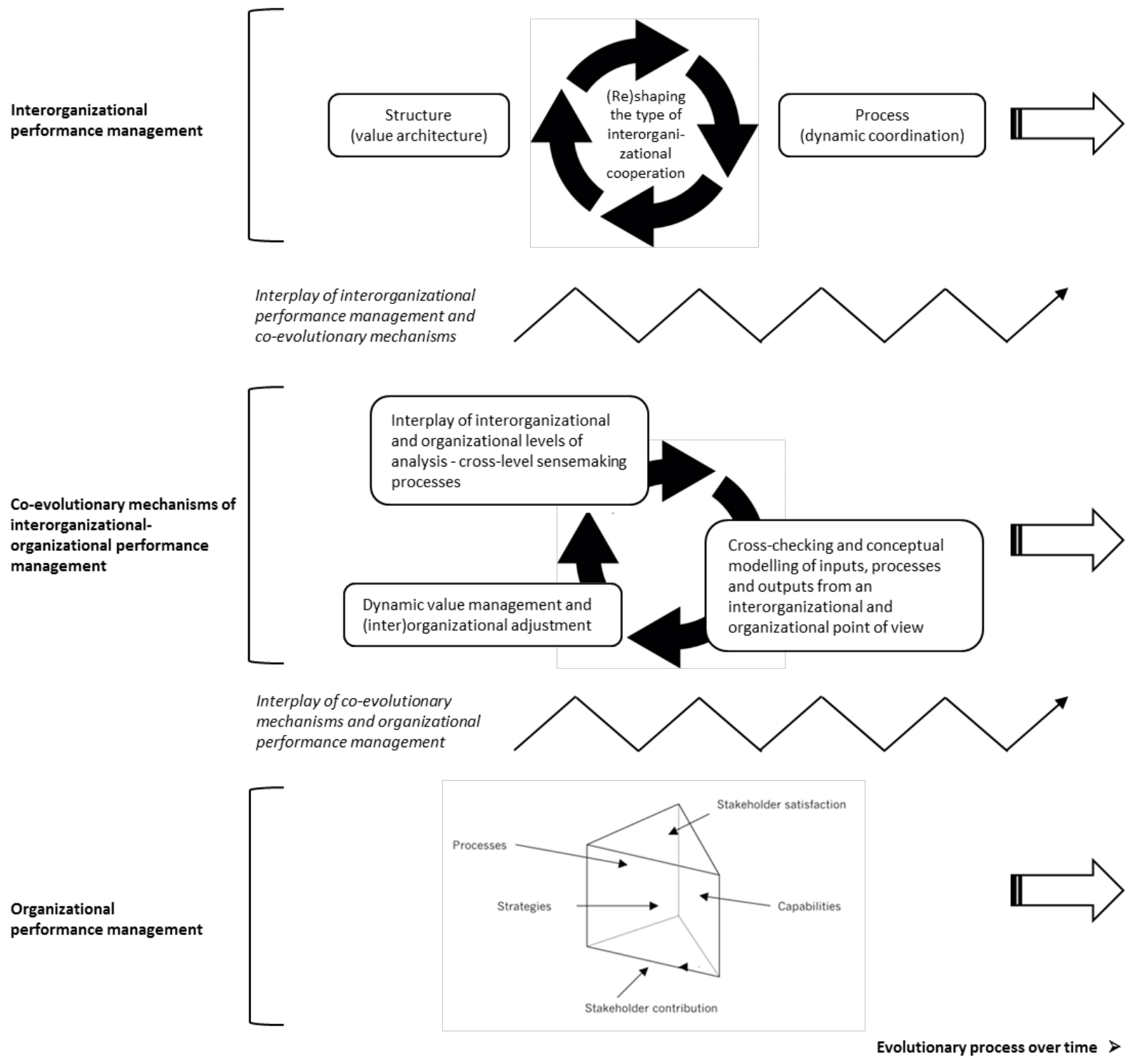

Figure 3. A co-evolutionary model of inter-organizational performance management, organizational performance management model from Neely and Adams (2003). 
To conclude this section, cooperation implies that organizations co-evolve and that they need to manage three mechanisms effectively to sustain value for each partner. The co-evolutionary model builds on the structure and process views earlier presented. On one hand, it shows how value architecture can be operationalized and maintained at inter-organizational and organizational levels. On the other hand, it provides a multi-level context for differentiation and integration processes. The specific nature of our model of inter-organizational performance management depends on sectoral features and relational properties on dimensions such as frequency of transactions, risks, trust, innovation pressure and value creation complexity. In line with contingency theorizing, these features and properties influence inter-organizational governance (Jones et al., 1997) and thereby performance management.

While co-evolutionary theorizing seems to assume equal weight of the entities that are connected (in our case inter-organizational versus organizational levels). In practice, this assumption of equality may have to be released. In some cases, 'measure locally (organizational level) and manage globally (inter-organizational level) ${ }^{26}$ may prevail, with 'managing' at the global level having more weight than 'measuring' at the organizational level. This could occur when organizations have built a solid relationship and are primarily concerned with making the cooperation successful. In other cases, 'measure globally (inter-organizational level) and manage locally (organizational level)' may apply. For instance, when organizations start to cooperate and need to build their network picture while emphasizing their own organization's interest.

\subsection{DISCUSSION AND CONCLUSION}

Inter-organizational cooperation has become a prominent mode of value creation, yet researchers have repeatedly stressed ambiguity, difficulty to interact across organizational boundaries, and risk of failure (Van Fenema et al., 2014; Thomson and Perry, 2006). Hence, new challenges have emerged for performance management which have not been adequately addressed (Bititci et al., 2012). The purpose of this review paper is to offer academics and practitioners a dynamic model of managing inter-organizational performance. Our review of background literature identified five approaches that help us deal with disciplinary strands of research pertaining to how organizations create value (Franco-Santos et al., 2012).

\footnotetext{
${ }^{26}$ We thank one of the reviewers for this insight.
} 
We found strategic-economic, performance management, supply chain management, organizational and marketing approaches. We then adopted a value creation architecture perspective and transposed it to the inter-organizational level. Inter-organizational value creation is understood as the interplay of value management processes, governance processes, and business capability processes. The dynamic coordination of these processes depends on differentiation and integration efforts. Depending on their choices and responses, organizations move through episodes of differentiation and integration. A co-evolutionary approach comprising three mechanisms provides a model for dynamic inter-organizational performance management. Which specific implications does this model have for inter-organizational performance management research? We elaborate on complex and heterogeneous inter-organizational performance management.

\subsubsection{COMPLEX INTER-ORGANIZATIONAL PERFORMANCE MANAGEMENT}

Our model offers a starting point for dynamically managing performance across organizations. However, in today's global and further digitizing business world, the complexity of interorganizational cooperation increases. First, in some markets, the performance (products, services, solutions) itself becomes so complex that organizations need new processes to dynamically design, execute and deliver value (Caldwell and Howard, 2010). Second, linear value chain relationships tend to be replaced by multi-sided, reciprocal networks, for instance the network of hotels - brokering sites - customers (Wynstra et al., 2015; Rysman, 2009; Orlikowski and Scott, 2015). 'Who gives and receives what to and from whom' is no longer a transactional quid-pro-quo matter but embedded in a complex network. Third, organizations engage in a multi-sourcing strategy, dividing service work across multiple suppliers (Levina and Su, 2008). And fourth, performance-based contracting shifts risks and responsibilities across organizational boundaries. These complexity-inducing trends affect the architectural processes (value management processes, governance processes, and business capability processes). Ambiguity is likely to increase and hence the responsibility at the organizational and interorganizational level. For instance, organizations may shift from product exchange towards a service or even performance-based relationship. This alters the performance management dynamics, triggering new differentiation and re-integration episodes. In some cases, a network orchestrator may take on the role of defining, controlling and optimizing performance (Busquets, 2010), in other cases, more decentralized, federated governance structures are preferred depending on for instance the number of organizations and trust level (Provan and Kenis, 2008). 


\subsubsection{HETEROGENEOUS INTER-ORGANIZATIONAL PERFORMANCE MANAGEMENT}

Finally, inter-organizational networks become more heterogeneous (Felin and Hesterly, 2007; Bridoux et al., 2011). In some sectors, initiatives emerge that enhance the heterogeneity of interorganizational cooperation, for instance public-private cooperation (Tang and Shen, 2013; Kivleniece and Quelin, 2012; Brinkerhoff and Brinkerhoff, 2011), open collaboration (Levine, 2014), triple helix projects (Perkmann, 2011; Shinn, 2002), or shared value creation (Porter and Kramer, 2011). Companies experience the need to take secondary groups of stakeholders into account when deciding on new products or major actions (Hall and Martin, 2005), or to work with other categories of organizations such as NGOs (Dahan et al., 2010). They consider themselves participants in an ecosystem of actors with a variety of roles and mutual relationships (Weiller and Neely, 2013). Heterogeneity is inevitably associated with differentiation: organizations need to sort out who they want to deal with and for what purposes. Organizations have their own performance management frameworks which need to be related in accordance with the desired relationship. Shifting to integration implies developing a common framework for governing performance (Perkmann, 2011). This could encompass measures for input, output and network characteristics (Kohl et al., 2015). Responsibility may require institutional structures to monitor collective interests (Matinheikki et al., 2016). Higher levels of heterogeneity will increase the costs of integration efforts; the likelihood of new differentiation episodes is high. Eventually, each organization participating in a heterogeneous network needs to decide how to link its own performance management to the network, and to determine whether and to what extent continued cooperation bears relevance to executing its primary strategy.

From a requisite variety perspective (Ashby, 1968), complexity of inter-organizational cooperation may demand new studies on how organizations manage their internal expertise and vertical-horizontal stratification. New communities may emerge that link an organization's professionals in a way that extends current understanding of alliance capabilities (Kale et al., 2002; Pyrko et al., 2017). Such organizational communities may shape the co-evolutionary mechanisms as they contribute to sensemaking, modelling and dynamic value management. How intra-organizational communities relate across organizational boundaries needs further research. In some cases, a single point of access is preferred (e.g. a few boundary spanner from each organization) when trust is low and risks of cooperation spillover effects are high (Williams, 2010). In other cases, a comprehensive cross-organizational community is advocated to leverage cooperation; this applies to crisis situations or conditions of goal congruence across organizations (Van Baalen and Van Fenema, 2009). 


\subsubsection{CONCLUSION}

Performance management is a pivotal field in management science, drawing on multiple approaches that reflect different disciplines. We distinguished strategic-economic, performance management, supply chain management, organization, and marketing approaches. The field faces new challenges such as coming to grips with inter-organizational cooperation. This paper contributes to theorizing on inter-organizational performance management. It identifies five approaches and integrates these using value creation architecture and dynamic coordination concepts. Structure and process underpin a co-evolutionary model that shows through which mechanisms inter-organizational and organizational performance management can be managed over time.

The confines of a review paper imply some limitations. Our co-evolutionary model offers a first step towards refined theorizing on inter-organizational performance management. An in-depth research program is required to develop conceptual linkages across the approaches suggested here. Moreover, empirical research could study success and failure of inter-organizational cooperation to elicit insights for (inter)organizational performance management (Mahon, 2007). The paper explores implications for research, linking inter-organizational performance management to participating organizations' primary strategy, and performance implications of complex and heterogeneous networks in which organizations increasingly participate. Future research could explore these new dimensions of inter-organizational cooperation and leverage the five approaches to this end. 
6 TOWARDS ALLIANCE PERFORMANCE MANAGEMENT IN SERVICE LOGISTICS

$\begin{array}{ll}\text { AUTHORS } & \text { Keers B.B.M . } \\ & \text { Van Fenema P.C } \\ \text { PUBLICATION OUTLET } & \text { Journal of Organization Design Vol. } 4 \text { No. } 1 \\ \text { ADDRESSES } & \text { RQ 4: What role do partners' values play in ensuring } \\ & \text { participating organizations' individual and collective } \\ & \text { success? } \\ \text { STATUS } & \text { Published }\end{array}$

\subsection{ABSTRACT}

This study explores the management of important values for service alliance success. A literature review outlines why alliances are useful from a strategic perspective, and how we can understand their stakeholder value. This reveals research gaps between existing knowledge and management practice. Subsequently, a holistic multiple-case study method is used to analyze for six organizations attempting to form a service alliance - how the inter-organizational dimensions of stakeholder value adds to the success of an alliance business strategy. Though alliance objectives may be shared between partners, when exploring the intra-organizational drivers behind their strategies we observe that most terminal values differ between partners. When exploring the underlying alliance capabilities, we discovered some conflicting instrumental values incurring the risk of an alliance asymmetrically benefitting one of the partners. Managers must acknowledge these differences and consider their impact, otherwise they may reduce chances of alliance success. The research is focused on the establishment of vertical service alliances within the maritime sector, including private-private as well as public-private initiatives. It extends the alliance management literature in the sense of providing a framework for achieving intra- and inter-organizational fit. The results lead to the design of an interorganizational success map. With its comprehensive multi (strategic) stakeholder orientation, such a map can be used by alliance managers to understand management's considerations and trade-offs between the variety of alliance's performance drivers. The paper extends traditional alliance measurement and organizational development models being used by managers today. The new conceptual thinking can enhance new studies and best practices on successful interorganizational design. 
In a globally connected world, organizations increasingly partner to reinforce their strategic positioning (Parmigiani and Rivera-Santos, 2011). Many recognize the need for interorganizational cooperation to become innovative in creating new business-opportunities (Taplin, 2006). An alliance can serve to access complementary resources and skills that reside within other companies (Caldwell and Howard, 2010; Dyer et al., 2001) and to contribute to an organization's own strategy (Pintelon et al., 2006). As such, alliance management constitutes a strategic activity (Schifrin, 2001). At a strategic level, alliances with selected partner organizations become pivotal for combining processes and capabilities (Tjemkes et al., 2012). Consequently, performance management topics increasingly extend beyond organizational boundaries (Bititci et al., 2005; Bobbink and Hartmann, 2014) - to include alliances (Tjemkes et al., 2012; Verdecho et al., 2012).

Because of this, new management challenges arise. This may result from alliance managers finding it difficult to manage the multiple alliance stakeholders; partners' view on the alliance may prove incompatible; business process coordination appears too complex and costly; or synergetic advantages prove not to materialize (Gulati et al., 1994; Gulati et al., 2012; Schilke and Goerzen, 2010). In addition, despite their strategic motivation, CEOs are hesitant to invest in strategic partnerships without a clear prospect of additional value. (We use 'value' and the plural word 'values' in the sense of organizational performance, not abstract principles an organization adheres to). As a consequence, effective alliance performance management is of growing importance to strategic managers.

While current research offers rich insights in successfully managing organizational business models (Bacharach et al., 1996; Neely et al., 2001; Solaimani and Bouwman, 2012), managing the combination of alliance partner processes and capabilities introduces complementary research questions (Bititci et al., 2005; Weiller and Neely, 2013). How do alliances influence existing business models and success factors? And an inter-organizational entrepreneurial question: which new opportunities for value creation do alliances enable?

The objective of our study is to explore in the context of alliance performance management what role partners' values play in ensuring their own and collective success. Alliances are understood here as an innovation that affects both participating organizations internally and externally. For instance, internally, an alliance may have a positive impact in the sense of offering access to new expertise (Gnyawali and Park, 2011). And externally, towards the partners' markets, combining products and services may underpin new value propositions (Harrison et al., 2001; Ye et al., 2012). Conceptually, we draw on research on alliances, value creation and performance management. We have conducted empirical qualitative research in the maritime 
sector, examining managers' strategic motivations for forming alliances and their conceptualization of alliance success in relation to their organization's values.

\subsection{ALLIANCE PERFORMANCE MANAGEMENT: CONCEPTUAL FRAMING}

\subsubsection{ALLIANCES: DEFINITION AND SCOPE}

The term alliance covers a broad range of relationships, from short-term projects to long lasting relationships (Long and Zhai, 2010). In general, alliances as a collaborative initiative aim at synergy, expecting benefits obtained to exceed individual organizations' efforts (Ireland et al., 2002). An alliance can be distinguished from other inter-organizational relationships; it can be positioned between transactional exchanges (simple, discrete, one-time events), and highly relational new organizational forms such as networks or joint ventures. Alliances can be shaped by informal handshake agreements as well as formal contracts (Geyskens et al., 2006; Kale and Puranam, 2013). Ultimately, they seem to be based on a self-interested orientation of organizations (Chang et al., 2008), but can become an innovative breeding ground for leveraging on new, win-win, business opportunities (Taplin, 2006).

\subsubsection{VALUE OF ALLIANCES}

To date, literature has mostly explored why organizations focus on business cooperation as a means for joint value creation. Theoretical perspectives such as inter-organizational cooperation theory (Jones and Lichtenstein, 2008; Oliver, 1991), alliance theory (Dyer et al., 2001) or the extended Resource Based view (eRBV) (Caldwell and Howard, 2010) offer conceptual underpinnings for cooperation as a business trend. Less attention has been paid to the value generation and appropriation process. In order to ensure alliance legitimacy, corporate decision makers - alliance managers - need to secure the support of all relevant stakeholders such as shareholders and investors, employees, customers, suppliers (including the alliance partner), competitors and public organizations (Chang et al., 2008; Hillman and Keim, 2001). The success of the alliance depends on the ability to take into account the underlying economic and social purposes of stakeholders. This requires partners to have insight on each other's stakeholders and to manage values in such a manner that the alliance's system at large is supported (Draulans et al., 2003; Tjemkes et al., 2012).

An important issue is how alliance managers can manage the trade-off between maximizing alliance value and at the same time serving their own stakeholders' interests. Research has shown that alliance failures are mostly related to the motivation for cooperation and the 
alliance's scope. Scope is one of the most challenging, comprehensive and critical activities in alliance performance management (Joncas et al., 2002). The process of 'scoping' includes coming to know stakeholders' values and preferences for outcomes. Uncovering, shaping and reinforcing the contribution of stakeholders' value proves crucial to the accomplishment of strategic efforts (Schein, 1990). Since values can influence the outcome of performance, they can be considered factors enabling or disabling the alliance strategy. Managing these factors is important to the organization's success (Maclntosh, 2012). At the same time, coming to know the partner's values increases trust (by understanding why the partner acts as it does), and managing values is important for alliance performance. Stakeholder value refers to the (desired) wealth of the party concerned, such as employees' job satisfaction. There are different methods for identifying stakeholder value (see Appendix A).

Following Rokeach's framework regarding individual values, a distinction can be made between instrumental values (facilitating capabilities) and terminal values (strategic objectives) (Rokeach, 1973). Rokeach postulates that instrumental values inform one's decision-making and course of action to attain terminal values. Moreover, he was one of the first to emphasize that values interact. Based upon Adkins et al. (1996), we can stipulate that the level of agreement and the connections between instrumental and terminal values organizations espouse demonstrate the level of congruence. Values congruence facilitates the achievement of long-term objectives. Further, understanding the incongruence of values helps managers to determine actions that might decrease operational differences (Adkins et al., 1996).

\subsubsection{VALUE OPERATIONALIZED: TOWARDS ALLIANCE PERFORMANCE MANAGEMENT}

Since an alliance consists of inter-organizational exchanges, partners must understand the different values of all participating organizations. Assessment of alliance performance, however, often lacks metrics to assess the congruence of underlying strategic values (Tjemkes et al., 2012). In operationalizing value, we seek to bridge both strategic topics (e.g. stakeholders, business models) and operational measurement. Performance management frameworks such as the PRISM framework (Neely et al., 2001) offer a good starting point. This framework is built on five views and questions (Neely et al., 2002):

1. Stakeholder Satisfaction: Who are our stakeholders and what do they want and need?

2. Stakeholder Contribution: What do we want and need from our stakeholders?

3. Strategies: What strategies do we need to put in place to satisfy these sets of wants and needs? 
4. Processes: What processes do we need to put in place to satisfy these sets of wants and needs?

5. Capabilities: What capabilities - bundles of people, practices, technology and

infrastructure - do we need to put in place to allow us to operate our processes more effectively and efficiently?

The PRISM framework helps organizations develop their own success maps, a logical, abstracted structure for understanding drivers of performance. "The success map encapsulates those things that the business has to deliver if it is to achieve its overall financial goals" (Neely et al., 2001). Based on a success map, organizations can work on questions to develop measures for performance data collection and analysis. This approach challenges organizations to develop constructs that supposedly drive revenues and costs, and to articulate their reasoning on how these are related. Organizations, both public and private, can thereby improve their strategic focus and internal coherence (Bacharach et al., 1996; Baden-Fuller and Morgan, 2010). An example of a success map - limited here to values - is shown in Figure 1.

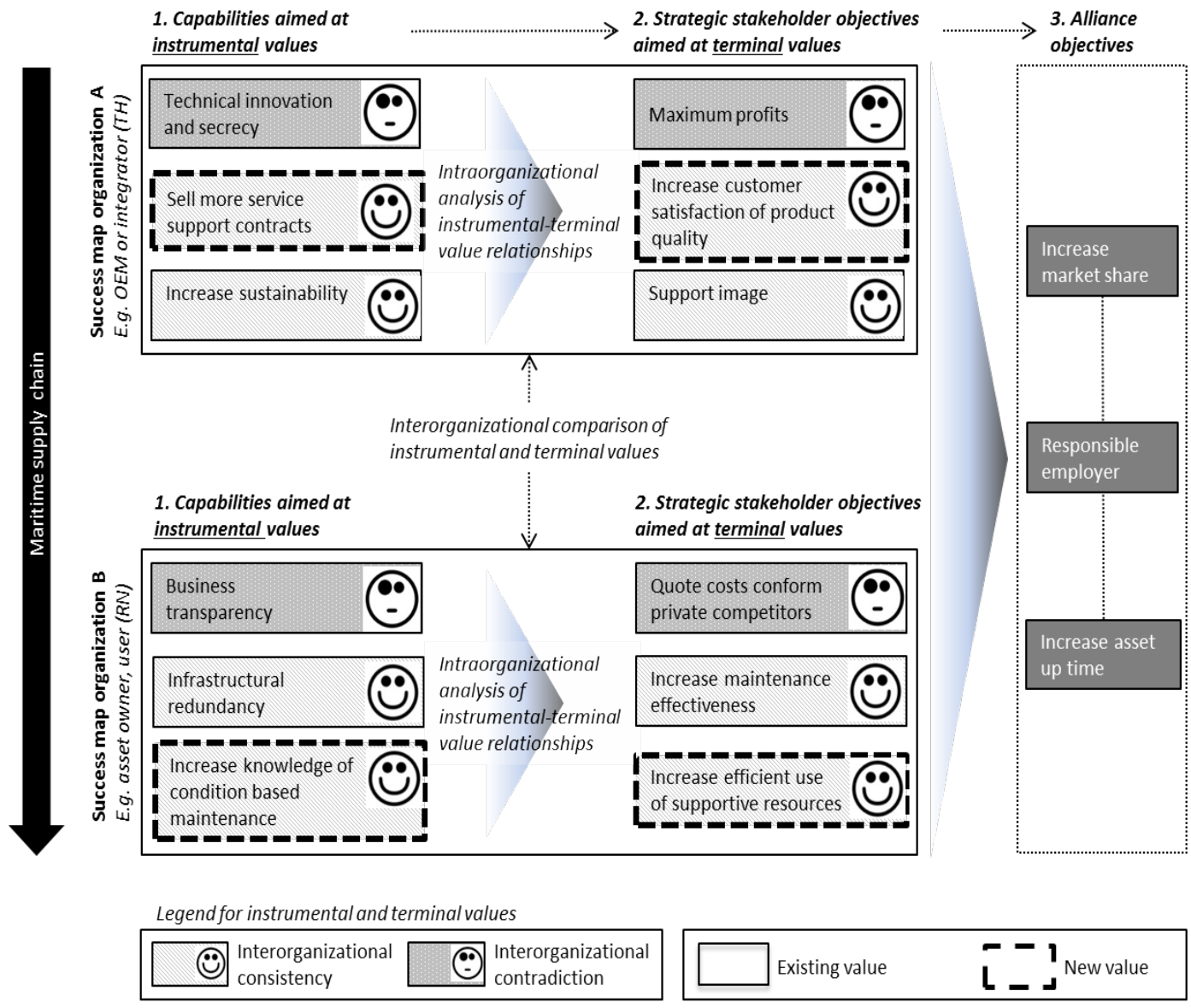

Figure 1. Alliance value map 
We envision organizations moving back and forth between their own success map and interorganizational dimensions of value during the formation stages of an alliance (see Table 1). They can consider the structural features of their success map and insert these into the alliance process (inside out). Conversely, the alliance is likely to impact their success map (outside in), since it is likely to affect existing values and may create new unexpected values. Our empirical work examines these dynamics in the maritime service logistics sector. We have studied alliance formation involving six organizations (multinationals and (semi) public organizations).

Table 1. Alliance life cycle phases and performance management

\begin{tabular}{|c|c|c|c|}
\hline \multirow[b]{2}{*}{$\begin{array}{l}\text { Alliance life cycle } \\
\text { phases (Dyer et al., } \\
\text { 2001): }\end{array}$} & \multicolumn{3}{|l|}{ Scope: } \\
\hline & $\begin{array}{l}\text { Organizational } \\
\text { success map (5 views } \\
\text { and questions) (Neely } \\
\text { et al., 2001) }\end{array}$ & $\begin{array}{l}\text { Alliance impact on } \\
\text { organizational success } \\
\text { map }\end{array}$ & $\begin{array}{l}\text { Inter-organizational } \\
\text { cooperation for materializing } \\
\text { alliance value }\end{array}$ \\
\hline & & $\begin{array}{l}>\text { Inside-out process }> \\
<\text { Outside-in process }<\end{array}$ & \\
\hline Pre-alliance phase & $\begin{array}{l}\text { Partners develop their } \\
\text { organizational success } \\
\text { maps }\end{array}$ & & \\
\hline $\begin{array}{l}\text { Alliance business case } \\
\text { phase }\end{array}$ & & $\begin{array}{l}\text { Partners consider the } \\
\text { alliance's potential for } \\
\text { impacting their } \\
\text { organizational success } \\
\text { maps }\end{array}$ & \\
\hline $\begin{array}{l}\text { Partner assessment and } \\
\text { selection phase }\end{array}$ & & & Partners initiate cooperation \\
\hline $\begin{array}{l}\text { Alliance negotiation and } \\
\text { governance phase }\end{array}$ & & $\begin{array}{l}\text { Partners consider impact } \\
\text { on their organizational } \\
\text { success maps }\end{array}$ & $\begin{array}{l}\text { Partners elaborate on alliance's } \\
\text { cooperation framework }\end{array}$ \\
\hline $\begin{array}{l}\text { Alliance management } \\
\text { phase }\end{array}$ & $\begin{array}{l}\text { Partners may adapt their } \\
\text { organizational success } \\
\text { maps based on alliance } \\
\text { experiences }\end{array}$ & & \\
\hline $\begin{array}{l}\text { Assessment and } \\
\text { termination phase }\end{array}$ & $\begin{array}{l}\text { Partners may decide to } \\
\text { terminate the alliance } \\
\text { due to a lack of positive } \\
\text { effects on their } \\
\text { organizational success } \\
\text { maps }\end{array}$ & & \\
\hline
\end{tabular}




\subsubsection{DESIGN}

To understand how organizations' values relate to a potential alliance partner's values and how an alliance can contribute to their own success, we have designed a holistic multiple-case study method. The case context is a large study focused on alliance formation within the Dutch maritime sector. In exploring the success factors for service logistics alliances, we traced the most significant intra-organizational strategic values and underlying capabilities.

We have focused specifically on vertical service alliances between different types of organizations. Given involvement in the assets' (i.e. ships) total life cycle, we assume organizations have an ability not only to strengthen their individual performances but also to influence organizations up- or downstream. 'Vertical' is understood here as sequentially linked contributors to value creation. In the maritime sector we find original equipment manufacturers (OEM's) of naval systems (e.g. radar, engines), system integrators (SI) (e.g. shipyards), service suppliers, and asset owners (AO) using the systems for their business processes (e.g. navy, tug towing, offshore investigation services). We focus specifically on organizations within one single sector, being the maritime industry, since this sector has boosted efforts to form service alliances as a strategy to increase efficient and predictive maintenance. The sector's ambition is driven by the observation that maintenance constitutes a significant part of a ship's exploitation costs and that system downtime may lead to a substantial loss of revenues for asset owners (Peeters et al., 2012). In the past, top management tended to ignore maintenance by just considering it as a part of manufacturing overheads (Pintelon et al., 2006). In today's perspective, they are viewing maintenance and overhaul from a broader angle, adopting innovative strategies for designing, modifying and maintaining assets.

\subsubsection{DATA COLLECTION}

We collected data at the organizational level from multiple sources: interviews, interorganizational project meetings and secondary sources (corporate documents and theses). Face-to-face interviews were conducted with 20 managers from 6 public and private organizations. We interviewed experts representing different skills or responsibilities, such as purchase managers, service managers, lawyers and senior executives. Interviews were set up using a semi-structured protocol to give room for the interviewees' experience. They were written in the interviewee's native language (Dutch) to prevent misperception. The semistructured interview protocol matched the alliance formation stage as earlier described. We focused on the initial stage of alliance formation, exploring the values of stakeholders and their 
motivation in the sense of preferences for alliance outcomes and the relationship between organizational capabilities and alliance strategy. We also attended a number of interorganizational meetings from which we drafted minutes or field notes.

To ensure accurate information was provided, neither the interviewees' nor the organizations' names are disclosed.

\subsubsection{DATA ANALYSIS}

To analyze the interrelation between alliance objectives, strategic values and capabilities we have adopted a method of content analysis of our data, being "a systematic, replicable technique for compressing many words of text into fewer content categories based on explicit rules of coding" (Stemler, 2001). From this, we constructed a structured data table to present the findings on organizational processes and capabilities, stakeholder requirements, and alliance contributions across the six organizations.

To examine how intra-organizational performances relate to alliance success and vice versa, we have drafted alliance success maps to explore intra- and interorganization relationships between different values and strategic objectives. Our initial approach of success maps evolved during the analysis phase into a model for examining congruence of instrumental and terminal values within organizations, and to relate these values across organizations. We analyzed alliance objectives and instrumental-terminal values for the three categories of stakeholders (original equipment manufacturers (OEMs), system integrators, and asset owners). In some cases, terminal values change over time, and we analyzed how this influenced the alliance formation process.

\subsubsection{QUALITY}

To increase the validity and reliability of the presented responses, all interviewees were asked to read, and if needed, revise the transcription. The same procedure was adopted for the drafted minutes. To supplement the primary data gathered by interviews and informal conversations, secondary data was collected by examining a broad range of corporate documents, maritime sector newspapers, and by studying master and bachelor theses tied to the research project. This information was triangulated with the information gathered during the interviews and meetings, to increase reliability and internal validity of research findings (Yin, 2009). 


\subsection{FINDINGS}

Our data deals with an early stage of alliance formation. Since data collection occurred at the organizational and inter-organizational level, we present our findings and analysis accordingly. We present our findings and interpret them using our conceptual framework and underlying literature.

\subsubsection{ORGANIZATIONAL VALUES ACROSS THE SUPPLY CHAIN}

Organizations considering an alliance explore inter-organizational relationships that move beyond traditional quid-pro-quo exchanges (Jones and Lichtenstein, 2008; Sobrero and Schrader, 1998; Tjemkes et al., 2012). In our case, expertise and information from customers allow OEMs and system integrators (SIs) to improve their organizational learning and product/service development processes. Asset owners (AOs), on the other hand, were most interested in learning more about products and services that would extend their own knowledge about maintenance processes. Organizational success maps express what an organization wants to achieve and which drivers may contribute or hinder success (Neely et al., 2001). In order to understand how an alliance can contribute to the success of an organization, we first explored the intra-organizational interrelation between organization's values and objectives. We found that success maps - limited here to values - are characterized by organizations' positioning in maritime supply chains. Most OEMs adopt an alliance strategy as a supportive (secondary) strategy to improve the quality of their differentiation or cost strategy. In addition, we found that OEMs struggle to resolve internal strategic ambivalence (e.g. partially moving from product towards service business models, shifting from go-it-alone towards alliances). As success drivers change with shifting business strategies, the design of organizational processes shifts as well (Gerritse et al., 2014). Consequently, fitting processes and capabilities to new business strategies presents a formidable challenge (Bacharach et al., 1996). Product-oriented OEMs face operational tensions when partially shifting towards a service-based business model. Most OEMs focus on cooperation with a customer, rather than with system integrators and service providers, as these relationships tend to become competitive.

With respect to how an organization's values relate to a potential alliance partner's values, our findings showed a common interest in seeking new knowledge by means of cooperation with (horizontal) partners having complementary knowledge. Partners' strategies for forming an alliance are caused by an emphasis on service and by a shift towards a 'customer function' orientation (i.e. how does an asset support operational customer functions such as 'power' for 
transporting). These notions have surfaced in the literature on procurement and industrial marketing (Bacharach et al., 1996; Grönroos, 2011a; Neely, 2008). Value for customers takes center stage rather than an offering by itself (Chandler and Vargo, 2011). Alliance outcomes are primarily focused on service innovation and expansion of services packages. Since the input from organizations within the alliance involves core capabilities, to expand their quality requires an equal commitment from partners. Furthermore, in comparison to both OEMs and SIs, most asset owners and users seem to have a different approach towards motivating alliance participation. Depending upon their capabilities, asset owners seek other suppliers to improve organizational performance.

Private asset owners are being confronted with OEMs' and SIs' desire to experiment with new business models (Caldwell and Howard, 2010). This might also explain their approach when exploring partners' inputs to the alliance. To counter possible relationship asymmetry, private asset owners tend to focus on balancing the alliance outcome by inserting risk and reward penalties as a means to balance power. This formalizes the relationship and limits the development of new values. In contrast, public organizations face different market dynamics. For example, the Dutch Navy has been facing budget cuts that jeopardize its own maintenance base. Fewer ships mean less maintenance work; this threatens long-term sustainment of maintenance capabilities. Moreover, the Navy needs to consider elaborate public regulation on procurement aimed at transparency rather than relationship building with particular upstream suppliers. At the same time, SIs and OEMs may seek to benefit from the Navy's expertise and resources (e.g. for testing). Agreeing on value exchange thus represents a formidable challenge. The findings on organizational values and alliance objectives are summarized in Table 2. 
Table 2. Alliance objectives and instrumental and terminal values

\begin{tabular}{|c|c|c|c|}
\hline $\begin{array}{l}\text { Category of } \\
\text { organizations }\end{array}$ & Instrumental Values & Terminal Values & Alliance Objectives \\
\hline $\begin{array}{l}\text { Original Equipment } \\
\text { Manufacturer (OEM) }\end{array}$ & $\begin{array}{l}\text { Aimed at extending customer- } \\
\text { centric, full service offering }\end{array}$ & $\begin{array}{l}\text { Best product offering } \\
\text { New terminal values: } \\
\text { servitization, globalization }\end{array}$ & $\begin{array}{l}\text { Using core capabilities to } \\
\text { provide products and } \\
\text { services to AOs }\end{array}$ \\
\hline $\begin{array}{l}\text { System Integrator } \\
\text { (SI) }\end{array}$ & $\begin{array}{l}\text { Aimed at locating equipment } \\
\text { for asset owners }\end{array}$ & $\begin{array}{l}\text { Services with a transaction } \\
\text { focus } \\
\text { New terminal values: } \\
\text { collaborative services } \\
\text { (relationship focus) with } \\
\text { horizontal partners }\end{array}$ & $\begin{array}{l}\text { Acquiring extended } \\
\text { knowledge for and by } \\
\text { providing services to AOs }\end{array}$ \\
\hline Asset Owner (AO) & $\begin{array}{l}\text { Aimed at business } \\
\text { transactions with OEMs } \\
\text { instead of cooperation }\end{array}$ & $\begin{array}{l}\text { Public organizations: asset } \\
\text { availability, independence } \\
\text { New terminal values public } \\
\text { organizations: } \\
\text { capability sustainment, avoid } \\
\text { lock-in and strong } \\
\text { dependence on suppliers, } \\
\text { cost effectiveness } \\
\text { Private organizations: asset } \\
\text { availability } \\
\text { New terminal values } \\
\text { private organizations: } \\
\text { reliability, minimize disruption } \\
\text { of operations, collaboration } \\
\text { with upstream partners, cost } \\
\text { effectiveness avoid lock-in } \\
\text { and strong dependence on } \\
\text { suppliers }\end{array}$ & $\begin{array}{l}\text { Provided with cost- } \\
\text { effective products and } \\
\text { services from OEMs and/ } \\
\text { or Sls }\end{array}$ \\
\hline
\end{tabular}

\subsubsection{DYNAMICS AMONG ALLIANCE PARTNERS}

Alliance formation confronts two sets of values and success maps: those of an organization considering an alliance and those of its potential partner(s). Dependencies begin to appear between the organizations, which may lead to collaborative success. Our findings support the opinion that different values and success maps can nurture alliance formation. The alliance success map articulates areas of cooperation while leaving room for each organization to assess 'integration' or 'interlocking of value horizons' (Henneberg and Mouzas, 2008). Recent work on control towers in logistics makes this notion palpable: operations from different organizations are at least virtually integrated (Pieri, 2012). In the alliance projects we studied, such multi-organizational concepts are being introduced. It echoes earlier work on network orchestration (Busquets, 2010; Dhanaraj and Parkhe, 2006) and virtual organizations, i.e. 
organizations that coordinate their business processes and services without losing their own identity and legal structure (Danesh et al., 2013; Katzy and Crowston, 2007).

Reverting to the organizational level success maps, values may be similar and aligned or perhaps contradictory (Tatham, 2013), and they can change during the cooperation. We examined how organizations' values relate to potential alliance partners' values (see Table 3). That is, we have compared the intra-organizational success maps between alliance partners to explore the similarities and differences between their values. We found that organizations face several challenges by analyzing both inter-organizational and intra-organizational comparison of instrumental and terminal values.

Table 3. Comparison of features across the six potential alliance partners

\begin{tabular}{|c|c|c|c|}
\hline $\begin{array}{l}\text { Organi- } \\
\text { zations }\end{array}$ & $\begin{array}{c}\text { Processes and capabilities: } \\
\text { What capabilities influence our } \\
\text { achievements (institutional } \\
\text { values)? }\end{array}$ & $\begin{array}{l}\text { Stakeholder requirements: } \\
\text { What are our main strategic } \\
\text { objectives (terminal values)? }\end{array}$ & $\begin{array}{c}\text { Alliance contribution: } \\
\text { What do we offer and desire } \\
\text { from the alliance? }\end{array}$ \\
\hline \multicolumn{4}{|c|}{ Original Equipment Manufacturer } \\
\hline PC & 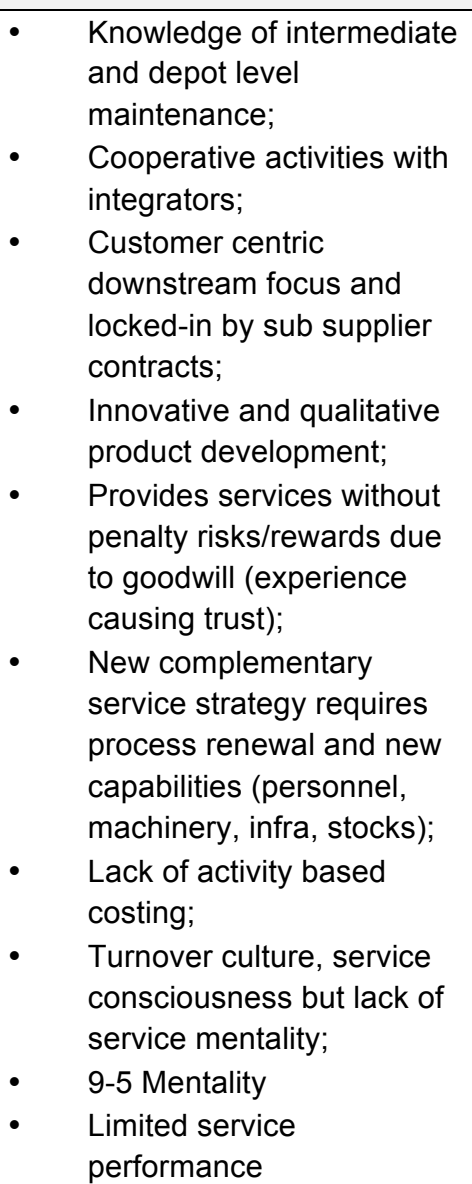 & $\begin{array}{l}\text { - Offering service level } \\
\text { agreements to customers } \\
\text { with maintenance } \\
\text { knowledge but insufficient } \\
\text { capacity; } \\
\text { Interested to work with } \\
\text { integrator for development } \\
\text { of innovative maintenance } \\
\text { methods to improve } \\
\text { service quality. }\end{array}$ & $\begin{array}{l}\text { Offer: } \\
\text { Service provision as } \\
\text { complementary to the } \\
\text { differentiation strategy } \\
\text { (new innovative products } \\
\text { or increased quality of } \\
\text { renowned products); } \\
\text { Maximal system up time } \\
\text { by performing effective } \\
\text { preventive maintenance. } \\
\text { In addition, when total } \\
\text { care is provided } \\
\text { (controlling operational } \\
\text { planning), maintenance } \\
\text { costs might be } \\
\text { decreased. }\end{array}$ \\
\hline
\end{tabular}




\begin{tabular}{|c|c|c|c|c|}
\hline & $\bullet$ & $\begin{array}{l}\text { measurements; } \\
\text { Good relationship with } \\
\text { DM. }\end{array}$ & & \\
\hline TH & • & $\begin{array}{l}\text { Design and production of } \\
\text { innovative electronics; } \\
\text { Strive for quicker service } \\
\text { response times by } \\
\text { problem analysis; } \\
\text { New complementary } \\
\text { service strategy requires } \\
\text { process renewal and } \\
\text { capabilities such as (to be } \\
\text { sourced) additional service } \\
\text { personnel, machinery, } \\
\text { infra, spare stocks; } \\
\text { Minor investments in } \\
\text { service development since } \\
\text { its significance is } \\
\text { uncertain; } \\
\text { Lead service contracts } \\
\text { with sub-suppliers exist } \\
\text { occasionally; } \\
\text { Sub-supplier selection and } \\
\text { product design is } \\
\text { insufficiently based on } \\
\text { service requirements and } \\
\text { costs;] } \\
\text { Good relationship with RN. }\end{array}$ & $\begin{array}{l}\text { - Maintain primary } \\
\text { knowledge focus in the } \\
\text { field of production; } \\
\text { Ambition to also provide } \\
\text { condition based through } \\
\text { life service support, to } \\
\text { deliver customers' } \\
\text { requiring maximal system } \\
\text { uptime (primarily not for } \\
\text { cost reduction); } \\
\text { More intense cooperation } \\
\text { with customers, to explore } \\
\text { and understand } \\
\text { (operational) } \\
\text { interests/requirements; } \\
\text { Despite alliance, of jobs } \\
\text { and job positions need to } \\
\text { be preserved. }\end{array}$ & $\begin{array}{l}\text { Desire: } \\
\text { Intermediate } \\
\text { maintenance support to } \\
\text { increase product service } \\
\text { quality. } \\
\text { Offer: } \\
\text { - Sharing of depot level } \\
\text { maintenance knowledge }\end{array}$ \\
\hline \multicolumn{5}{|c|}{ System Integrator } \\
\hline $\mathbf{A L}$ & • & $\begin{array}{l}\text { Tailor made product } \\
\text { integration, interface } \\
\text { development; } \\
\text { Customer centric } \\
\text { downstream focus; } \\
\text { Long term, efficient } \\
\text { intermediate or depot level } \\
\text { maintenance or training } \\
\text { offering on behalf of } \\
\text { suppliers or on customer } \\
\text { request; } \\
\text { Good relationship with PC; } \\
\text { Limited global support } \\
\text { capabilities (distribution } \\
\text { network). } \\
\text { Installation of sensors at } \\
\text { systems to attain } \\
\text { operational performance } \\
\text { data for condition based } \\
\text { maintenance. } \\
\text { Maintenance and spare } \\
\text { part planning. }\end{array}$ & $\begin{array}{l}\text { - } \quad \text { Values focus on } \\
\text { requirements: } \\
\text { - Expand global (scaled) } \\
\text { service offerings. }\end{array}$ & $\begin{array}{l}\text { Desire: } \\
\text { Interested to work with } \\
\text { horizontal partner with } \\
\text { complementary } \\
\text { knowledge to increase } \\
\text { service package offering } \\
\text { (market expansion); } \\
\text { Interested to work with } \\
\text { asset owner on new } \\
\text { systems to attain data } \\
\text { and develop and test } \\
\text { efficient maintenance } \\
\text { plan (instead of } \\
\text { purchasing performance } \\
\text { knowledge of OEM). }\end{array}$ \\
\hline DM & • & $\begin{array}{l}\text { Technological product } \\
\text { development and } \\
\text { integration; } \\
\text { Customer centric }\end{array}$ & $\begin{array}{l}\text { - Increase effectiveness of } \\
\text { preventive and condition } \\
\text { based maintenance; } \\
\text { - Increase efficiency of }\end{array}$ & $\begin{array}{l}\text { Desire: } \\
\text { Extend product quality } \\
\text { through life time to } \\
\text { increase customer }\end{array}$ \\
\hline
\end{tabular}




\begin{tabular}{|c|c|c|c|c|}
\hline & $\bullet$ & $\begin{array}{l}\text { downstream focus; } \\
\text { Provision of performance- } \\
\text { based maintenance advice } \\
\text { and contracts; } \\
\text { Enough and experienced } \\
\text { personnel, material and } \\
\text { infrastructure. }\end{array}$ & $\begin{array}{l}\text { logistic maintenance } \\
\text { support; } \\
\text { Exploit previous customer } \\
\text { experience into new } \\
\text { product or service } \\
\text { offerings to increase } \\
\text { company image. }\end{array}$ & $\begin{array}{l}\text { satisfaction and thereby } \\
\text { increase market share. }\end{array}$ \\
\hline \multicolumn{5}{|c|}{ Asset Owner } \\
\hline RN & $\begin{array}{l} \\
\bullet \\
\bullet \\
\bullet\end{array}$ & $\begin{array}{l}\text { 24/7 mentality; } \\
\text { Business transparency; } \\
\text { Flexible operations since } \\
\text { strategic volatility due to } \\
\text { political dynamics; } \\
\text { Infrastructural redundancy; } \\
\text { Shortage of technical and } \\
\text { purchasing specialists; } \\
\text { Limited process } \\
\text { registration; } \\
\text { Large amount of business } \\
\text { interactions on the basis of } \\
\text { break-fix maintenance; } \\
\text { Desire to increase } \\
\text { knowledge of condition } \\
\text { based maintenance. }\end{array}$ & $\begin{array}{l}\text { - Increase intermediate level } \\
\text { maintenance knowledge } \\
\text { (system analysis, project } \\
\text { management); } \\
\text { - Quick results; } \\
\text { - Increase stock response } \\
\text { times and decrease costs. } \\
\text { - } \quad \text { Maintain redundancy of } \\
\text { personnel for JIT } \\
\text { intermediate level } \\
\text { maintenance; } \\
\text { Share infrastructure, } \\
\text { machinery, and } \\
\text { performance data to } \\
\text { reduce costs. } \\
\text { Maintain control over } \\
\text { operational performance; } \\
\text { Not interested in total care } \\
\text { service contracts; } \\
\text { Scheduling to solve } \\
\text { expensive market; } \\
\text { mechanism; } \\
\text { Quick results to motivate } \\
\text { stakeholders; } \\
\text { Interested to work with } \\
\text { OEM to share infra and } \\
\text { maintenance knowledge. }\end{array}$ & $\begin{array}{l}\text { Desire: } \\
\text { - } \quad \text { Increased maintenance } \\
\text { effectiveness for } \\
\text { maximization of system } \\
\text { uptime (profits); } \\
\text { - Increased efficient } \\
\text { (condition based) } \\
\text { maintenance; } \\
\text { Decrease and sharing } \\
\text { system failure risks; } \\
\text { Achieve long term } \\
\text { results. } \\
\text { Offer: } \\
\text { Infrastructure \& } \\
\text { resources }\end{array}$ \\
\hline SL & $\bullet$ & $\begin{array}{l}\text { Local maintenance } \\
\text { personnel (cultural } \\
\text { differences); } \\
\text { Personnel incapable to } \\
\text { conduct efficient } \\
\text { intermediate level } \\
\text { maintenance; } \\
\text { Large amount of business } \\
\text { interactions on the basis of } \\
\text { break-fix maintenance; } \\
\text { Limited amount of spare } \\
\text { parts locally stored; } \\
\text { Central storage of spare } \\
\text { parts and global fine } \\
\text { distribution network. }\end{array}$ & $\begin{array}{l}\text { - Increase intermediate level } \\
\text { maintenance knowledge } \\
\text { (system analysis, project } \\
\text { management); } \\
\text { - } \quad \text { Increase efficient planned } \\
\text { maintenance; } \\
\text { - } \quad \text { Increase JIT spare parts; } \\
\text { - Maintain control over } \\
\text { operational performance; } \\
\text { Not interested in total care } \\
\text { service contracts; } \\
\text { Estimate maintenance } \\
\text { quality or cost } \\
\text { improvement to motivate } \\
\text { CEOs; } \\
\text { Interested to work with } \\
\text { OEM to attain knowledge. }\end{array}$ & $\begin{array}{l}\text { Desire: } \\
\text { Efficient planned } \\
\text { maintenance to maximize } \\
\text { uptime for increase of } \\
\text { profits and decrease of } \\
\text { costs. } \\
\text { Offer: } \\
\text { System performance } \\
\text { data. }\end{array}$ \\
\hline
\end{tabular}


Considering the inter-organizational comparison of the value drivers behind the shared alliance objectives, two instrumental and two terminal values seemed to contrast. Concerning the terminal values, we found a case where the public asset owner considered offering services to third parties, that is, customers of the OEM. This should be organized under the umbrella of a service alliance between the OEM and the public asset owner. In terms of value, however, the OEM desired maximum profits. This was in conflict with the public asset owner, being forced by regulation to offer third party services that conform to market prices. Here the instrumental values leading to the terminal values were also in conflict: the OEM strives for technological innovation and secrecy, whereas the public asset owner needs to share information in order to allow others to see what activities are being performed.

Again, the qualification of value differences is important to understand whether there is a tendency for cohesion enhancement or disruption in achieving alliance success. Since these represent existing rather than new values, the initiative might tend to overlook the underlying drivers. Nevertheless, proper attention must be given to sort them out; otherwise they will become bottlenecks in a successful partnership. Furthermore, the mixture of similar and conflicting values implies that external management of processes and capabilities will become difficult when the alliance commences. A thin line separates external activities that serve similar values and those incurring the risk of asymmetrically benefitting one of the partners. As such, partners need to demarcate their area of cooperation, assign responsibilities, draw contracts or at least settle on gentlemen agreements, and operationalize risk management and the allocation of benefits and costs (Doz, 1996; Yadav et al., 2003).

Concerning the intra-organizational comparison of values, organizations need to understand the relationship between instrumental and terminal values. Rather than thinking of alliance formation as a one-time effort, our findings suggest that it should be a continuing process to monitor partners' alignment of intra-organizational values. Terminal values keep evolving as organizations push their strategic innovation agendas. We found organizations struggling with the organizational implications of new strategic concepts (e.g., 'servitization' (Neely, 2008)) and new strategic realities (e.g., budget reductions in the Navy). Conflicting intra-organizational values are an early sign of business discontinuity and upcoming change, having an effect on the alliance coherence. Obtaining insight into conflicting intra-organizational values is valuable in understanding where to focus managerial attention when negotiating and monitoring alliance performance. 
As organizations consider or embark on the path of alliance relationships, opportunity and risk go hand in hand. With organizational level performance in mind, this study explores how six public and private organizations in the maritime supply chain go about forming alliances. Their interest stems from market characteristics (e.g., shrinking defense budgets), new concepts (e.g., servitization (Neely, 2008)), and sourcing innovations (e.g., performance based contracting (Kleemann and Essig, 2013)). Our findings help to explain the role values play in alliances.

\subsubsection{ALLIANCES AND VALUE: TOWARDS INTER-ORGANIZATIONAL PERFORMANCE MANAGEMENT}

Current research increasingly acknowledges the external dimension of organizational performance. This includes both external societal impacts of organizational activities (Gopalakrishnan et al., 2012; Wolf, 2011), performance across supply chains (Craighead et al., 2009; Trkman et al., 2010), and performance of the 'extended' enterprise (Bititci et al., 2005; Bobbink and Hartmann, 2014). Our findings indicate that alliance managers need to take multiple purposes into account and encompass an integrated view, rather than emphasizing particular dimensions of outcome measurement such as costs and productivity (Bititci et al., 2012). Moreover, with customer orientation taking center stage, performance management intersects with inter-organizational value relationships (Chandler and Vargo, 2011; Peronard, 2014). Our findings on alliance formation underscore this trend, yet they reveal the complexity for managers to serve their organization's objectives while opening up the organization to external cooperation.

Our findings cut across three levels: intra-organizational, inter-organizational, and alliance. Organizations strategize on alliance formation and articulate their joint intentions. Our findings suggest that future research should combine intra-organizational analysis of performance management and success drivers with inter-organizational analysis of value drivers. Compared with non-cooperative transactions where performance boils down to achievement against service levels, alliances call for more external transparency. Also, alliance success is likely to depend on weighing contradictory values against those that are consistent across organizations. Dealing with only partial consistency of values across organizations is an increasingly acknowledged feature of organizational coordination (Bacharach et al., 1996; Donnellon et al., 1986) and inter-organizational cooperation (Uiterwijk et al., 2013). 


\subsubsection{ALLIANCES AS A CHALLENGE OF GOVERNANCE AND STRATEGIC RELATIONSHIP MANAGEMENT}

Traditional research on governance presents clear-cut options: market (buy), hierarchy (make), and clan (ally) (Ouchi, 1980). An alliance may fit the clan option, yet theory's emphasis on relational and trust aspects obscures the complexities from a value perspective. Moreover, categorization of ideal forms has given way to theories that show these complexities and the blurring of inter-organizational boundaries (Bradach and Eccles, 1989; Caldwell and Howard, 2010; Ghoshal and Moran, 1996). Reflecting on our findings, an alliance has market aspects in the sense of organizations looking for a good deal that serves their terminal values. They are also aware of power differences and drivers of each organization's business model. An alliance has hierarchical properties as organizations are expected to share ideas and operational information and to co-innovate. These complexities imply that organizations move quite slowly during alliance formation. Middle management tests the ground for potential tensions, searches for areas of commonality, and solidifies internal approval from top management and employees. Organizations seem to clash, at least somewhat, on the type of relationship they seek. Most upstream organizations, such as OEMs and SIs, tend to look for input from downstream organizations to improve their products and services. In addition, some strive for long-term partnerships in a cooperative fashion. Downstream organizations, such as AOs, act according to a customer-centric logic. They expect upstream organizations to increase transparency and to develop a cooperative attitude. Downstream organizations, focused on their core business, may neglect the development of their own marketing and operational strategies to exchange resources with upstream partners.

Our findings suggest that the alliance formation process can be facilitated by academic and consultancy support. Future research may study how relationships evolve in an industrial sector (Berends et al., 2011), how stakeholders are engaged (Ho, 2007), and to what extent organizations 'open up' to counterparts. Moreover, our vertical supply chain study can be extended towards horizontal alliances (Van Fenema et al., 2014). An example of a horizontal alliance would be a 'co-opetitive' relationship aimed at joint procurement or co-development of products and services (Gnyawali and Park, 2011; Van Fenema and Loebbecke, 2014).

\subsubsection{OPERATIONALIZING VALUE IN ALLIANCES}

Our findings show that new alliances must address two main issues in operationalizing value. First, the participating organizations may shift from traditional procurement towards performance-based service contracts (Kleemann and Essig, 2013). While the procurement 
mode offers well-known routines for specifying work and tendering, performance-based contracts present alliance partners with new challenges. For suppliers, performance-based contracting may present a major risk but it may also offer opportunities for controlling customer operations and making a good profit. For customers, the comfort of being taken care of may be threatened by a concern of paying too much and by hesitation to trust the supplier. Alliances wanting to use performance-based contracts may draw on IT and manufacturing literature where outsourcing is common place (Dedrick and Kraemer, 2010; Oshri et al., 2007). Service-based performance management should build on detailed measurement of operations and linking data to business, technical and service metrics (Keller and Ludwig, 2003).

Second, organizations transitioning towards a cooperative mode have to develop criteria for joint operations and measures for organizational and alliance level performance. Alliance partners must specify their 'common playground', avoiding areas with conflicting instrumental and terminal values. Demarcating common playground from no-go areas will help to relieve concerns of an alliance moving in a direction that does not serve partners' interests. Alliance activities can be limited to particular products and services; measurement then depends on internal data being cleansed for external use. Organizations move step by step to ensure that their interests are being met as long-term investments pay off. Future research might explore how measurement relates to the direction an alliance takes, which information processing challenges are to be taken care of, and who are involved in operationalization.

\subsubsection{METHODS FOR ALLIANCE PERFORMANCE RESEARCH: PROCESS AND THE ROLE OF CONCEPTS}

Our role as researchers transformed during the course of the study. We started off with a round of analysis-oriented interviews befitting a traditional case study. Gradually, our role is shifting towards a co-facilitator of the alliance formation process. This role shift has implications on the conceptual side as well. Analysis oriented research aims at developing a model to describe and understand reality and to extend theory (Romme and Endenburg, 2006). The co-facilitator role suggests an action research approach aimed at designing and influencing organizations' reality (Bititci et al., 2005). As such, we will test the relevance of our alliance success map for alliance formation by conducting workshops with alliance partners. The concept then becomes a vehicle for presenting new concepts to organizations to influence their thinking, in the tradition of management concepts such as the Balanced Scorecard (Kaplan and Norton, 1996). Obviously, both approaches can work in a mutually reinforcing manner, with analysis feeding design, design impacting organizations, and analysis studying the impact (Romme and Endenburg, 
2006). Future research may explore how researchers can take on different role in studying and influencing values measurement.

\subsubsection{IMPLICATIONS FOR PRACTICE}

Our findings encourage practitioners to reflect on their organization's success map, eliciting the inter-organizational influences of intra-organizational instrumental and terminal values. When relating to the alliance partner, collective understanding of consistent and contradicting values can demarcate why and how cooperation can benefit all organizations. Once the alliance kicks off, ongoing monitoring of value performance and impact ascertains sustainability of the alliance. After all, organizations develop their business models and capabilities in a partially independent fashion. Alliance managers face, in addition to their external work, a complex internal role of rallying business units, top management, and employees to support the alliance. Their communication and cognitive skills have to be outstanding in order to support boundary-crossing processes (O'Mahony and Bechky, 2008). Moreover, an entrepreneurial attitude is paramount when chartering new ground.

\subsection{CONCLUSION}

From our study, we conclude that values represent a complex architecture for organizations and alliances. Different levels of organizations are involved in the process of constructing this architecture. Moreover, new stakeholders may have to be taken into account such as international headquarters and national government. Alliance success thus requires careful navigation and major efforts to sufficiently - not perfectly - align and protect stakeholder interests. 


\section{APPENDIX A}

Stakeholder analysis, uncovering stakeholder value, begins with stakeholder identification. Primary and secondary stakeholders are distinguished. The first have a formal, official or contractual relationship with the organization and are vital for its survival, whereas the second merely affect the organization's success. The most important stakeholders are owners, employees, customers, government, local community and business-partners. Usually, relationships between alliance stakeholders are interactive; e.g. the government regulates the market, but organizations also influence political decision-making (Ho, 2007). According to $\mathrm{Ho}$, it is said to be helpful to identify stakeholders being key to successful performance by categorizing them according to their interest and impact (power) (Eden, 1996). Stakeholders can have positive or negative interests in the organization's strategy, while the depth of the relationship influences stakeholder impact. Through understanding the interest and impact, managers can develop competitive or cooperative strategies for managing them.

Jensen (2001) furthermore stresses long term value maximization of the organization as a key objective and a criterion for selecting pivotal strategic values. He calls it „Enlightened Value Maximization”, derived from the „Value Maximization” notion and stakeholder theory. He suggests to define a true (single dimensional) score for measuring performance for the organization or division which should be consistent with the overall strategy, and then to measure the most important stakeholders' values (as performance drivers) to understand how to maximize the score. In contrast, Earl and Clift (1999) propose to weigh value trade-offs for reflecting different stakeholders' priorities. The basic premise is that important attributes to maximize an alliance's objective are given high weights, while unimportant ones are given low weights (Earl, 1999). 


\section{A NARRATIVE PERSPECTIVE ON ORGANIZATIONAL CHANGE AND ALLIANCE FORMATION}

$\begin{array}{ll}\text { AUTHORS } & \text { Keers B.B.M. } \\ & \text { Van Fenema P.C. } \\ & \text { Van Ommen N. } \\ \text { PUBLICATION OUTLET } & \text { Organization } \\ \text { ADDRESSES } & \text { RQ 5: Which factors are likely to affect differences between } \\ & \text { an alliance and its participants' narratives? And how does } \\ & \text { this influence interorganizational performance? } \\ \text { STATUS } & \text { Submitted }\end{array}$

\subsection{ABSTRACT}

Organizations increasingly harbor multiple strategies to deal with complex, shifting networks. They engage in complex external relationships such as alliances to innovate their value creation practices. At the organizational level, dealing with pluralistic (multiplex) strategies remains illunderstood. The goal of this study is to gain insight in the cohesion between organization-level and alliance narratives. This study explores how a high-tech company (called TechCo) shifts towards servitization, and wrestles with strategic multiplexity as it forms a service alliance with its major public customer. We examine how TechCo seeks to combine narratives tied to its organization and alliance formation efforts. Relying on narrative network theory, we conceptualize value, capability, and social narratives. A qualitative case approach was adopted to examine how organizations can change while they form an alliance. We reflect on interdependence, tension and meaning construction across narrative networks. The discussion explores implications for pluralistic strategizing and proposes our approach as a process view on shifting narratives that enable organizations to change coherently. Practical implications include how narrative networks can be actively managed.

\subsection{INTRODUCTION}

\subsubsection{ALLIANCES REVISITED}

Over the last twenty years there has been an accelerating growth of organizations forming strategic alliances (Tjemkes et al., 2012). A strategic alliance can be defined as a shared 
cooperative strategy in which two or more independent organizations commit, by informal handshake agreements or formal contracts, to reinforce or complement each other's critical capabilities - referring to skills, knowledge, resources and processes - for an extended period of time (Kleemann and Essig, 2013; Ter Wiel, 2012). Parties have the intention to increase their individual strategic value by means of the alliance. Alliances exist as interactions among members of partnering organizations. They may become meaningful over time when interactions stabilize (Weick and Westley, 1996; Weick, 1995). An organization might be motivated to form a strategic alliance when it faces strategic gaps in critical capabilities and when developing these internally would be too expensive or would take too long. By means of an alliance, unlike conventional sourcing and service agreements, an organization can get access to a subset of another organization's capabilities. Furthermore, the collaborative initiative aims at synergy in the hope that the benefits obtained will exceed individual efforts (Ireland et al., 2002). In such cases, strategic alliances may become a pivotal tool to maintain a firm's sustainable competitive edge (Jiang, 2007).

Despite its potential, successful realizations of alliances tends to remain scarce (Lowe et al., 2016). One of the reasons is that we are still at an early stage of learning how to manage such partnerships (Tang and Shen, 2013).

To improve understanding of alliance management, many researchers have explored the field of strategic alliances in different ways. As such, literature on alliance management is diverse, but two research approaches seem to dominate. On the one hand, using a classical approach, researchers have explored critical factors influencing inter-organizational performance such as resources alignment among partner firms (Das and Teng, 2000) or profitability (Reuer and Miller, 1997). On the other hand, more behaviourally-oriented studies found that learning processes within the alliance (Berg and Hamilton, 1998), or relational dimensions between partners encompassing themes such as mutual trust, commitment, and cultural compatibility - drive alliance outcomes (Osterwald and Pigneur, 2010; Baden-Fuller and Mangematin, 2015; Dyer and Singh, 1998; Nenonen and Storbacka, 2010; Heikkilä et al., 2014).

Researchers have stressed that organizations are embedded in different kinds of interdependent relationships, each of them influencing organizational performance (Shipilov, 2012). Since within these relationships interests may diverge (Kivleniece and Quelin, 2012; Brinkerhoff and Brinkerhoff, 2011; Dahan et al., 2010), organizations face a challenge of combining strategic alignment and organizational transformation. This challenge of strategizing requires an active, context-aware and complex management process (Jarzabkowski et al., 2007; Jarzabkowski and Fenton, 2006). Research on strategizing so far has in particular focused on the organization as unit of analysis, exploring the management of strategic dualities (Birkinshaw et al., 2016), 
strategies for balancing intra-organizational tensions (Ansari et al., 2014), changes to organizational identity and knowledge (Corley and Gioia, 2004; Nag et al., 2007), and combination of diverse narratives within an organization (Dalpiaz et al., 2016).

Research is lacking on the relationship of an organization with its alliance to understand the management challenge thereof. In other words, how can pluralistic strategizing be interpreted when considering participants' enactment of alliance strategy in conjunction with their own change process. In fact, participants' internal change can be at odds with their alliance as they have to deal with new and sometimes conflicting alliance stakeholder demands (Pache and Santos, 2010), and alliance investments at the expense of business capabilities (Sirmon et al., 2007)

\subsubsection{NARRATIVES INTERRELATING ALLIANCES AND ORGANIZATIONS}

Cohesion of narratives internal and external to the organization influences performance outcomes as related studies on congruence (Edwards, 1994) and dissonance have proposed (Bacharach et al., 1996). Hence, the goal of this study is to gain insight in the cohesion between organization-level and alliance narratives. While alliance narratives may emphasize the strength of joint interests, some participants may strategically move away from their counterpart due to fears of (identity) entrapment. Narratives are considered cognitive maps to process and communicate past experiences; they enable reconstruction of plausible histories underlying one's current position and anticipated future (Weick, 1979). Narratives relate to who we are, they determine our actions, and as such our process of becoming. Also, convincing narratives can shape 'hearts and minds', and as such construct events within organizations (Beynon, 1973; Mitroff and Kilmann, 1975). Identifying and analysing dominant narratives opens windows to monitor performance and estimate future events. By studying the relationship between organizations' and alliance's sense making apparatus, we may be able to estimate whether future actions will diverge or harmonize. In addition, examining narratives' cohesion may enhance understanding of performance differences between alliances, and offer a new perspective on what alliance performance management involves.

To enhance alliance management success, the rationale of this study is to increase understanding of the cohesion between alliance narratives and organizational narratives. Conceptually, we follow recent work on strategy as practice (Fenton and Langley, 2008; Jarzabkowski et al., 2015). We adopt a strategic narrative lens (Landrum, 2008), being interested in learning more of the relationships between narrative networks (Pentland, 2007) and inter-narrative tensions. Subsequently, we examine the usefulness of this approach with empirical research. 
The main contribution of this research is to explore the interfacing of organizational strategy and alliance formation by connecting strategic narrative and alliance management literature. These two streams tend to remain disconnected, with the first stream sticking to an intra-organizational unit of analysis. By providing insight in the relationship between organizational and alliance narratives, this paper contributes to the emerging literature on alliance performance management, and helps to study social processes and management of interests across organizations.

The paper is structured as follows. The conceptual background section discusses alliance management, narrative network theory, and considerations necessary for assessing the cohesion between alliance- and organization-level narratives. We then describe the empirical case study conducted at TechCo, a high-tech multinational firm forming an alliance with one of its major public customers. Subsequently, we analyse the level of cohesion and discuss both the performance implications and extent to which cohesion in this case can be increased.

\subsection{CONCEPTUAL BACKGROUND}

Acknowledging research that considers organizations as open systems (Berchicci, 2013), alliances are approached as a phenomenon consisting of inter- and intra-organizational processes (Lewin et al., 2011; Porac et al., 2002).

\subsubsection{ALLIANCE MANAGEMENT AS AN INTERORGANIZATIONAL PROCESS}

The study of alliances has become central within organizational research as alliances offer organizations the ability to generate additional value (Ahuja, 2000). Relational rents might be achieved that extend organizational performance (Dyer and Singh, 1998; Oliver, 1990). This triggers the question: 'When facing strategic gaps in critical capabilities, why do not all firms form alliances?' (Ahuja, 2000: 317). The answer to this question lies in the process of alliance formation which demands considerable pre-investments for the development of alliance capabilities and maintenance thereof without a guarantee of positive results. Moreover, partners require idiosyncratic organizational changes which cannot readily be recovered (Mukherjee et al., 2013).

The organizational development of alliance capabilities relates to, first, the development of collaborative capacity. According to Huxham, organizations need 'the capacity and readiness ... to collaborate' (Huxham, 1993). Collaborative capacity also refers to employees being collaboratively oriented without losing sight of organizational interests (Van Fenema and 
Loebbecke, 2014), and able to absorb external knowledge to foster an organization's capacity to learn from their partner (Lane and Lubatkin, 1998).

Second, alliance management requires social or relational capital. It refers to the quality of the interaction at the personal level between alliance partners (Kale et al., 2000: 221). Relational capital significantly impacts the ability of a firm to successfully manage the dual objectives of learning from its partner and protecting its own core proprietary assets. It encompasses the compatibility of corporate cultures and the convergence of organizational characteristics. Relational capital facilitates alliance partners to rely on each other through trust mechanisms (Arino et al., 2001); it is characterized by transfer of particularly tacit know-how, which makes it easier to gain access to and understand each other (Butler Jr, 1995; Gulati, 1998).

Third, alliances require investments in joint strategy formation. Huxham (1993) studies alliances in the public service sector in the UK. One of his conclusions is that successful alliances are 'particularly concerned with the development of a strategy which can be owned jointly by the organizations involved' (Huxham, 1993). Similarly, authors stress the importance of a 'complementarity driver for alliance formation' (Chung et al., 2000). In particular when organizations are different, development and implementation of a joint strategy is likely to be contingent and incremental (Huxham, 1993).

Fourth, an alliance rallies organizations acting in their own contexts. An alliance implies that organizations change the way they relate to other organizations. Michailova and Ang (2008) found that alliances are positively influenced by successful organizational adaption. They state that alliances 'need to comply with regulatory, normative and cognitive conditions to gain, maintain and develop legitimacy' (Michailova and Ang, 2008: 21). Fifth, alliances require some form of conflict management as tensions in inter-organizational relationships may rise due to the partial nature of their overlap (Van Fenema and Loebbecke, 2014). 'Conflict often exists in any alliance relationship on account of the inherent dependencies involved in such interactions' (Borys and Jemison, 1989: 235). Alliance partners may face inequality in terms of size, markets, resources and opportunities available to individual organizations in the network (Burt, 1997). Lin relates equality to social capital (Lin, 2008). Key elements of this approach are: a strong two-way communication (Cummings, 1984), honest and open communication lines (Granovetter, 1985), and reliance on experienced managers for conflict management processes (Kale et al., 2000; Day, 1995: 297). Considering the latter, one may conclude that: 'competent alliance managers will negotiate structure and operate alliances in ways that allow such firms to secure attractive alliance partners and to minimize the chances of alliance mismanagement due to for example poor conflict resolution' (Lambe et al., 2002: 
154). Conflict management thus emphasizes the need for strong interpersonal skills in conjunction with a strategic awareness for mutual interests.

\subsubsection{ALLIANCE MANAGEMENT AS AN INTRAORGANIZATIONAL PROCESS}

Open organizations' interaction with others cannot be understood without considering internal processes that partially intersect with the alliance partners. Organizations increasingly explore multiple strategic logics (Dalpiaz et al., 2016) as they experiment in different markets with product-service combinations (Meier et al., 2010). Gone seems the era of organizations sticking to a single business model with a fixed set of value propositions and stable, transaction-oriented input and output relationships with the external world. Our understanding of strategic organizational alignment - e.g. traditional business-IT alignment models (Henderson and Venkatraman, 1993) - needs to be updated in the sense of becoming more dynamic and pluralistic. Scholars propose a dynamic, socio-cognitive view on business models (Baden-Fuller and Mangematin, 2015; Merli, 2013; Loock and Hacklin, 2015) in which the process of articulation seems more important than an actual model - which is likely to have a short time span of relevance. Others refer to strategic multiplexity (Shipilov, 2012) and organizational pluralism (we use both terms interchangeably), denoting the need to combine multiple possibly conflicting strategies and multiple internal cultures and identities (Jarzabkowski and Fenton, 2006). According to the latter study, organization-level strategizing and organizing can be related in an interdependent, destructive and imbalanced manner.

Reverting to our own study, a pluralistic view invites reinterpreting an organization's preinvestments required for alliancing. Several themes come to the fore. First, collaborative capacity aimed at a partner organization may benefit workers' internal networking, but it may also increase scarcity in terms of internal resources. Second, externally oriented social capital may feed internal networks (Kang et al., 2007), yet internal culture and identity may suffer. Ambiguity may increase as organizations change (Corley and Gioia, 2004) and internal coherence destabilizes (Nag et al., 2007). Third, joint strategy formation may affect the extent to which an organization autonomously defines its own strategy. While alliance strategizing may support an organization's strategy (Keers and Van Fenema, 2015), the process of joint strategy formation may influence participants in the internal strategizing process (Jarzabkowski et al., 2007; Pateli, 2009). Independence of an organization's strategic process and thereby its autonomy may be at stake. Fourth, organizational pluralism involves multiple contexts geared towards particular offerings, e.g. combining industrial and cultural products (Dalpiaz et al., 2016) or regulatory and market context (Jarzabkowski et al., 2013). Yet this challenge impacts alliancing as well. Partners' contexts may evolve in a dissociated manner, challenging the 
organization to combine internal alignment with staying tuned to its dynamically evolving partner. And fifth, conflict management required for dealing with tensions emanating from the interorganizational relationship may absorb resources from the organization that may be required for organizational responsibilities and value creation (Sirmon et al., 2007).

In summary, the management dilemma concerning the pre-investments and long-term commitments for the development of alliance capabilities is thus depending on strategic interests and internal processing of external dependence and pluralism. Internal processes related to the alliance are embedded in the organization's strategic processes, and they co-evolve with interorganizational alliance processes (Koza and Lewin, 1998). To better understand this coevolution, in particular cohesion of internal and external alliance processes, we turn to narrative theory.

\subsubsection{ADOPTING A NARRATIVE PERSPECTIVE}

Narratives and ordering. Organizations consist of stakeholders dynamically enacting narratives within and outside their boundaries (Pentland, 2007; Pentland, 1999; Pagani, 2013; Boje, 1991). A narrative 'requires a plot, as well as coherence' (Boje, 2001: 1). A narrative network focuses on the interrelation of narrative elements, combining ideas on (inter)action patterns and associated processes of meaning and value (Donnellon et al., 1986). Narratives entangle and order thoughts, communications, data, events, actions and material elements (Blaschke et al., 2012; Doolin, 2003; Montfort, 2007). People can '... order(s) ... relevant issues through telling and relating the details into context'. A narrative refers to ordering that reveals some sort of 'plot' shaped in a temporal structure (Aarikka-Stenroos, 2010). Through narratives, people construct shared meaning and organizational realities (Boyce, 1995). Narrative networks provide insight in the changing and stable nature of what stakeholders think and do (Eaton et al., 2011). The network itself consists of narrative fragments, i.e. elements such as actions, thoughts, and material elements, which get dynamically linked in people's minds and experiences (Hayes et al., 2011). Narrative fragments may involve a core group of stakeholders enacting a particular narrative value network, e.g. focused on products, services or a particular policy (Gehman et al., 2013; Wynstra et al., 2015; Meier et al., 2010) or a more complex multi-stakeholder network involved in value creating networks (Reypens et al., 2016; Möller and Rajala, 2007). Network patterns may prove stable in an abstract sense, also called the ostensive aspect of routines (Feldman and Pentland, 2003). On the other hand, narrative fragments and their mutual linkages and affordances (their possible use) are likely to vary (Pentland, 2015). Literature on narratives of ordering examines how people develop stories to order their experiences, create realities and examine what is desirable or possible (Moran et al., 2008; 
Dunford and Jones, 2000). The performance of organizational activities is emphasized, '...draw(ing) on work in the sociology of technology that posits a materially heterogeneous, sociotechnical reality' (Doolin, 2003). 'Order' is not ex ante determined by structures and imposed (e.g. plans, designs), but negotiated (Maines, 1982; Allen, 1997). It concerns organizational, social-technical ordering (Goffman, 1983; Barley, 1986; Barley, 1998) and value ordering, i.e. what is exchanged and appreciated (Lorand, 2000; Gehman et al., 2013). Narrative ordering is achieved through ongoing interactions (Doolin, 2003) that constitute emerging narrative networks (Pentland, 1999; Pentland, 2007). For example, service calls processing has been studied (Brown, 2004) leading to identification of series of 'moves' (Pentland, 1992). Other work, focusing not so much on action sequences but on strategic topics, explores value propositions, market scripts or industry recipes (Storbacka and Nenonen, 2011; Spender, 1989; Levina and Ross, 2003). This suggests different approaches to orient research on narrative networks.

Two types of analytical approaches to narratives. Narrative network theory commonly distinguishes sequential steps: actants, narrative fragments, narratives, and narrative networks (Pentland, 2007; Pentland, 1999). Using narrative network theory, a distinction can be made between an action versus a strategic orientation. First, an action orientation identifies action elements and orders these in a narrative, like a storyboard underpinning a movie (ex ante), or an operational process of buying an airline ticket (during or after actions) (Pentland, 2007). 'Narrative fragments, like molecules, can fit into many different narratives and include a combination of actants and actors (e.g., "the patient picked up the phone", "the nurse viewed the chart")' (Hayes et al., 2011). This interpretation of fragments in action oriented narrative network theory suggests an observable starting point for the theory. Narratives are considered

'... particular sequences of coherent functional events with a logical sequence (beginning, middle, and end) that is dependent upon the view of the "narrator" (e.g., "The patient picked up the phone and dialled the hospital appointment line in order to make an appointment with her primary care physician."). Continuing our metaphor, like polymers or proteins, narratives have some sort of unity of purpose or overall coherence' (Hayes et al., 2011).

Researchers can analyse action dependencies over time, sites, and technologies. As a final step in the action oriented version of narrative network theory, they can identify narrative networks which 'include actants and actions coupled into both potential and actual fragments, which can be connected in a variety of ways into both potential and actual narratives' (Hayes et al., 2011: 166). The narrative network abstracts an emerging plot based on the narrative resulting from the preceding step. 
Second, adopting a strategic orientation, narrative network theory implies that actions in a timespace frame are no longer the primary building block for analysis. Fragments remain a conceptual building block yet without their situated, time-space properties. They take on a strategic meaning, becoming more content-driven, i.e. what does the fragment say about strategic processes and how is it embedded in these processes. We propose the following steps for strategic narrative network analysis:

Step 1 Identify narrative fragments

Step 2a Identify organizational narrative networks

Step $2 b$ Identify alliance narrative networks

Step 3 Interrelate Organizational and Alliance Narratives

To start off, narrative fragments in the second approach refer to content elements of what people think and say to understand their practice, context and problems, and to express what they would like to achieve. While action-oriented narrative network theory proposes as a next step - upon identifying fragments - a narrative as a 'particular sequence of functional events that cohere' (Pentland, 2007: 787-788), for strategic use this step does not add value since fragments are not actions in a particular time-space configuration. The time sequence per se does not reveal an ordering of fragments. At the same time, step 2 of narrative network analysis proves essential: 'actants and actions (are) coupled into fragments or potential fragments and connected into narratives and potential narratives' (Pentland, 2007: 787-788). Such narratives may vary depending on the goals of a study. In studies fitting the first approach, narratives provide detailed insight in actors, temporally sequenced actions, outcomes and contextual timespace details, and dynamics of routines (Deken et al., 2016). For the second strategic approach, more abstraction is chosen to understand narratives' strategic impact (Garud et al., 2014; Jarzabkowski and Sillince, 2007). We apply this step to the organization and alliance. The internal structure of these narratives can be 'bracketed', i.e. labels can be proposed to describe the narrative (Weick et al., 2005). Step 3 constitutes a final phase in a strategic approach to narrative networks. We add this concluding step which is interrelating narrative networks (Higgins et al., 2014; Sonenshein, 2010; Hawkins and Saleem, 2012) to understand the organization-alliance interplay. To some scholars, strategic narrative networks may relate in an interdependent, destructive or imbalanced mode (Jarzabkowski and Fenton, 2006). As further explained in the findings section, we analyse the narratives in terms of their interdependence (i.e. cross-narrative impacts), possible contradictions (tensions) between narratives (Higgins et al., 2014) and meaning construction (Sonenshein, 2010). But first, concluding our theory section, we seek to operationalize narratives to enable our empirical research. 


\subsubsection{OPERATIONALIZING NARRATIVES}

Using narrative network theory in a strategic sense offers a tool for analysing how organizational stakeholders co-construct their strategic position (Dunford and Jones, 2000). Their narratives express who they are as an organization (Czarniawska, 1997; Ibarra and Barbulescu, 2010), and how they make sense of what they (want to) do and how they (want to) interact (Fenton and Langley, 2008; Landrum, 2008). Stakeholders contextualize their efforts as they develop, connect and change narratives (Garud et al., 2014; Starkey and Crane, 2003). Researchers emphasize the increasingly pluralistic, dynamic, and reciprocal nature of strategic narratives. For instance, suppliers focus their efforts on what matters to their customers' contextual narrative (e.g. services, solutions), rather than on their own product-based narrative (London et al., 2015; Chandler and Vargo, 2011). As such, narratives may cross boundaries between traditional roles of designers and users (Orlikowski and Robey, 1991), and entangle stakeholders with different roles in complex ecosystems (Reypens et al., 2016). In our case, an alliance introduces a new form of interaction and new narratives beyond mere inter-organizational transactions (Zajac and Olsen, 1993; Tjemkes et al., 2012). We distinguish three types of narratives that engage actors within and between organizations: value, capabilities, and social narratives. Alliances involve constructing a collaborative identity that matches organizational interests, combining resources, and building a social fabric within and across organizations.

\section{Value Narratives}

The first type of narrative expresses how stakeholders can be satisfied. We elaborate on intraand inter-organizational aspects. For organizations, researchers have proposed business models and value propositions as a means to understand how actors such as entrepreneurs articulate value narratives (Martins et al., 2015; Levina and Ross, 2003). Organizations currently struggle in a highly dynamic environment to define their core story (Aaltio-Marjosola, 1994; Abdallah and Langley, 2013; Jarzabkowski and Fenton, 2006). Across organizations, business models can become networked as they focus on for instance a collective vision (Julkunen, 2016), or complex customer solutions and integrated value chain management (Möller and Rajala, 2007). Researchers propose firm-centric versus network-embedded business models to denote the extent to which an organization's success depends on others (Bankvall et al., 2017). How can intra- and inter-organizational value narratives be related? We distinguish contradiction and cohesion. Contradiction between organizational and alliance narratives implies that the collective narrative has detrimental effects on organizational narratives or vice versa. For instance, over time, effectiveness of a firm-centric or a network-level business model may deteriorate or get disrupted (Håkansson and Lundgren, 2006; Bankvall et al., 2017). Another 
example would be cooperation leading to a loss of knowledge required for an organizational narrative (Loebbecke et al., 2016). The collective narrative delegitimizes the organizational narrative (Joutsenvirta, 2011). In contrast, with cohesion of narratives, organizational narratives complement and reinforce the collective narrative and vice versa (Rossignoli and Ricciardi, 2014). Business models of cooperating partners would 'fit' (Sydow et al., 2015) and organizations' brands are effectively interrelated at the network level (Mäläskä et al., 2011). Organizations become better rooted in their environment (Starkey and Crane, 2003). A cohesive process can entail mutually beneficial innovation advantages, cost reduction, access to each other's supply base or markets and so forth (Calia et al., 2007; Van Fenema et al., 2014).

\section{Capability Narratives}

The second type of narrative refers to the use of resources and application of knowledge and skills by business processes and managerial activities (Vesalainen and Hakala, 2014), both within and between organizations (Pentland, 2007). Resources constituting capabilities (Kor et al., 2007) and resource management processes (Sirmon et al., 2007) change over time and they vary across organizations. Narratives on organizational capabilities concern for instance use of technology. Researchers have focused on the construction of unique narratives to cater to organizational requirements (Alvarez and Urla, 2002). Appropriation of technology by organization members implies a unique narrative of situated technology use (Orlikowski, 2005). The term "inter-organizational capabilities" has been interpreted as technology use to connect members of different organizations involved in an overarching business process or cooperative effort. This appears rather complex as adaptation pertains to the unique properties of two or more organizations (Boersma et al., 2012; Majchrzak et al., 2000). A study combining intra- and inter-organizational resource processes points at internal and external meta-routines for absorptive capacity (Volberda and Lewin, 2003).

Capability narratives may contradict or cohere. Organizational and alliance narratives may contradict when technology is 'sticked' to a particular organization (Von Hippel, 1994) without much relevance to the alliance. Contradiction may also occur when linking action patterns beyond transactive exchange of outputs entails too much effort, for instance due to constraining organizational forms such as a hierarchy (Volberda and Lewin, 2003). Cohesive narratives, on the other hand, imply that organizational resource processes offer interesting value to the alliance. For instance, when the same technology can yield benefits (Greve and Seidel, 2015), or when one organization's set of (unique) resources are combined in a novel manner to another organization's set of resources (Vandaie and Zaheer, 2014; Dyer and Singh, 1998). Cross- 
organization action patterns may leverage resource affordances and generate novel value (Dionysiou and Tsoukas, 2013; Galunic and Rodan, 1998).

\section{Social Narratives}

Finally, the third type of narrative concerns human agency within and between organizations cognition, talk and action (Kaplan, 2011a; Hardy et al., 1998). Scholars have emphasized organizations' sociocognitive processes, decision making and actions that influence resources and strategic positioning (Aspara et al., 2013; Rindova and Fombrun, 1999). Examples of social processes include sense making, acting, identity formation and commitment (Nag et al., 2007). Organizational narratives concern the social fabric of organization members interacting to understand the organization in relation to the environment (Maitlis and Christianson, 2014), (re)shape an identity (Gioia et al., 2013) and create product and service stories (Hansen, 2017). They engage in transformative processes of creating products and services (Wikstrom and Normann, 1994). Recent work on routines explores action patterns of one organization in relation to another organization, i.e. selection of a partner for cooperation (Deken et al., 2016). While scholars have assumed a distinction between markets (without much inter-organizational agency) and hierarchy (leveraging interactions), alliances represent a third hybrid governance option (Geyskens et al., 2006; Makadok and Coff, 2009). Hence, social narratives emerge between organizations (Zajac and Olsen, 1993). From an inter-organizational angle, researchers have examined narratives in the sense of people constructing partially collaborative identities across organizations (Kourti, 2015; Törmälä and Gyrd-Jones, 2017), and shaping and using concepts, objects and authorative texts (Lawrence et al., 1999; Koschmann et al., 2012). Organizations would need to define a 'collection of concepts sufficient to sustain the collaboration' (Lawrence et al., 1999: 486-487). This differs from markets where organizations can engage in transactions relying largely on externally constructed concepts (Callon et al., 2007).

Social narratives may contradict each other or prove cohesive. Contradiction of social narratives occurs when understandings, identity formation and action prove too diverse and unrelated (Finney, 2002; Hardy et al., 2005). For instance, a potential partner may not be interested in a proposal, thereby shortcutting an organizational selection process (Deken et al., 2016). Or pursuing an alliance might take too much coordination effort or jeopardize the social fabric at the organizational level. Cohesion, on the other hand, implies that mutual interest exists; shared meanings and identities can be achieved without risk to each organization. Boundary spanning identity construction shifts '... the focus of organizational identity from a self-in-isolation to a self- 
in-relation perspective' (Isbell, 2912). It involves discursive legitimacy within and between organizations (Maguire and Hardy, 2005).

We assume that for an alliance to perform successfully, cohesion of narratives between partnering organizations and the alliance across the three dimensions should be effectuated in order not to compromise either the alliance or the organizational strategy. Cohesion might imply a thin line between these two strategies. Our empirical work examines this topic for a supplier of high-tech equipment starting an alliance with its major customer.

\subsection{RESEARCH METHODS}

\subsubsection{DESIGN AND CONTEXT}

Using the three dimensions of narratives as an analytical lens, we examine by means of a qualitative case study content elements of alliance and organizational narratives (Pentland, 2007; Hardy et al., 1998). According to Yin, case studies are best used when a 'how' or 'what' question is posed in a setting where the researcher can have (almost) no control over the behavioural events: 'They suit qualitative study environments in which in-depth knowledge on a particular organizational phenomenon has to be gained' (Yin, 2009). The single case study with embedded units of analysis involves a technology firm operating within the maritime industry further referred to as TechCo - and its service alliance (with one of its public customers). We are interested in narratives of TechCo and its alliance narratives as expression of complex embedded practices (Jarzabkowski et al., 2015). We have focused deliberately only on TechCo and not on their public alliance partner Public $\mathrm{Co}^{27}$ to tease out the contradiction-cohesion features of TechCo's internal strategy and the alliance. The organization was selected on the basis of its accessibility to do research; the organization participated in a larger research project jointly with several research institutes and was willing to host this study.

We gained access to TechCo in a period (Q1 and Q2 2014) when they worked on forming a service alliance with PublicCo based on their long-standing product co-development relationship. In addition to being a customer, PublicCo develops the interface software for the systems purchased from TechCo. The motivation behind TechCo's service alliance efforts is caused by TechCo's organization evolving from a 'project-based product delivery relationship' with customers (i.e. not a strong focus on post-project services) towards a 'product life cycle relationship' (i.e. more extensive service-based support of customers). The organization feels

\footnotetext{
${ }^{27}$ Not the real name for reasons of confidentiality. PublicCo is a major public organization that includes amongst others units for technology development and product procurement, maintenance, and operations.
} 
the pressure to develop successful long-term relationships in which the creation of mutual value with customers is deemed more important than sustaining a traditional, static buyer-supplier approach. In business-to-business literature this is referred to as servitization of products and increasing reciprocity of value creation ('co-creation') ( $\mathrm{Ng}, 2010$; Edvardsson et al., 2011). For its customers using sophisticated assets, TechCo seeks to reduce costs of corrective maintenance and to increase the predictability of maintenance. The company has observed a shift of business logic. Earlier they faced a situation of 'rich' public clients, small numbers of production volume and client-specific orders. Nowadays, the business logic can be characterized as one in which customer budgets are under pressure, TechCo products in use by customers become obsolete and TechCo should change towards a product life cycle approach (rather than being focused on New Product Development and project success). In the future, the desire is to move towards 'contracts for availability' of assets in which client-specific demands are met but the entire production and sales process is generic in nature. The company describes this shift vividly as one from hunting (scoring and delivering on product orders) towards farming (long term relationships with customers). TechCo offers service support packages but struggles to adapt its organization to match a business model that complements the traditional product-based model. In an era in which the workforce ages and technological expertise becomes scarce, cooperation with PublicCo serves to better coordinate and exploit knowledge. The alliance with PublicCo was eventually signed at a strategic level in Q4 2014. The authors have maintained contact with TechCo since then.

\subsubsection{DATA COLLECTION}

Our data collection concentrated on TechCo's representatives in the alliance and members of TechCo without a direct role within the alliance. We were interested in how they make sense of their organization's shift towards service collaboration and alliance actions. Specifically, we zoomed in on differences between the narratives of both groups, as narratives mirror social worlds (what is going on) and show how employees (will) act (Pentland, 2007; Pentland, 1999). The research project was kicked off with a group meeting including the researchers and TechCo professionals. Our base at TechCo was the Customer Services and Support department. This unit was interested in the research objective as part of their servitization initiative. It consists of 131 employees charged with the task of carrying out the complete cycle of service support: from bid to aftersales. The various data collection approaches are summarized in Table 1. 
Table 1 Data Collection at TechCo

\begin{tabular}{ll}
\hline Interview and interaction details & Number of interactions and interviewee role \\
\hline Group meeting researcher with TechCo & 1 \\
Informal conversations & 9 with managers \\
& 5 with employees \\
Structured interviews & 2 with board members \\
& 5 with managers \\
& 4 with employees \\
Group interview researcher with TechCo & 1 including 4 managers and 2 directors \\
Joint meetings with customer PublicCo in which & 1 \\
researchers also participated & 1 \\
Interview with customer PublicCo & Several \\
Joint meetings within service logistics research & \\
project & 1 \\
Gaming session with TechCo and PublicCo staff & Approx. 30 \\
\hline Total number of interactions &
\end{tabular}

First, several informal conversations were held to explore themes relevant to this study. This setup was decided upon after an initial meeting with the manager of the department of Customer Services and Support. At the end of the conversation, to start a 'snowballing' process, interviewees were asked to come up with names of people, activities, or documents that they perceived relevant for answering this study's research question. Next, semi-structured interviews were held with the people proposed, aimed at looking more closely at our research objective. We adopted a semi-structured interview approach allowing us to address interview objectives in a flexible manner (Singleton and Straits, 2005). Key to this approach is the use of an interview protocol consisting of questions and topics in a logical order (Lofland and Lofland, 1995). Initial interactions had limited structure just to learn from TechCo employees more about their context. Gradually, in conjunction with refining our conceptual understanding, the interview protocol was adjusted to cover topics pertaining to the alliance as well as organization strategy. The themes and sensitizing concepts mentioned in the conceptual background section on alliance formation were used in the interview protocol to elicit interviewees reflection. In addition to the individual interviews, researchers participated in several joint meetings of TechCo managers including those involved in the alliance formation. In addition, researchers observed a 'serious gaming' event involving TechCo and PublicCo employees simulating the alliance. From the meetings and observations, field notes were made. The interviews were audio-recorded and transcribed in full. 
Verbatim transcriptions were sent to the interviewees afterwards to verify the correctness of the information. Some comments were received and transcripts were adjusted accordingly, then filed and used for analysis.

\subsubsection{DATA ANALYSIS}

While qualitative analysis is sometimes regarded a messy process (Gehman et al., 2013), we have structured and reflected on the steps taken to arrive at our final data structure. The data analysis co-evolved with the data collection, i.e. recurrent discussions amongst the researchers and interactions with the interviewees refined our understanding of the case in relation to the research objective. Transcripts of interviews were analysed with the help of the data analysis matrix of Miles and Huberman (1994). Transcripts were displayed and categorized (e.g. an alliance or organizational narrative). Data analysis was then performed with the post-coded content analysis method (Bauer and Gaskell, 2000). This process was informed by the steps of narrative network analysis as proposed in the theory section. Summaries were reviewed by the researchers. Next, we further interpreted the narrative network fragments, their relationships, and interrelatedness of narrative networks using the three types of narratives. We compared organizational and alliance narratives which enabled us to examine contradiction-cohesion between alliance and organizational narratives. More precisely, we reflected on synergies or possible tensions between the formation of the service alliance on the one hand, and on the other hand TechCo's strategy shift from product innovation towards integrating services.

\subsubsection{RESEARCH QUALITY}

For qualitative research, researchers emphasize validity and reliability to reflect research quality (Sinkovics and Ghauri, 2008). First, validity consists of credibility and transferability. Credibility is ensured by respecting the original perspectives of the researchers that provided literature for this study. For the theoretical basis, this research relied on academic work selected by queries of the researchers in common digital libraries at a business school, concept-based discussions among the researchers, interactions in the academic field, and interactions with TechCo and PublicCo practitioners. For credibility, the view and perspective of a source must be respected. Literal transcripts and cross-checks provide credible data interpretations. With respect to transferability: this research takes place in a specific high-tech context which influences transferability of the eventual results. The qualitative character of a case study makes it usually hard to transfer results to other sectors, i.e. merely conceptual generalization (Yin, 2009). It implies that a similar research, with a similar theoretical framework and empirical measurement methods might generate different results in different sectors (for instance in the non-public 
sector) or at different companies (for instance service-based instead of product-based companies). Methods scholars, however, claim that results can be generalizable to other contexts in a conceptual sense (Yin, 2009) or as a story (Eisenhardt, 1991). We concur with this notion. As mentioned, servitization permeates business-to-business literature, so organizations in other sectors struggling with similar challenges may benefit from the results reported here. Second, reliability is operationalized using dependability and confirmability. Dependability is ensured by keeping transcripts, summary documents and audio files available upon request. Furthermore, the process of data analysis is executed stepwise, from transcribing to coding and filling matrices (Miles and Huberman, 1994). Confirmability of this research relies on the recording and documenting of interviews. This provides the possibility for reviewers of this study to confirm the existence and nature of the empirical data.

\subsection{FINDINGS: WRESTLING WITH ORGANIZATIONAL CHANGE AND ALLIANCE FORMATION}

The focus of our analysis, TechCo's organizational change and alliance formation, resulted in a distinction between organizational and alliance narratives. This matches our unit of analysis. Using this distinction, we examine and later interrelate these narratives using the three operationalizing categories from our theory section: value, capability, and social narratives. We use the notions of contradiction and cohesion to reflect on inter-narrative relationships.

\subsubsection{ORGANIZATIONAL AND ALLIANCE NARRATIVE NETWORKS}

\section{Organizational Narrative Networks}

First, a set of organizational narratives emerged during our analysis of the data. These narratives expressed how employees of the organization perceived and interpreted the flow of incoming information about the actions of their organization with respect to its service alliance undertaking. There was a general consensus among managers of the firm interviewed that there was a need to adjust the organizational business model from a product-centric towards a product-service business model. Value narratives expressed that the integration of product development and services was considered necessary to optimize TechCo's value offering and to affirm its quality orientation. However, although consensus was achieved, it did not mean that everyone thought that a service alliance with PublicCo was necessarily the best option in this respect, or that they were sure it would work. Narratives in relation to TechCo's capabilities revealed that its service capability was considered somewhat poor (motivating the alliance initiative). This stemmed from the lack of maintenance knowledge and organizational context 
characteristics that obstruct integrating provision of services. A key characteristic appears TechCo's long-proven success of product innovation as a competitive strategy within a niche market. This urges the organization to ensure product excellence, yet it undermines the sense of urgency to invest in service provisioning and hence the service alliance with PublicCo. Other capability narratives include the structural deficit of technical personnel (making it difficult to integrate service design into product development), and a bureaucratically differentiated organization based on product development and support services (making it hard to form service teams around products).

Lastly, social narratives expressed the long-term relationship of trust between TechCo and PublicCo. This was based on product co-development, exchange of capital resources, and the fact that many employees of TechCo are former employees of PublicCo. However, due to TechCo's internal differentiation, the level of trust differed across the numerous lines of communications and interpersonal relationships between TechCo and PublicCo. In addition, social narratives expressed cultural differences between both organizations, for instance difference in work mentality and the remuneration systems.

\section{Alliance Narrative Networks}

Second, we analysed our data derived from representatives of TechCo with responsibilities for alliance formation (i.e. alliance employees). We focused on how they made sense of their alliance actions. Value narratives hardly emerged from our data. Ideas on complex customer solutions, integrated value chain management, and an alliance business model were (still) missing. Our data does show aspects of social and capability narratives. With respect to these narratives, we identified internal coherence of the group of alliance employees with whom formation challenges are faced. Alliance managers are adopting a comprehensive conflict management approach and a methodical style of negotiation aimed at surfacing mutual interests. This would balance 'what is in it for you and for us', and resolve areas of tension. Though at the same time, alliance managers appear a proponent of formalizing the relationship through contractual arrangements, requiring explicit statements of mutual obligations and rights. In addition, as the relationship co-evolved in conjunction with the alliance formation process, we observed the development of a collaborative identity based on identifying common goals, working procedures, routines, habits, and even a shared sense of humour. This served the relationship development and opportunities for benefitting from alliance formation. However, concerning capability narratives, our data also emphasized conflicting internal TechCo interests regarding different views on profits, stocks, work locations, and different ways of working associated with the public versus private nature of TechCo and PublicCo. 


\subsubsection{INTERRELATING ORGANIZATIONAL AND ALLIANCE NARRATIVES}

To address our research goal, we relate organizational and alliance narratives. This relating refers to the quality of the relationship between the narratives. Literature proposes qualifying adjectives like 'interdependent', 'destructive' and 'imbalanced' (Jarzabkowski and Fenton, 2006). Related studies refer to the level of tension or paradox, the latter defined as 'contradictory yet interrelated elements that exist simultaneously and persist over time' (Smith and Lewis, 2011: 382). Other research challenges to look beyond positive or negative qualification of the relationship between narratives of different stakeholders. Rather, researchers suggest to explore 'why' particular narratives are developed, and which meaning construction underpins a narrative (Sonenshein, 2010: 503). We consider the 'why' of narratives and the quality of their relationship in conjunction. In fact, our analysis so far offers a first glimpse of the 'why', which we can reflect upon after examining the relationship between narratives. Building on our conceptual approach, our analysis of inter-narrative relationships uses three sensitizing concepts: interdependence (for initial filtering), contradictory nature (tension), and cohesion. Next, we show how organizational and alliance narratives relate, structured by the three categories value, capability and social narratives.

\section{Interrelating Value Narratives}

First, meaning construction of TechCo's narratives emphasize the need to integrate service in their value offering for customer satisfaction. Yet these narratives echo doubt regarding whether a service alliance is the best means. Alliance narratives indicate potential differences between alliance and organizational interests and hence the need for contractual arrangements to formalize relational exchange. As earlier mentioned, ideas on the alliance business model were not yet fully shaped. This incurs the risk that (in the long term) the collective undertaking leads to negative effects. In the alliance with its focus on services, PublicCo should offer maintenance services for legacy technology to TechCo customers given PublicCo's strong resource base. Conversely, TechCo should take care of PublicCo's maintenance needs for in particular advanced, recent technologies. Yet this setup might result in negative outcomes which disrupt the balancing of both parties' give and take. Dealing directly with TechCo customers PublicCo might become a competitor within the market of TechCo's maintenance services. This might delegitimise the alliance for TechCo. PublicCo can resell its own TechCo products to other customers with service packages. These courses of action might serve the alliance yet cannibalise TechCo's own service business. Likewise, when TechCo's sales of innovative products increases, it may be at the expenses of the alliance's customer base. As such the inter- 
narrative relationship is characterized by a mixed bag of interdependence, somewhat vague notions of potential cohesion, yet also lingering fears of future contradiction.

Interrelating Capability Narratives

Second, both the service alliance and TechCo depend on a niche labor market for high-tech personnel. In the current time of scarcity of engineers, the alliance and TechCo may compete for experts for performing services (the alliance's core business) versus integrated product and service development (TechCo's core strategy). In addition, whereas the alliance business model and its management are developed from scratch, it implies for TechCo a transition from a differentiated organization towards a more integrated and open organization. This will cost additional resources to enact such a transition. In addition, contrary to alliance stakeholders, TechCo's product-related internal stakeholders consider integration of services a disruption of their current work processes. Separation of TechCo's product versus service resources would reflect these stakeholders' thoughts. Also, geographical work relocation as a consequence of the alliance coming into being meets resistance from TechCo personnel and may lead to resignations. Both aspects may jeopardize TechCo's technology leadership capability. As such the inter-narrative relationship is characterized by contradiction due to resource scarcity and different orientation of narratives. Potential advantages of resource management at the alliance level, such as PublicCo serving TechCo customers and alleviating pressure on TechCo resources, seem somewhat remote in the narratives we encountered.

\section{Interrelating Social Narratives}

Third, with respect to the social narratives we observed a contradiction between organizational and alliance narratives. Alliance narratives expressed trusting relationships among alliance employees. We observed a difference in the construct of stories. First, alliance managers were selected and worked dedicated in an alliance working group. This selection and intensive communication promoted a close relationship among team members and increased the drive to be motivated and dedicated (Beal et al., 2003). Group cohesiveness developed over time between alliance managers from TechCo and PublicCo. Signs of cohesiveness include shared values, beliefs, humour, and sharing of advice among alliance managers to 'get the job done' (materialize alliance formation). And second, alliance managers carefully disclose information to construct desirable narratives. They drive a positive alliance narrative. It is through these desirable narratives that alliance managers hope to control the beliefs and actions of necessary change agents. Yet elsewhere in the organization, employees were not as intensely engaged in the formation process. Their cognitive and emotional buy-in was far less (Rindova and Petkova, 2007), a challenge which the alliance managers did not consider their responsibility. Alliance 
managers tended to focus on their internal leaders to keep these updated. When alliance managers contacted employees in the counterpart organization, they received mixed or sometimes even negative signals. The alliance's social narrative thus did not (yet) impact the organizations in a powerful way.

\subsection{DISCUSSION AND CONCLUSION}

This paper investigates by a narrative lens how an organization relates to its alliance. We focus on the cohesion between value, capability and social narratives. Exploring narratives provides insight on employees' action (Deken et al., 2016), while exploring narratives' cohesion with regard to their content helps to increase understanding of their strategic impact (Garud et al., 2014; Jarzabkowski and Sillince, 2007). There is much research on alliance management and organizational narratives. Nevertheless, there is limited research on the interfacing of organizational strategy and alliance formation. In our case, such interfacing is required to capture possible tensions between the formation of the service alliance on the one hand, and on the other hand an alliance partner's strategic organizational change (TechCo's transition from product innovation towards integrating services which in their view underpins the alliance). Put differently, to improve alliance management, there is a need for a comprehensive understanding of the complex strategizing challenges involved with co-creating value in an alliance. This paper explores the organizational practice of implementing an alliance strategy as a strategic reorientation, along with the formation of an alliance. To operationalize this practice analysis, we focus on the extent of contradiction-cohesion between alliance and organizational narratives influencing performance outcomes. Narrative network theory was used in the attempt to reveal fragments of organization and alliance oriented narratives and to relate these. As results of the case study suggest, there is a contradiction between organizational narratives indicating different levels of relationship trust, and alliance narratives expressing a high level of group cohesion. In addition, the capability narratives indicate tension concerning the shortage of engineers, geographical work location, and business structure. Moreover, the results suggest an interdependence between organizational and alliance value creation, in which case the alliance may - over time - conflict some of the participant organization's stakeholder interest. 


\subsubsection{CONTRIBUTIONS}

Alliance research has fallen short of identifying why some organizations are more successful in alliance management than others. The analysis of this study has uncovered that the relationship between alliance and organizational narratives may be essential in this respect. We extend this idea by noting that as such, participant organizations in the alliance may not necessarily face the same substantive challenges and thus may differ in management success. Our results shine light on the management challenges that lie at the root of strategic complexity. We build on and expand the few research attempts how intra-organizational practices relate to interorganizational performance, and vice versa (Ireland et al., 2002). Our results suggest that qualifying the relationship between alliance and organizational narratives is complex and involves a high level of uncertainty. At one moment, potential positive or negative implications are simply unknown. Moreover, these implications depend on future organizational and alliance actions and environmental dynamics. Narrative analysis shows which narrative interrelates with which quality. This offers a basis for a longitudinal study on organizational and alliance performance. The study thereby complements current literature on strategic organizational narratives (Landrum, 2008), strategic uncertainty (Abdallah and Langley, 2013), and strategizing and organizing in pluralistic contexts (Jarzabkowski and Fenton, 2006; Denis et al., 2007). It extends the notion of pluralism to the alliance as an inter-organizational phenomenon.

\subsubsection{IMPLICATIONS FOR PRACTICE}

There are also a few important managerial implications. Practitioners can benefit from this study's insights as it increases awareness of the fact that they must deal with multiple contexts: the habitat of their organization and its alliance(s). Concepts like open innovation (Segers, 2015; Lichtenthaler, 2011) and shared value creation (Porter and Kramer, 2011; Austin and Seitanidi, 2012) point towards organizations that seek to live with the tension between who they are and what they offer to or receive from whom. After an era of allowing other organizations to support non-core functions (Goddard, 1997), external relationships now intersect with the very core of an organization's business model. Managers thus operate in a flux of constant opening-up, reembedding and coordinating organizational processes. This impacts the value offering of organizations.

In addition, organizations work 360 degrees with partners to create network value (Lowe et al., 2016; Heikkilä et al., 2014). The value is derived from complex and shifting relationship experiences. Moreover, value experience depends on numerous touchpoints (Chandler and Vargo, 2011; Pagani, 2013). Managers may concentrate on developing positive experiences to develop relationship trust and cohesiveness. This will present new challenges to managers. For 
one, cognitive demands of managers thus move towards quickly sensing and exploiting narratives, rather than concentrating on the success of their business model alone (Tikkanen et al., 2005; Teece, 2007). Tensions between narratives can be considered an occasion for change. Managers need to transform and align their organization's narratives towards those of the alliance in an entrepreneurial fashion. Articulating clear business models for the alliance seems a new capability that extends organizational business modelling. This study gives some suggestions in this respect, moving transformation and alignment thereby beyond the traditional notions of organizations changing their structures. Value, capability and social narratives need to be addressed in parallel or at least with substantial attention over time. This raises questions on when to engage organizational employees in the alliance.

Finally, having analysed the level of cohesion between organizational and alliance narratives and having discussed the performance implications, the question remains how cohesion in this case can be enhanced? Derived from our findings, we can provide for each of the narrative dimensions a suggestion to promote cohesion. We suggest (referring to capability narratives) to build close ties with research universities and universities of applied sciences to ease tensions on the labor market, and to communicate new frames to positively influence employees' thoughts, confidence, and behaviour towards the alliance (with respect to the social narratives). Lastly (referring to the value narratives), to enhance alliance management success the thin line between organizational and alliance interests must be controlled, and ideally strengthened, over time. This requires a hybrid approach to balance organizational and alliance interests while simultaneously serving various underlying stakeholder interests. Regular monitoring of value narratives seems paramount to avoid derailing of an alliance.

\subsubsection{IMPLICATIONS FOR RESEARCH}

Our research suggests internal implications of alliance formation e.g. for the workforce, interpersonal relationships, and stakeholder management. Moreover, it stresses that alliance management involves inter-organizational coordination as well as managing intra-organizational challenges of transformation and alignment. The study thereby contributes to a better understanding of multiplexity as a relational topic (Shipilov, 2012). Our research also fits in the emerging research stream that acknowledges multiple narratives (Higgins et al., 2014). Multiplicity of narratives - within and between organizations - calls for new analytical approaches that study how narratives interrelate (Jarzabkowski and Fenton, 2006). We have contributed to this emerging stream of research with our examination of interdependence, tension and meaning construction. More work is required to deepen inter-narrative 
understanding, e.g. intertextual theory examining the interplay of text and conversation (Koschmann et al., 2012).

In addition, future research might connect not only the categories of narratives we distinguish (value, capability, and social), but also categories based on levels of analysis and abstraction. For instance, action based narratives can be related to meaning and value based narratives. This may require a multimethod approach that on the one hand merges qualitative and quantitative views on narratives. On the other hand, multiple ontologies and epistemological stances might be explored in the sense of constructivist and positivist research. While a positivist approach would show how observable sociomaterial reality (actions, resources, context) is changing, constructivist research elicits meanings. Researchers would thus 'complicate' their research approach. An example would be analytics research that 'mines' business processes (Van der Aalst, 2012; Pentland et al., 2011), but can also be used for revealing patterns in qualitative data (Schreier, 2015). The resulting two types of stories can be related relying on a dialectical or sequential (Lee, 1991) approach. Moreover, such micro, 'bottom-up' research on what organization members do complements strategic approaches to socio-cognitive business model and network literature (Furnari, 2015; Aspara et al., 2013; Tikkanen et al., 2005; Martins et al., 2015).

Our paper's single-organization focus on TechCo in an alliance formation phase presents limitations that can be mitigated in two ways. On the one hand, similar research at PublicCo might be conducted to eventually show the 'soul searching' for two partners and to relate their stories. On the other hand, narratives' interrelationship could also be studied in a longitudinal manner to explore how they evolve within and across organizations. 


\title{
REQUIREMENTS
}

\section{"Proper Planning and Preparation Prevents Poor Performance"}

\author{
(Stephen Keague)
}




$\begin{array}{ll}\text { AUTHORS } & \text { Keers B.B.M. } \\ & \text { Van Fenema P.C. } \\ & \text { Zijm, W.H.M. } \\ \text { PUBLICATION OUTLET } & \text { Journal of Organizational Change Management Vol. } 30 \\ & \text { Issue } 5 \\ \text { ADDRESSES } & \text { RQ 6: Which intra-organizational management practice } \\ & \text { should be developed in conjunction to organizational } \\ & \text { learning to enhance alliance capability? } \\ \text { STATUS } & \text { Published }\end{array}$

\subsection{ABSTRACT}

Organizations have formed alliances to combine their resources and achieve new business advantage. Yet while alliances proliferate, little is known of whether and how they work in practice. The purpose of this paper is to examine an organization's operational alignment and change in the process of alliance formation. A literature study explores the strategic importance of assessing and aligning organizations' operations for alliancing. Empirically, a case study has been conducted to provide insight in the degree of operational alignment and change required for a maritime organization forming a service alliance with its supplier. Managers indicate a complex set of organizational capabilities required for improving operating process to successfully execute their alliance strategy. Two improvement trajectories are found to be used by alliance managers for aligning operations with alliance strategy and changing their organization: development of a corporate alliance infrastructure, and nurturing a collaborative business culture. The paper introduces a new conceptual model of the alliance formation process, addressing the cyclical character of the pre-formation stage in which intra- and interorganizational management considerations alternate.

\section{INTRODUCTION}

The need of organizations to invest in (supply chain) cooperation has increased over the past decade, in particular in knowledge-intensive industries (Boje, 1991). Arguments include the extended lifetime of complex technological systems and decreased budgets. This makes supply 
chain players more than ever depending on each other's knowledge to optimize maintenance to maximize system availability and minimize total costs of ownership. Inter-organizational cooperation goes by many names, ranging from pure transactional exchanges as simple, discrete, one-time events, to highly relational new organizational forms such as networks or joint ventures (Geyskens et al., 2006; Kale and Puranam, 2013). Theoretical perspectives as provided by inter-organizational cooperation theory (Jones and Lichtenstein, 2008; Oliver, 1991) and alliance theory (Dyer et al., 2001), or by the extended Resource Based view (eRBV) (Caldwell and Howard, 2010), offer conceptual foundations for inter-organizational cooperation. While alliances proliferate, little is known of whether and how they work in practice. Hence, this paper focuses on this form of inter-organizational cooperation. With an alliance, two independent organizations join forces with the intention of increasing the organizations' strategic value by means of reinforcing or complementing each other's critical capabilities for an extended period of time (Kleemann and Essig, 2013; Nag et al., 2007). The potential of an alliance strategy is believed to be considerable: if implemented correctly, it can dramatically improve an organization's market position or public performance (Parker and Van Alstyne, 2005). As such, it becomes important for an organization to understand how it can improve its overall alliance performance. This, in combination with the high alliance failure rate (Lowe et al., 2016) triggered numerous alliance researchers to explore critical factors influencing alliance performance. Scholars have focused in particular on the inter-organizational relationship level, providing a vast amount of literature in which among other things trust, communication, cultural compatibility, and balance of power and control emerge as pivotal factors affecting performance (Arino et al., 2001; Kale et al., 2002; Lunnan and Haugland, 2008). Nonetheless, considering the organizations involved, it is critical to understand how the intra-organizational managerial processes, routines, tools, and mechanisms underlying affect the inter-organizational level performance (Ireland et al., 2002). Studies exploring the intra-organizational level address the concept of alliance capability to explain the differences between organizations' alliance management success. They identify specific firm characteristics and study rare, valuable, and difficult to imitate resources at the organizational level to explain performance difference between organizations' alliance portfolios. These studies in particularly underscore the importance of having alliance experience to realize potential learning effects that might enhance alliance performance, and as such stress the importance of underlying management techniques and mechanisms referring to e.g. the creation of a dedicated alliance function and an open and interactive business culture to gather, generalize, institutionalize, and disperse knowledge about alliance management (Clegg et al., 2002; Draulans et al., 2003; Kale and Singh, 2009). This literature contributes to the picture that the skills of alliance partners are a key factor in managing alliances successfully (Draulans et al., 
2003). These skills or alliance competences - referring to the organizational ability for finding, developing and managing alliances - have a direct positive effect on the success of an alliance (Lambe et al., 2002).

However, striking is the contrast between on the one hand studies on alliance capability focusing particularly on developing alliance knowledge, and on the other hand internal learning processes on alliance management (Draulans et al., 2003). With the latter processes, some authors even assume alliance capability to be a proxy for alliance experience (Kale et al., 2002). Internal learning processes may be an important practice in which most organizations lack alliance experience (Gulati et al., 2012).

The notion of alliance capability is rooted in theoretical perspectives that approach the subject from knowledge and integration issues, such as the competence-based view of the firm, the learning organization, absorptive capacity, and the knowledge-based theory of the firm (Sluyts et al., 2012). Consequently, the examination of the organization as a complex transformation system - that undertakes an alliance as organizational change to survive and prosper in the future - came almost irretrievably into oblivion. Little research has been devoted so far to exploring from an organizational change perspective organizations' way of working and necessary reorganization for successful alliance performance. In addition, since in general there is within organizations insufficient alliance management capacity available (Mamavi et al., 2015), we believe too little is known about necessary modifications to organizational design and capabilities for organizational change in order to become effective in meeting the alliance objectives. Therefore, we explore the organizational practice of implementing an alliance strategy as a strategic reorientation. We are interested in learning more of organizational competencies necessary for an organization's functioning to the alliance strategic need. This paper is structured as follows. The first section introduces the concept of strategic alliances, organizational change/ alignment, and the theoretical gap this paper is addressing. The second section reviews the alliance management literature and discusses organizational aspects to be considered when assessing an organization system's current performance in relation to its participation in alliance formation. The third section describes the empirical research performed, followed by the fourth section which discusses the findings regarding an organization's alliance implementation issues and their causes to be addressed by organizational change management.

The main contribution of this research to the scholarly literature is to explore strategic alliance performance by connecting organizational change management and the alliance management literature. These two streams so far tend to be addressed as stand-alone areas. By insights given into organizations' way of organizing work and required changes, this paper contributes to 
the emerging literature on alliance performance management, and helps to explain why some alliances form at a slow pace or even fail.

\subsection{A REVIEW OF ALLIANCE PERFORMANCE MANAGEMENT}

\subsubsection{RETHINKING STRATEGY: THE ROLE OF INTER-ORGANIZATIONAL RELATIONSHIPS}

Inter-organizational cooperation has been a well-established phenomenon for several decades, but there is an increased scientific interest in alliances since the 1990s (Douma, 1997). An important reason for this increased interest is formed by the shifting views on organizational strategy. Within the mainstream literature regarding business innovation, competitive success has been attributed to the generative capability of a single, stand-alone organization. Starting by Porter's market-based view (1980), organizations are considered entities capable of creating value on their own. They compete with others by developing an excellent product or service and a generic strategy. Subsequently, Shapiro (1989) suggests that organizations require capabilities to enhance their competitiveness. On the basis of these resource-based approaches and following the premise that competitive advantage is always temporary, theorizing on capabilities to act competitively has shifted towards dynamic capabilities (Pagani, 2013). Dynamic capabilities reflect the organization's ability to integrate, build, and reconfigure internal and external competencies to cope with rapidly changing environments (Teece et al., 1997). This view provides the basis of the relationship strategy. A relationship strategy concerns a strategic focus where the individual firm balances its interests and actions in interaction with others for the collective needs of supply chain organizations (Ford and Gadde, 2002). Similarly, Wilkinson and Young stress that strategic options result from the organization's capability to apply knowledge within its environment (Wilkinson and Young, 2002). It contributes to the rise of the extended resource based view: a view in which organizations form inter-organizational relationships to gain access to complementary resources and skills that reside in other companies (Pintelon et al., 2006). Increasingly inter-organizational relationships (IORs) have become viewed as a type of strategic driver, a 'conditio sine qua non' for business success (Loebbecke et al., 2016). Hence, there exists a close interplay between the overall strategy of the company and the role of IORs in that strategy (Parker and Van Alstyne, 2005). IORs exist in different types, e.g. in- or outsourcing relationships, networks, alliances, joint ventures and mergers and acquisitions (Albert and Whetten, 1985). Others argue that forms of relationships can be differentiated by the intensity of cooperation (from low transactional to high 
relational) and type of interdependency (from horizontal or pooled interdependency to vertical or sequential interdependency) (Toor and Ogunlana, 2010). Similarly, Kale and Puranam (2013) distinguish between purely transactional exchanges and highly relational exchanges. The first can be characterized as simple, discrete, one-time partner transactions. The latter concerns the pooling of critical capabilities and intertwinement of operations, requiring intense management involvement, for strategic value enhancement over prolonged periods of time, by the establishment of new organizational forms such networks or joint ventures. The differentiation between forms of IORs is conceptually depicted in Figure 1.

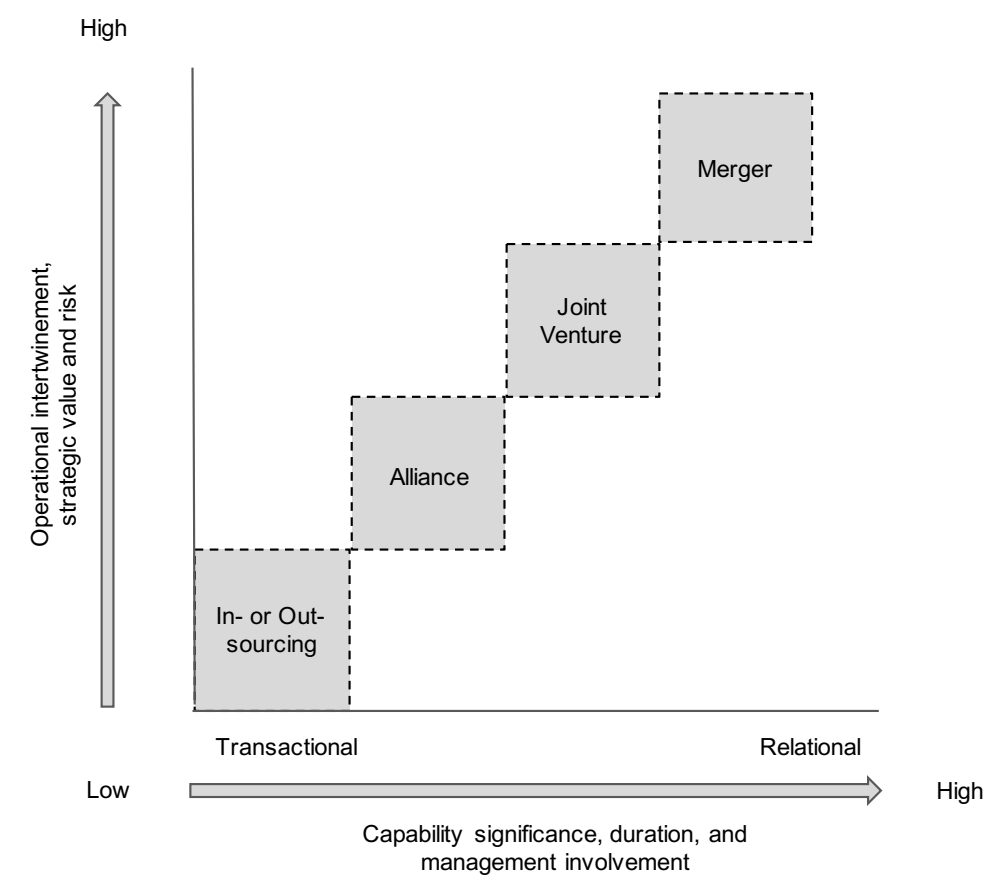

Figure 1. Forms of Inter-organizational Relationships

As can be seen in Figure 1, forms of IORs differ in the degree to which they are intertwined or separated from partners' operations, and as such in the strategic potential and risks of the longterm endeavor (Cropper et al., 2008).

An alliance is positioned between truly transactional exchanges and highly relational exchanges (Geyskens et al., 2006; Kale and Puranam, 2013). The main reason why organizations pursue a strategic alliance is to fill critical capabilities gaps for sustaining or increasing their strategic business value (Cropper et al., 2008). Alliances offer organizations relatively fast and flexible access to necessary complementary resources, competencies, knowledge, new markets, or they enable cost and risk reduction for a prolonged period of time (Das and Teng, 2000; Dyer et al., 
2001; Inkpen, 1996). To this end the organizations involved share (a subset of) their own capabilities (Berends et al., 2011).

Since alliancing concerns a strategic reorientation, redesign and realignment of organizational components is usually necessary to a certain degree. Organizations adapt their processes, structures, and resources that are interconnected with the alliance (Andreeva and Ritala, 2016; Bamford et al., 2003; Susini, 2004). In addition, readiness to change a certain way of working is required to guarantee low resistance and the chance of a successful implementation (Imran et al., 2016). The interconnection of the organization with the alliance is visualized in Figure 2.

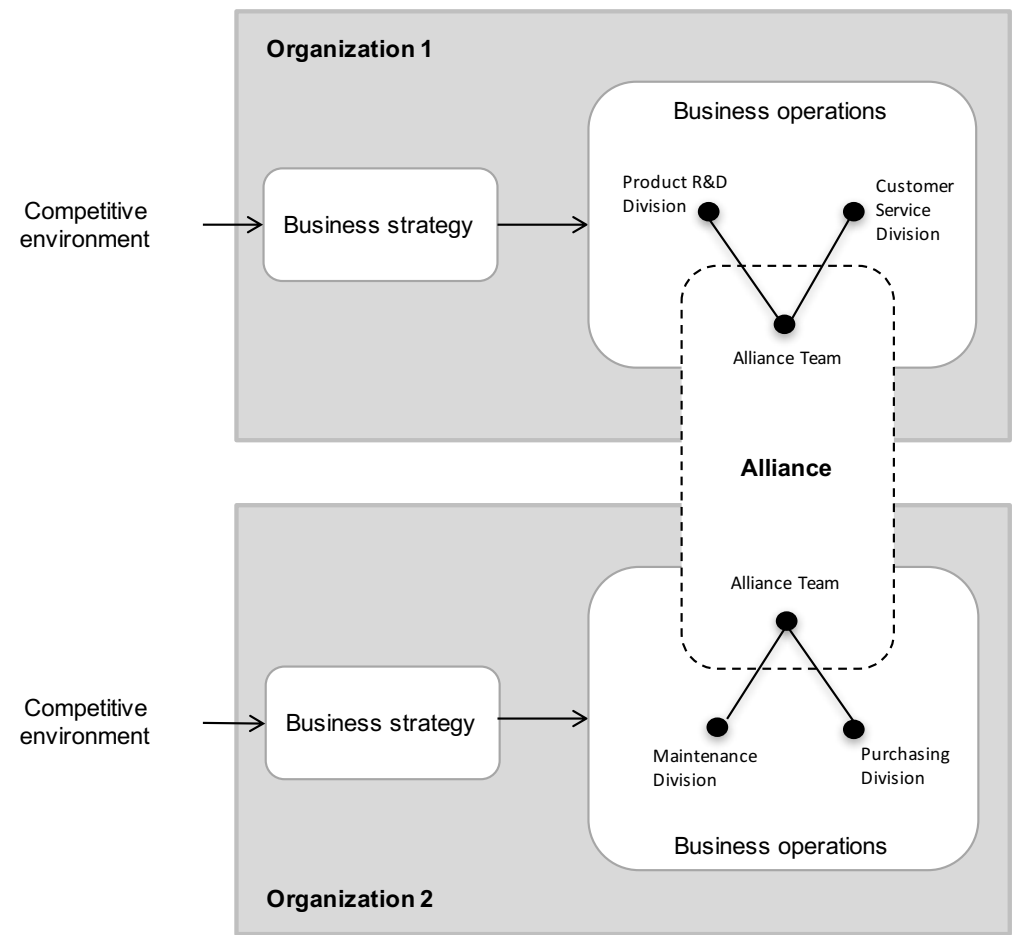

Figure 2. Organizations and Alliancing

\subsubsection{ORGANIZATIONAL CHANGE AS PART OF ALLIANCE CAPABILITY}

Substantial research has been carried out to explore the phenomenon of alliances in terms of their performance and factors to improve their success. Alliance researchers have focused in particular on the inter-organizational (both business and personal) relationship as a unit of analysis (Das and Teng, 2003; Parker and Van Alstyne, 2005; Tjemkes et al., 2012; Van Aken et al., 2016). Their studies explore basic mechanisms for working together, joint decision-making, and governing the alliance relationship. Moreover the role of alliance managers has been 
examined as well as the activities deployed throughout the alliance development process, also referred to as the alliance lifecycle (Das and Teng, 2002; Kaplan and Norton, 2004; McKelvey, 2004; Montfort, 2007; Sluyts et al., 2012; Tjemkes et al., 2012). According to their findings, relational characteristics such as mutual trust, cultural similarities, objectives compatibility, balance of power and control, and inter-organizational learning have significant effects on performance (Franco, 2011; Kale et al., 2002; Kale et al., 2000; Lunnan and Haugland, 2008; Schilke and Goerzen, 2010).

Other alliance researchers have explored drivers of an organization's ability to successfully manage alliances. Referred to as alliance capability, they explore organizational competencies (series of activities and processes) which can positively influence alliance outcome (Sluyts et al., 2012). Their studies in particularly focus on developing alliance capability by means of learning from past collaborative experience to overcome future challenges (Anand and Khanna, 2000; Simonin, 1997). The alliance capability literature exemplifies that organizational learning capability is developed by combining competencies at the organizational, group and individual level to effectively capture, institutionalize, and share alliance management know-how within organizational boundaries (Argote, 2013; Hsu and Chang, 2014; Von Krogh et al., 2012; Zollo and Winter, 2002).

Organizational capabilities are described as important higher order resources, competencies or multi-level spanning capabilities. They are coordinated by business processes and managerial activities, and include valuable resources, knowledge, and skills (Helfat and Peteraf, 2003; Vesalainen and Hakala, 2014). Since an organizational capability usually acts as a cospecialized element in the organizational system (Vesalainen and Hakala, 2014), alliance capability does not only depend on the organizational learning capability. Developing successful alliance management also requires leveraging organizational learning for changing management practice. As such, we wonder which practice should be developed in conjunction to organizational learning?

\subsection{METHODOLOGY}

\subsubsection{CONTEXT AND DESIGN}

Our empirical research is designed to explore which 'other' capabilities - referring to higher order competencies - are necessary for organizational change in favor of an organization's alliance performance. We use a qualitative instrumental case study to explore the thoughts of key members of an alliance management team. An instrumental case study design has been used to 
obtain new insights for which the case plays a facilitating role (Eisenhardt, 1989b; Rai and Tang, 2014; Yin, 1989). The case study involves a maritime public organization attempting to establish service alliances with some of its system suppliers. These alliances were meant to implement condition based maintenance to enhance the operational availability of ships and to reduce the capital costs of its fleet. Their service alliance objectives are to group partners' technological expertise and to increase the utilization of resources by providing services for customers of their suppliers. The organization operating within the maritime industry was selected on the basis of its expertise of conducting operational assessments (due to government regulations to assess service alliance possibility for every new system purchase), expected (future) dependence on alliances, and accessibility to do research (the organization participated in a larger research project jointly with several research institutes). The project's ambition comes from supply chain partners requiring knowledge alliances to optimize systems' functionality and service maintenance (Kerkhof, 2016). In addition, inter-organizational cooperation in this particular maritime sector has been problematic for years (Levering et al., 2013). The organization of study employs 2,400 people on an average annual budget of 113M Euros. The number of system repairs currently amounts to 12,000 per year. For reasons of confidentiality, the name and a more detailed description of the company are not included.

\subsubsection{RESEARCH PROCESS AND DATA COLLECTION}

The scope of the case study was limited to the first half year of 2014. During this period, the organization was restructured at the corporate level, implementing a new ERP system and in the pre-formation phase of forming a service alliance with a major manufacturer of among other things radar systems. Data of various sorts were collected, including semi-structured in-depth interviews with key members of the alliance management team, informal conversations with senior managers, and corporate documents.

In-depth interviews as a qualitative interview technique enables the gathering of detailed information from a relatively small number of respondents (Boyce and Neale, 2006). In total 15 key managers with knowledge pertaining to and roles within the process of alliancing were interviewed. We relied on purposeful sampling, starting with the CEO, and subsequently included other managers recommended by interviewees. Managers were screened on the basis of 1 . having at least 10 years of experience within the organization to ensure their ability to offer a representative operational assessment, and 2. representing a cross section of functional areas and hierarchical levels, such as purchasing managers, service managers, lawyers, senior executives, and operational engineers, to obtain a comprehensive view (see Table 1). 
Table 1. Overview of Interviews

\begin{tabular}{lll}
\hline Management Level & Interviewee Role & Number of Interviews \\
\hline Strategic level & CEO and former CEO & 2 \\
\cline { 2 - 3 } & Staff member & 1 \\
\cline { 2 - 3 } & Managing director & 1 \\
\cline { 2 - 3 } & Chief alliance unit & 1 \\
\cline { 2 - 3 } & Chief procurement & 2 \\
\cline { 2 - 3 } & System project leader & 1 \\
\hline Tactical level & Purchasing manager & 1 \\
\cline { 2 - 3 } & Logistics manager & 2 \\
\cline { 2 - 3 } & System maintenance planner & 3 \\
\hline Operational level & Operational manager & 15 \\
\hline Total number of interviews & & 2 \\
\hline
\end{tabular}

Interviews were set up by a semi-structured protocol to increase the reliability of the research (Yin, 2009). The interview questions were structured based on the design determinants of the organizational system functionality (Cummings and Worley, 2015). The interview protocol was written in the interviewee's native language to prevent misperception of research questions. The questionnaire included questions such as:

- What are the objectives of the organization to adopt a service alliance strategy?

- How does the organization currently perform with respect to achieving these objectives?

- How does the organization manage the change of inputs incidental to alliancing? Are there implications for the way work is currently organized (with regard to the design components)?

- Which specific higher order competencies are important to modify the organizational system's functionality (to make the design components fit each other) to produce the desired alliance outcomes?

The interview questions were distributed beforehand to allow the interviewees to reflect on them. The interviews lasted approximately 1.5 hours and were conducted individually. This enabled people to feel comfortable when expressing their views. Verbatim transcriptions were made during these interviews and along with a draft of the case study report sent to the interviewees afterwards to verify the correctness of the information. Some comments were received and 
transcripts were adjusted accordingly, then filed and used for analysis. We examined a broad range of corporate documents and maritime sector newspapers as secondary data. Publicly available information from the organization's Intranet was also collected.

\subsubsection{DATA ANALYSIS}

First, since the data analysis perspective applied determines one's findings, we modified Cummings and Worley's (2015) model for diagnosing the organization level. That is, we combined it with Ainsworth and Feyerherm's (2016) model for organizing the transorganizational system, to cater for alliance characteristics. As such, we modified the organization level model based on the changed inputs and outputs by alliancing, to study its implications for the organizational system in the sense that there may need to be changes to or realignment of design components and higher order competencies for this purpose. The resulting model for diagnosing an organization's alliance capability is depicted in Figure 3.

Inputs

Outputs

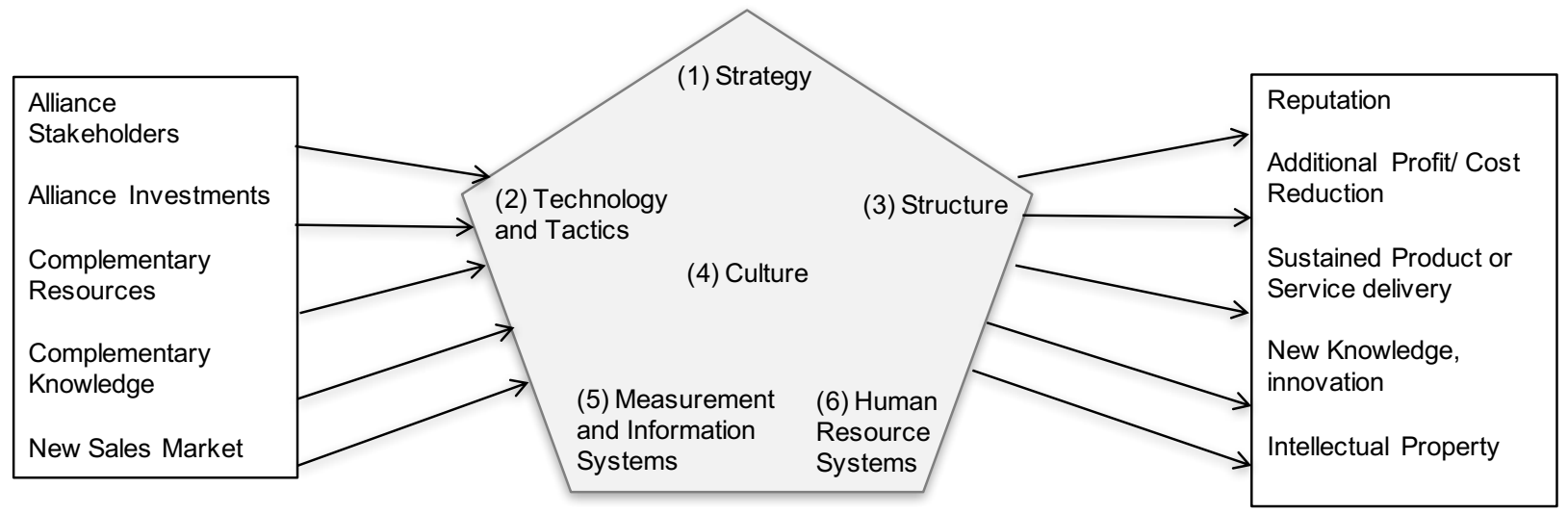

Figure 3. Input-transformation-output Model for Diagnosing Alliance Capability

The model shows both the new inputs and outputs by alliancing, and the organizational design components that play a role. As can be seen, an organization's input content is changed as a result of the arrival of new stakeholders, investments required for alliance development, the inclusion of complementary resources and knowledge from the alliance partner, and entering a new sales market. These inputs are organized by the design components to produce the desired output. An organization's output includes among other things its external reputation, intellectual property, and - considering the alliance objectives - the achievement of additional profits or cost 
reduction. Furthermore, output includes the sustainment of product or service delivery, and development of new knowledge and innovation. Figure 3 also shows key transformation design components, i.e. (1) Strategy, (2) Technology and Tactics, (3) Structure, (4) Culture, (5) Human Resource System, and (6) Measurement and Information Systems. Strategy represents an organization's strategic objectives, intent, and functional policies, providing explicit direction, and setting priorities for decision-making concerning organizational activities. Technology and tactics concern the way in which inputs and strategy are converted into operations, and includes methods, coordination among tasks, and equipment. Structure represents the organizing mode to allocate and coordinate work. Measurement systems include methods of assessing process activities and their impact on performance. Information Systems include methods and tools used to specifically collect, categorize, and distribute information throughout the organization. Human resource systems include mechanisms for selecting, developing, and evaluating employees' skills, knowledge, and behaviour. Finally, organization culture represents the basic norms and values shared by organization members, guiding thoughts and actions (Ainsworth and Feyerherm, 2016; Cummings and Worley, 2015).

Second, based on the developed model for diagnosing an organization's alliance capability, we analyzed how inputs impacted the transformation design components. We analyzed the data by means of a post-coded content analysis method (Bauer and Gaskell, 2000). This method helped to summarize the data into meaningful category themes. We first highlighted words within the data referring to either the inputs or design components. Successively we categorized the finding based on their coherence to higher order competencies required for organizational change.

\subsubsection{RESEARCH QUALITY}

To secure data quality, we considered completeness of the data, consistency and construct validity (Henneberg and Mouzas, 2008). Concerning completeness of the data, we interviewed in total 15 key managers with knowledge pertaining to and roles within the process of alliancing, corresponding to approximately $75 \%$ of the focus group. To secure consistency, primary data gathered by the interviews was triangulated with the information from corporate documents (Yin, 2009). Validity was effectuated by assessing whether the capabilities were indeed coordinated by business processes and managerial activities, and included valuable resources, knowledge, and skills (Vesalainen and Hakala, 2014). To secure the accuracy of research findings, we verified the capabilities discovered by means of informal conversations with senior managers. 


\subsection{RESEARCH FINDINGS}

\subsubsection{ALLIANCE INPUTS' IMPLICATIONS FOR DESIGN COMPONENTS}

There was a general consensus among the managers interviewed that there was a need to adjust the organization design components given the inputs (see Figure 3 ) by alliancing to produce the desired output. First of all, current organizational deficiencies manifesting in alliance performance ineffectiveness, were associated with an absence of unambiguously defined and imposed alliance objectives. Explicit managerial direction and priorities for decision-making concerning organizational activities were clearly missing. Second, the organization seemed to lack knowledge for developing a business plan in which details of how to achieve the organization's alliance objectives would be elaborated. Third, a strongly fragmented organizational structure focused on departmental task accomplishment, making performance assessments and decision-making at the alliance level difficult. Fourth, we observed a mismatch of the business culture due to an internal rather than an external focus and as such a complacent and somewhat careless attitude as regards to exploiting partners' resources and knowledge. Fifth, an insufficient level of collecting, mining, and sharing performance data as well as alliance expertise and knowledge was apparent. And finally, the organization seemed to lack skills for selecting and developing marketing and stakeholder management skills to pursue partnership opportunities. Moreover, the organization has insufficient knowledge to deal with counter-productive regulations (e.g. in the area of product and service acquisition) that withstand smooth alliance formation.

\subsubsection{CAPABILITIES REQUIRED FOR ORGANIZATIONAL CHANGE}

As a result, a set of interrelated capabilities emerged during our analysis to change organizational practices in favor of alliance performance. These capabilities involve allocation of resources, specific knowledge, activating processes and activities. Specifically, the organizational capabilities concerned: "development of alliance management skills", "effective information infrastructure", "adequate strategic decision-making", and "learning capability" (Figure 4). 
- Individual learning ability;

- Dedicated alliance functions to institutionalize experience;

- Communication and knowledge sharing mechanisms;

- Evaluation procedures.
- Managers' analytical and problem solving capability;

- Sufficiently available information and knowledge of the organizational system's functionality and interest;

- Appropriate decision-making structure.
Empowered and motivated managers;

- Alliance education and training in practice;

- Restriction to the rotation system for changing personnel for further development of alliance management competencies.

Figure 4. Unpacking Alliance Capabilities

Before elaborating on the capabilities, we note that this bundle of capabilities can positively influence organizations' alliance management success. Its rests heavily on the development of employee skills (by experience or training) and an effective organizing mode to coordinate knowledge for inter-organizational cooperation as well as performance information. Capabilities enable the specification and sharing of strategic alliance objectives as well as measurement of progress. New capabilities emerge as a result of allocation of valuable resources, knowledge, and skills and coordination.

With respect to the specific capabilities mentioned, "development of alliance management skills" rests among other things on empowered managers, alliance education and training in practice, and a restriction to the rotation system for changing personnel (common in large commercial and military organizations) for further development of alliance management competencies. An "effective information infrastructure" depends on the willingness to register, share, and interpret data, the skill to adequately develop and use a business information system for this purpose, and a practice in which such activities are rewarded. "Adequate strategic decision-making" rests on managers' analytical and problem solving capability, sufficiently available information and knowledge of the organizational system's functionality and interest, and an appropriate decision- 
making structure. "Learning capability" stems from several arguments made during the informal conversations with senior managers supported our interview results. They pointed to the importance of personalities and skills to negotiate with alliance stakeholders, to be able to define alliance milestones and go through a business planning process, and to institutionalize alliance experience in clear alliance directives and procedures. Similarly, they highlighted a general restraint to register, share, and organize (performance) information of systems as well as departments. Furthermore, senior managers acknowledged their strategic weakness in both providing explicit directions to and setting organization priorities for the alliance. This seemed to be caused by a lack of reliable business information to support decision-making, and an unclear and complicated alliance decision-making structure. The latter structure resulted on the one hand in unawareness of responsibility distribution, and on the other hand in a tendency of people with no responsibility to interfere in the decision-making process.

\subsection{DISCUSSION AND CONCLUSIONS}

This paper investigates from an organizational change perspective the organization as a complex transformation system. We focus on an organization forming an alliance and requiring particular capabilities for ensuring alliance performance. There is much research on alliance capabilities. Nevertheless, most research focuses on processes within the organization that foster knowledge dissemination and integration. Current work provides insight in the development of alliance capability by means of building on alliance experiences (Anand and Khanna, 2000; Draulans et al., 2003; Kale and Singh, 2009; Zollo and Winter, 2002).

Notwithstanding their significant contribution, limited attention has so far been paid to explaining how a learning capability is converted into a way of working that increases an organization's alliance effectiveness. In addition, limited insight has been provided in alliance capability differences between organizations with similar experience. As a consequence, studies on alliance capability have been criticized for not clarifying the content and process of developing an alliance capability (Gulati, 1998; Heimeriks, 2005). Hence, there is a need for a comprehensive understanding of how firms can internalize alliance experience and knowledge mechanisms to develop their organizational system in such a way as to improve their alliance management.

This paper explores the organizational practice of implementing an alliance strategy as a strategic reorientation, with a view to reveal organizational competencies necessary to fit an organization's functioning to the strategic needs of an alliance. As results of this case study 
suggest, organizations require a set of interacting alliance capabilities that facilitate the development of alliance management practices and consequently performance outcomes.

\subsubsection{RESULTS PLACED IN A LARGER CONTEXT}

Although the findings reveal a set of organizational capabilities considered necessary to change the organization for the benefit of alliance management, two key questions remain. First: how should organizations develop such capabilities? Derived from our findings we suggest two organizational change trajectories to be used concomitantly in favor of developing the four capabilities. A directive and imposed top-down implemented change, as well as a development oriented bottom-up approach. As depicted in Figure 5, the two trajectories promote development of three types of organizational capital (organization, information and human) which we derived from our data analysis.

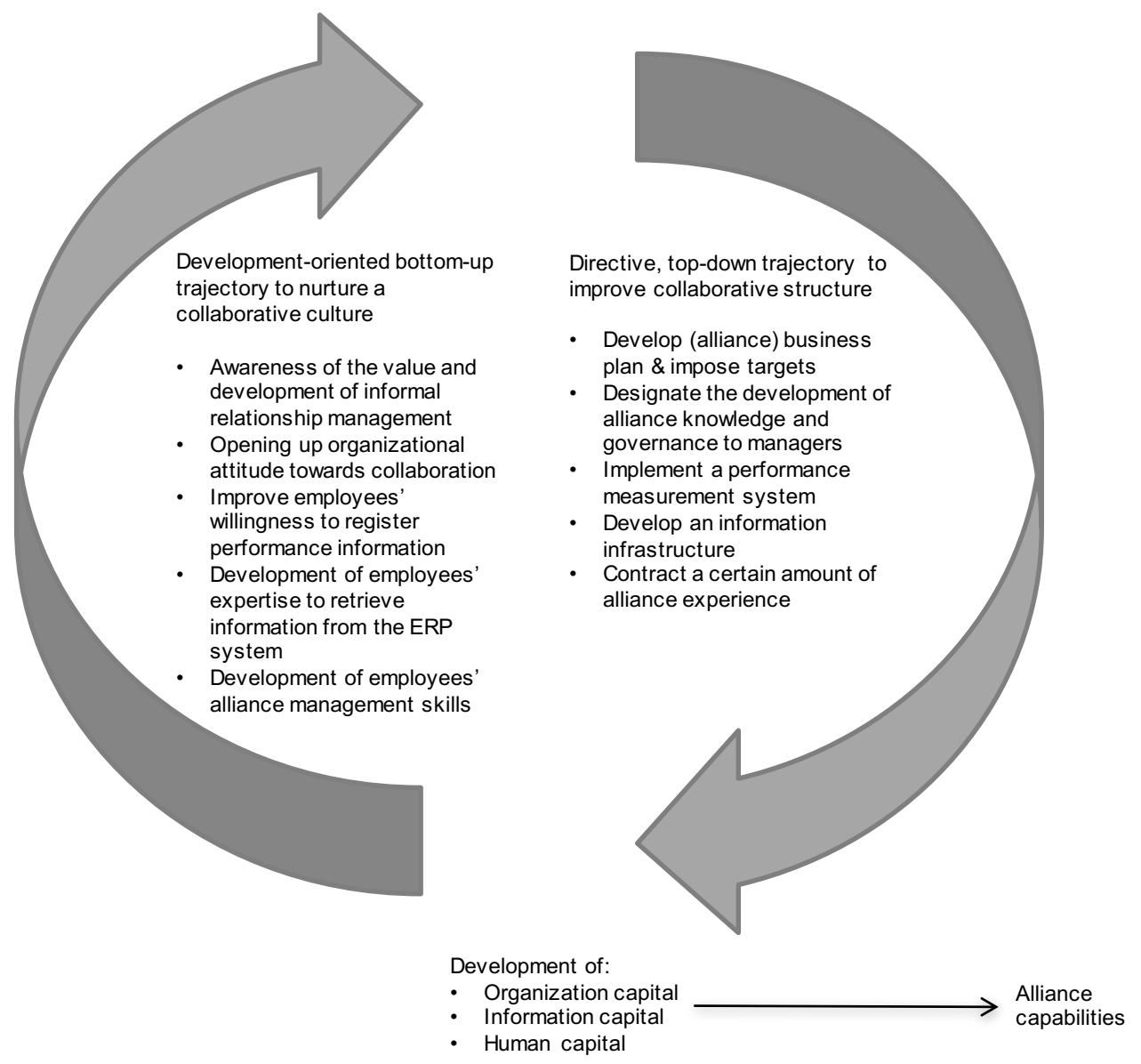

Figure 5. Organizational Change Trajectories for Alliance Capabilities. 
Implementing an alliance strategy challenges the organization to adapt and realign its forms of capital. The two trajectories to change an organization's diverse forms of capital are in line with earlier research (Bamford et al., 2003; Beer and Nohria, 2000). Where we suggest a top-down directive change, Beer and Nohria (2000) refer to a 'hard' approach, and where we suggest a bottom-up approach, they call it a 'soft' approach. Substantively, the trajectories both affect the development of human, information and organizational capital, however the methods differ. The relevance of implementing both approaches is backed by Bamford et al. (2003), stressing in accordance with our results the importance of developing alliance targets, guidelines, and decision-making structure, together with employee's expertise and a collaborative business culture. Our results suggest that an organization's ability to leverage its prior experiences might include its ability to carry out these two change trajectories. This underscores the suggestion that alliance capability is a difficult resource at the organization level (Gulati, 1998). Furthermore, regarding the momentum of carrying out these two change trajectories, a second question is: when to put these trajectories in motion? Elaborating on what is known of consecutive management activities in alliances (Das and Teng, 2002), it seems appropriate to include the activity of performing an introspection of alliance readiness and capabilities as early as possible in the alliance formation process. This is because the development of capabilities generally takes a long time (Capasso et al., 2005). Taking this into account can explain why alliance formation can be a cumbersome process and why seeds of failure may be sown in an early stage (Mitsuhashi and Greve, 2009).

\subsubsection{THEORETICAL AND PRACTICAL IMPLICATIONS}

Referring to the main conclusions of this study, several contributions can be identified. First, alliance research has fallen short of clearly defining critical components and their interrelationship that underlie the development of an alliance capability. The analysis of this study has sought to uncover the process that lies at the roots of alliance capability. This study has found that alliance capability is related to organizational change capability. In addition, our results contribute to organizational learning theory, by finding a set of capabilities essential to make use of prior experiences. Our results shine light on these intra-firm capabilities that facilitate the transition of alliance experience into better alliance management performance. We build on and expand the few research attempts to explain how organizations leverage their alliance experience and develop their alliance management practice (Kale et al., 2002; Sarkar et al., 2009; Simonin, 1997). By suggesting that the intra-firm antecedents play a role in alliance management success, the results help to address our insufficient understanding of the 
components of an alliance capability (Ireland et al., 2002). Hence, this study complements current literature conceptualizing alliance capability management as organizational resources or instruments to be implemented at the edge of the organization to relate to its alliance partner and dynamic environment (Draulans et al., 2003). Specifically, our results show far-reaching internal implications of alliance formation, e.g. for culture, information technology, leadership skills, HRM. This frames alliance management not only as a cross-organization coordination process (Gittell and Weiss, 2004; Lewin et al., 2011), but also as a process that needs to be strongly embedded within the organization (Jones and Lichtenstein, 2008). In an era of disruptive innovation and increasing inter-organizational networking (Nylén and Holmström, 2015; Yoo et al., 2012), our findings contribute to a new field of alliance research by stressing that introspection and the development of change capabilities complements externally-oriented efforts of an organization.

There are also a few important managerial implications. Practitioners can benefit from this study's insights as it increases awareness of intra-organizational changes in relation to alliancing. We emphasize processes to translate an alliance ambition into operationalized plans. These would better prepare organizations for their final decision on starting up an alliance or not. In addition, a set of capabilities is suggested with which organizations can embed their lessons learned to turn knowledge into action and with that develop their alliance management ability. In addition, in line with other studies, the results suggest the importance of certain alliance management resources and mechanisms, such as conducting trainings for the development of alliance management skills, and implementing an alliance database for capturing, sharing, and disseminating alliance knowledge - all in support of strategic alliance decision-making (Mandal et al., 2003; Teece et al., 1997). However, the study's results extend current wisdom by giving an idea of the interrelationship between internal processes and mechanisms that underlie successful alliance management at the organizational level (see Figure 4). Insight in these internal processes was missing (Heimeriks, 2005), yet they seem useful for managers to make sense of scholars' diverse alliance management suggestions.

\subsubsection{LIMITATIONS AND FUTURE RESEARCH}

Despite the contributions of this study, it is subject to several limitations. First, this study does not verify the extent to which the suggested capabilities are actually needed. Instead, this study presumes that managers' consideration given to these capabilities reflects their need. It would for example be interesting to investigate whether this set of capabilities is adequate. Second, although the validity of the set of capabilities is verified in various ways, the interrelationship between capabilities is implicit. Our results suggest it is likely that only together they facilitate 
alliance management. Future research should try to extend our analysis by empirically verifying the interaction effects among the suggested capabilities. Third, interesting for future research is also to examine the relationship between the organizational capabilities and inter-firm antecedents of alliance performance. Fourth, presence of the capabilities for proper alliance management does not necessarily guarantee successful alliance performance. Further research might explore the enactment of capabilities. Last, given the instrumental case study used, more research is required to validate and substantiate our findings on necessary capabilities for alliance management by type of organization or industry. 


\section{RISK MANAGEMENT FOR THE FORMATION STAGE OF PUBLIC-PRIVATE PARTNERSHIPS}

AUTHORS

PUBLICATION OUTLET

ADDRESSES

STATUS
Keers B.B.M.

Van Fenema P.C.

Dito, S.

International Journal of Project Management

$\mathrm{RQ}$ 7: How is integrated risk management carried out with regard to alliance projects? And which governance principles should be incorporated to improve management effectiveness?

Submitted for $2^{\text {nd }}$ review

\subsection{ABSTRACT}

The number of public-private partnerships has been increasing in recent years. For example, public organisations' in-house asset maintenance has become harder to carry out costeffectively due to the increased complexity of integrated technological systems and the lack of economies of scale. Yet, organisations are still learning how to successfully establish these partnerships while literature remains inconclusive. This article explores risk management practice underlying partnership formation by means of a dual case study of two PPP projects. The results suggest that organisations face several intolerable risks linked to project governance and project management responsibilities. These risks can be related to formation events and understood in terms of underlying risk factors. In addition, cross-case analysis showed different levels of risk awareness. Outcome dissimilarity, finally, seems related to difference of senior management involvement in PPP formation. Drawing on these findings, a framework for risk management for PPP formation projects has been developed.

\subsection{INTRODUCTION}

Over the last twenty years there has been an accelerating growth of interorganisational collaboration. Simultaneous with this increase, research on interorganisational relationships (IORs) grew in importance (Dekker, 2004) across several social science disciplines such as economics, strategy, and management research. Many types of IORs have been studied to understand the reasons for and conditions under which organisations form relationships (Oliver, 
1991). Research has examined various types of relationships, such as outsourcing, strategic alliances, networks, and partnerships (Anderson, 2001, Mohr and Spekman, 1994, Pitsis et al., 2004).

In an attempt to increase understanding of and to improve the (low) success rate of interorganisational collaboration initiatives, organisational researchers have studied factors associated with IORs' success, the latter defined as the achievement of goals and performance expectations (Mohr and Spekman, 1994). They found that these boundary-spanning forms of economic activities have several implications for the role of management control within and between firms. These stem from the extension of the scope of management control which becomes no longer confined to the legal boundaries of the organisation (Dekker, 2004). Being particularly interested in the determinants of management success, researchers study and describe various mechanisms of governance for IOR control (Das and Teng, 2001, Elmuti and Kathawala, 2001, Grandori, 1997, Ireland et al., 2002, Koppenjan, 2005). This has led to a discussion of the complementarity or subsidiarity of formal and informal control mechanisms (Dyer and Singh, 1998, Gulati and Singh, 1998, Ring and Van de Ven, 1992, Smith et al., 1995). Although many studies examine risks associated with entering and maintaining successful IORs, few explore organisations' ability to manage risks as a determinant of the success of their IOR. The actual management of risks is hardly explored (Elmuti and Kathawala, 2001). Yet the control of risks is an important factor to be carefully considered by organisations in the process of IOR formation (Provan and Sydow, 2008). To address this concern, the purpose of this study is to conceptualise, analyse and evaluate an organisation's approach to managing risks within the process of IOR formation, in this case PPP, and to provide some suggestions for improvement. Formation refers to the initial stage of building an IOR (Dyer et al., 2001, Koppenjan, 2005). Risks can be understood as 'the result of a threat with adverse effects to a vulnerable system' (Haimes, 2016: 56). Hence, formation risks concern the possibility that a partnership - considered a system here - collapses due to threats originating in the participating organisations or their environment. The paper is restricted to one form of IOR, that of a public-private service maintenance partnership, an example of Public-Private Partnerships (PPP). In this context, a public and a private organisation team up and pool complementary knowledge, skills, and resources over a longer period of time to perform and secure (enhanced) service and maintenance on public as well as commercial systems (Chang et al., 2008, Kleemann and Essig, 2013). Such an example resembles experiences at the British Navy which acquired merchant vessels and one tanker and pursued a contract for their longterm service under Foreland Shipping. Known as the "Strategic Sealift Service', the ships were leased to the Ministry of Defence, and during periods in which they were not in use by the Navy 
they were commercially exploited by the service provider. Such relationships are a relatively new phenomenon in for example the Defence industry. Hence, researchers are still at an early stage of learning how to setup and manage them. Our research looked at two case studies in the maritime industry, one still waiting for success after more than four years, and the other one successful in establishing a service alliance. The service alliance is considered an example of a PPP.

The remaining of the paper is structured as follows. The next section introduces the phenomenon of public-private service maintenance partnerships, describes the process of partnership formation and the role of strategic risk management in this respect, and starts addressing the theoretical gap within the literature. The fourth section describes the empirical research performed, while the final section discusses the findings with respect to factors that affect its risk management. The paper concludes with a discussion of implications.

\subsection{BACKGROUND}

\subsubsection{PUBLIC-PRIVATE PARTNERSHIPS}

Since they became fashionable some 40 years ago, the concept of public-private partnerships (PPPs) has been discussed in many studies (Bovaird, 2004). Growing appreciation of the importance of market mechanisms, coupled with the success of privatisation in various countries underlie the increased interest in the PPP phenomenon. PPPs have become a rather popular institutional arrangement, as they are perceived to remedy a lack of dynamism in traditional public service delivery (Jamali, 2004). PPPs concern working arrangements based on a mutual long-term commitment between a public sector organisation and an organisation outside the public sector (Bovaird, 2004). While PPPs were originally treated as a derivative of the privatisation movement, there is a growing consensus today that PPPs do not simply mean the introduction of market mechanisms or the privatisation of public services. PPPs rather imply a sort of collaboration to pursue common goals, while leveraging joint resources and capitalizing on the respective competences and strengths of the public and private partners (Nijkamp et al., 2002, Pongsiri, 2002). Although the concept is subject to discussion, the term PPP has been commonly used to describe a spectrum of possible relationships between public and private actors for the provision or management of public goods and services (Grimsey and Lewis, 2002). Various incentives underlie the formation of PPPs, and the spectrum of PPPs includes a wide diversity of arrangements. Incentives include the sharing of risks, mutual learning opportunities, and provision of economies of scale or scope (Bovaird, 2004). 
As depicted in Figure 1, the form of the partnership depends among other things on the legal status, assignment of responsibilities, and allocation of governance roles (Jamali, 2004).

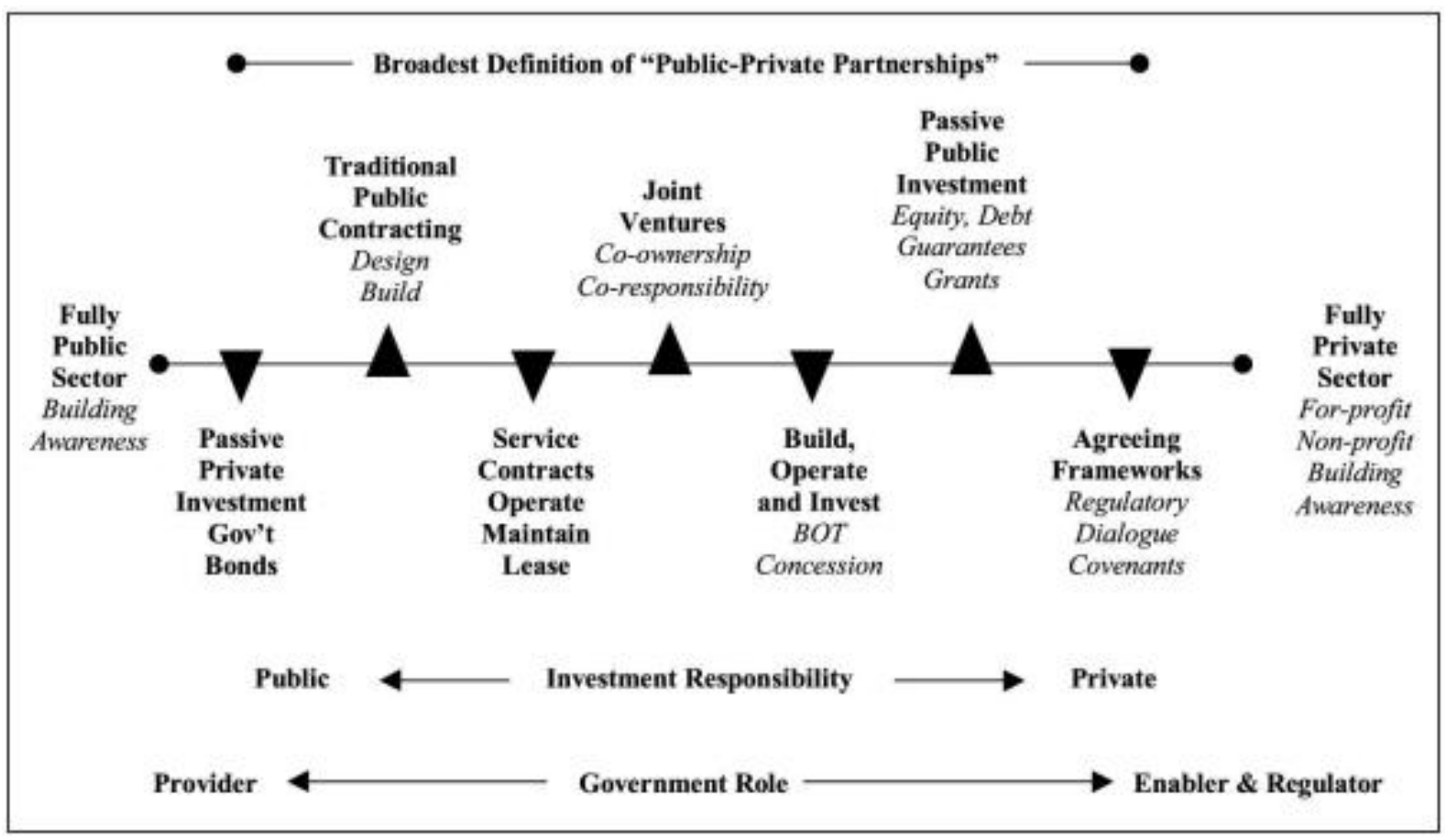

Figure 1. The spectrum of public-private partnerships, (Jamali, 2004) referring to (Gidman et al., 1995).

Studies have explored industry-level factors linked with partnership formations, in addition to exploring which organisations tend to partner with. Different perspectives on formation suggest that firms ally with those organisations with which they have the greatest strategic interdependence, with which they already established social ties, and with which they have a structural connection within the network (Gulati et al., 2000, Oliver, 1990). Industry factors and organisational conditions may also explain tie formation between public and private organisations. For example, research on science and technology has identified that in biotechnology a factor linked with public-private formation includes the knowledge gap between private life science companies and public research institutions. In this case the partnership is set up to leverage complementarities and potential synergies between public and private knowledge assets (Rausser et al., 2000). In the area of technology development and maintenance, researchers have stressed that integrated technology has made it increasingly difficult for private system manufacturers and public maintenance providers to develop all relevant knowledge for optimal functioning themselves (Kerkhof et al., 2016, Pateli, 2009). 
While facing a decrease of technically skilled personnel due to ageing of the existing workforce and a decline of technical students (Taplin, 2007), organisations in the developed world increasingly decide to form cross-sector partnerships. Health scientists have identified societal incentives for public and private health organisations to collaborate (Nelson et al., 1999). In the aerospace and Defence industries, public management scholars emphasize risk and cost sharing as important motives for public and private organisations to co-develop, co-maintain, co-operate, or co-exploit a product or a service in time of recession (Dussauge and Garrette, 1993, Van Ham and Koppenjan, 2001).

\subsubsection{PUBLIC-PRIVATE RISK MANAGEMENT}

Substantial efforts have been taken to uncover the dynamic processes that underlie the development of individual partnerships. Using case studies, scholars have sought to uncover the formal and informal processes that unfold in interorganisational relationships, and sought to increase understanding of factors that influence the development of stages through which relationships may proceed (Gulati, 1998). In particularly they have focused on formation processes. Research as indicated factors which not only seem to determine formation outcomes, but may also obstruct the successful functioning of the relationship in a later stage (Koppenjan, 2005). The formation stage includes interactive negotiation and assessment processes in which actors among other things explore initial conditions such as shared objectives, costs, risks, and benefits, define their interorganisational business model, and plan the alignment of processes prior to engaging in a formal agreement (Van Ham and Koppenjan, 2001). In addition, they consider secondary hazards of such relationships and their ability to control them, for example concerning increased management complexity, loss of autonomy, and information asymmetry (Provan, 1984, Williamson, 1981). Besides, specific public-private governance issues have been surfaced such as conflicting public-private objectives (e.g. environmental sustainability versus high profits), conflicting 'good' governance norms (e.g. operational transparency versus commercial confidentiality), blurring of accountability, and clash of cultures (Bovaird, 2004). When these risks are not properly addressed during the formation, they may represent a latent weakness of the partnership and cause high switching costs or sometimes even bankruptcy later on (Luo et al., 2008). Although an overwhelming amount of literature points out the numerous risks involved (Bobbink and Hartmann, 2014, Hartley, 2008, Humphries and Wilding, 2004, Koppenjan, 2005, Levering et al., 2013, Tatham, 2013), literature on partnerships has not thoroughly assessed the actual risk management practice. According to literature, good risk management practice involves a staged process of successful risk identification, evaluation, and implementation of measures to control the risks 
(Akintoye et al., 2008). Yet this generic approach remains silent on actual public-private risk management practices. Hence, to gain a deeper understanding of these practices and to provide suggestions for their development, we conducted to two case studies which are introduced in the next section.

\subsection{METHOD}

\subsubsection{CONTEXT AND DESIGN}

The research context stems from a government-funded research programme focusing on the improvement of the predictability of maintenance and service logistics demand on one hand, and the development of service logistics concepts and supply chain collaboration between maritime organisations on the other hand. The programme includes 2 public and 9 private organisations, including fleet owners, Original Equipment Manufacturers (OEMs), and maintenance and service logistics providers. The organisations represent a cross-section of the professional Dutch maritime maintenance industry. Based on this large research programme, two qualitative case studies have been conducted. Both case studies involve one public maritime organisation, owning a fleet and performing in-house maintenance.

The first case concerns a partnership project between this fleet owner, a ship-builder and a logistic service provider for outsourcing the upkeep of new tugboats. The project's ambition was to decrease the capital costs of the tugboats by means of central warehousing of the participating organisations' logistic and maintenance goods, and by commercial exploitation of the tugboats during periods in which they are not in use by the public owner. The project has been in progress for more than four years and adjusted, without tangible results so far.

The second case seems much more successful, involving a service alliance project between the same public fleet owner and its radar system manufacturer. Their PPP was aimed at pooling maintenance resources, to be used for public and commercial services. Objectives in this context include enhancing and sustaining organisations' maintenance knowledge as well as reducing their capital costs. The public organisation of focus was selected based on its expertise of conducting introspections of its public-private partnership ability (being obligated by government regulation during system acquisition), expected (future) dependence on publicprivate partnerships, and willingness to participate in research on this matter. In addition, public-private cooperation in Dutch maritime sector has been problematic for years, with limited 
levels of innovation, ineffective communications and distrust (Levering et al., 2013). The maritime organisation in The Netherlands employs 2,400 people on an average annual budget of $113 \mathrm{M}$ Euros. The number of system repairs currently amounts to 12,000 per year.

For reasons of confidentiality, the name and a more detailed description of the company are not included.

\subsubsection{RESEARCH PROCESS AND DATA COLLECTION}

The scope of the case studies was limited from mid 2014 until the end of 2016. During the study, it was decided that the first project had to restart midway, while the second project has been given approval to continue towards operation. The former can be considered a project that so far has not been successful, while the latter project has produced successful results (i.e. establishing a service alliance). The contrasting outcomes between the cases raised the question whether the public organisation's process of managing risks differed between cases and if so, how and why. The two cases offered an excellent opportunity for cross-case comparison since the pivotal public organisation is the same. Data was collected from multiple sources and in multiple phases.

During the first phase, a workshop was organised to identify risks in the first case. This presented an opportunity which stemmed from a sub-research trajectory within the larger research programme which was not available for the second case. Within the workshop a partnership strategy map (Kaplan and Norton, 2004) was developed to decide upon shared stakeholder objectives, and subsequently identify underlying risks concerning business processes and capabilities jeopardizing their successful achievement. Figure 2 depicts this map and - as will elaborated later - associated risks.

Subsequently, during phase 2, a small-scale survey was developed and distributed among 44 industry representatives participating in the larger research programme in which the two case studies were embedded. The survey aimed to explore the likelihood of the identified risks; participants were asked to score each of the risks by their order of magnitude of likelihood (per PPP project) and effect (impact score) on the basis of a common pre-developed qualitative descriptor (Kinney and Wiruth, 1976). A total of 33 responses were received, resulting in a response rate of $75 \%$, which is relatively high compared to other surveys on inter-cooperation (Vlaar et al., 2006).

During the third phase, twelve in-depth interviews were conducted with key managers of the public organisation. In-depth interviews, as a qualitative interview technique, enable gathering 
of detailed information to enhance in-depth understanding. The data collection strategy relied on purposeful sampling (Patton, 2002), starting with the staff representatives of the organisation and subsequently including managers recommended by interviewees for having a role in the PPP projects. This ensured their ability to offer a representative assessment. Also, the inclusion of a variety of different management functions and management levels was considered to obtain a comprehensive view. Interview questions were semi-structured to enable the respondents to talk openly and express their opinion. The interviews focused on exploring whether interviewees were aware of the risks, and questions were asked regarding the possibility of risk materialising and risk management. This provided a better view of risk factors and measures. The interviews lasted from 2 to 2.5 hours. The various data collection approaches are summarized in Table 1.

Table 1. Data collection

\begin{tabular}{ll}
\hline Interview and interaction details & Number of interactions \\
\hline Phase 1 - Workshop for case 1 & 1 including multiple participants \\
Phase 2 - Survey & 44 respondents \\
Phase 3 - Semi structured interviews & 2 Staff Representatives \\
& 4 Alliance Managers \\
& 1 Chief On-shore Logistic Support \\
& 2 Chief Procurement Managers \\
& 2 Chief Engineers \\
\hline Total number of interactions & 1 Chief Assortment Manager \\
\hline
\end{tabular}




\subsubsection{DATA ANALYSIS}

Data analysis proceeded in accordance with the three phases.

First, risks were identified using the partnership strategy map and they were displayed in a table. For each risk, a description was provided of the issue at hand.

Second, based on the results of the surveys, levels of risk were determined based on the average of the products of likelihood and impact. Subsequently, the risks were assigned to selfdeveloped score groups (see Table 2) in order to deduce the desired risk responses (Kinney and Wiruth, 1976).

Table 2. Risk score groups

\begin{tabular}{ll}
\hline Risk Rank & Definition and Desired Response \\
\hline High & Definition: Intolerable risk to be avoided. \\
Desired Response: Do not start or continue the formation activity at this risk level, \\
since the event will prevent the desired outcome of PPP formation and is hazardous \\
to the own organisation. \\
Definition: Undesirable risk to be reduced. \\
Desired Response: This event needs to be seriously modified to establish \\
formation on time, within budget or to the required quality or specification. \\
Definition: Tolerable risk to be reduced. \\
Desired Response: Prepared to take this risk as long as the risk is monitored and \\
risk management measures are applied to reduce the risk. \\
Dery Low \\
Definition: Acceptable risk without further actions. \\
Desired Response: This risks is considered acceptable without any specific \\
management options in view of performance success.
\end{tabular}

Third, by means of content analysis the data of the interview transcriptions was systematically searched to find instances of potential risk scenarios and factors in their immediate context. Then, the risk factors were sub-categorized by their source (type) to reduce the number of factors (Kinney and Wiruth, 1976). Having identified sources of risks helped to gain a deeper understanding of corresponding risk ownership roles and responsibilities (i.e. management areas of responsibility). A risk owner should be the one who best understands what needs to be done and who has been given mandate to implement what is required (Krane et al., 2012). Table 3 presents indicators of the different risk factor types and areas of responsibility. The indicators of the types of risk factor were primarily derived from current literature (Kinney and 
Wiruth, 1976), whereas indicators of types of management responsibility were developed based on the data obtained.

Table 3 Indicators of key variables

\begin{tabular}{|c|c|c|}
\hline Variable & Indicator & Sample quote from interviews \\
\hline \multicolumn{3}{|l|}{ Types of factors: } \\
\hline $\begin{array}{l}\text { Organisational Factor } \\
\text { (e.g. size, business and information } \\
\text { structure, management support, } \\
\text { security culture, policy, legislation) }\end{array}$ & $\begin{array}{l}\text { Factors of the organisation that } \\
\text { contribute to risks }\end{array}$ & $\begin{array}{l}\text { "Due to organisational } \\
\text { fragmentation, it is difficult to } \\
\text { identify risk owners" (\#1) }\end{array}$ \\
\hline $\begin{array}{l}\text { Human Factor } \\
\text { (e.g. management knowledge, } \\
\text { communication skills, judgement } \\
\text { competence (e.g. risk awareness)) }\end{array}$ & $\begin{array}{l}\text { Factors of individual attitude and } \\
\text { behaviour that contribute to risks }\end{array}$ & $\begin{array}{l}\text { "The success of cooperation } \\
\text { depends on individual performance" } \\
(\# 5)\end{array}$ \\
\hline $\begin{array}{l}\text { Technical Factor } \\
\text { (e.g. system and network complexity, } \\
\text { compatibility, vulnerability) }\end{array}$ & $\begin{array}{l}\text { Factors of technology that } \\
\text { contribute to risks }\end{array}$ & $\begin{array}{l}\text { "SAP is generating management } \\
\text { information, but not a lot so far" (\#4) }\end{array}$ \\
\hline \multicolumn{3}{|l|}{ Types of management responsibility: } \\
\hline Project Governance & $\begin{array}{l}\text { The framework for effective project } \\
\text { decision making (it concerns key } \\
\text { decisions that shape the project and } \\
\text { its direction, e.g. defining roles and } \\
\text { responsibilities, management } \\
\text { control processes, and reporting) }\end{array}$ & $\begin{array}{l}\text { "... my reporting to the board was } \\
\text { always postponed, since they had } \\
\text { more important things to take care } \\
\text { off" (\#4) }\end{array}$ \\
\hline Process Management & $\begin{array}{l}\text { The ensemble of activities of } \\
\text { planning and monitoring project } \\
\text { progress and development }\end{array}$ & $\begin{array}{l}\text { "We had developed and agreed } \\
\text { upon a project programme, } \\
\text { whereupon we got together with the } \\
\text { project teams every six weeks" (\#4) }\end{array}$ \\
\hline Project Management & $\begin{array}{l}\text { Principles, techniques, and tools } \\
\text { used for planning, executing, and } \\
\text { monitoring project processes }\end{array}$ & $\begin{array}{l}\text { "I do believe we should monitor the } \\
\text { project performance better, although i } \\
\text { is very difficult for us to define KPIs } \\
\text { and collect performance information" } \\
(\# 2 ; \# 6)\end{array}$ \\
\hline
\end{tabular}


Lastly, data were examined for possible discrepancies between applied and desired risk responses. Interviewees are referred to by numbers.

\subsubsection{RESEARCH QUALITY}

Data quality elements included completeness of the data, consistency and construct validity (Henneberg and Mouzas, 2008). Concerning completeness of the data, in-depth interviews were performed with all the public organisation's key middle and senior managers having a role in the process of PPP formation. To secure consistency, data was gathered from different sources (the alliance strategy map, the surveys and the in-depth interviews) and triangulated (Yin, 2009). For construct validity, interviews were conducted on the basis of an interview protocol (Fielding and Thomas, 2008). To secure the accuracy of research findings, results were verified by means of informal conversations with senior managers.

\subsection{RESEARCH FINDINGS}

\subsubsection{RISK IDENTIFICATION AND CATEGORISATION}

By means of the partnership strategy map (see Figure 2) and the cross-industry survey in the research programme, seven common risks within the process of PPP formation were identified. The figure shows a common strategy map framework which should be read from top to bottom to reason from foundation (values) to desirable output (mission). We added the risks we found to the map elements, they are depicted in boxes with italics lining at the levels business processes, employees and organisation, and values. 


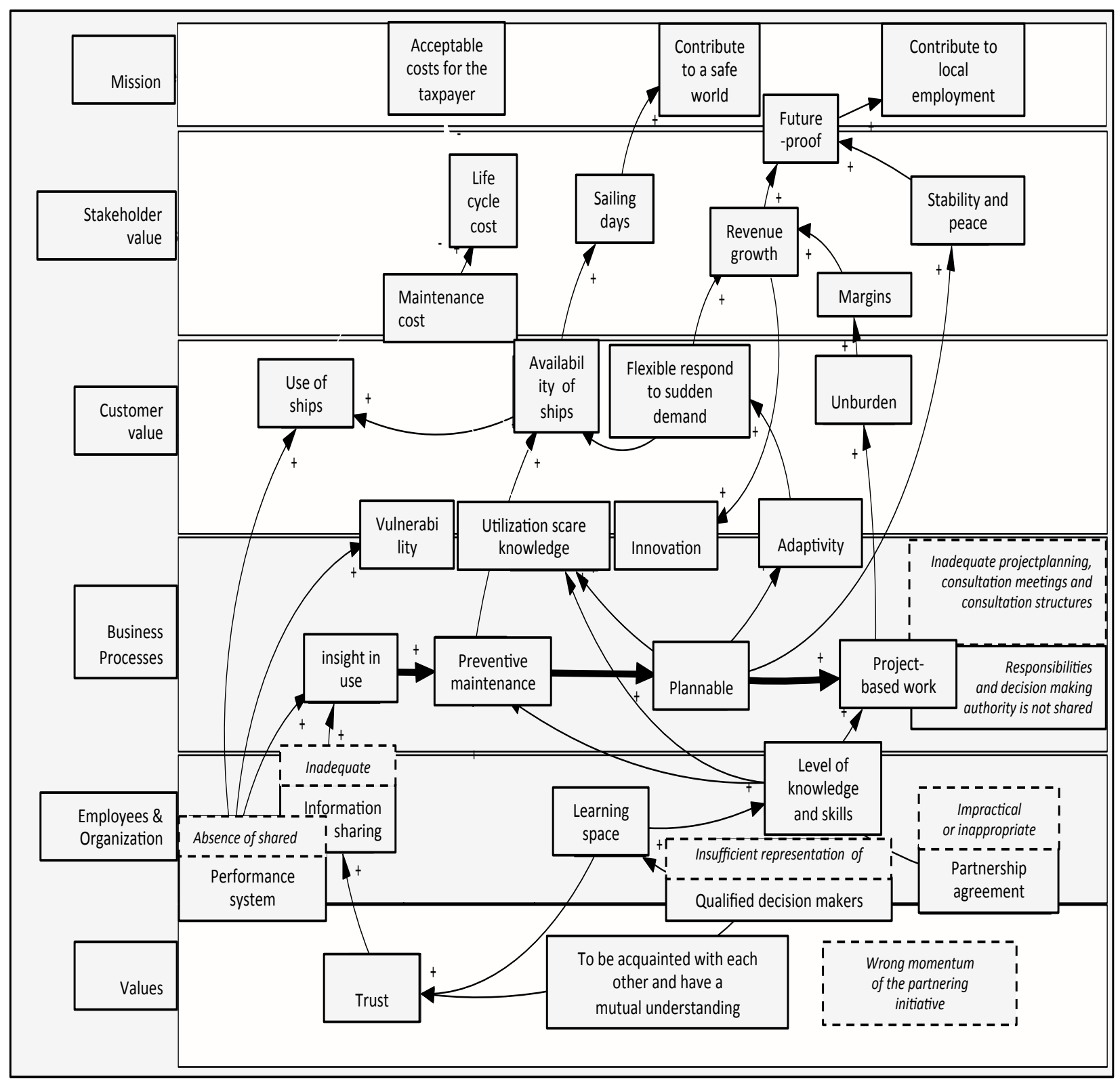

Fig. 2. The partnership strategy map of case 1 
Table 4 provides an overview of the risks identified in Figure 2. Where meaningful, it links these to the sequence of formation events and shows scores based on likelihood times impact. This lead to a priority (prio) categorisation which was used for sequencing the risks.

Table 4. Risk priority

\begin{tabular}{|c|c|c|c|c|c|}
\hline Risk & $\begin{array}{l}\text { Formation } \\
\text { Event Related } \\
\text { to Risk }\end{array}$ & Likelihood & Impact & Score & $\begin{array}{l}\text { Risk } \\
\text { Priority } \\
\text { No. }\end{array}$ \\
\hline $\begin{array}{l}\text { Insufficient representation of } \\
\text { qualified people in the } \\
\text { decision-making process of } \\
\text { defining the shared } \\
\text { objectives }\end{array}$ & $\begin{array}{l}\text { Strategy } \\
\text { formulation }\end{array}$ & 6.5 & 11 & 71.5 & 1 \\
\hline $\begin{array}{l}\text { Absence of a shared } \\
\text { performance system } \\
\text { including collaborative- } \\
\text { based performance } \\
\text { matrices to determine and } \\
\text { evaluate performance }\end{array}$ & $\begin{array}{l}\text { Operational } \\
\text { alignment and } \\
\text { formal } \\
\text { agreement }\end{array}$ & 5.3 & 11 & 58.3 & 2 \\
\hline $\begin{array}{l}\text { Partners do not deligate } \\
\text { partnership responsibilities } \\
\text { and decision-making } \\
\text { authority with respect to } \\
\text { process owners within their } \\
\text { organisation }\end{array}$ & N.A. & 8 & 7 & 56 & 3 \\
\hline $\begin{array}{l}\text { Impractical or inappropriate } \\
\text { partnership agreement }\end{array}$ & N.A. & 7.3 & 7 & 51.1 & 4 \\
\hline $\begin{array}{l}\text { Wrong momentum of the } \\
\text { partnering initiatives }\end{array}$ & $\begin{array}{l}\text { Operational } \\
\text { assesment }\end{array}$ & 6.8 & 7 & 47.6 & 5 \\
\hline $\begin{array}{l}\text { Inadequate data and } \\
\text { information sharing between } \\
\text { employees of both } \\
\text { organisations }\end{array}$ & N.A. & 5.8 & 7 & 40.6 & 6 \\
\hline $\begin{array}{l}\text { Inadequate project } \\
\text { planning, consultation } \\
\text { meetings and consultation } \\
\text { structures }\end{array}$ & $\begin{array}{l}\text { Partner selection } \\
\& \text { negotiation }\end{array}$ & 6.7 & 3 & 20.1 & 7 \\
\hline
\end{tabular}


The risks are subsequently described in the same sequence of priority and by their respective response category. Based on the content and score of risks, we distinguish Intolerable risks to be avoided up to risk 5, and Undesirable risks to be reduced for risks 6 and 7.

Intolerable risks to be avoided

1. The highest risk relates to the insufficient representation of qualified employees to determine the partnership objectives. This potentially concerns leadership lacking strategic directives and mandate, management skills, and occurrence interpersonal conflicts. It manifests early during formation. If ignored, it may result in unproductive cooperation causing formation delay or even partnership abortion. As such, this risk is considered to have a show-stopping effect on formation.

2. The risk with the second most negative effect on formation concerns the absence of a shared performance system including collaborative-based performance matrices to determine and evaluate performance. It includes a common set of measures to monitor performance, track progress towards outcomes, and to learn what is and is not working in the group's collective approach (Graham, 2016). Employees responsible for formation fail to grasp its significance or lack performance data. Although this risk does not always occur, it may manifest itself after choosing the PPP partner and when planning the formal establishment. It hampers the control of achieving formation within budget and on time.

3. The most likely risk concerns the fact that partners do not assign responsibilities and decision-making authority with respect to partnership processes within their organisation. As such, there is absence of an partnership hierarchical structure with authority and decision-making ability to coordinate and align actions between partners. The problem can arise due to partners' lack of knowledge of the specific tasks that need to be carried out, or due to lack of a clear hierarchical structure within each partners' own organisation. Consequently, the PPP has difficulties in achieving collective goals, or it is likely to operate in an inefficient manner.

4. Another risk often occurring concerns the establishment of an impractical or inappropriate partnership agreement during the final formation event. Impractical 
implies that there are issues concerning the fair distribution of liability and accountability, and equal distribution of profits and expenses between public and private partners. Inappropriate refers to business ethics and integrity practices by which the organisations deal with stakeholders when compliance with internal procedures or (international) legislation is in jeopardy. As a result, undesirable organisational behaviour is not managed ex ante and may interfere with PPP operations.

5. The final intolerable risk has to do with the moment at which the partnership initiative is launched, influencing managers' capabilities and their intent to manage the project. If there are too many other business issues with higher priority, there is little involvement and participation of managers to develop the strategic plan for cooperation. In addition, fleet owners may become vendor locked-in when they make a service proposal after system acquisition instead of before. Hence, they may become dependent on the strategic interest of the OEM since they are unable to swith to another vendor without major costs and efforts.

\section{Undesirable risks to be reduced}

6. A less likely risk concerns the inadequate sharing of information between employees of both organisations, which should be controlled before the partnership becomes operational to enable joint operations. There are a number of potential behavioral causes referring to employees' misunderstanding or their inability to transfer relevant information.

7. The risk with the least negative effect on successful PPP formation concerns inadequate project planning, consultation meetings and consultation structures between partners. The risk implies problems with respect to effective and efficient control of formation progress. It manifests within the alliance board and project workgroups. 


\subsubsection{RISKS ALLOCATION AND ASSOCIATED ISSUES}

By analysing the data, risks were assigned to appropriate types of project responsibility that may be allocated in a typical large organisation. These types of responsibility structured the presentation of results, followed by a within-type sequencing based on the earlier introduced risk scores. Tables $5 \mathrm{a}$ and $5 \mathrm{~b}$ provide a bird's-eye view of the results, which are subsequently described. The table is split for readability, with Table 5a presenting risks associated with project governance and process management (the first two responsibilities), and Table 5b presenting those associated with project management (the final responsibility). These three types of management responsibility are elaborated upon after the tables. Potential risk factors with their performance impact were identified and assigned to being either an organisation, human, or technical risk factor. That is, the last column identifies the type of risk factor (large category and specific example) as a step to better understanding the various needs for risk management measures. 
Table 5a. Risk factors and areas of responsibility (project governance and proces management)

\begin{tabular}{|c|c|c|c|c|}
\hline Risk & $\begin{array}{l}\text { Type of } \\
\text { Responsibility }\end{array}$ & $\begin{array}{l}\text { Potential Risk } \\
\text { Factors }\end{array}$ & Performance Impact & Type of Risk Factor \\
\hline \multirow{3}{*}{$\begin{array}{l}\text { Insufficient } \\
\text { representation of } \\
\text { qualified people in the } \\
\text { decision-making } \\
\text { process of defining } \\
\text { the strategic } \\
\text { objectives } \\
\text { (prio } 1 \text { risk) }\end{array}$} & \multirow[t]{3}{*}{$\begin{array}{l}\text { Project } \\
\text { Governance }\end{array}$} & $\begin{array}{l}\text { People without } \\
\text { strategic directives } \\
\text { and mandate }\end{array}$ & $\begin{array}{l}\text { Task conflict leading } \\
\text { to delayed formation }\end{array}$ & $\begin{array}{l}\text { Organisational Factor } \\
\text { - Distribution of } \\
\text { responsibilities }\end{array}$ \\
\hline & & $\begin{array}{l}\text { People with } \\
\text { clashing } \\
\text { personalities }\end{array}$ & $\begin{array}{l}\text { Relationship conflict } \\
\text { leading to } \\
\text { dysfunctional teams } \\
\text { and poor outcomes }\end{array}$ & $\begin{array}{l}\text { Organisational Factor } \\
\text { - Employee } \\
\text { relationships }\end{array}$ \\
\hline & & $\begin{array}{l}\text { People without the } \\
\text { necessary } \\
\text { knowledge or } \\
\text { personality traits }\end{array}$ & $\begin{array}{l}\text { Process conflict } \\
\text { leading to loss of } \\
\text { motivation and } \\
\text { representatives } \\
\text { dropping out }\end{array}$ & $\begin{array}{l}\text { Organisational Factor } \\
\text { - Management } \\
\text { selection }\end{array}$ \\
\hline \multirow[t]{2}{*}{$\begin{array}{l}\text { Wrong momentum of } \\
\text { the partnering } \\
\text { initiative } \\
\text { (prio } 5 \text { risk) }\end{array}$} & \multirow[t]{2}{*}{$\begin{array}{l}\text { Project } \\
\text { Governance }\end{array}$} & $\begin{array}{l}\text { Failure of senior } \\
\text { management to give } \\
\text { quidens to the } \\
\text { partnership due to } \\
\text { other businesses } \\
\text { priorities }\end{array}$ & $\begin{array}{l}\text { Impossible to develop } \\
\text { a strategic plan }\end{array}$ & $\begin{array}{l}\text { Organisational Factor } \\
\text { - Business } \\
\text { prioritisation }\end{array}$ \\
\hline & & $\begin{array}{l}\text { The foundation of } \\
\text { the relationship } \\
\text { between partners is } \\
\text { already laid during } \\
\text { system acquisition, } \\
\text { new negotiations } \\
\text { about how to } \\
\text { organize the } \\
\text { relationship for } \\
\text { system } \\
\text { maintenance are } \\
\text { superfluous }\end{array}$ & $\begin{array}{l}\text { Lack of strategic } \\
\text { rationale, commitment }\end{array}$ & $\begin{array}{l}\text { Organisational Factor } \\
\text { - Business } \\
\text { coordination }\end{array}$ \\
\hline \multirow[t]{3}{*}{$\begin{array}{l}\text { Inadequate project } \\
\text { planning, consultation } \\
\text { meetings and } \\
\text { structures } \\
\text { (prio } 7 \text { risk) }\end{array}$} & \multirow[t]{3}{*}{$\begin{array}{l}\text { Process } \\
\text { Management }\end{array}$} & $\begin{array}{l}\text { Level of } \\
\text { representatives } \\
\text { does not match the } \\
\text { level of significance } \\
\text { of the issue at hand }\end{array}$ & $\begin{array}{l}\text { Process conflict } \\
\text { leading to loss of } \\
\text { motivation and } \\
\text { representatives } \\
\text { dropping out }\end{array}$ & $\begin{array}{l}\text { Organisational Factor } \\
\text { - Project structure }\end{array}$ \\
\hline & & $\begin{array}{l}\text { The need for } \\
\text { consultation is not } \\
\text { aligned with the } \\
\text { amount of issues at } \\
\text { hand }\end{array}$ & $\begin{array}{l}\text { Task conflict leading } \\
\text { to delayed formation }\end{array}$ & $\begin{array}{l}\text { Organisational Factor } \\
\text { - Project planning }\end{array}$ \\
\hline & & $\begin{array}{l}\text { The need of a } \\
\text { consultation } \\
\text { moment is not } \\
\text { aligned with the } \\
\text { timeline of a } \\
\text { decision }\end{array}$ & Inefficient meetings & $\begin{array}{l}\text { Organisational Factor } \\
\text { - Project planning }\end{array}$ \\
\hline
\end{tabular}


Table 5b. Risk factors and areas of responsibility (project management)

\begin{tabular}{|c|c|c|c|c|}
\hline Risk & $\begin{array}{l}\text { Type of } \\
\text { Responsibility }\end{array}$ & $\begin{array}{l}\text { Potential Risk } \\
\text { Factors }\end{array}$ & Performance Impact & $\begin{array}{l}\text { Type of Risk } \\
\text { Factor }\end{array}$ \\
\hline \multirow{3}{*}{$\begin{array}{l}\text { Absence of a } \\
\text { shared performance } \\
\text { system including } \\
\text { collaborative-based } \\
\text { performance } \\
\text { matrices to } \\
\text { determine and } \\
\text { evaluate } \\
\text { performance } \\
\text { (prio } 2 \text { risk) }\end{array}$} & \multirow[t]{3}{*}{$\begin{array}{l}\text { Project } \\
\text { Management }\end{array}$} & $\begin{array}{l}\text { Lack of shared } \\
\text { vision for the } \\
\text { system and its } \\
\text { relation to achieve } \\
\text { broader goals }\end{array}$ & Lack of initiative & $\begin{array}{l}\text { Human Factor - } \\
\text { Knowledge and } \\
\text { competence }\end{array}$ \\
\hline & & Inadequate IT & $\begin{array}{l}\text { Inability to implement IT- } \\
\text { based resources }\end{array}$ & $\begin{array}{l}\text { Technical Factor - } \\
\text { Technology }\end{array}$ \\
\hline & & $\begin{array}{l}\text { Lack of information } \\
\text { organisation and } \\
\text { governance }\end{array}$ & $\begin{array}{l}\text { Lack of supply chain } \\
\text { information }\end{array}$ & $\begin{array}{l}\text { Organisational } \\
\text { Factor - Information } \\
\text { management }\end{array}$ \\
\hline \multirow{2}{*}{$\begin{array}{l}\text { Partners do not } \\
\text { deligate partnership } \\
\text { responsibilities and } \\
\text { decision-making } \\
\text { authority to process } \\
\text { owners within their } \\
\text { organisation } \\
\text { (prio } 3 \text { risk) }\end{array}$} & \multirow[t]{2}{*}{$\begin{array}{l}\text { Project } \\
\text { Management }\end{array}$} & $\begin{array}{l}\text { Partners lack of } \\
\text { knowledge of the } \\
\text { specific tasks need } \\
\text { to be carried out }\end{array}$ & Lack of coordination & $\begin{array}{l}\text { Human Factor - } \\
\text { Supply chain } \\
\text { knowledge }\end{array}$ \\
\hline & & $\begin{array}{l}\text { Lack of a clear } \\
\text { hierarchical } \\
\text { structure within } \\
\text { partners' own } \\
\text { organisation }\end{array}$ & Lack of control & $\begin{array}{l}\text { Organisational } \\
\text { Factor - Business } \\
\text { structure }\end{array}$ \\
\hline \multirow[t]{2}{*}{$\begin{array}{l}\text { Impractical or } \\
\text { inappropriate } \\
\text { partnership } \\
\text { agreement } \\
\text { (prio } 4 \text { risk) }\end{array}$} & \multirow[t]{2}{*}{$\begin{array}{l}\text { Project } \\
\text { Management }\end{array}$} & $\begin{array}{l}\text { Lack of an } \\
\text { appropriate } \\
\text { partnership } \\
\text { business plan in } \\
\text { which among other } \\
\text { things is } \\
\text { determined: (1) the } \\
\text { level of liability } \\
\text { each partner is } \\
\text { responsible for, (2) } \\
\text { how profits and } \\
\text { expenses will be } \\
\text { shared, (3) } \\
\text { dissolution and } \\
\text { expulsion rules }\end{array}$ & $\begin{array}{l}\text { Business transactions are } \\
\text { not pre-secured }\end{array}$ & $\begin{array}{l}\text { Organisational } \\
\text { Factor - } \\
\text { Formal } \\
\text { arrangements }\end{array}$ \\
\hline & & $\begin{array}{l}\text { Not in accordance } \\
\text { with internal } \\
\text { procedures or } \\
\text { (inter)national } \\
\text { legislation, such as } \\
\text { the Law 'Market } \\
\text { and Government', } \\
\text { and the European } \\
\text { Tendering Act }\end{array}$ & $\begin{array}{l}\text { Chance of being sued or } \\
\text { formation shut down }\end{array}$ & $\begin{array}{l}\text { Organisational } \\
\text { Factor - Regulatory } \\
\text { compliance }\end{array}$ \\
\hline
\end{tabular}




\begin{tabular}{|c|c|c|c|c|}
\hline \multirow{5}{*}{$\begin{array}{l}\text { Inadequate } \\
\text { information sharing } \\
\text { between employees } \\
\text { of both } \\
\text { organisations } \\
\text { (prio } 6 \text { risk) }\end{array}$} & \multirow[t]{5}{*}{$\begin{array}{l}\text { Project } \\
\text { Management }\end{array}$} & $\begin{array}{l}\text { Fear for } \\
\text { (intentional) misuse } \\
\text { of operational } \\
\text { resources }\end{array}$ & $\begin{array}{l}\text { Difficulties in achieving } \\
\text { the partnership goals due } \\
\text { to lack of trust/ } \\
\text { engagement }\end{array}$ & $\begin{array}{l}\text { Human Factor - } \\
\text { Trust }\end{array}$ \\
\hline & & $\begin{array}{l}\text { Employees are } \\
\text { unwilling to share } \\
\text { information to } \\
\text { maintain their } \\
\text { status and } \\
\text { influence } \\
\text { (knowledge is } \\
\text { power) }\end{array}$ & $\begin{array}{l}\text { Unilateral focus on } \\
\text { individual objectives }\end{array}$ & $\begin{array}{l}\text { Human Factor - } \\
\text { Behaviour }\end{array}$ \\
\hline & & $\begin{array}{l}\text { Business partners } \\
\text { use (expert) } \\
\text { information as } \\
\text { bargaining power }\end{array}$ & Unilateral focus & $\begin{array}{l}\text { Organisational } \\
\text { Factor - Behaviour }\end{array}$ \\
\hline & & $\begin{array}{l}\text { Lack of relevant } \\
\text { information sharing } \\
\text { due to lack of } \\
\text { common } \\
\text { understanding and } \\
\text { terminology }\end{array}$ & $\begin{array}{l}\text { Miscommunication posing } \\
\text { a risk to successful } \\
\text { performance }\end{array}$ & $\begin{array}{l}\text { Human Factor - } \\
\text { Supply chain } \\
\text { knowledge }\end{array}$ \\
\hline & & $\begin{array}{l}\text { Lack of } \\
\text { (interorganisational) } \\
\text { information } \\
\text { structure }\end{array}$ & $\begin{array}{l}\text { Inadequate flow of } \\
\text { information }\end{array}$ & $\begin{array}{l}\text { Organisational } \\
\text { Factor - Process } \\
\text { structure }\end{array}$ \\
\hline
\end{tabular}


We derived from the data three types of management responsibility which are accountable for PPP risk management and linked to the risks sorted by their score (Table 4).

\section{Management Responsibility 1: Project Governance}

The results indicate that two intolerable risks - concerning the presence of an inadequate management delegation, and the wrong momentum for the partnership - fall under the responsibility of project governance. These risks are to be secured by senior management. Their commitment, guidelines, and mandate is necessary to set direction, ensure that the PPP receives the necessary resources, and to give representatives power and back-up to act.

\section{Management Responsibility 2: Process Management}

An undesirable risk is related to process management activities. It concerns issues regarding inadequate project planning, consultation meetings and structures. It encompasses activities such as the arrangement of meetings between functional specialists, security of effective inter- and intraorganisational communications, and coordination of business efforts between partners. These activities are key for a consistent approach for managing the development process of the partnership.

\section{Management Responsibility 3: Project Management}

Four undesirable risks are related to partnership operations. Indicating interrelationship of risks, one of them concerns the lack of decision-making delegation to process owners due to insufficient mandate given by project governance owners. Others relate to the absence of an appropriately defined business arrangement, inadequate performance metrics, and inadequate interorganisational information sharing. Similar factors underly these risks, referring to lack of guidelines, domain knowledge, and trust.

Subsequently, the strategic risk management process was analyzed and compared between the two alliance projects. The results suggest a difference in risk awareness and control measures taken, ostensibly caused by not consciously and proactively dealing with risks at an early stage and in a structured way. Instead, risks and control measures are inventoried and applied in an arbitrary manner. Timely and structural riskanalysis and continuous attention to riskmanagement by (top) management, can help the decision making concerning the feasibility of allianceformation. 


\subsection{DISCUSSION AND CONCLUSIONS}

\subsubsection{REFLECTION AND FRAMEWORK DEVELOPMENT}

This paper contributes to addressing the lack of understanding of organisations' risk

management practice within the process of PPP formation. It conceptualises, analyses and

evaluates an organisation's approach to managing risks when attempting to form public-private service maintenance partnerships, and it identifies associated management issues with the aim to give suggestions for performance improvement.

Drawing on the study findings, a framework for the risk management of PPP formation projects has been developed (see Figure 3). The framework can be used by both researchers and practitioners to consider formation events requiring sound management and coverage of their risks.

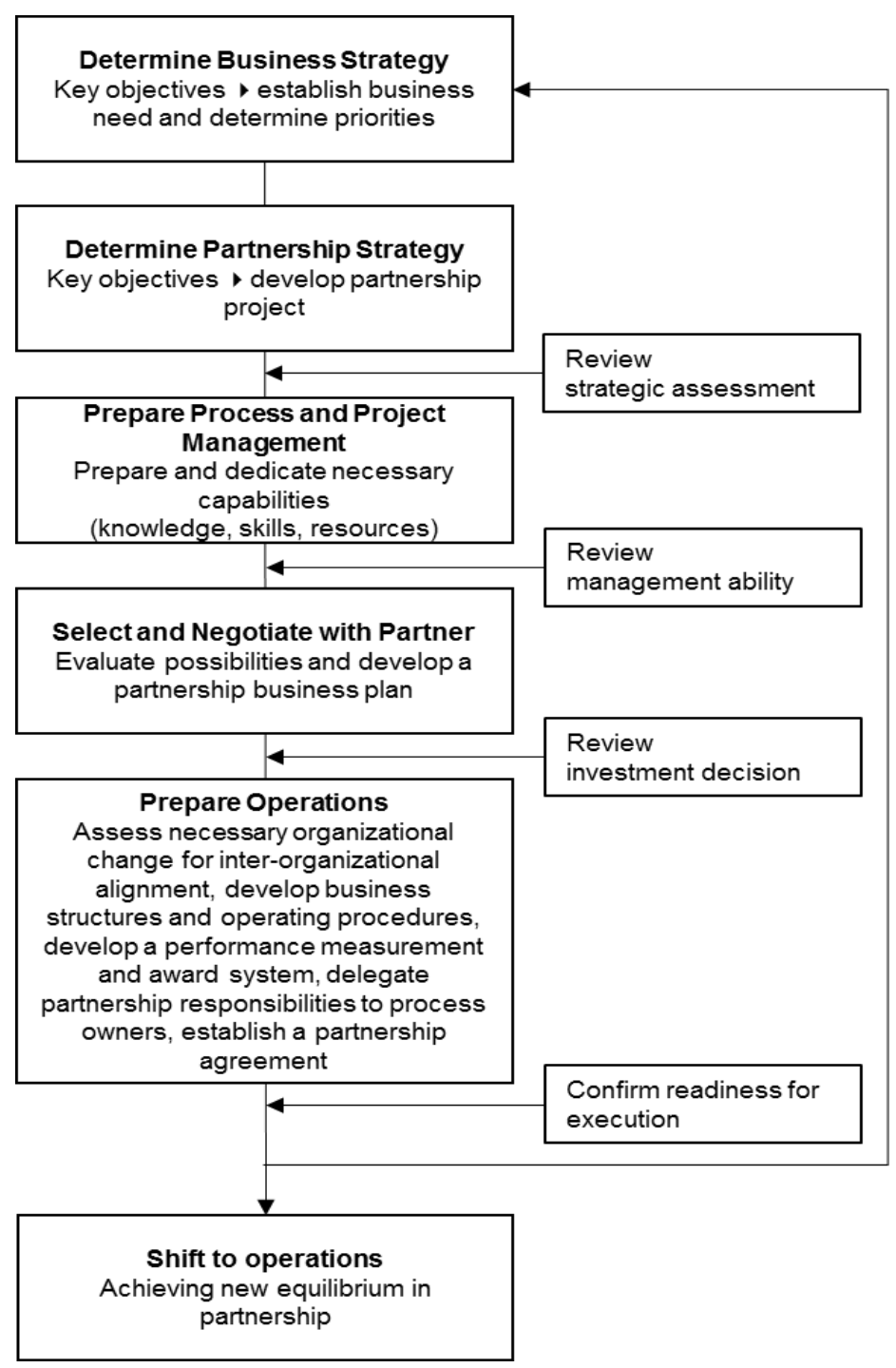

Figure 3. A Framework for risk management of PPP formation projects 


\subsubsection{RESULTS PLACED IN A LARGER CONTEXT}

Although the findings reveal different levels of risk responsibility which should jointly be involved to control the process of PPP formation, a remaining question is: How to improve the effectiveness of risks management? Derived from the study findings and in line with earlier research, two dimensions can be distinguished focused on proper risk allocation. They concern on one hand risk management involvement, and on the other hand commitment. We relate these dimensions to the responsibilities earlier distinguished.

In line with Abednego and Ogunlana (2006), with regard to involvement, project governance requires a long-term effort of senior management to secure strategic 'fit' of the project with the overall business objectives, and investments of resources for process and project management (Akintoye et al., 2008: 60, Abednego and Ogunlana, 2006). In contrast, project management requires more short-term involvement of specialists on specific issues, while day-to-day supervision is necessary for process management.

Second, commitment has been perceived to be a matter of choice (Thornton, 1970). Senior managers responsible for project governance and process managers should have commitment to the PPP, whereas project management specialist may be more committed to their profession. The latter group is partially included in the project on top of their role in routine operations. Especially with respect to risk owners that need to be strongly committed: when they are not engaged by the risk bearing entity, they should have incentives to manage the partnership risks effectively or else they may suffer from inaction or counterproductive behaviour (Spira and Page, 2003).

\subsubsection{THEORETICAL AND PRACTICAL IMPLICATIONS}

First, with respect to the content of the risk factors identified, our results suggest that control and trust mechanisms are required simultaneously to cover the diversity of risk factors. This partially answers the much debated question of the complementarity between informal and formal control mechanisms (Gurcayiliar-Yenidogan, 2014). By suggesting that especially organisational and human types of risk factors play a role in risk management success (Tables $5 a$ and $5 b$ ), the results build on and expand the few research attempts to explain the link between risks, trust, and control (De Man and Roijakkers, 2009). Second, this study has found that risk awareness, management involvement and commitment are related to types of management responsibility. Our results shine light on both these types of responsibility and the far-reaching internal implications for organizing management and control. We thereby contribute to emerging research on how intraorganisational governance influences the development of public-private partnerships (Brinkerhoff and Brinkerhoff, 2011, Ebrahim et al., 2014, Gurcayiliar-Yenidogan, 
2014, Klijn and Koppenjan, 2012, Pateli, 2009, Ruuska et al., 2011). Specifically, the results help to address the insufficient understanding of PPP risk management practice, and to extend current framing of IOR as a cross-organisation coordination process (Gittell and Weiss, 2004, Lewin et al., 2011). There are also a few important managerial implications. Practitioners can benefit from this study's insights as it increases awareness of flaws within their risk management practice in relation to public-private partnership projects. The types of management responsibility enable reflection on organisations' level of capability before they make the final decision on starting up a PPP initiative or not. In addition, in line with other studies, the results suggest the importance of partnership management knowledge, skills and certain mechanisms helping an organisation to improve its partnership performance.

\subsubsection{LIMITATIONS AND FUTURE RESEARCH}

Despite the contributions of this study, it is subject to several limitations. First, this study does not verify the extent to which the issues associated with risk management are really faced and complete. Instead, this study presumes that managers' consideration of them reflects their ability to deal with them successfully. It would for example be interesting to investigate whether addressing these issues proves adequate. Second, although the validity of the types of responsibilities is verified in various ways, interrelationship between them has remained implicit. Our results suggest it is likely that only together they facilitate integrated risk management. Future research should try to extend our analysis by empirically verifying the interaction effects among them. Third, successful risk management does not necessarily guarantee successful partnership performance. Researchers might explore the enactment of risk management capabilities. And finally, an essential point of departure for follow-up research may be to study managerial cognition regarding the interpretation of risks, or managerial interest in controlling them. 
212 


$\begin{array}{ll}\text { AUTHORS } & \text { Keers B.B.M. } \\ & \text { Van Fenema P.C. } \\ & \text { Markerink L. } \\ \text { PUBLICATION OUTLET } & \text { Journal of Information Technology Theory and Application } \\ \text { ADDRESSES } & \text { RQ 8: How do PPPs organize their data governance and } \\ & \text { what improvements are necessary? } \\ \text { STATUS } & \text { Submitted for 2nd review }\end{array}$

\subsection{ABSTRACT}

Data availability and data analytics are expected to have a major impact on organizations, expanding the role of Enterprise Systems beyond intra-organizational coordination of business processes. Organizations acknowledge the advantages of data sharing as a means to innovate and enhance customer value. At the same time, companies often fear that data sharing may limit their autonomy and even harm their competitive position, hence it is natural that they wonder how data governance might help to mitigate such risks. Studies on this subject seem to be scarce. Therefore, this research explores how data governance within a data sharing collaboration between public and private organizations can be developed and implemented. The findings elaborate activities pertaining to three areas: Information Management Maturity (IMM), Collaborative Readiness (CR), and Organizational Change Capacity (OCC) across development and implementation phases. This processual approach extends the data governance literature and enables practitioners and researchers to enact and reflect upon the emergence of interorganizational data governance. The paper concludes with implications for research and practice.

\subsection{INTRODUCTION}

Objectives such as improving public services in quality and effectiveness and making operations more efficient have forced public organizations using complex technology to explore new partnership arrangements with their industrial suppliers (Pollitt and Bouckaert, 2004). This includes public organizations that use increasingly sophisticated assets in infrastructure and 
security sectors (Bobbink and Hartmann, 2014; Hartley, 2008; Humphries and Wilding, 2004; Koppenjan, 2005; Levering et al., 2013; Tatham, 2013). They face strategic challenges regarding the use of complex, IT-intensive technologies for extended lifetimes up to 30 years while at the same time being confronted with decreased budgets for system maintenance as well as labor shortages. These challenges have driven their pursuit to enter into tighter forms of collaboration with their suppliers in an attempt to implement service innovation (e.g. perform dynamic rather than preventive or reactive maintenance) and its associated business transformation (Humphries and Wilding, 2004; Klievink et al., 2016). Dynamic or condition-based maintenance involves observing or measuring the condition of systems like ships, rail tracks or aircraft and use this information to predict potential failure occurrences. Such predictions enable better alignment of maintenance activities or system replacement and optimized orchestration of spare parts supply in a 'Just In Time' mode or based upon operational schedules (Brax and Jonsson, 2008). Dynamic maintenance requires the sharing of product data and information, spanning organizational boundaries between supply chain network partners (Levina \& Vaast, 2005). When effectively controlled, data and information sharing ${ }^{28}$ between supply chain actors can improve decision-making with regard to ordering, allocating capacity, and operational planning. This may facilitate quick responses, increase utilization of resources, reduce inventory levels, and lower costs (Samaddar et al., 2006; Schemm and Legner, 2008). However, the required control across supply chain actors proves to be a daunting task.

Researchers studying inter-organizational value creation and performance management have repeatedly reported challenges with information sharing across organizational boundaries (Crié and Micheaux, 2006; Otto et al., 2011), in particular when value creating relationships change from unidirectional product seller-buyer towards bidirectional and multisided networks. In this new configuration, organizations struggle to co-create service and repair offerings, allocate roles, and organize accountabilities and revenues (Wende, 2007). In addition, collaborative outcomes must be secured against information misuse due to self-interested behavior (Bellamy and Raab, 2005; Dyer and Hatch, 2006), and knowledge leakages which could be harmful to the strategic positions of participants (Möller and Rajala, 2007). Moreover, sharing product quality information between a supplier and an asset owner as input for maintenance planning can be problematic when warranty periods have not yet expired. For instance, the supplier may monitor and analyze a customer's potentially excessive behavior, and conclude that actual use patterns deviate from normal, contracted use. And finally, actual efficiency improvements by novel combination of inter-firm activities may not take place (Ladley, 2012). Hence, new knowledge

${ }^{28}$ We use data management and information management interchangeably. 
development by inter-organizational information sharing is not easily ensured, nor is the process of its implementation to improve performance well known. To increase control, interorganizational governance could be set-up (Wareham et al., 2014). Yet academic research on inter-organizational data governance, a subdomain of inter-organizational governance, is still in its infancy. Approaches to inter-organizational data governance mainly address technical issues (Otto et al., 2011; Schäffer and Leyh, 2017), data quality management activities and decision areas, or focus on designing a configuration model (Andersson, 2015; Schemm and Legner, 2008; Wende, 2007). Previous research falls short of analyzing the ability of organizations to embark upon the required changes of mechanisms and processes once the data governance design is implemented in practice (Crie and Micheaux, 2006; Ladley, 2012). Data governance does not only consist of the design and exercise of authority and control over data management. It also involves the development and implementation of rules, standards, and policies, including the management of the organizational change process to implement the (new) governance orchestration and techniques (Ladley, 2012). This calls for attention to the temporal dimension of data governance. This chapter seeks to contribute to such a process-based approach to theorizing. Specifically, the purpose of this chapter is to provide insight in key management activities affecting an organization's ability to develop and implement inter-organizational data governance. To this end, it develops and validates a conceptual framework that explores the phases and content of implementing inter-organizational data governance. Validation takes the form of a qualitative case study on an inter-organizational research consortium. Our framework helps to gain understanding of the complexity of managing the interplay of organizational and inter-organizational aspects by identifying activities across the phases of developing and implementing inter-organizational data governance.

The remainder of this chapter is structured as follows. The next section reviews the interorganizational data sharing and governance literature, and discusses pivotal areas to effectively implement inter-organizational data governance. We then describe our empirical research, followed by the results and a discussion of implications of the findings for research and practice. 


\subsubsection{INTER-ORGANIZATIONAL DATA SHARING}

Several studies on innovation and service management describe the advantages of interorganizational partnerships for the development of knowledge (Kerkhof et al., 2016; Kuijken et al., 2017; Loebbecke et al., 2016; Nooteboom, 2008; van Broek and van Veenstra, 2015). With respect to the process involved, often open frequent communication is named as an important principle for these value-enhancing partnerships (Christopher, 2011; Grönroos, 2011). Open communication also promotes greater understanding of complex competitive issues related to supply chain success (Grant, 1996; Kogut and Zander, 1996). In addition, inter-organizational information sharing can lower overall transaction costs and enhance a supply chain's transaction value (Klijn, 2010). It may furthermore encourage confidence, build cooperation and trust, and reduce dysfunctional conflict (Giudici et al., 2016). In this respect, especially within aircraft, railway, and defense industries, efforts have been raised to implement tighter forms of collaboration between vertical supply chain partners, caused by the need to extend lifetimes and the high exploitation costs of industrial capital goods (van Fenema et al., 2014). With the aim to enhance the coordination of maintenance and logistic process activities, these initiatives require cross-organizational sharing and exchange of information concerning technological design, systems' degradation, or failure behavior and anticipated future usage profiles (Carlile, 2004; Rowley, 2007). However, despite the ambitions and the potential benefits, practice reflects organizations' inability to embark upon the challenges associated with interorganizational coordination of knowledge and information sharing (Engel, 2015; Hsu and Chang, 2014; Maas et al., 2014; Qureshi and Evans, 2015; Schemm and Legner, 2008). These performance challenges are related to technological, political, policy, and organizational conditions (Yang and Maxwell, 2011) as they influence the embedding of practices in their technological, social, and innovative context (Hsiao et al., 2006).

First, regarding the technological conditions, since organizations often utilize different types of hardware and software, a major challenge is to integrate heterogeneous information systems of different platforms, data standards, schemas and data qualities (Yang and Maxwell, 2011). Moreover, because of security and confidentiality matters, it is critical to develop a system that can handle access authorization to shared information (Alshboul et al., 2015). Second, with regard to political and policy challenges, conditions refer to legislation and policies influencing data sharing. Legal and policy regulations can enhance or create barriers for inter-organizational data sharing (Constantiou and Kallinikos, 2015). Third, organizational conditions refer to the complexity of managing interactions between individuals both within and across organizations. 
This is especially the case when there exist different organizational standards and values concerning data and information sharing, absence of trust (due to concerns of autonomy loss, information interpretation incapability, or information misuse due to self-interested behavior), and power plays are involved (Arino et al., 2001; Bellamy and Raab, 2005; Dyer and Hatch, 2006; Gil-Garcia et al., 2007; Yang and Maxwell, 2011). In addition, a prerequisite for the exchange of data and information is the presence of common or adaptable operational procedures, control mechanisms and work flows to enable sharing (Premkumar et al., 2005). It touches upon the ability to change operations in order to support functioning in a cross-organizational manner (Busi and Bititci, 2006). To provide a framework for inter-organizational data sharing that also addresses the associated challenges, scholars have introduced and studied the concept of data governance.

\subsubsection{INTER-ORGANIZATIONAL DATA GOVERNANCE}

For effective and efficient inter-organizational performances, integrated governance is essential (Jones et al., 1997; Patel, 2002; Provan and Kenis, 2008). Governance refers to formal structures and controls concerning decision making, as well as processes, social practices, and activities (Bevir, 2013). Data governance concerns activities that ensure data is managed in accordance with organizational objectives; it is resembles auditing (Ladley, 2012).

Data governance can be interpreted as an existing or emerging practice. For inter-organizational data governance, we elaborate on the emergence perspective since many collaborating organizations struggle with effective data governance. Derived from existing literature (Chong and Tan, 2012; Khatri and Brown, 2010; Yang and Maxwell, 2011), we can now define data governance as a staged implementation process of Design and Planning, Deployment, and Application and Monitoring the exercise of authority, control, and shared decision-making by means of rules, policies, procedures, structure, roles and responsibilities. These in turn outline and enforce rules of engagement, decision rights, and accountabilities for proper information management (Mosley, 2008). Information management concerns the actual touching, moving, tracking, and managing activities of the data and information assets (Ladley, 2012). Data governance ensures data quality and lifecycle, access and security management, master data management, as well as data principles, and business intelligence (Kaisler et al., 2013; McAfee and Brynjolfsson, 2012).

Whereas data governance is an enterprise program and effort, we believe that interorganizational data governance is an extended enterprise program and effort (Bobbink et al., 2016; Busi and Bititci, 2006): it affects the partners' entire organization (Dyer, 2000). Interorganizational data governance is not limited to the IT department, as other business areas are 
likely to be changed when it comes to managing inter-organizational information. Moreover, 'data governance needs to be implemented iteratively, in a carefully designed deployment' (Ladley, 2012: 18). Elaborating on existing (professional) knowledge (NASCIO, 2009), we argue that the development and implementation of inter-organizational data governance implies an evolution of the current state of mechanisms and business processes. Effectiveness of this evolutionary process depends on the ability of organizations to take necessary actions for that purpose. Specifically, related to this ability, Ladley (2012) identifies three specific focus areas to assess, which structure our empirical work: each organization's current information management maturity, its collaborative readiness, and its organizational change capacity.

Information management maturity of an organization presumes a proactive approach to information. It includes how the organization acquires and produces information, and how well the organization uses and manages this asset to its advantage (regarding analyses, decisionmaking, product, and process development). Assessing the current level of information maturity helps to identify the required improvement of the leverage and quality of data (Bitterer, 2007; SAS, 2008). An assessment of collaborative readiness reviews the organizational capability to implement collaborative elements such as the allocation of collaborative resources, skills, and knowledge. These elements allow for the use of data and content to operate in a crossorganizational manner under a formal program of collaborative processes (Durugbo and Riedel, 2013; Romero et al., 2009). The assessment of an organization's change capacity focuses on determining whether the organization can adapt to the new policies, procedures, structure, roles, and responsibilities. In other words, whether it can embrace the change required, or will run into resistance (Judge and Douglas, 2009). Following Ladley's (2012) line of reasoning, our goal is to gain a deeper understanding of key management activities associated with these three pivotal areas across phases of development and implementation of inter-organizational data governance.

\subsection{METHOD}

\subsubsection{CONTEXT AND DESIGN}

Given the purpose of this chapter, a qualitative case study was conducted on the development and implementation of inter-organizational data governance for two data sharing partnership projects, by examining organizations' transformation ability and related key management activities. An exploratory, instrumental case study design was used to obtain new insights for which the case plays a facilitating role (Eisenhardt, 1989; Rai and Tang, 2014; Yin, 2003). 
The unit of analysis involved a maritime public organization - further referred to as the service "Customer" - attempting to establish data sharing partnerships with two of its system suppliers further referred to as "Supplier A" and "Supplier T" - on two maintenance projects. Both projects were meant to implement a condition based maintenance concept as a means to enhance system up-time and reduce capital costs, for which an organizational exchange of system operations and service maintenance data is a precondition. The unit of analysis was selected based on its accessibility to conduct research. That accessibility was guaranteed by the researchers' participation in a larger research project of service innovation. The long-term involvement of the author in the research and design of this larger research project guaranteed full access to case details. This allowed for gaining a deeper understanding of organizational management capacity. The organization of study employs 2,400 people on an average annual budget of $113 \mathrm{M}$ Euros. The number of system repairs currently amounts to 12,000 per year. The organization consists of different departments: Maintenance, Procurement, Security, and a Front-office for Operations. The Maintenance department is responsible for performing the actual maintenance and upkeep of systems and platforms. The Procurement department is responsible for the purchasing of spare-parts and consumption articles (like lubricants). The Security department takes care of security of business information, and the Front-office liases between end users and maintenance providers. Supplier $A$ is an organization that produces and services electronic components and installations internationally. Supplier $\mathrm{T}$ is an international electronics company which is active in the area of security and information technology. For reasons of confidentiality, the names and more detailed descriptions of the organizations are not revealed.

While current literature provides some insights in performance challenges related to interorganizational coordination of knowledge and sharing of information, empirical case study research was considered necessary to flesh out specific activities making up the successful development and implementation of inter-organizational data governance. A methodological fit is ensured when the current state of literature accords to the research design (Edmonson \& McManus, 2007; Malgonde and Bhattacherjee, 2014). As also discussed in Section 2.2, we derived three areas as sensitizing concepts for empirical work (van den Hoonaard, 1997): information management maturity, collaborative readiness, and organizational change capacity. An inductive case setup was decided upon to develop theory (Eisenhardt, 1989); this implies the use of key concepts rather than an elaborate ex ante framework (Yin, 2003). Finally, development and implementation suggest a sequence of phases. We therefore structured our case study along a processual rather than an explanatory line (Mohr, 1982). Three stylized phases were adopted in accordance with common literature on implementation and inter- 
organizational development: design and planning; deployment; application and monitoring (Dyer et al., 2001; vom Brocke and Rosemann, 2015).

\subsubsection{RESEARCH PROCESS AND DATA COLLECTION}

The case study took place in 2016-2017. It covered the period in which the projects evolved form exploring shared objectives, the signing of a letter of intent for collaboration, towards implementation of the public-private partnership. Multiple research instruments were employed in order to collect data, such as progress meeting reports, informal conversations with senior managers, and notes taken from a development-oriented workshop. This data was combined with insights gathered from a series of in-depth interviews conducted throughout both projects. In-depth interviews as a qualitative interview technique enables the gathering of detailed information from a relatively small number of respondents (Boyce and Neale, 2006). A total of twelve interviews were conducted based on purposeful sampling. As pointed out above, we secured that respondents represented a cross-section of functional areas and hierarchy levels (see Table 1). We explored key activities geared towards future inter-organizational data governance. The interviews were conducted individually and lasted approximately 1-2 hours. All transcriptions were shared with respondents for fact checking.

Table 1. Overview of interviews

\begin{tabular}{|l|l|c|}
\hline Management Level & Role & Number of interviewees \\
\hline Strategic & CEO and former CEO & 2 \\
\cline { 2 - 3 } & Staff member/ Policy Advisor & 1 \\
\cline { 2 - 3 } & $\begin{array}{l}\text { Head of Maintenance } \\
\text { Department }\end{array}$ & 1 \\
\cline { 2 - 3 } & Head of Procurement & 2 \\
\cline { 2 - 3 } & Project Leader & 1 \\
\hline Tactical & Member of the Security & \\
& Department & 1 \\
\hline Operational & & 2 \\
\hline Total number of interviews & & 1 \\
\cline { 2 - 3 } & Logistic Manager & 12 \\
\cline { 2 - 3 } & System Maintenance Planner & 1 \\
\hline
\end{tabular}




\subsubsection{DATA ANALYSIS}

Our inductive analysis relied on post-coded content analysis (Bauer and Gaskell, 2000) using a selective coding approach. Relying on a semi-structured inductive method, rather than a grounded approach, selective coding helps to leverage pre-developed concepts: it enables integration and refinement of conceptual categories (Wolfswinkel et al., 2011). Iterative cycles of data analysis allowed for new insights to emerge (Schakel et al., 2016). While our initial analysis included intra-organizational data governance, discussions amongst the authors and interactions with the reviewers led to a sharper focus on inter-organizational data governance, and hence to better relate the resulting story to the research purpose. The conceptual framework presented under results reflects our final insights. In particular, we display the results in a matrix, with the vertical axis representing the three areas (Information Management Maturity, Collaborative Readiness, and Organizational Change Capacity) and the horizontal axis the three stages (Design and Planning, Deployment, Application and Monitoring).

\subsubsection{RESEARCH QUALITY}

Research quality is usually decomposed in quality dimensions such as completeness, consistency, reliability, and internal and external validity (Henneberg and Mouzas, 2008). Concerning completeness of the data, we interviewed in total 12 key managers with knowledge pertaining to and roles within the partnership development process, corresponding to approximately $75 \%$ of the focus group. Consistency was achieved by triangulating data from various sources (Yin, 2013). We strived for reliability by using an interview protocol, documenting our research process and providing transparency thereof (Kirk and Miller, 1986). And finally, internal validity, i.e. trustworthiness (Golafshani, 2003), was effectuated by assessing amongst the researchers and with interviewees whether the used concepts matched (i.e. the areas and phases we used) and data triangulation. External validity in case study research, i.e. conceptual generalization (Yin, 2003), requires reflection on the type of organization studied and its industry. Our research suggests that conceptual generalization may be limited to organizations in the public sector that use high-tech resources and are involved in complex supply chains with a limited number of suppliers (Hearnshaw and Wilson, 2013; Provan and Lemaire, 2012). Moreover, on the supply side, we included organizations that operate on low volume, complex product-service systems (Caldwell and Howard, 2010). 


\subsection{RESEARCH FINDINGS}

In this section, we briefly present our analysis of the case in terms of the key activities for the development and implementation of inter-organizational data governance as the case revealed. The elaborate conceptual framework that resulted covering the content of implementing interorganizational data governance is shown in Figure 1. We categorized the activities identified and the results in matrix form, as explained in Section 3.3. 


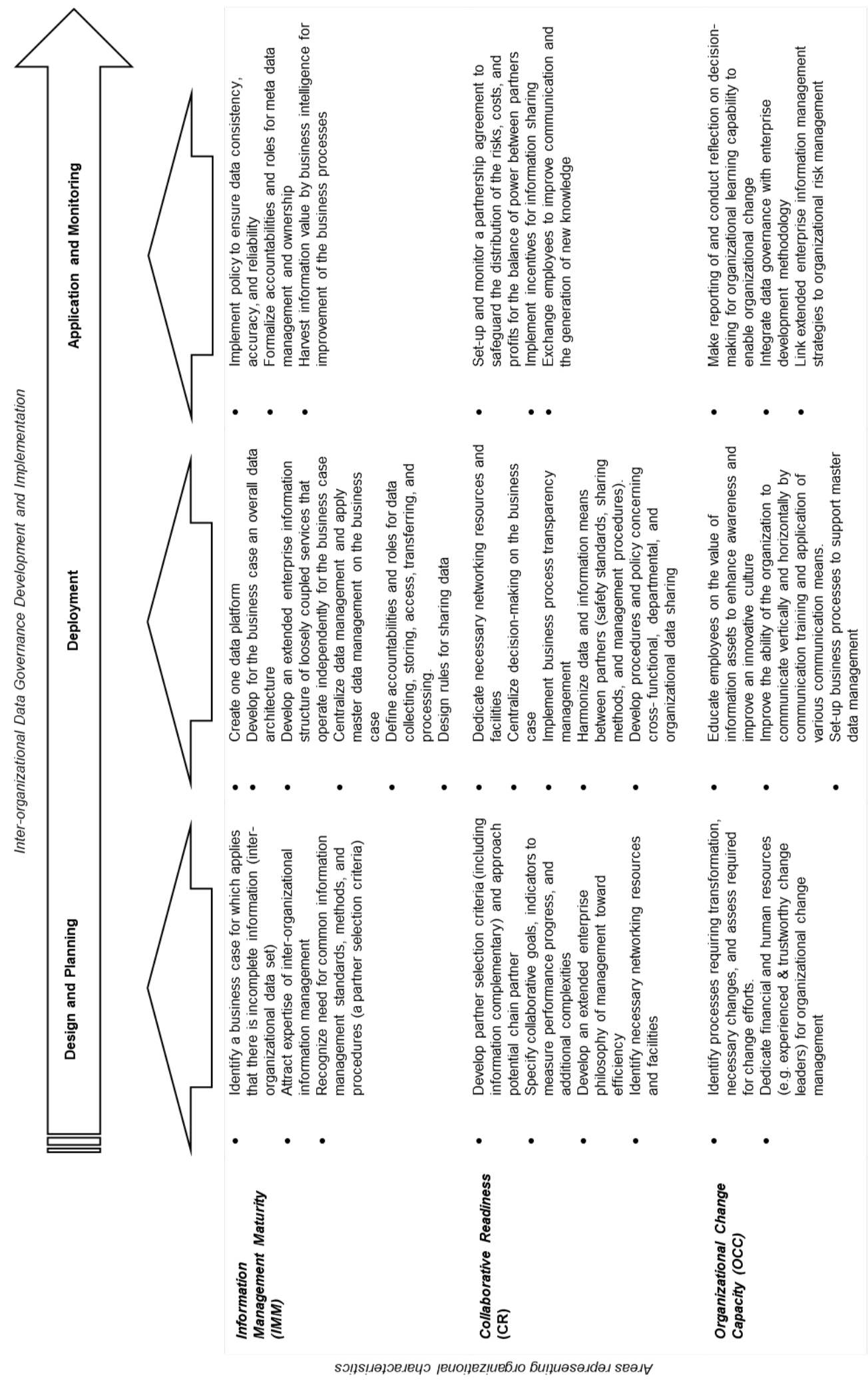

Figure 1. Framework for inter-organizational data governance 


\subsubsection{DESIGNING AND PLANNING INTER-ORGANIZATIONAL DATA GOVERNANCE}

The case study organization is motivated to pursue inter-organizational partnerships for the development of (service) knowledge. It acknowledges value delivery deficiencies caused by inadequate business (and as such network) process decision-making and incomplete interorganizational data sets. Subsequently, to improve a company's business processes (and therefore network performance), necessary changes and resources are identified which guide the search for a partner with the necessary complementary information.

In addition, the inter-organizational information pursuit is complemented by the organization's initial governance efforts concerning the acquisition of inter-organizational information management expertise to refine the exact data need and partner qualification. The organization's activities to increase the collaborative readiness relate to partner selection, definition of collaborative goals, identification of necessary networking resources and facilities, as well as the development of a collaborative philosophy. Lastly, activities employed by the organization relating to organizational change include the identification of inefficient processes requiring change, processes requiring inter-organizational alignment, and change efforts (including the allocation of financial and human resources) required to that end. Broadly speaking, activities concerning information management anticipate cooperation and change efforts.

\subsubsection{DEPLOYING INTER-ORGANIZATIONAL DATA GOVERNANCE}

The case study organization performs most of its activities for the development and implementation of inter-organizational data governance during the deployment phase. Within this phase, the ability to manage information is elevated to a higher level by the establishment of a centralized inter-organizational span of control, including the development of master data management on the business case (comprising an extended enterprise data platform, architecture, information structure, as well as data quality and business intelligence management). To the same end, the organization acknowledged the need for different collaboration efforts to enhance communication between partners, like harmonization and application of new data management mechanisms, centralization of decision-making, implementation of business process transparency management, and development of policy and procedures for data sharing. In addition, recognizing that these improvement efforts may encounter resistance, respondents mentioned the importance of providing employees training on inter-organizational communication and the use of data management, as well as the need to educate employees on the value of information assets to develop a positive yet realistic attitude 
towards innovation. Lastly, empowerment for taking adequate actions aimed at change was considered necessary to de-centralize and anchor data governance in the organization.

\subsubsection{APPLYING AND MONITORING INTER-ORGANIZATIONAL DATA GOVERNANCE}

The application and monitoring of inter-organizational data governance requires in particular efforts with respect to the formalization of accountability allocation, roles, and ownership concerning data management and partnership performance. This formalization is achieved through policy and partnership arrangements. Moreover, it includes setting up safeguards regarding data access and implementing incentives for information sharing and new knowledge generation (e.g. by exchanging employees across organizations). Lastly, the application of interorganizational data governance calls for integration into risks management structures, as well as reflection on decision-making to identify lessons learned.

\subsection{DISCUSSION AND CONCLUSION}

There is a need for a comprehensive understanding of what it takes to govern interorganizational data sharing (Ladley, 2012). This paper investigates from a process perspective the ability of organizations to implement inter-organizational data governance to adress key challenges. We focus on management activities affecting an organization's ability to develop and implement inter-organizational data governance, since studies on inter-organizational data governance have been criticized for not clarifying the content and process with which it is implemented.

Based upon existing literature and the case study, a conceptual integrative framework is developed with key activities for implementing inter-organizational data governance. It shows that the ability to implement data governance exists of employing a complex variety of management actions concerning information maturity, collaboration, and organizational change, throughout a staged process of development and implementation phases.

The developed integrative framework offers a promising insight into the phases and content of implementing inter-organizational data governance. It indicates and differentiates various activities related to the ability of organizations to develop and implement inter-organizational data governance. Our study focuses on a niche topic that offers a critical extension of literature on the intertwinement of intra- and inter-organizational performance management (Bititci et al., 2012; Busi and Bititci, 2006). That is, the research adds to the limited insight concerning organizational aspects affecting data governance performance (Wende, 2007), and 
understanding of why organizations continue to struggle with managing inter-organizational performance (Dekker, 2004). Moreover, our work intends to improve understanding of the applicability of organizational change capacity for various types of change trajectories (Judge and Douglas, 2009). In addition, the framework developed may help researchers assessing inter-organizational data governance aspects from a process or explanatory view. It can be a useful instrument for practitioners and consultants seeking to better understand, prepare for, or enhance an organization's ability to control inter-organizational data sharing. Activities across phases can undergird innovation roadmaps common in adjacent fields (Kalakota and Robinson, 2003; Mohammed et al., 2008). Compared to explanatory research on factors influencing interorganizational governance, an advantage of developing a roadmap for development and implementation is that problems can be identified and addressed for each phase. This way, practitioners can enact complex change, making a systematic process without overstretching their organization.

There are still several limitations of this study to be noted. First, while our research examines challenges associated with inter-organizational data sharing, we evaluate the ability to implement inter-organizational data governance on the basis of intra-organizational conditions (Pellettier, 2006). Second, although our research suggests a sequential line-up of management activities for development and implementation of inter-organizational data governance, future research should try to extend this analysis by empirically verifying interaction effects across the three areas constituting the organizational ability 'to govern or be governed' (Ladley, 2012). Third and finally, given the case study design we used, similar or quantitative research in related industries is required to validate and substantiate our findings. Moreover, industry-level or maybe cross-sector research can provide new insights in data sharing across organizations in the digital era (Loebbecke and Picot, 2015; Reypens et al., 2016; Schäffer and Leyh, 2017). 


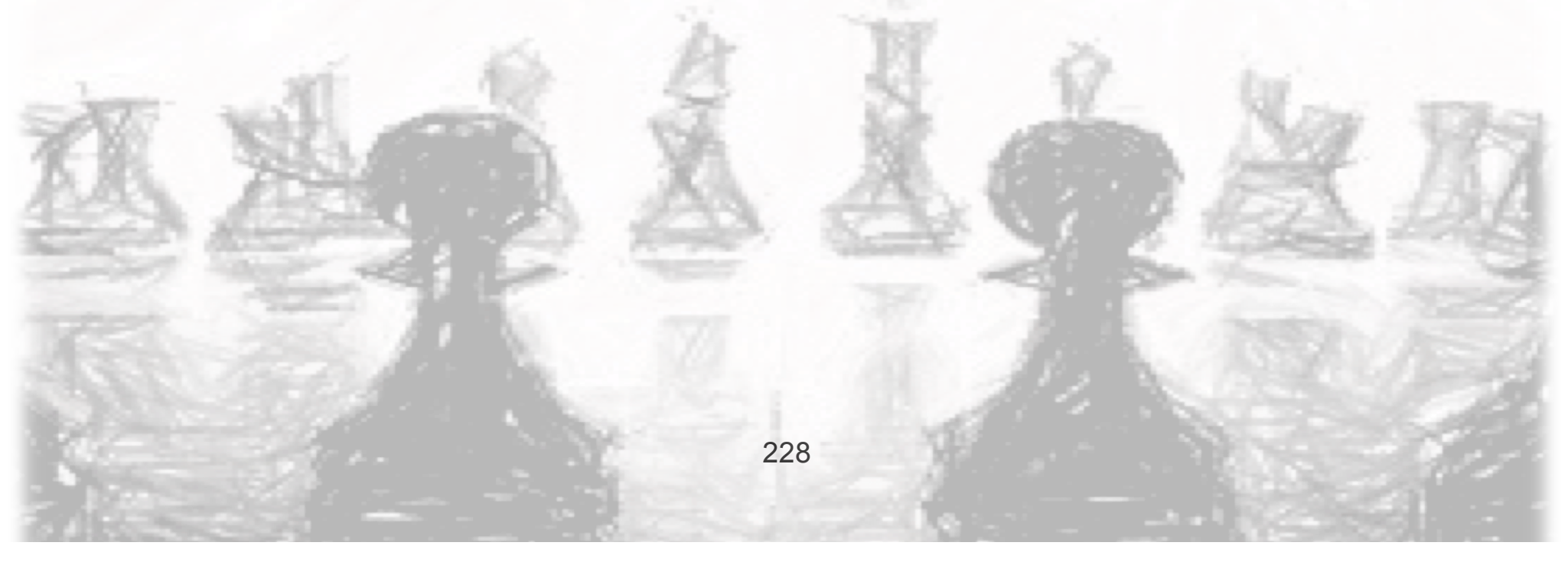


PART C: CONCLUDING REFLECTIONS AND LEADS FOR FUTURE RESEARCH 


\subsection{CHAPTER SETUP}

This chapter is structured as follows. First, we return to the research questions formulated in Chapter 2 along the three research themes context, process, and requirements, and describe the findings of the accompanying studies. Next, we explain how the answers contribute to the two objectives of this dissertation. Then, the scientific and managerial implications are discussed, followed by describing the limitations of this dissertation, as well as suggestions for future research.

\subsection{SUMMARY OF FINDINGS}

\section{Context}

$R Q$ 1: What is the reason for the emergence of the strategic motivation to form a (service) alliance? And how is it considered to increase value both individually and collectively?

By means of a literature review, the first study sketches the strategic motivations underlying the intent of organizations to pursue an alliance on services, vertically, horizontally or in a hybrid manner, and explores organizational aspects of new cooperative business models. The results suggest that organizations form service alliances instead of selecting other IOR forms to increase customer value by empowering their service delivery while reducing stakeholder costs and retaining in control of the value creating process. Their strategic motivations are provided by contextual characteristics such as increased global competition, shrinking government budgets, price pressures and the need to deliver high service levels of sustainable products. To increase the cost-effective generation of value, chain organizations bundle or synchronize the process activities horizontally, vertically, or in a hybrid manner. Innovative inter-organizational concepts such as Vendor Managed Inventory emerge from these developments. In consequence, this requires management to transform and coordinate a company's business model with and align its operations to its partner while securing autonomy. Likewise, changes to internal business processes may be necessary, including the development of relationship coordination mechanisms, leading to management costs. In addition, since efforts to develop the business relationship must go hand in hand with interpersonal relationship actions, management should also consider the harmonization of e.g. personal interests, expertise and chemistry. 
The results of the study should encourage future researchers to examine the consequences for organizational management in terms of resources and capabilities due to the strategic multiplexity of organizations, e.g. by increasing insight in the practice of multi-stakeholder management. Following this line of thought, this calls for research on structures and mechanisms organizations possess to govern the relationship processes. Such an approach represents micro-RBV theorizing, complementing RBV (Foss, 1997).

\section{Process}

$R Q$ 2: How can content be inserted into a process view on business network innovation, without losing the power of a strong process philosophy, and how can such an effort enable research in a methodological sense?

The second study reflects on business network innovation. The development of innovative relationships brings a diversity of new management challenges, like how to organize the set-up and manage processes for generating innovation, and how to qualify successful performance (Perkmann, 2011). The existing literature has mainly focussed on understanding strategic motives of organizations to collaborate and pursue innovation, as well as on required management skills (Fleming, 2007), network capability (Vesalainen and Hakala, 2014) and interorganizational coordination mechanisms (Faems et al., 2005; Gurcayiliar-Yenidogan, 2014). These studies have contributed to the recognition of the relationship as a distinct form of governance (Moretti, 2016), in which innovation is the process or product of the successful exchange of knowledge (Pittaway et al., 2004). The emerging tradition of a strong view on value creation and innovation offers a solid platform for researching innovation, yet studies following this view have hardly explored the content dimension (themes and topics) where the coexploration is about. In addition, when academics study the process of innovation, their models tend to be conceptual, lacking empirical evidence of their applicability and practical relevance (Hobday, 2005). As such, although it is highly relevant to understand how cooperative - and at the same time competitive - relationships evolve, it is essential to incorporate a perspective on the evolution of the content of work and value creation. That is, it is important to understand during the development of the business relationship, how employees' interests, values, ideas, and (the structure of) operational activities change (or could be changed), such that they propel the organizations forward around pre-established important content themes and topics, and lead to the creation of new ideas on the network-level (Vaara and Whittington, 2012). By means of a review of the literature on (inter)organizational innovation, we have refined the understanding of 
business content within process-based research on network innovation. Successively, we discussed different research philosophies for approaching the process and content dimension of network innovation as objects of study. Building on a strong process perspective, we introduce pragmatism and encapsulation to develop a method for studying business network innovation. Related to that, the findings call for action on researchers to descend from studying the development of the IOR formation process towards incorporating a view on the development of the business content to contribute to the advancement of the innovation process and content development.

$R Q$ 3: What are the implications of the dynamic process of inter-organizational value creation for inter-organizational performance management?

Elaborating on the operational readiness and changing organizational capabilities and interests of partners, the third study explores by means of a literature review the dynamics of interorganizational relationships performance management. While existing multidisciplinary studies describe the strategic motive for alliancing, alliance development phases, and related challenges to overcome, insight is missing in the evolution of inter-organizational performance and the management dynamic that goes with it. Based on a developmental perspective on both interorganizational relationship management, value creation, and dynamic coordination theory we have elaborated a developmental view on inter-organizational performance management. Since the development of the inter-organizational relationship consists of alternating episodes of interorganizational differentiation and integration, i.e. concerning the forces of organizational change, business partners either grow closer or apart, performance management responses evolve in conjunction with this dynamic process. Response actions taken can either stimulate, attenuate, or counteract existing demerging or coalescent forces. This constitutes an inter-episode transition influencing the further development of the relationship.

The study contributes to the development of a theory on inter-organizational performance management by taking a combined perspective on strategic-economic theory, organization theory, supply chain theory, marketing theory, and performance management theory. Thereby the study explains the dynamics of managing process episodes of inter-organizational differentiation and integration. The results contribute to an improved insight into the dynamic evolution of inter-organizational relationships and performance management. They furthermore increase awareness of the management opportunities for change during inter-episodes of the collective development process, interesting for future research to explore. 
$R Q$ 4: What role do partners' values play in ensuring participating organizations' individual and collective success?

The fourth study explores at the inter-organizational level the role of partners' stakeholder values in alliance performance. By means of case study research we examined whether an organization's values were similar or contradictory to the potential alliance partner's values. We have developed an alliance value map to explore the value drivers behind the shared objectives. The results show some conflict and tensions between inter-organizational performance drivers (manifesting in e.g. trust issues between partners), due to contradictory instrumental and terminal values of the potential partners. This challenges organizations to pay attention to the alignment of conflicting stakeholder values, as their interrelationship influences joint action. In addition, as intra-organizational values keep evolving (e.g. to meet new challenges), it seems useful for partners to continuously monitor alliance coherence and redefine their 'common playground'. As such, alliance managers need to include an inter-organizational stakeholder view and take their values into account.

The findings add a value perspective to existing knowledge on the importance of interorganizational coordination, and suggest potential for future research to explore how these stakeholder values can be changed in favor of joint operations. In addition, research might explore whether values' shift can be used as an alliance performance indicator.

$R Q$ 5: Which factors are likely to affect differences between narratives of the alliance and its participants? And how does this influence interorganizational performance?

The fifth study contributes to existing research on stakeholder values and meaning, by exploring the relationship between strategic narratives of the organization and those of the alliance. Strategic narratives are constructs of reality, made by employees through their thinking and making sense of (organizational) actions. Narratives influence the motivation for organizational change and course of action (Starkey and Crane, 2003). This study explores the organizational practice of implementing an alliance strategy as a strategic reorientation, along with the formation of an alliance. Adopting a narrative lens, we investigated how an organization relates to its alliance.

The study focuses on both the organization and the alliance as strategizing phenomena, and explores value, capability and social tensions between the two, influencing business stability and change in parallel with joint growth and development. The result of the qualitative case study suggests that there is a contradiction between organizational narratives indicating different 
levels of relationship trust, and alliance narratives expressing a high level of group cohesion. In addition, the capability narratives indicate tension concerning the shortage of engineers, geographical work location, and business structure. Moreover, the results suggest an interdependence between organizational and alliance value creation, in which case the alliance may - over time - run counter to the interests of some of the participating organization's stakeholders. As such, future research might explore how to influence strategic narratives in favour of their relationship.

\section{Requirements}

$R Q$ 6: Which intra-organizational management practice should be developed in conjunction to organizational learning to enhance alliance capability?

Under the concept of alliance capability, existing studies stress the importance of an organization's learning capability (Anand and Khanna, 2000; Draulans et al., 2003; Kale and Singh, 2009; Zollo and Winter, 2002). However, little is known about how learning capability is converted into a better way of working. In addition, since an organizational capability usually acts as a co-specialized element in the organizational system (Vesalainen and Hakala, 2014), we concluded that alliance capability not only depends on the organizational learning capability. Instead, based on a literature review, the study argues that developing successful alliance management requires leveraging organizational learning for changing management practice. As such, we wondered which practice should be developed in conjunction to organizational learning, hence a case study was conducted to investigate this question. We developed a model for diagnosing an organization's alliance capability, which was subsequently used for data analysis. The results indicated that in addition to learning capability, three other interacting capabilities facilitate the development of alliance management practices and consequently performance outcomes. These three capabilities are: 'the development of alliance management skills', an effective information infrastructure', and 'adequate strategic decision-making'. 'The development of alliance management skills' depends among other things on empowered managers, alliance education and training in practice, and poses a restriction on the rotation system for personnel (common in large commercial and military organizations) for further development of alliance management competencies. An 'effective information infrastructure' depends on the willingness to register, share, and interpret data, the skill to adequately develop and use a business information system for this purpose, and a practice in which such activities are rewarded. 'Adequate strategic decision-making' relies on managers' analytical and problem 
solving capability, sufficient information and knowledge of the organizational system's functionality and interest, and an appropriate decision-making structure. Lastly, two improvement trajectories were found to be used simultaneously in favour of developing the four capabilities. One includes a directive top-down imposed method, while the other involves a bottom-up approach for sustainable development of alliance capability.

The sixth study increases the understanding of the role of an organization's introspection within the alliance formation process. The study complements research on externally oriented management techniques (Draulans et al., 2003) as well as alliance capability including learning process (Kale et al., 2002; Kale and Singh, 2007), by revealing more far-reaching internal implications of alliance formations (referring to necessary change capabilities and trajectories). The results thereby suggest that future research should consider alliance management as a functionality embedded within the organization to bring about organizational change.

$R Q$ 7: How is integrated risk management carried out with regard to alliance projects? And which governance principles should be incorporated to improve management effectiveness?

Regarding the management of IOR performance risks, it is observed that in general organizations struggle to manage a diversity of risks involved, with some projects being more successful than others. With the aim to increase understanding of project performance differences and the practice of risk management, the seventh study identified that in the case of public-private service partnerships, a number of common risks occur during formation. In order of priority these risks include: (1) insufficient representation of qualified employees to determine the partnership objectives, which potentially concerns leadership because of a lack of strategic directives and mandate, a lack of necessary management skills, and the occurance of interpersonal conflicts; (2) the absence of a shared performance system including collaborativebased performance matrices to determine and evaluate performance. It includes a common set of measures to monitor performance, to track progress towards outcomes, and to learn what is and is not working in the group's collective approach (Graham, 2016). Employees responsible for formation fail to grasp its significance or lack performance data; (3) partners do not assign responsibilities and decision-making authority with respect to partnership processes within their organization. As such, there is absence of an alliance hierarchy structure with authority and decision-making ability to coordinate and align actions between partners. The problem can arise due to partners' lack of knowledge of the specific tasks that need to be carried out, or due to lack of a clear hierarchy structure within partners' own organization. Consequently, the cooperation 
has difficulties in achieving the alliance goals, or operates in an inefficient manner; (4) impractical or inappropriate partnership agreement during the last formation event. Impractical implies that there are issues concerning the fair distribution of liability and accountability, and equal distribution of profits and expenses between public and private partners. Inappropriate refers to business ethics and integrity practices by which the organizations perform with respect of interested parties which are not in compliance with internal procedures and (international) legislation. As a result, undesirable organizational behaviour is not pre-secured interfering alliance operations; (5) the moment at which the partnership initiative is launched, influencing management's capability and intent to manage the project. If there are too many other business issues with higher priority, there is little involvement and participation of managers to develop the strategic plan for cooperation. In addition, fleet owners become vendor locked-in when they make a service proposal after system acquisition instead of before. Hence they may become dependent on the strategic interest of the OEM since they are unable to switch to another vendor without major costs and efforts; (6) inadequate sharing of information between employees of both organizations, which should be controlled before the partnership becomes operational to enable joint operations. There are a number of potential behavioural causes referring to employees' misunderstanding or their inability to transfer relevant information; (7) inadequate project planning, consultation meetings and consultation structures between partners. This risk implies problems with respect to effective and efficient control of the progress of formation. It manifests within the partnership board and project workgroups. Further data analysis suggests that most of the risks concern Project Governance and Project Management responsibilities. In addition, there seems to be an interrelationship between risks considering their underlying factors and the formation events to which they refer. Cross-case analysis identified that risk awareness differed between cases. Morover, the difference between the two cases with respect to senior management involvement and committment, seems to play an important role in their outcome dissimilarity.

The seventh study contributes to emerging research on how governance capability influences the development of alliances. More precisely, the results of the study show that alliance projects, although exposed to similar risk factors, differ in terms of risk management effectiveness. It becomes clear that this is ostensibly caused by not consciously and proactively dealing with risks at an early stage and in a structured way. Instead, risks and control measures are inventoried and applied in an arbitrary manner. Timely and structural riskanalysis and continuous attention to riskmanagement by (top) management, can help the decision making concerning the feasibility of allianceformation.Drawing on the study findings, a framework for the risk management of PPP formation projects has been developed. The framework can be used 
by both researchers and practitioners, to consider formation events requiring sound management and coverage of their risks.

RQ 8: How do PPPs organize their data governance and what improvements are necessary?

Inter-organizational ambitions include excelling in data governance (Van Broek and Van Veenstra, 2015). There is a need for a comprehensive understanding of what it takes to govern inter-organizational data sharing (Ladley, 2012). The eight study investigates from a process perspective the ability of organizations to implement inter-organizational data governance to adress key challenges. It focuses on management activities affecting an organization's ability to develop and implement inter-organizational data governance, since studies on interorganizational data governance have been criticized for not clarifying the content and process with which it is implemented. Based upon existing literature and the case study, a conceptual integrative framework is developed with key activities for implementing inter-organizational data governance. It shows that the ability to implement data governance exists of employing a complex variety of management actions concerning information maturity, collaboration, and organizational change, throughout a staged process of development and implementation phases. The developed integrative framework offers a promising insight into the phases and content of implementing inter-organizational data governance. It indicates and differentiates various activities related to the ability of organizations to develop and implement interorganizational data governance. The development of this integrative framework builds upon previous research on data governance and business partnerships, as it categorizes the complex diversity of governance aspects to be considered when initiating data sharing partnerships, and delineates definable processes that are therefore relevant.

\subsection{CONTRIBUTION OF RESULTS TO RESEARCH OBJECTIVES}

In order to improve understanding of the interwinement of organizational and inter-organizational performance management, and to improve organizational development aimed at enabling the formation of alliances, the overall goal of this dissertation is to explore contextual characteristics underlying alliance strategy formulation that will drive the development of the relationship, as well as organizational functional requirements with respect to transformation and development of alliance management. Our aim was to provide insight in the intertwinement of organizational and inter-organizational performance management in relation to alliancing. 
The research studies provide valuable insights in the strategic motivations, employees logics, and governance capabilities that underpin successful alliance formation management. Table 2 provides an overview of the contribution of the eight research studies to the first research objective by means of developing propositions, and the second research objective in a practical manner. 
Table 2. Contribution of the studies to dissertation objectives.

\begin{tabular}{|c|c|c|}
\hline $\begin{array}{l}\text { Research } \\
\text { Study } \\
\text { (RS) }\end{array}$ & $\begin{array}{l}\text { Research Objective } 1: \\
\text { Develop IOR theory concerning the } \\
\text { intertwinement between intra- } \\
\text { organizational and inter-organizational } \\
\text { performance management. }\end{array}$ & $\begin{array}{l}\text { Research Objective 2: } \\
\text { Identify a set of principles for organizational } \\
\text { development aimed at the evolution of alliances. }\end{array}$ \\
\hline 1 & $\begin{array}{l}\text { Proposition 1: With regard to the intent of } \\
\text { organizations to develop service alliances, } \\
\text { environmental factors are a double-edged } \\
\text { sword as they affect both partner's } \\
\text { cooperation motivation and management } \\
\text { ability. }\end{array}$ & $\begin{array}{l}\text { Organizations require transformation of their business } \\
\text { model and alignment of their operations with their } \\
\text { partner to develop a cooperative way of working. } \\
\text { Consequently, organizations need to: } \\
\text { - } \quad \text { assign responsibilities for workflow redesign; } \\
\text { implement interventions for process change } \\
\text { and development; } \\
\text { develop inter-organizational governance } \\
\text { mechanisms and a social structure to } \\
\text { coordinate relationship activities and control } \\
\text { performance. }\end{array}$ \\
\hline 2 & $\begin{array}{l}\text { Proposition 2: To support business network } \\
\text { innovation, a strong process perspective on } \\
\text { developing the collaborative process } \\
\text { requires embedding a content centric view } \\
\text { to understand innovation pertaining to } \\
\text { strategic intent and value transformation. }\end{array}$ & $\begin{array}{l}\text { To fuel network innovation, organizational researchers } \\
\text { and developers need to insert content into a strong } \\
\text { process view; they need to follow steps originating in } \\
\text { pragmatism to develop solutions for 'felt difficulties'. }\end{array}$ \\
\hline 3 & $\begin{array}{l}\text { Proposition 3: The process of inter- } \\
\text { organizational value creation is erratic and } \\
\text { as such its management is dynamic. }\end{array}$ & $\begin{array}{l}\text { Organizations must be aware and alert to take } \\
\text { advantages of partnership demerging or coalescing } \\
\text { forces from the organization. }\end{array}$ \\
\hline 4 & $\begin{array}{l}\text { Proposition 4: The interrelationship between } \\
\text { alliance stakeholders' values impacts } \\
\text { collective performance. }\end{array}$ & $\begin{array}{cl}\text { Organizations need to: } \\
\qquad \quad \text { apply an inter-organizational stakeholder } \\
\text { view; and, } \\
\text { continuously monitor and align } \\
\text { instrumental and terminal values of } \\
\text { partnering organizations. }\end{array}$ \\
\hline 5 & $\begin{array}{l}\text { Proposition 5: Alliance performance is } \\
\text { subject to congruence between } \\
\text { organizational and alliance narratives. }\end{array}$ & $\begin{array}{l}\text { Organizations need to consider and address elements } \\
\text { of tension between their value, capability, and social } \\
\text { narrartives and those pertaining to the alliance. }\end{array}$ \\
\hline 6 & $\begin{array}{l}\text { Proposition 6: Alliance management } \\
\text { concerns not only a cross-organization } \\
\text { coordination process, but also a process } \\
\text { that needs to be strongly embedded within } \\
\text { the organization. Moreover, intra-firm } \\
\text { antecedents related to organizational } \\
\text { change capability faciltate the translation of } \\
\text { alliance experience into better alliance } \\
\text { management performance. }\end{array}$ & $\begin{array}{l}\text { To improve their alliance capability, organizations } \\
\text { should develop their alliance management skills, the } \\
\text { effectiveness of their information infrastructure, and the } \\
\text { adequacy of strategic decision-making, which are } \\
\text { necessary to convert their learning capability into an } \\
\text { improved way of working. }\end{array}$ \\
\hline 7 & $\begin{array}{l}\text { Proposition 7: The succes of alliance } \\
\text { formation projects is subject to timely and } \\
\text { structural risk analysis and continuous } \\
\text { attention to riskmanagement by (top) } \\
\text { management. }\end{array}$ & $\begin{array}{l}\text { Organizations need to integrate strategic risk } \\
\text { management within their process of (alliance) strategic } \\
\text { planning. }\end{array}$ \\
\hline 8 & $\begin{array}{l}\text { Proposition 8: The ability of organizations to } \\
\text { implement inter-organizational data } \\
\text { governance exists of employing a complex } \\
\text { variety of management actions concerning } \\
\text { information maturity, collaboration, and } \\
\text { organizational change, throughout a staged } \\
\text { process of development and implementation } \\
\text { phases. }\end{array}$ & $\begin{array}{l}\text { Organizations should assess and when necessary make } \\
\text { developmental efforts to their information management } \\
\text { maturity, collaborative readiness, and organizational } \\
\text { change capacity, prior to initiating a data sharing } \\
\text { partnership. }\end{array}$ \\
\hline
\end{tabular}




\subsection{IMPLICATIONS FOR RESEARCH}

This dissertation has three main implications for research: (1) it provides an integrated perspective on alliance management by examining organizational conditions and their effect on inter-organizational performance; (2) the findings build on and allow researchers to relate different strategic management perspectives in the context of alliance formation, including innovation management, supply chain management, organizational design and change management, data governance, risk management, and strategic narratives. This offers the beginning of a more coherent and richer approach to alliance performance management; (3) the thesis combines and interrelates different inter-organizational research streams.

Combining different theoretical paradigms and strategic management perspectives as a theoretical lens, enabled to derive coherent insights into a variety of intra-organizational conditions that affect inter-organizational level performance. Drawing on these findings, a conceptual model of alliance performance management is developed. It represents and relates different management perspectives and associated organizational conditions impacting alliance performance management (see Figure 1).

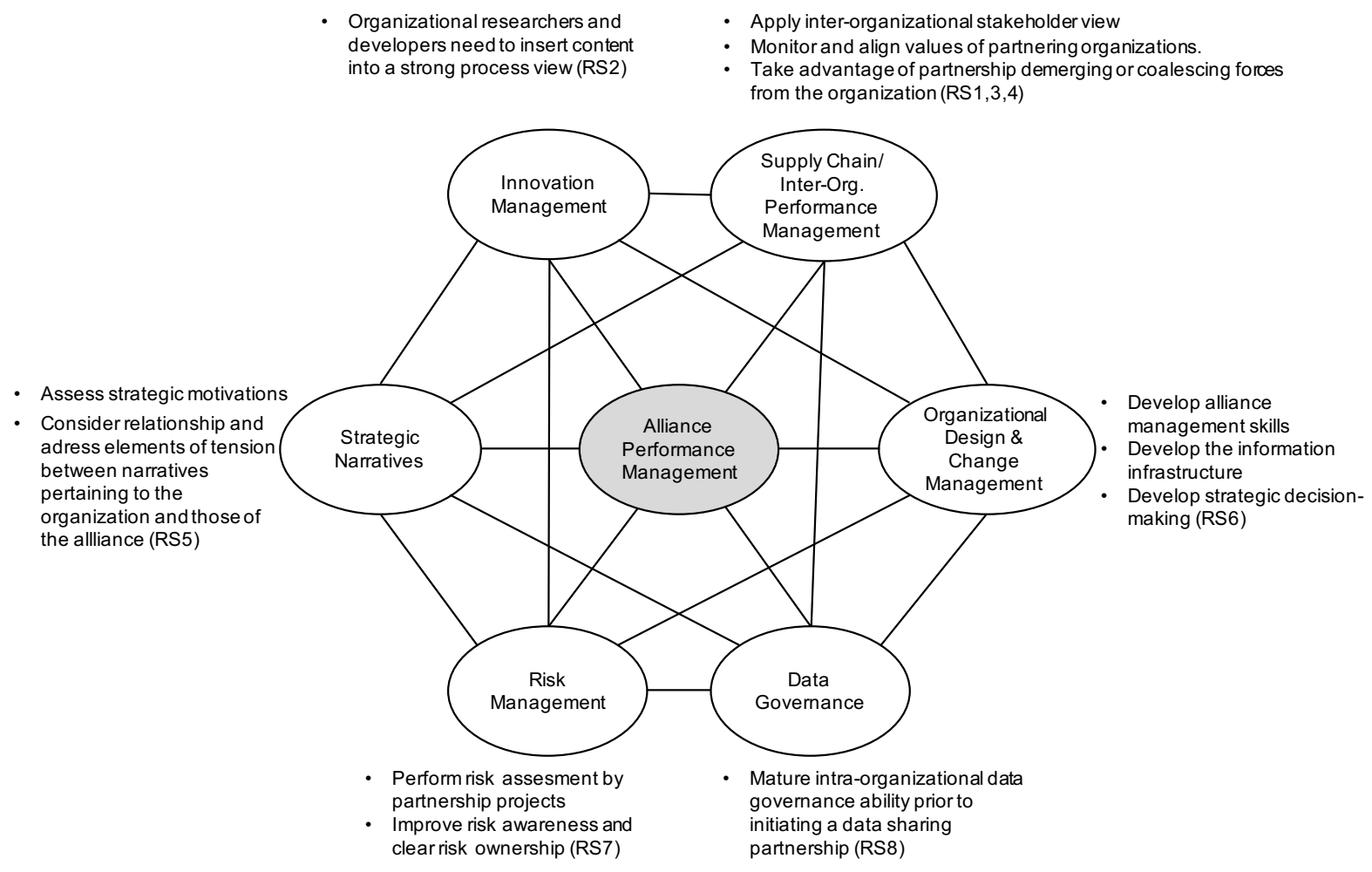

Figure 1. Conceptual model of alliance management and organizational conditions 
Elaborating on the study results, we argue that in order to manage performance of intensified inter-organizational cooperation, organizations need to make investments in development of their own organization to create the preconditions for alliance strategy implementation.This demands a 'readiness for inter-organizational cooperation' approach, as opposed to a (formalized and generic) strategic planning method (Ansoff, 1965) or a 'let's just do it' approach (based on merely formulating an open-ended strategy (Abdallah and Langley, 2013) and relying on gradually emerging experience) as according to our results some apply in reality. A 'readiness for inter-organizational cooperation' approach sits inbetween both. It entails semistructured strategic vision and boundaries, proactive interorganizational project management with room to act and strategic commitment, intraorganizational development, and frequent evaluation of macro, meso, and micro factors affecting the effective realization of the alliance strategy (Akaka et al., 2013). The latter enables forecasting the performance impact of factors and presumes the necessary organizational ability to control them. But also, the real time nature of alliance management is acknowledged, by incorporating flexibity within strategic alliance management to adapt to changing conditions and unexpected events. Hence, alliance capability should be seen as a stream of economic and social development activities within a dynamic process by which alliance performance is realized. In this way, the thesis contributes to a better understanding of the phenonemon alliance capability. Moreover, the results contribute to the inter-organizational relationship management literature through a combination of a structured literature analysis and case study findings. While this literature tends to focus on communication, learning and control, the thesis acknowledges the importance of organizational strategy and developing organizations' internal processes to reflect their readiness for alliance formation.

\subsection{IMPLICATIONS FOR PRACTICE}

Practitioners can use the dissertation findings to (1) create awareness and a better understanding of the various intra-organizational conditions affecting inter-organizational performance, and (2) apply the suggested principles for organizational development aimed at the evolution of alliances. More specifically, they can do so by assessing the correctness of strategic motivations underlying an alliance initiative. These motivations drive business transformation and inter-organizational coordination efforts in pursue of cooperation success. In this respect, management should also take into account the relationship between multiple employee narratives, intra-organizational as well as inter-organizational, in terms of managing 
tensions and creating balance between the logics underlying actions for sustained business development.

In addition, the findings suggest that prior to launching an alliance, management should conduct a thorough assessment of the organizational readiness in terms of their management capability to identify and pursue relationship opportunities, establish a sound business plan, develop wellfunctioning inter-organizational processes (e.g. for information and cost sharing), develop a supportive collaborative/open culture, cover associated project risks, and institutionalize collaborative know-how and experience. Moreover, management should be able to recognize the value of and respond to episodes of inter-organizational differentiation and integration, as the process of inter-organizational value creation is in fact erratic and as such requires dynamic management. Along with this capability, organizations should be able to perform interorganizational stakeholder management and develop a set of capabilities for a mature data governance organization. The strategy map, organizational design models, and data governance framework developed within this dissertation may prove useful to shape the innovation process.

\subsection{LIMITATIONS}

Alliances are highly contextual they may be subject to different internal and external factors, and as such vary in performance. In order to get a better understanding of alliance performance, each alliance was considered a unique case in which alliance management of the participating organizations was explored by qualitative research. An issue with the applied research method that deserves attention is the known limitation of generalizability in qualitative research (Yin, 2015). Since each of five empirical studies had an exploratory nature aimed to enhance understanding of organizational conditions for successful alliance strategy implementation, more empirical research is needed to draw generalizable managerial lessons from it and develop theory.

Second, in dealing with conditions for alliance formation, this dissertation suggests that internal aspects are relevant, but so are externalities. Regional factors and density of ties within networks for example have been found to influence the performance of the inter-organizational system (Gilsing et al., 2008), which is a topic beyond the scope of this dissertation. Lastly, most assessments reported in this dissertation are performed by means of interviews, workshops, surveys and observations. As such, proposed performance improvements are not thoroughly validated. To actually contribute to the development of alliance performance, we 
stress the importance of applying more action research, so that real-life problems can be worked with by interventions. It will not only increase science's opportunity to validate findings, but also enhance the appeal of alliance research to business managers, and improve triple helix innovation. Several other researchers have proposed action research as an appropriate methodology for integrating science and business to improve innovation (Andriessen, 2007; Cagliano et al., 2005). Yet, few researchers have reported work actually drawing on action research (Cropper et al., 2008). Based on our experiences we conjecture this lack of action research persists because changes are required for a cooperative research process consisting of multiple levels of social interactions between the business, academic, and government parties involved. Insights in (how to innovate) the action research process for developing alliances are so far underdeveloped in the literature (Crossan and Apaydin, 2010), providing an opportunity for future research.

\subsection{FUTURE RESEARCH}

The aim of this dissertation was to explore the organizational conditions (including actions, resources and capabilities, and their underlying motivations and logic) for successful alliance strategy implementation. In particular, we wanted to explore how organizational conditions affect alliance performance, with emphasis on what is needed in terms of organizational transformation. It is striking that in general there is no lack of management interest and delegation in alliance projects, since the alliance value-creation potential seems commonly understood. Nevertheless, analysis of our findings shows first of all, a lack of organizational readiness in terms of organizational intertwined - rather than centralized within a business function (as often suggested) - alliance management capability, refering to allocation specific resources and management knowledge, activating (information) processes and organizing decision-making activities (e.g. deciding upon alliance management mandate). Next to this, we experience some reticence in relation to developing alliance capability concerning the pre-investements and efforts required for this purpose. This may manifest in among other things the lack of a genuine policy for alliance capability development, lack of partnership development directives, and hence also their lack of implementation. In addition, a management approach applied was expressed as "Let's just launch the collaboration and learn what works and what does not". We argue that such an approach grants organization members room to experiment yet it runs the risk of disregarding the decision-making process intended to establish successful alliance, leading to increased business risks and potential legal uncertainties (Berglund and Thompson, 2015). We believe that it takes management notification 
and acceptance of the necessity to pre-invest in developing alliance capability because, as our findings suggest, the functioning of the collaborative value system requires specific management actions in advance of alliance strategy implementation and achievement of collaborative value. On the other hand, there is also an internal problem of enacting a multiplicity of strategic goals/stakeholder values, which makes it difficult to justify alliance investments while there is absence of a clear profit forecast. As such, it is important to consider that decisions regarding alliance investments are not only influenced externally by thoughts on how the partner will behave, but also internally by pluralistic organizational tensions (Jarzabkowski and Fenton, 2006). In this respect, another management issue concerns the persuading stakeholders with a negative attitude and perception (e.g. for employee commitment and tailored policy) (Hamel and Prahalad, 2005). As such, alliance management competencies such as value judgement and persuasiveness may be highly important concerning the content and process of alliance decision-making. In this respect, we encounter the field of cognitive science (Schein, 1985). We propose that alliance management and with that inter-organizational performance can be scrutinized in future studies, especially from the viewpoints of cognition. We believe it is important for future alliance management research to proceed to this micro/individual performance level - which we only touched upon - for example by studying the alignment of 'categories of thought' between the people for the achievement of multiple strategic goals, joint objectives, and trust (Jarzabkowski and Sillince, 2007, Nooteboom, 1999). For example, it may be interesting to study how (e.g. by selection or socialization) the interrelationship between organizational and alliance narratives can be improved. The difference in interests and cognitive distance between managers within an organization and of partnering organizations, the practice of mental alignment and influencing narratives, and the effect of such an achievement on alliance performance may generate new scientific insights. 
248 
Aaltio-Marjosola, I. (1994). From a "Grand Story" to Multiple Narratives? Studying an Organizational Change Project. Journal of Organizational Change Management, 7(5), 5667.

Aarikka-Stenroos, L., Jaakola, E. (2012). Value Co-creation in Knowledge Intensive Business Services: A Dyadic Perspective on the Joint Problem Solving Process. Industrial Marketing Management, 41(1), 15-26.

Abdallah. C., Langley, A. (2013). The Double Edge of Ambiguity in Strategic Planning. Journal of Management Studies, 51(2), 235-264.

Abednego, M.P., Ogunlana, S.O. (2006). Good Project Governance for Proper Risk Allocation in Public-Private Paternerships in Indonesia. International Journal of Project Management, 24(70, 622-634.

Abrahamsen, M.H., Henneberg, S.C., Huemer, L., Naude, P. (2016). Network Picturing: An Action Research Study of Strategizing in Business Networks. Industrial Marketing Management, In Press.

Adkins, C.L., Ravlin, E.C., Meglino, B.M. (1996). Value Congruence Between Coworkers and its Relationship to Outcomes. Group and Organization Management, 21(4), 439-462.

Agarwal, R., Selen, W. (2009). Dynamic Capability Building in Service Value Networks for Achieving Service Innovation. Decision Sciences, 40(3), 431-475.

Agterberg, M., Van den Hooff, B., Huysman, M., Soekijad, M. (2010). Keeping the Wheels Turning: The Dynamics of Managing Networks of Practice. Journal of Management Studies, 47(1), 85-108.

Ahuja, G. (2000). The Duality of Collaboration: Inducements and Opportunities in the Formation of Interfirm Linkages. Strategic Management Journal, 21(3), 317-343.

Ainsworth, D., Feyerherm, A.E. (2016). Higher Order Change: A Transorganizational System Diagnostic Model. Journal of Organizational Change, 29(5), 769-781.

Akaka, M.A., Vargo, S.L., Lusch, R. (2013). The Complexity of Context: A Service Ecosystems Approach for International Marketing. Journal of International Marketing 21(4), 1-20.

Akintoye, A., Beck, W., Hardcastle, C. (2008). Public-Private Partnerships: Managing Risks and Opportunities. Hoboken: Wiley-Blackwell.

Albert, S., Whetten, D.A. (1985). Organizational Identity. In L. L. Cummings and B. M. Staw (Eds.), Research in Organizational Behavior (Vol. 7, 263-295). Greenwich: JAI Press.

Allen D. (1997). The Nursing-Medical Boundary: A Negotiated Order? Sociology of Health and IIIness, 19(4), 498-520.

Almeida, P. (1996). Knowledge Sourcing by Foreign Multinationals: Patent Citation Analysis in the U.S. Semiconductor Industry. Strategic Management Journal, 17(Winter), 155-165.

Alshboul, Y., Wang, Y., Nepali, R. (2015). Big Data LifeCycle: Threats and Security Model. Paper presented at the Americas Conference on Information Systems, Puerto Rico.

Alvarez, R., Urla, J. (2002). Tell Me a Good Story: Using Narrative Analysis to Examine Information Requirements Interviews during an ERP Implementation. ACM SIGMIS Database, 33(1), 38-52.

Alvesson, M. (1998). The Business Concept as a Symbol. International Studies of Management \& Organization, 28(3), 86-108.

Amit, R., Zott, C. (2001). Value Creation in E-business. Strategic Management Journal, 22(6/7), 493-520.

Anand, B.N., Khanna, T. (2000). Do Firms Learn to Create Value? The Case of Alliances. Strategic Management Journal, 21(3), 295-315.

Ancona, D.G., Bresman, H. (2007). X-teams: How to Build Teams That Lead, Innovate and Succeed. Boston, MA: Harvard Business School Press.

Andersen, P.H., Medlin, C.J. (2016). Transient Commitments and Dynamic Business Networking. Industrial Marketing Management, 58, 11-19. 
Anderson, E., Weitz, B. (1992). The Use of Pledges to Build and Sustain Commitment in Distribution Channels. Journal of Marketing Research, 29(1), 18-34.

Anderson, J.C. (1995). Relationships in Business Markets: Exchange Episodes, Value Creation, and Their Emperical Assessment. Journal of the Academy of Marketing Science, 23(4), 346-350.

Anderson, J.C., Håkansson, H., Johanson, J. (1994). Dyadic Business Relationships within a Business Network Context. Journal of Marketing, 58(4), 1-15.

Anderson, J.C., Narus, J.A. (1990). A Model of Distributor Firm and Manufacturer Firm Working Partnerships. Journal of Marketing, 54(1), 42-58.

Anderson, P.S. (2001). Market, Hierarchy, and Trust: the Knowledge Economy and the Future of Capitalism. Organization Science, 12(2), 215-234.

Anderson, S.W., Christ, M.H., Dekker, H.C., Sedatole, K.L. (2015). Do Extant Management Control Frameworks Fit the Alliance Setting? A Descriptive Analysis. Industrial Marketing Management, 46, 36-53.

Andersson, A. (2015). Communication Barriers in an Interorganizational ERP-Project. International Journal of Managing Projects in Business, 9(1), 214-232.

Andersson, U., Gaur, A., Mudambi, R., Persson, M. (2015). Unpacking Interunit Knowledge Transfer in Multinational Enterprises. Global Strategy Journal, 5(3), 241-255.

Andreeva, T., Ritala, P. (2016). What are the Sources of Capability Dynamism? Baltic Journal of Management, 11(3), 238-259.

Andriessen, D. (2007). Combing Design-Based Research and Action Research to Test Management Solutions. Paper presented at the 7th World Congress Action Learning, Action Research and Process Management, Groningen.

Ansari, S., Reinecke, J., Spaan, A. (2014). How are Practices Made to Vary? Managing Practice Adaptation in a Multinational Corporation. Organization Studies, 35(9), 1313-1341.

Ansoff, H.I. (1965). Corporate Strategy. New York: McGraw Hill.

Argote, L. (2013). Organizational Learning: Creating, Retaining and Transferring Knowledge. New York: Springer.

Arino, A., De la Torre, J., Ring, P.S. (2001). Relational Quality: Managing Trust in Corporate Alliances. California Management Review, 44(1), 109-131.

Armbrecht Jr., F.M.R., Chapas, R.B., Chappelow, C.C., Farris, G.F., Friga, P.N., Hartz, C.A., Whitwell, G.E. (2001). Knowledge Management in Research and Development. ResearchTechnology Management, 44(4), 28-48.

Arya, B., Lin, Z. (2007). Understanding Collaboration Outcomes From an Extended ResourceBased View Perspective: The Roles of Organizational Characteristics, Partner Attributes, and Network Structures. Journal of Management, 33(5), 697-723.

Arya, D. (2011). Shared Services Arrangement in a Decentralising Healthcare Environment Will it Work? Australian Health Review, 35(3), 290-293.

Ashby, W.R. (1968). Variety, Constraint, and the Law of Requisite Variety. In W. Buckley (Ed.), Modern Systems Research for the Behavioral Scientist. Hawthorne, NY: Adline de Gruyter.

Aspara, J., Lamberg, J.-A., Laukia, A., Tikkanen, H. (2013). Corporate Business Model Transformation and Inter-Organizational Cognition: The Case of Nokia. Long Range Planning, 46(6), 459-474.

Austin, J.E., Seitanidi, M.M. (2012). Collaborative Value Creation: A Review of Partnering Between Nonprofits and Businesses. Part 2: Partnership Processes and Outcomes. Nonprofit and Voluntary Sector Quarterly, 41(5), 929-968.

Avery, D.R., Thomas, K.M. (2004). Blending Content and Contact: The Roles of Diversity Curriculum and Campus Heterogeneity in Fostering Diversity Management Competency. Academy of Management Learning \& Education, 3(4), 380-396.

Bacharach, S.B. (1989). Organizational Theories: Some Criteria for Evaluation. Academy of Management Review, 14(4), 496-515. 
Bacharach, S.B., Bamberger, P., Sonnenstuhl, W. (1996). The Organizational Transformation Process: The Micropolitics of Dissonance Reduction and the Alignment of Logics of Action. Administrative Science Quarterly, 41(3), 477-506.

Baden-Fuller, C., Mangematin, V. (2015). Introduction: Business Models and Modelling Business Models. In C. Baden-Fuller and V. Mangematin (Eds.), Business Models and Modelling (Advances in Strategic Management, Volume 33) (pp. xi-xxii). Bingley, United Kingdom: Emerald.

Baden-Fuller, C., Morgan, M.S. (2010). Business Models as Models. Long Range Planning, 43(2-3), 156-171.

Bakker, S., Van Lente, H., Meeus, M. (2011). Arenas of Expectations for Hydrogen Technologies. Technological Forecasting and Social Change, 78(1), 152-162.

Balcik, B., Beamon, B.M., Krejci, C., Muramatsu, K.M., Ramirez, M. (2010). Coordination in Humanitarian Relief Chains: Practices, Challenges and Opportunities. International Journal Production Economics, 126(1), 22-34.

Ballantyne, D., Frow, P., Varey, R.J., Payne, A. (2011). Value Propositions as Communication Practice: Taking a Wider View. Industrial Marketing Management, 40(2), 202-210.

Bamford, J.D., Gomes-Casseres, B., Robinson, M.S. (2003). Mastering Alliance Strategy: A Comprehensive Guide to Design, Management, and Organization. San Francisco: John Wiley \& Sons.

Bankvall, L., Dubois, A., Lind, F. (2017). Conceptualizing Business Models in Industrial Networks. Industrial Marketing Management, 60(1), 196-203.

Barley, S.R. (1986). Technology as an Occasion for Structuring: Evidence from Observations of CT Scanners and the Social Order of Radiology Departments. Administrative Science Quarterly, 31(1), 78-108.

Barley, S.R. (1990). The Alignment of Technology and Structure Through Roles and Networks. Administrative Science Quarterly, 35(1), 61-103.

Barley, S.R. (1998). On Technology, Time, and Social Order: Technically Induced Change in the Temporal Organization of Radiological Work. In: Dubinskas FA (ed) Making Time:

Ethnographies of High Technology Organizations. Philadelphia: Temple University Press.

Barlow, J., Bayer, S., Curry, R. (2006). Implementing Complex Innovations in Fluid MultiStakeholder Environments: Experiences of 'Telecare'. Technovation, 26(3), 396-406.

Barrett, M., Davidson, E., Prabhu, J., Vargo, S.L. (2015). Service Innovation in the Digital Age: Key Contributions and Future Directions. MIS Quarterly, 39(1), 135-154.

Barnett, W.P., Carroll, G.R. (1995). Modeling Internal Organizational Change. Annual Review of Sociology, 21, 217-236.

Barney, J. (1991). Firm Resources and Sustained Competitive Advantage. Journal of Management, 17(1), 99-120.

Barringer, B.R., Harrison, J.S. (2000). Walking a Tightrope: Creating Value Through Interorganizational Relationships. Journal of Management, 26(3), 367-403.

Basbøll, T. (2012). Legitimate Peripheral Irritations. Journal of Organizational Change Management, 25(2), 220-235.

Bastl, M., Mark, J., Lightfoot, H., Evans, S. (2012). Buyer-Supplier Relationships in a Servitized Environment: An Examination with Cannon and Perreault's Framework. International Journal of Operations \& Production Management, 32(6), 650-675.

Batt, P.J. (2004). Managing Collaboration within Networks and Relationships. Industrial Marketing Management, 33(3), 169-174.

Bauer, M.W., Gaskell, G. (2002). Biotechnology - the Making of a Global Controversy. Cambridge: Cambridge University Press.

Beal, D.J., Cohen, R.R., Burke, M.J., McLendon, C.L. (2003). Cohesion and Performance in Groups: A Meta-analytic Clarification of Construct Relations. Journal of Applied Psychology, 88(6), 989-1004.

Bauer, M.W., Gaskell, G. (2000). Qualitative Researching with Text, Image and Sound: A Practical Handbook for Social Research. Thousand Oaks, CA: Sage. 
Beamon, B.M., Balcik, B. (2008). Performance Measurement in Humanitarian Relief Chains. International Journal of Public Sector Management, 21(1), 4-25.

Bechky, B.A. (2003). Sharing Meaning Across Occupational Communities: The Transformation of Understanding on a Production Floor. Organization Science, 14(3), 312-330.

Bednarek, R., Paroutis, S., Sillince, J. (2016). Transcendence through Rhetorical Practices: Responding to Paradox in the Science Sector. Organization Studies, Preprint.

Beer, M., Nohria, N. (2000). Cracking the Code of Change. Harvard Business Review, 78(3), 133-141.

Bellamy, C., Raab, C. (2005). Joined-up Government and Privacy in the United Kingdom: Managing Tensions between Data Protection and Social Policy, Part II. Public Administration, 83(2), 393-415.

Bensaou, M. (1997). Interorganizational Cooperation: The Role of Information Technology. An Empirical Comparison of U.S. and Japanese Supplier Relations. Information Systems Research, 8(2), 107-124.

Benson, J.K. (1975). The Interorganizational Network as a Political Economy. Administrative Science Quarterly, 20(2), 229-249.

Berchicci, L. (2013). Towards an Open R\&S system: Internal R\&D Investment, External Knowledge Acquisition and Innovative Performance. Research Policy, 42(1), 117-127.

Berends, J.J., Van Burg, E., Van Raaij, E.M. (2011). Contacts and Contracts: Cross-Level Network Dynamics in the Development of an Aircraft Material. Organization Science, 22(4), 940-960.

Berg, J.N., Hamilton, R.T. (1998). Born to Fail? International Strategic Alliances Experiences of New Zealand Companies. Journal of International Business \& Entrepreneurship, 6(1-2), 63-76.

Berghöfer, A., Wittmer, H., Rauschmayer, F. (2008). Stakeholder Participation in Ecosystembased Approaches to Fisheries Management: A Synthesis from European Research Projects. Marine Policy, 32(2), 243-253.

Berglund, M., Thompson, D. (2015). Choosing Wisely: Increasing Alliance Value through Collaborative Decision-making. Strategic Alliance Management, Q3.

Besharov, M.A., Smith, W.K. (2014). Multiple Institutional Logics in Organizations: Explaining their Varied Nature and Implications. Academy of Management Review, 39(3), 364-381.

Bevir, M. (2013). A Very Short Introduction to Governance. Oxford: Oxford University Press.

Beynon, H. (1973). Working for Ford, London: Pelican.

Bharadwaj, A., El Sawy, O.A., Pavlou, P.A., Venkatraman, N. (2013). Digital Business Strategy: Toward a Next Generation of Insights. MIS Quarterly, 37(2), 471-482.

Bhaskaran, Sreekumar R., Krishnan, V. (2009). Effort, Revenue, and Cost Sharing Mechanisms for Collaborative New Product Development. Management Science, 55(7), 1152-1169.

Biesta, G.J.J. (2010). Why 'What Works' Still Won't Work: From Evidence-Based Education to Value-Based Education. Studies in Philosophy and Education, 29(5), 491-503.

Biemans, W.G. (1995). Developing a Medical Equipment Innovation within a Complex Network. In H. Håkansson, I. Snehota (Eds.), Developing Relationships in Business Networks. London: Routledge.

Bigley, G.A., Roberts, K.H. (2001). The Incident Command System: High Reliability Organizing for Complex and Volatile Task Environments. Academy of Management Journal, 44(6), 1281-1299.

Birkinshaw, J., Bouquet, C., Barsoux, J.L. (2011). Top 10 Lessons on the New Business of Innovation. Sloan Management Review(September), 28-34.

Birkinshaw, J., Crilly, D., Bouquet, C., Lee, S.Y. (2016). How Do Firms Manage Strategic Dualities? A Process Perspective. Academy of Management Discoveries, 2(1), 51-78.

Birkinshaw, J., Hamel, G., Mol, M.J. (2008). Management Innovation. Academy of Management Review, 33(4), 825-845.

Bititci, U., Garengo, P., Dörfler, V., Nudurupati, S. (2012). Performance Measurement: Challenges for Tomorrow. International Journal of Management Reviews, 14(3), 305-327. 
Bititci, U., Mendibil, K., Martinez, V., Albores, P. (2005). Measuring and Managing Performance in Extended Enterprises. International Journal of Operations \& Production Management, 25(4), 333-353.

Bitterer, A. (2007). Gartner's Data Quality Maturity Model. Stamford, CT: Gartner Inc.

Björk, K.-M., Collan, M., Kyläheiko, K. (2012). Evaluation of an Information Systems Investment into Reducing the Bullwhip Effect. Paper presented at the 17th International Symposium on Inventories, Budapest, Hungary.

Blaschke, S., Schoeneborn, D., Seidl, D. (2012). Organizations as Networks of Communication Episodes: Turning the Network Perspective Inside Out. Organization Studies, 33(7), 879906.

Bloch, H.P. (2013). Consider both Actual and Virtual Spare Parts Inventory. http://www.hydrocarbonprocessing.com, May 1, 2013(Available from http://www.hydrocarbonprocessing.com/Article/3198969/Consider-both-actual-and-virtualspare-parts-inventory.html?Articleld=3198969).

Bobbink, M.L., Hartmann, A. (2014). Extended Enterprise Performance Management: A Value Co-creation Perspective. Paper presented at the Performance Management: Designing the High-Performance Organization, Aarhus, Denmark.

Bobbink, M.L., Hartmann, A., Dewulf, G. (2016). Sustaining Extended Enterprise Performance: A Value Co-creation Perspective. Journal of Organization Design, 5(3).

Boersma, K., Wagenaar, P., Wolbers, J. (2012). Negotiating the 'Trading Zone'. Creating a Shared Information Infrastructure in the Dutch Public Safety Sector. Journal of Homeland Security and Emergency Management, 9(2), 1-26.

Boje, D.M. (1991). The Storytelling Organization: A Study of Story Performance in an OfficeSupply Firm. Administrative Science Quarterly, 36(1), 106-126.

Boje, D.M. (2001). Narrative Methods for Organizational and Communication Research, London: Sage.

Bøllingtoft, A., Müller, S., Ulhøi, J.P., Snow, C.C. (2012). Collaborative Communities of Firms: Role of the Shared Services Provider. In A. Bøllingtoft, L. Donaldson, G. P. Huber, D. D. Håkonsson and C. C. Snow (Eds.), Collaborative Communities of Firms (Information and Organization Design Series). New York: Springer.

Boudreau, K.J., Lakhani, K.R. (2009). How to Manage Outside Innovation. Sloan Management Review(July 1), http://sloanreview.mit.edu/article/how-to-manage-outside-innovation/.

Bovaird, T. (2004). Public-private Partnerships: from Contested Concepts to Prevalent Practice. International Review of Administrative Sciences, 70(2), 199-215.

Borys B and Jemison D. (1989) Hybrid Arrangements as Strategic Alliances: Theoretical Issues in Organizational Combinations. Academy of Management Review,14(2), 234-239.

Boyce, C., Neale, P. (2006). A Guide for Designing and Conducting In-Depth Interviews for Evaluation Input. Watertown: Pathfinder International.

Boyce, M.E. (1995). Collective Centring and Collective Sense-Making in the Stories and Storytelling of One Organization. Organization Studies, 16(1), 107-137.

Bradach, J.L. (1997). Using the Plural Form in the Management of Restaurant Chains. Administrative Science Quarterly, 42(2), 276-303.

Bradach, J.L., Eccles, R.G. (1989). Price, Authority, and Trust: From Ideal Types to Plural Forms. Annual Review of Sociology, 15, 97-118.

Brax, S.A., Jonsson, K. (2008). Developing Integrated Solution Offerings for Remote Diagnostics: A Comparative Case Study of Two Manufacturers. Integrated Solution Offerings, 29(5), 539-560.

Bridoux, F., Coeurderoy, R., Durand, R. (2011). Heterogeneous Motives and the Collective Creation of Value. Academy of Management Review, 36(4), 711-730.

Brinkerhoff, D.W., Brinkerhoff, M. (2011). Public-Private Partnerships: Perspectives on Purposes, Publicness, and Good Governance. Public Administration and Development, 31, 2-14.

Brown, D., Abbasi, A., Lau, R. (2015). Predictive Analytics. IEEE Computer Society, 30(2). 6-8. 
Brusoni, S. (2013). The Limits to Specialization: Problem Solving and Coordination in 'Modular Networks'. Organization Studies, 26(12), 1885-1907.

Burgelman, R.A. (1996). A Process Model of Strategic Business Exit: Implications for an Evolutionary Perspective on Strategy. Strategic Management Journal, 17, 193-214.

Burt, R.S. (1997) The Contingent Value of Social Capital. Administrative Science Quarterly, 42(2), 339-365.

Busi, M., Bititci, U. (2006). Collaborative Performance Management: Present Gaps and Future Research. International Journal of Performance and Productivity Management, 55(1), 725.

Busquets, J. (2010). Orchestrating Smart Business Network Dynamics for Innovation. European Journal of Information Systems, 19(4), 481-493.

Butler, J.K. (1995). Behaviour, Trust and Goal Achievement in a Win-win Negotiating Role Play. Group \& Organization Management, 20(4), 586-501.

Buvik, A., Reve, T. (2002). Inter-firm Governance and Structural Power in Industrial Relationships: the Moderating Effect of Bargaining Power on the Contractual Safeguarding of Specific Assets. Scandinavian Journal of Management, 18(3), 261-284.

Bygballe, L.E., Håkansson, H., Ingemansson, M. (2014). An Industrial Network Perspective on Innovation in Construction. In F. Orstavik, A. Dainty, C. Abbott (Eds.), Construction Innovation. Chichester, UK: Wiley.

Cagliano, R., Caniato, F., Corso, M., Spina, G. (2005). Collaborative Improvement in the Extended Manufacturing Enterprise: Lessons from an Action Research Process. Production Planning \& Control, 16(4), 345-355.

Caldwell, N., Howard, M. (Eds.) (2010). Procuring Complex Performance: Studies of Innovation in Product-Service Management. Oxford: Routledge.

Caldwell, N., Howard, M. (2014). Contracting for Complex Performance in Markets of Few Buyers and Sellers: The Case of Military Procurement. International Journal of Operations \& Production Management, 34(2), 270-294.

Calia, R.C., Guerrini, F.M., Moura, G.L. (2007). Innovation Networks: From Technological Development to Business Model Reconfiguration. Technovation, 27(8), 426-432.

Callon, M. (1991). Techno Economic Networks and Irreversibility. In J. Law (Ed.), A Sociology of Monsters: Essays on Power, Technology and Domination. London: Routledge \& Kegan.

Callon, M., Millo, Y., Muniesa, F. (Eds.). (2007). Market Devices. Malden, MA: Wiley-Blackwell.

Cambra-Fierro, J., Florin, J., Perez, L., Whitelock, J. (2011). Inter-firm Market Orientation as Antecedent of Knowledge Transfer, Innovation and Value Creation in Networks. Management Decisions, 49(3), 444-467.

Canhoto, A.I., Quinton, S., Jackson, P., Dibb, S. (2016). The Co-production of Value in Digital, University-Industry RD Collaborative Projects. Industrial Marketing Management, 56(SI), 86-96.

Candell, O., Karim, R., Soderholm, P. (2009). eMaintenance - Information Logistics for Maintenance Support. Robotics and Computer-Integrated Manufacturing, 25(6), 37-944.

Canterino, F., Shani, A.B., Coghlan, D., Brunelli, M.S. (2016). Collaborative Management Research as a Modality of Action Research: Learning from a Merger-Based Study. Journal of Applied Behavioral Science, 52(2), 157-186.

Cantwell, J., Dunning, J.H., Lundan, S.M. (2010). An Evolutionary Approach to Understanding International Business Activity: The Co-evolution of MNEs and the Institutional Environment. Journal of International Business Studies, 41(4), 567-586.

Capasso, A., Dagnino, G.B., Lanza, A. (2005). Strategic Capabilities and Knowledge Transfer within and between Organizations: New Perspectives form Acquisitions, Networks, Learning and Evolution. Cheltenham: Edward Elgar Publishing Inc.

Carlile, P.R. (2004). Transferring, Translating, and Transforming: An Integrative Framework for Managing Knowledge Across Boundaries. Organization Science, 15(5), 555-568.

Carlile, P.R., Rebentisch, E.S. (2003). Into the Black Box: The Knowledge Transformation Cycle. Organization Science, 49(9), 1180-1195. 
Carlisle, S., Kunc, M., Jones, E., Tiffin, S. (2013). Supporting Innovation for Tourism

Development through Multi-stakeholder Approaches: Experiences from Africa. Tourism Management, 35, 59-69.

Carter, C.R., Rogers, D.S., Choi, T.Y. (2015). Toward the Theory of the Supply Chain. Journal of Supply Chain Management, 51(2), 89-97.

Cederlund, C. (2015). Managing Meaning in Complex Business Networks. Industrial Marketing Management, 48, 89-100.

Chan, Y., Reich, B.H. (2011). Rethinking Business-IT Alignment. In B.D. Galliers and W.L. Currie (Eds.), The Oxford Handbook of Management Information Systems. New York: Oxford University Press.

Chan, Y.E., Huff, S.L., Barclay, D.W., Copeland, D.G. (1997). Business Strategic Orientation, Information Systems Strategic Orientation, and Strategic Alignment. Information Systems Research, 8(2), 125-150.

Chandler, J.D., Vargo, S.L. (2011). Contextualization and Value-in-context: How Context Frames Exchange. Marketing Theory, 11(1), 35-49.

Chang, S.C., Chen, S.S., Lai, J.H. (2008). The Effect of Alliance Experience and Intellectual Capital on the Value Creation of International Strategic Alliances. Omega, 36(2), 298-316.

Chau, M., Atabakhsh, H., Zeng, D., Cheng, H. (2001). Building an Infrastructure for Law Enforcement Information Sharing and Collaboration: Design Issues and Challenges. Paper presented at the National Conference on Digital Government, Los Angeles.

Cheng, T.C.E., Choi, T.-M. (2010). Innovative Quick Response Programs in Logistics and Supply Chain Management. Heidelberg: Springer.

Chenhall, R.H., Langfield-Smith, K. (2007). Multiple Perspectives of Performance Measures. European Management Journal, 25(4), 266-282.

Chesbrough, H., Di Minin, A., Puiccaluga, A. (2013). Business Model Innovation Paths. In L. Cinquini, A. Di Minin, R. Varaldo (Eds.), New Business Models and Value Creation: A Service Science Perspective. Milan: Springer.

Chia, R. (1995). From Modern to Postmodern Organizational Analysis. Organization Studies, 16(4), 579-604.

Chia, R. (1996). The Problem of Reflexivity in Organizational Research: Towards a Postmodern Science of Organization. Organization, 3(1), 31-59.

Chia, R., MacKay, B. (2007). Post-processual Challenges for the Emerging Strategy-as-practice Perspective: Discovering Strategy in the Logic of Practice. Human Relations, 60(1), 217242.

Chong, J.L., Tan, F.B. (2012). IT Governance in Collaborative Networks: A Socio-Technical Perspective. Pacific Asia Journal of the Association for Information Systems, 4(2), 31-48.

Christopher, M.G. (2011). Logistics \& Supply Chain Management (4th ed.). Harlow, UK: Prentice Hall.

Chung, S.A., Singh, H., Lee, G.M. (2000). Complementarity, Status Similarity and Social Capital as Drivers of Alliance Formation. Strategic Management Journal 21(1), 1-22.

Cinquini, L., Di Minin, A., Varaldo, R. (2013). New Business Models and Value Creation: A Service Science Perspective. Milan: Springer.

Clegg, S.R., Pitsis, T.S., Rura-Polley, T., Marosszeky, M. (2002). Governmentality Matters: Designing an Alliance Culture of Inter-Organizational Collaboration for Managing Projects. Organization Studies, 23(3), 317-337.

Cohen, W.M., Levinthal, D.A. (1990). Absorptive Capacity: A New Perspective on Learning and Innovation. Administrative Science Quarterly, 35(1), 128-152.

Collier, P. (2007). The Bottom Billion: Why the Poorest Countries Are Failing and What Can Be Done About It. New York: Oxford University Press.

Combs, J.G., Ketchen Jr, D.J. (1999). Explaining Interfirm Cooperation and Performance: Toward a Reconciliation of Predictions from the Resource-based View and Organizational Economics. Strategic Management Journal, 20(9), 867-888. 
Comez, N., Cakanyildirim, M., Stecke, K.E. (2012). Negotiated Transsipment Prices. Paper presented at the 17th International Symposium on Inventories, Budapest, Hungary.

Constantiou, I., Kallinikos, J. (2015). New Games, New Rules: Big Data and the Changing Context of Strategy. Journal of Information Technology, 30(1), 44-57.

Corley, K.G., Gioia, D.A. (2004). Identity Ambiguity and Change in the Wake of a Corporate Spin-off. Administrative Science Quarterly, 49(3), 174-208.

Craighead, C.W. , Tomas, G., Hultb, M., Ketchen Jr., D.J. (2009). The Effects of InnovationCost Strategy, Knowledge, and Action in the Supply Chain on Firm Performance. Journal of Operations Management, 27(5), 405-421.

Crié, D., Micheaux, A. (2006). From Customer Data to Value: What is Lacking in the Information Chain? Journal of Database Marketing \& Customer Strategy Management, 13(4), 282299.

Cropper, S., Ebers, M., Huxham, C., Smith Ring, P. (2008). The Oxford Handbook of InterOrganizational Relations. Oxford: Oxford University Press.

Crossan, M.M., Apaydin, M. (2010). A Multi-Dimensional Framework of Organizational Innovation: A Systematic Review of the Literature. Journal of Management Studies, 47(6), 1154-1191.

Crowston, K. (1997). A Coordination Theory Approach to Organizational Process Design. Organization Science, 8(2), 157-175.

Culpan, R. (2014). Open Innovation Through Strategic Alliances: Approaches for Product, Technology, and Business Model Creation. New York: Palgrave Macmillan.

Cummings, T.G. (1984) Trans-organizational Development. Research in Organizational Behavior, 6, 367-422.

Cummings, T.G., Worley, C.G. (2015). Organization Development and Change (15th ed.). Ohio: South-Western College Publishing.

Czarniawska B. (1997) Narrating the Organization: Dramas of Institutional Identity, Chicago: University of Chicago Press.

Dahan, N.M., Doh, J.P., Oetzel, J., Yaziji, M. (2010). Corporate-NGO Collaboration: Co-creating New Business Models for Developing Markets. Long Range Planning, 43, 326-342.

Dalpiaz, E., Rindova, V.P., Ravasi, D. (2016). Combining Logics to Transform Organizational Agency: Blending Industry and Art at Alessi. Administrative Science Quarterly, 44, 1-46.

Danesh, M.H., Raahemi, B., Kamali, S.M.A., Richards, G. (2013). A Framework for Process and Performance Management in Service Oriented Virtual Organizations. International Journal of Computer Information Systems and Industrial Management Applications, 5, 203-215.

Das, T.K., Teng, B. (2000). A Resource-Based Theory of Strategic Alliances. Journal of Management, 26(1), 31-61.

Das, T.K., Teng, B. (2001). Trust, Control, and Risk in Strategic Alliances: An Integrated Framework. Organization Studies, 2(22), 251-283.

Das, T.K., Teng, B. (2002). The Dynamics of Alliance Conditions in the Alliance Development Process. Journal of Management Studies, 39(5), 725-746.

Das, T.K., Teng, B. (2003). Partner Analysis and Alliance Performance. Scandinavian Journal of Management, 19(3), 279-308.

Davenport, T. (2010). The New World of "Business Analytics". Portland, OR: International Institute for Analytics.

Davenport, T. (2013). Enterprise Analytics: Optimize Performance, Process, and Decisions Through Big Data. Upper Saddle River, NJ: Pearson.

Davis, J.P. (2010). Agency and Knowledge Problems in Network Dynamics: brokers and Bridges in Innovative Interorganizational Relationships. Sloan School of Management Working Paper, January 12, 2010.

Davison, R.M., Martinsons, M.G., Kock, N. (2004). Principles of Canonical Action Research. Information Systems Journal, 14(1), 65-86.

Day, G.S. (1995). Advantageous Alliances. Journal of the Academy of Marketing Science, 23(4), 297-300. 
De Coning, C., Friis, K. (2011). Coherence and Coordination: The Limits of the Comprehensive Approach. Journal of International Peacekeeping, 15(1-2), 243-272.

De Man, A.-P., Roijakkers, N. (2009). Alliance Governance: Balancing Control and Trust in Dealing with Risks. Long Range Planning, 42(1), 75-95.

De Martino, M., Errichiello, L., Marasco, A., Morvillo, A. (2013). Logistics Innovation in Seaports: An Inter-Organizational Perspective. Research in Transportation Business \& Management, 8(SI), 123-133.

De Vries, J. (2012). Organisational Barriers and Enablers to Vendor-Managed Inventory. Paper presented at the 17th International Symposium on Inventories, Budapest, Hungary.

De Wit, B., Meyer, R. (2010a). Strategy Synthesis: Resolving Strategy Paradoxes to Create Competitive Advantage. Florence, KY: Cengage Learning Business Press.

De Wit, B., Meyer, R. (2010b). Strategy: Process, Content, Context. An International Perspective (4th ed.). Hampshire, UK: South-Western.

Dedrick, J., Kraemer, K.L. (2010). Impacts of Internal and Interorganizational Information Systems on the Outsourcing of Manufacturing. Journal of Strategic Information Systems, 19(2), 78-95.

Deken, F., Carlile, P.R., Berends, J.J., Lauche, K. (2016). Generating Novelty Through Interdependent Routines: A Process Model of Routine Work. Organization Science, 27(3), 659-677.

Dekker, H.C. (2004). Control of Inter-Organizational Relationships: Evidence on Appropriation Concerns and Coordination Requirements. Accounting, Organizations and Society, 29(1), 27-49.

Dekker, H.C., Van den Abbeele, A. (2010). Organizational Learning and Interfirm Control: The Effects of Partner Search and Prior Exchange Experiences. Organization Science, 21(6), 1233-1250.

Dekker, R., Pince, C., Zuidwijk, R., Jalil, M.N. (2013). On the Use of Installed Base Information for Spare Parts Logistics: A Review of Ideas and Industry Practice. International Journal of Production Economics, 143(2), 536-545.

Demil, B., Lecocq, X. (2010). Business Model Evolution: In Search of Dynamic Consistency. Long Range Planning, 43, 227-246.

Denis, J.-L., Langley, A., Rouleau, L. (2007). Strategizing in Pluralistic Contexts: Rethinking Theoretical Frames. Human Relations, 60(1), 179-215.

Denyer, D., Tranfield, D., Van Aken, J.E. (2008). Developing Design Propositions Through Research Synthesis. Organization Studies, 29(2), 249-269.

DeSanctis, G., Poole, M.S. (1994). Capturing the Complexity in Advanced Technology Use: Adaptive Structuration Theory. Organization Science, 5(2), 121-147.

Devaux, A., Ordinola, M., Horton, D. (2011). Innovation for Development: The Papa Andina Experience. Lima, Peru: International Potato Center.

Dewey, J. (1910). How We Think. Lexington, MA: D.C. Heath.

Dewey, J. (1939). Theory of Valuation. Chicago: University of Chicago Press.

Dhanaraj, C., Parkhe, A. (2006). Orchestrating Innovation Networks. Academy of Management Review, 31(3), 659-669.

DiMaggio, P.J., Powell, W.W. (1983). The Iron Cage Revisited: Institutional Isomorphism and and Collective Rationality in Organizational Fields. American Sociological Review, 48(April), 147-160.

Dionysiou, D.D., Tsoukas, H. (2013). Understanding the (Re)Creation of Routines from Within: A Symbolic Interactionist Perspective. Academy of Management Review, 38(2), 181-205

Djelic, M.-L., Ainamo, A. (1999). The Coevolution of New Organizational Forms in the Fashion Industry: A Historical and Comparative Study of France, Italy, and the United States. Organization Science, 10(5), 622-637.

Donnellon, A., Gray, B., Bougon, M.G. (1986). Communication, Meaning, and Organized Action. Administrative Science Quarterly, 31(1), 43-55. 
Doolin, B. (2003). Narratives of Change: Discourse, Technology and Organization. Organization, 10(4), 751-770.

Doty, D.H., Glick, W.H. (1994). Typologies as a Unique Form of Theory Building: Toward Improved Understanding and Modeling. Academy of Management Review, 19(2), 230-251.

Douma, M.U. (1997). Strategic Alliances; Fit or Failure: PhD Dissertation, Twente University, Enschede, Netherlands.

Doz, Y.L. (1996). The Evolution of Cooperation in Strategic Alliances: Initial Conditions or Learning Processes? Strategic Management Journal, 17(S1), 55-83.

Doz, Y.L., Hamel, G. (1998). Alliance Advantage: The Art of Creating Value Through Partnering. Boston, MA: Harvard Business School Press.

Draulans, J., De Man, A.-P., Volberda, H.W. (2003). Building Alliance Capability: Management Techniques for Superior Alliance Performance. Long Range Planning, 36, 151-166.

Dunford, R., Jones, D. (2000). Narrative in Strategic Change. Human Relations, 53(9), 12071226.

Durugbo, C., Riedel, J.C. (2013). Readiness Assessment of Collaborative Networked Organisations for Integrated Product and Service Delivery. International Journal of Production Research, 51(2), 598-613.

Dussauge, P., Garrette, B. (1993). Industrial Alliances in Aerospace and Defence: An Emperical Study of Strategic and Organizational Patterns. Defense Economics, 4(1), 45-62.

Dyer, J.H. (1997). Effective Interfirm Collaboration: How Transactions Minimize Transactions Costs and Maximize Transaction Value. Strategic Management Journal, 18(7), 535-556.

Dyer, J.H. (2000). Collaborative Advantage: Winning Through Extended Enterprise Supplier Networks. New York: Oxford University Press.

Dyer, H., Hatch, W. (2006). Relation-specific Capabilities and Barriers to Knowledge Transfers: Creating Advantage Through Network Relationships. Strategic Management Journal, 27(8), 701-719.

Dyer, J.H., Kale, P., Singh, H. (2001). How to Make Strategic Alliances Work. Sloan Management Review, 42(4), 37-43.

Dyer, J.H., Nobeoka, K. (2000). Creating and Managing a High-Performance KnowledgeSharing Network: The Toyota Case. Strategic Management Journal, 21, 345-367.

Dyer, J.H., Singh, H. (1998). The Relational View: Cooperative Strategy and Sources of Interorganizational Competitive Advantage. Academy of Management Review, 23(4), 660679.

Eaton, B., Elaluf-Calderwood, S., Sorensen, C., Yoo, Y. (2011). Dynamic Structures of Control and Generativity in Digital Ecosystem Service Innovation: The Cases of the Apple and Google Mobile App Stores. London School of Economics, Working Paper 183.

Earl, G., Clift, R. (1999). Stakeholder Value Analysis: a Methodology for Intergrating Stakeholder Values into Corporate Environmental Investment Decisions. Business Strategy and the Environment, 8(2), 149-162.

Ebrahim, E., Battilana, J., Mair, J. (2014). The Governance of Social Enterprises: Mission Drift and Accountability Challenges in HJybrid Organizations. Research in Organizational Behavior, 34, 81-100.

Edelenbos, J., Klijn, E.-H. (2007). Trust in Complex Decision-Making Networks: A Theoretical and Empirical Exploration. Administration \& Society, 39(1), 25-50.

Eden, C. (1996). The Stakeholder/ Collaborator Strategy Workshop. In C. Huxham (Ed.), Creating Collaborative Advantage. London: Sage.

Eden, C., Ackermann, F. (2000). Mapping Distinctive Competencies: A Systemic Approach. Journal of the Operational Research Society, 51(1), 12-20.

Edmonson, A., McManus, S. (2007). Methodological Fit in Management Field Research. Academy of Management Review, 32(4), 1155-1179.

Edvardsson, B., Enquist, B., Johnson, R. (2005). Cocreating Customer Value Through Hyperreality in the Prepurchase Service Experience. Journal of Service Research, 8(2), 149-161. 
Edvardsson, B., Tronvoll, B., Gruber, T. (2011). Expanding Understanding of Service Exchange and Value Co-creation: A Social Construction Approach. Journal of the Academy of Marketing Science, 39(2), 327-339.

Edwards, J.R. (1994). The Study of Congruence in Organizational Behavior Research: Critique and a Proposed Alternative. Organizational Behavior and Human Decision Processes, 58(1), 51-100.

EGOS. (2013). EGOS 2014 call for papers sub-theme 28. http://www.egosnet.org/jart/prj3/egos/main.jart?rel=de\&reserve-mode=active\&contentid $=1368705858152$ \&subtheme id=1334581237452.

Ehret, M., Wirtz, J. (2010). Division of Labor between Firms: Business Services, NonOwnership-Value and the Rise of the Service Economy. Service Science, 2(3), 136-145.

Eisingerich, A.B., Rubera, G., Seifert, M. (2009). Managing Service Innovation and Interorganizational Relationships for Firm Performance: To Commit or Diversify? Journal of Service Research, 11(4), 344-356.

Eisenhardt, K.M. (1989a). Agency Theory: An Assessment and Review. Academy of Management Review, 14(1), 57-74.

Eisenhardt, K.M. (1989b). Building Theories from Case Study Research. Academy of Management Review, 14(4), 532-550.

Eisenhardt, K.M. (1991) Better Stories and Better Constructs: The Case for Rigor and Comparative Logic. Academy of Management Review, 16(3), 620-627.

El-Gohary, N.M., Osman, H., El-Diraby, T.E. (2006). Stakeholder Management for Public Private Partnerships. International Journal of Project Management, 24(7), 595-604.

Elmuti, D., Kathawala, Y. (2001). An Overview of Strategic Alliances. Management Decisions, 39(3), 205-217.

Elter, F. (2009). Strategizing in Complex Contexts. Saarbrücken: Vdm Verlag.

Engel, T. (2015). Information Sharing as a Competitive Supply Chain Strategy: Mapping the Various Antecedents. Technical University Munchen, Munchen.

Epstein, M.J., Roy, M.-J. (2001). Sustainability in Action: Identifying and Measuring the Key Performance Drivers. Long Range Planning, 34, 585-604. doi: 10.1287/inte.29.1.7

Espejo, R., Schuhmann, W., Schwaninger, M., Bilello, U. (1996). Organizational Transformation and Learning: A Cybernetic Approach to Management. Chichester: Wiley.

Estep, D. (2012). Shared Services: Enhanced Care. Navy Medicine, 2(4), 36-37.

Faems, D., Janssens, M., Madhok, A., Van Looy, B. (2008). Toward An Integrative Perspective on Alliance Governance: Connecting Contract Design, Trust Dynamics, and Contract Application. Academy of Management Journal, 51(6), 1053-1078.

Faems, D., Van Looy, B., Debackere, K. (2005). Interorganizational Collaboration and Innovation: Toward a Portfolio Approach. Journal of Product Innovation Management, 22(3).

Faleg, G., Giovannini, A. (2012). The EU between Pooling \& Sharing and Smart Defence: Making a Virtue of Necessity? Centre for European Policy Studies (CEPS) working paper. Available online: http://shop.ceps.be/system/files/book/2012/05/P\%26S and Smart Defence.pdf (Accessed: June 21, 2012).

Faraj, S., Jarvenpaa, S., Majchrzak, A. (2011). Knowledge Collaboration in Online Communities. Organization Science, 22(5), 1224-1239.

Faraj, S., Sproull, L. (2000). Coordinating Expertise in Software Development Teams. Management Science, 46(12), 1154-1568.

Farjoun, M., Ansell, C., Boin, A. (2015). Pragmatism in Organization Studies: Meeting the Challenges of a Dynamic and Complex World. Organization Science, 26(6), 1787-1804.

Faust, V., Christens, B.D., Sparks, S.M.A., Hilgendorf, A.E. (2015). Exploring Relationships among Organizational Capacity, Collaboration, and Network Change. Psychosocial Intervention, 24, 125-131.

Feldman, M.S. (2000). Organizational Routines as a Source of Continuous Change. Organization Science, 11(6), 611-629. 
Feldman, M.S., Pentland, B.T. (2003). Reconceptualizing Organizational Routines as a Source of Flexibility and Change. Administrative Science Quarterly, 48(1), 94-118.

Felin, T., Hesterly, W.S. (2007). The Knowledge-Based View, Nested Heterogeneity, and New Value Creation: Philosophical Considerations on the Locus of Knowledge. Academy of Management Review, 32(1), 195-218.

Feller, J., Parhankangas, A., Smeds, R., Jaatinen, M. (2013). How Companies Learn to Collaborate: Emergence of Improved Inter-Organizational Processes in R\&D Alliances. Organization Studies, 34(3), 313-343.

Fenton, C., Langley, A. (2008). Strategy as Practice and the Narrative Turn. Les cahiers de recherche du GéPS, ISSN: 1917-6228 6: 1-37.

Fielding, N., Thoman, H. (2008). Qualitative Interviewing. In: Gilbert, N. (ed.) Researching Social Life. London: Sage.

Fidler, S., MacDonald, A. (2011). Europeans Retreat on Defense Spending. Wall Street Journal, August 24, 2011.

Finney, A. (2002). Improving Multi-agency Coordination: Overcoming the Barriers to Communication - A Case Study. Crime Prevention and Community Safety, 4(4), 33-45.

Firat, A.F., Dholakia, N., Venkatesh, A. (1996). Marketing in a Postmodern World European Journal of Marketing 29(1), 40-56.

Fjeldstad, O.D., Snow, C.C., Miles, R.E., Lettl, C. (2012). The Architecture of Innovation. Strategic Management Journal, 33, 734-750.

Fleming, L., Waguespack, D.M. (2007). Brokerage, Boundry Spanning and Leadership in Open Innovation Communities. Organization Science, 18(2), 165-180.

Floden, R.E. (2009). Empirical Research without Certainty. Educational Theory, 59(4), 485-498.

Ford, D., Gadde, L. (2002). How Should Companies Interact in Business Networks? Journal of Business Research, 55, 133-139.

Forslund, H. (2012). Performance Management in Supply Chains: Logistics Service Providers' Perspective. International Journal of Physical Distribution \& Logistics Management, 42(3), 296-311.

Foss, N.J. (1997). Resources, Firms, and Strategies: A Reader in the Resource-based Perspective. Oxford: Oxford University Press.

Foss, N., Saebi, T. (2017). Fifteen Years of Research on Business Model Innovation: How Far Have We Come and Where Should We Go? Journal of Management, 43(1), 200-227.

Franca, C.L., Broman, G., Robert, K.-H., Basile, G., Trygg, L. (2017). An Approach to Business Model Innovation and Design for Strategic Sustainable Development. Journal of Cleaner Production, 140(Part 1), 155-166.

Franco, M. (2011). Determining Factors in the Succes of Strategic Alliances: An Emperical Study Performed in Portuguese Firms. European Journal of International Management, 5(6), 608-632.

Franco-Santos, M., Lucianette, L., Bourne, M. (2012). Contemporary Performance Measurement Systems: A Review of Their Consequences and a Framework for Research. Management Accounting Research, 23(2), 79-119.

Frandsen, S., Kuhn, T., Lundholdt, M. (2016). Counter-Narratives and Organization. New York: Routledge.

Franklin, R., Spinler, S. (2011). Shared Warehouses - Sharing Risks and Increasing Ecoefficiency. International Commerce Review, 10(March), 22-31.

Freeman, R.E. (2010). Strategic Management: A Stakeholder Approach. Cambridge: Cambridge University Press.

Frow, P., McColl-Kennedy, J.R., Hilton, T., Davidson, A., Payne, A., Brozovic, D. (2014). Value Propositions: A Service Ecosystems Perspective. Marketing Theory, 14(3), 327-351.

Frow, P., Nenonen, S., Payne, A., Storbacka, K. (2015). Managing Co-creation Design: A Strategic Approach to Innovation. British Journal of Management, 26(3), 463-483.

Furnari, S. (2015). A Cognitive Mapping Approach to Business Models: Representing Causal Structures and Mechanisms. In: Baden-Fuller C and Mangematin V (eds) Business Models 
and Modelling (Advances in Strategic Management, Volume 33). Bingley, United Kingdom: Emerald, 207-239.

Gadde, L.-E., Huemer, L., Håkansson, H. (2003). Strategizing in Industrial Networks. Industrial Marketing Management, 32(5), 357-364.

Gans, J., Ryall, M.D. (2017). Value Capture Theory: A Strategic Management Review. Strategic Management Journal, 38(1), 17-41.

Galaskiewicz, J. (1985). Interorganizational Relations. Annual Review of Sociology, 11(1), 281304.

Galunic, D.C., Rodan, S. (1998). Resource Recombinations in the Firm: Knowledge Structures and the Potential for Schumpeterian Innovation. Strategic Management Journal, 19(12), 1193-1201.

Garud, R., Gehman, J., Giuliani, A.P. (2014). Contextualizing Entrepreneurial Innovation: A Narrative Perspective. Research Policy, 43(7), 1177-1188.

Garud, R., Karnøe, P. (2003). Bricolage vs. Breakthrough: Distributed and Embedded Agency in Technology Entrepreneurship. Research Policy, 32(2), 277-300.

Garud, R., Rappa, M.A. (1994). A Socio-Cognitive Model of Technology Evolution: The Case of Cochlear Implants. Organization Science, 5(3), 344-362.

Garud, R., Tuertscher, P., Van de Ven, A.H. (2013). Perspectives on Innovation Processes. The Academy of Management Annals, 7(1), 773-817.

Gebauer, H., Kucza, G., Wang, C. (2011). Spare Parts Logistics for the Chinese Market. Benchmarking: An International Journal, 18(6), 748-768.

Gehman, J., Glaser, V.L., Eisenhardt, K.M., Gioia, D., Langley, A., Corley, K.G. (Forthcoming). Finding Theory-Method Fit: A Comparison of Three Qualitative Approaches to Theory Building. Journal of Management Inquiry.

Gehman, J., Trevino, L.K., Garud, R. (2013). Values Work: A Process Study of the Emergence and Performance of Organizational Values Practices. Academy of Management Journal, 56(1), 84-112.

Geiger, D. (2009). Revisiting the Concept of Practice: Toward an Argumentative Understanding of Practicing. Management Learning, 40(2), 129-144.

Gerritse, D., Bergsma, F.H.J, Groen, B.H. (2014). Exploration of Added Value Concepts in Facilities Management Practice: Learning from Financial Institutes. Paper presented at the 13th EuroFM Research Symposium, Berlin.

Geyskens, I., Steenkamp, J.-B.E.M., Kumar, N. (2006). Make, Buy, or Ally: A Transaction Cost Theory Meta-Analysis. Academy of Management Journal, 49(3), 519-543.

Ghaderi, H., Dullaert, W. (2012). An Empirical Investigation of Lead-Time Reduction in Purchasing Groups: Evidence from SMEs. International Journal of Logistics Systems and Management 13(3), 379-392.

Ghoshal, S., Moran, P. (1996). Bad for Practice: A Critique of the Transaction Cost Theory. Academy of Management Review, 21(1), 13-47.

Gibb, J. (2016). Network Learning: Episodes of Interorganizational Learning towards a Collective Performance Goal. European Management Journal, 35(1), 15-25.

Gibbert, M., Ruigrok, W., Wicki, B. (2008). Research Notes and Commentaries: What Passes a Rigorous Case Study? Strategic Management Journal, 29(13), 1465-1474.

Giddens, A. (1979). Central Problems in Social Theory: Action, Structure and Contradiction in Social Analysis. Berkeley, CA: University of California Press.

Giddens, A. (1986). The Constitution of Society: Outline of the Theory of Structuration. Berkeley, CA: University of California Press.

Gidman, P., Blore, I., Lorentzen, J., Schuttenbelt, P. (1995). Public-Private Partnerships in Urban infrastructure Services. UMP Working Paper Series 4, Nairobi: UNDP/Habitat/World Bank, 1-11.

Giegerich, B. (2012). NATO's Smart Defence: Who's Buying? Survival: Global Politics and Strategy, 54(3), 69-77. 
Gil-Garcia, J. R., Chengalur-Smith, I., Duchessi, P. (2007). Collaborative e-Government: Impediments and Benefits of Information-sharing Projects in the Public Sector. European Journal of Information Systems, 16(2), 121-133.

Gillier, T., Hooge, S., Piat, G. (2015). Framing Value Management for Creative Projects: An Expansive Perspective. International Journal of Project Management, 33(4), 947-960.

Gilsing, V., Nooteboom, B., Vanhaver, W., Duysters, G., Van den oord, A., (2008). Network Embeddedness and the Exploration of Novel technologies: Technological distance, betweenness Centrality and Density. Research Policy, 37(10), 1717-1731.

Gioia, D.A., Patvardhan, S.D., Hamilton, A.L., Corley, K.G. (2013). Organizational Identity Formation and Change. Academy of Management Annals, 7(2), 123-192.

Gioia, D.A., Thomas, J.B. (1996). Identity, Image, and Issue Interpretation: Sensemaking during Strategic Change in Academia. Administrative Science Quarterly, 41(3), 370-403.

Gittell, J.H., Weiss, L. (2004). Coordination Networks within and across Organizations: A Multilevel Framework. Journal of Management Studies, 41(1), 127-153.

Giudici, A., Kouropalatis, Y., Reinmoeller, P. (2016). The Relational Sensing of New Opportunities in Business Matchmaking Events. Paper presented at the Academy of Management Conference Proceedings.

Gnyawali, D.R., Park, B.-J. (2011). Co-opetition between Giants: Collaboration with Competitors for Technological Innovation. Research Policy, 40(5), 650-663.

Goddard, J. (1997). The Architecture of Core Competence. Business Strategy Review 8(1), 4352.

Goes, J.B., Park, S.H. (1997). Interorganizational Links and Innovation: The Case of Hospital Services. Academy of Management Journal, 40(3), 673-696.

Goffman E. (1983). The Interaction Order. American Sociological Review, 48(1), 1-17.

Golafshani, N. (2003). Understanding Reliability and Validity in Qualitative Research. The Qualitative Report, 8(4), 597-606.

Golant, B.D., Sillince, J., Harvey, C., Maclean, M. (2015). A Rhetoric-in-Context Approach to Building Commitment to Multiple Strategic Goals. Human Relations, 68(4), 607-631.

Gold, S. (2011). Bio-Energy Supply Chains and Stakeholders. Mitigation and Adaptation Strategies for Global Change, 16(4), 439-462.

Goldsmith, S., Georges, G., Burke, T.G. (2010). The Power of Social Innovation: How Civic Entrepreneurs Ignite Community Networks for Good. San Francisco: Jossey-Bass.

Gomes, P.J., Dahab, S. (2010). Bundling Resources across Supply Chain Dyads: The Role of Modularity and Coordination Capabilities. International Journal of Operations \& Production Management, 30(1), 57-74.

Goodhue, D.L., Thompson, R.L. (1995). Task-Technology Fit and Individual Performance. MIS Quarterly, 19(4), 213-235.

Gopalakrishnan, K., Yusuf, Y.Y., Musa, A., Abubakar, T., Ambursa, H.M. (2012). Sustainable Supply Chain Management: A Case Study of British Aerospace (BAe) Systems. International Journal of Production Economics, 140(1), 193-203.

Gospel, H., Sako, M. (2010). The Unbundling of Corporate Functions: The Evolution of Shared Services and Outsourcing in Human Resource Management. Industrial and Corporate Change, 19(5), 1367-1396.

Graham, D., Manikas, I., Folinas, D. (2013). E-Logistics and E-Supply Chain Management: Applications for Evolving Business. Hershey, PA: IGI Global.

Graham, K. (2016). Developing Shared Measurements. Retrieved 02-12, 2016, from http://www.collaborationforimpact.com/collective-impact/shared-measurement/

Grandori, A. (1997a). Governance Structures, Coordination Mechanisms and Cognitive Models. Journal of Management and Governance, 1(1), 29-47.

Grandori, A. (1997b). An Organizational Assessment of Interfirm Coordination Modes. Organization Studies, 18(6), 897-925.

Granovetter, M.S. (1985). Economic Action and Social Structure: The Problem of Embeddedness. American Journal of Sociology, 91(3), 481-510. 
Grant, R.M. (1996). Prospering in Dynamically-competitive Environments: Organizational Capability as Knowledge Integration. Organization Science, 7(4), 375-387.

Greve, H.R., Seidel, M.D.L. (2015). The Thin Red Line between Success and Failure: Path Dependence in the Diffusion of Innovative Production Technologies. Strategic Management Journal, 36(4), 475-496.

Griffith, T.L. (1999). Technology Features as Triggers for Sensemaking. Academy of Management Review, 24(3), 472-488.

Grimsey, D., Lewis, M.K. (2002). Evaluating the Risks of Public Private Partnerships for Infrastructure Projects. International Journal of Project Management, 20(2), 107-118.

Grönroos, C. (1984). A Service Quality Model and its Marketing Implications. European Journal of Marketing, 18(4), 36-44.

Grönroos, C. (2011a). Adopting a Service Logic in Manufacturing: Conceptual Foundation and Metrics for Mutual Value Creation. Journal of Service Management, 21(5), 564-590.

Grönroos, C. (2011b). A Service Perspective on Business Relationships: The Value Creation, Interaction and Marketing Interface. Industrial Marketing Management, 40(2), 240-247.

Grönroos, C. (2015). Relationality in the Service Logic of Value Creation. Journal of Services Marketing, 29(6/7), 463-471.

Grove, S.J., Fisk, R.P., John, J. (2000). Service as Theater: Guidelines and Implications. In T. A. Swartz and D. lacobucci (Eds.), Handbook of Services Marketing \& Management. Thousand Oaks, CA: Sage.

Grover, V., Kohli, R. (2012). Cocreating IT Value: New Capabilities and Metrics for Multifirm Environments. MIS Quarterly, 36(1), 225-232.

Gulati, R. (1998). Alliances and Networks. Strategic Management Journal, 19(4), 293-317.

Gulati, R. (1999). Network Location and Learning: The Influence of Network Resources and Firm Capabilities on Alliance Formation. Strategic Management Journal, 20(5), 397-420.

Gulati, R., Khanna, T., Nohria, N. (1994). Unilateral Commitments and the Importance of Process in Alliances. MIT Sloan Management Review(April).

Gulati, R., Nohria, N., Zaheer, A. (2000). Strategic Networks. Strategic Management Journal, 21(3), 203-215.

Gulati, R., Singh, H. (1998). The Architecture of Cooperation: Managing Coordination Costs and Appropriation Concerns in Strategic Alliances. Administrative Science Quarterly, 43(6), 781-814.

Gulati, R., Srivastava, S.B. (2014). Bringing Agency Back into Network Research: Constrained Agency and Network Action. In D. J. Brass, G. Labianca, A. Mehra, D. S. Halgin and S. P. Borgatti (Eds.), Contemporary Perspectives on Organizational Social Networks (73-93). Bingley, UK: Emerald.

Gulati, R., Wohlgezogen, F., Zhelyazkov, P. (2012). The Two Facets of Collaboration: Cooperation and Coordination in Strategic Alliances. The Academy of Management Annals, 6(1), 531-583.

Gupta, S., Polonsky, M. (2013). Inter-firm Learning and Knowledge-Sharing in Multinational Networks: An Outsourced Organization's Perspective. Journal of Business Research, http://www.sciencedirect.com/science/article/pii/S0148296313000738.

Gurcayiliar-Yenidogan, T. (2014). Complementarity Between Formal and Relational Governance Mechanisms in Inter-Organizational Networks: Combining Resource-Based and Relational Governance Perspectives. In J. Windsperger (Ed.), Interfirm Networks. Bern: Springer International

Gutek, B.A., Bhappu, A.D., Liao-Troth, M.A., Cherry, B. (1999). Distinguishing between Service Relationships and Encounters. Journal of Applied Psychology, 84(2), 218-233.

Haimes, Y.Y. (2016). Risk Modeling, Assessment, and Management. Hoboken: Wiley.

Håkansson, H. (2016). The Managerial Challenge of Business Interaction: Behind the Market Façade. IMP Journal, 10(1), 154-171.

Håkansson, H., Eriksson, A.K. (1993). Getting Innovations Out of the Supplier Networks. Journal of Business-to-Business Marketing, 1(3), 3-34. 
Håkansson, H., Ford, D. (2002). How Should Companies Interact in Business Networks? Journal of Business Research, 55(2), 133-139.

Håkansson, H., Lundgren, A. (2006). Industrial Networks and Technological Innovation. In K. K. Moller, D. T. Wilson (Eds.), Business Marketing: An Interaction and Network Perspective. Boston: Kluwer.

Håkansson, H., Snehota, I. (1995). Developing Relationships in Business Networks. London: Routledge.

Håkansson, H., Snehota, I. (1989). No Business is an Island: The Network Concept of Business Strategy. Scandinavian Journal of Management, 5(3), 187-200.

Håkansson, H., Waluszewski, A. (2002). Path Dependence: Restricting or Facilitating Technical Development? Journal of Business Research, 55(7), 561-570.

Håkansson, H., Waluszewski, A. (2016). "Methodomania"? On the Methodological and Theoretical Challenges of IMP Business Research. IMP Journal, 10(3), 443-463.

Håkansson, H., Waluszewski, A. . (2013). A Never Ending Story - Interaction Patterns and Economic Development. Industrial Marketing Management, 42(3), 443-454.

Halinen, A., Medlin, C.J., Törnroos, J.-A. (2012). Time and Process in Business Network Research. Industrial Marketing Management, 41(2), 215-223.

Hall, H., Tolbert, P. (2005). Organizations: Structures, Processes, and Outcomes. Upper Saddle River, NJ: Pearson Education.

Hall, J.K., Martin, M.J.C. (2005). Disruptive Technologies, Stakeholders and the Innovation Value-added Chain: A Framework for Evaluating Radical Technology Development. R\&D Management, 35(3), 273-284.

Hall, P.V., O'Brien, T., Woudsma, C. (2013). Environmental Innovation and the Role of Stakeholder Collaboration in West Coast Port Gateways. Freight Transport and Sustainability, 42(1), 87-96.

Hamel, G. (1991). Competition for Competence and Interpartner Learning within International Strategic Alliances. Strategic Management Journal, 12(S1), 83-103.

Hamel, G., Doz, Y., Prahalad, C.K. (1989). Collaborate With Your Competitors - And Win. Harvard Business Review(January-February), 133-139.

Hamel, G., Prahalad, C.K. (2005). Strategic Intent. Harvard Business Review, 83(7), 148-161.

Hampapur, A., Cao, H., Davenport, A. (2011). Analytics-driven Asset Management. IBM Journal of Research \& Development, 55(1, 2), 138-156.

Hansen, A.V. (2017). Narratives as Driver for Co-creating New Stories of Service. In: Sørensen $\mathrm{F}$ and Lapenta F (eds) Research Methods in Service Innovation: Services, Economy and Innovation series. Cheltenham, UK: Edward Elgar.

Hardy, C., Lawrence, T., Phillips, N. (1998). Talk and Action: Conversations, Narrative and Action in Interorganizational Collaboration. In: Grant D, Keenoy T and Oswick C (eds) Discourse and Organization. London: Sage.

Hardy, C., Lawrence, T.B., Grant, D. (2005). Discourse and Collaboration: The Role of Conversations and Collective Identity. Academy of Management Review, 30(1), 58-77.

Harland, C., Zheng, J., Johnsen, T., Lamming, R. (2004). A Conceptual Model for Researching the Creation and Operation of Supply Networks. British Journal of Management, 15(1), 121.

Harrison, J.S., Hitt, M.A., Hoskisson, R.E., Ireland, R.D. (2001). Resource Complementarity in Business Combinations: Extending the Logic to Organizational Alliances. Journal of Management, 27(6), 679-690.

Hart, C. (1998). Doing a Literature Review. Thousand Oaks: Sage Publications Inc.

Hart, O.D. (1991). Incomplete Contracts and the Theory of the Firm. In O. E. Williamson and S. G. Winter (Eds.), The Nature of the Firm: Origins, Evolution, and Development. New York: Oxford University Press.

Hartley, K. (2008). Collaboration and European Defence Industrial Policy. Defence and Peace Economics, 19(4), 303-315. 
Hawkins, M.A., Saleem, F.Z. (2012). The Omnipresent Personal Narrative: Story Formulation and the Interplay among Narratives. Journal of Organizational Change Management, 25(2), 204-219.

Hayes, G.R., Lee, C.P., Dourish, P. (2011). Organizational Routines, Innovation, and Flexibility: The Application of Narrative Networks to Dynamic Workflow. International Journal of Medical Informatics, 80(8), e161-e177.

Hearnshaw, E.J.S., Wilson, M.M.J. (2013). A Complex Network Approach to Supply Chain Network Theory. International Journal of Operations \& Production Management, 33(4), 442-469.

Heikkilä, M., Solaimani, S., Soudunsaari, A., Hakanen, M., Kuivaniemi, L., Suoranta, M. (2014). Performance Estimation of Networked Business Models: Case Study on a Finnish eHealth Service Project. Journal of Business Models, 2(1), 71-88.

Heimeriks, K.H. (2005). Developing Alliance Capabilities. Technische Universiteit Eindhoven, Eindhoven. (10.6100/IR583585)

Heimeriks, K.H., Bingham, C.B., Laamanen, T. (2014). Unveiling the Temporally Contingent Role of Codification in Alliance Success. Strategic Management Journal, 36(3), 462-473.

Helfat, C.E., Peteraf, M. (2003). The Dynamic Resource-Based View: Capability Lifecycles. Strategic Management Journal, 24(10), 997-1010.

Henderson, J., Venkatraman, N. (1993). Strategic Alignment: Leveraging Information Technology for Transforming Organizations. IBM Systems Journal, 32(1), 476.

Henfridsson, O., Bygstad, B. (2013). The Generative Mechanisms of Digital Infrastructure Evolution. MIS Quarterly, 37(3), 907-931.

Hennart, J-F. (2008). Transaction Costs Perspectives on Inter-Organizational Relations. In S. Cropper, M. Ebers, C. Huxham and P. S. Ring (Eds.), The Oxford Handbook of InterOrganizational Relations (339-365). Oxford: Oxford University Press.

Hennart, J.-F. (1993). Explaining the Swollen Middle: Why Most Transactions are a Mix of "Market" and "Hierarchy". Organization Science, 4(4), 529-547.

Henneberg, S.C., Mouzas, S. (2008). Final Customers' Value in Business Networks. In A.G. Woodside, F. Golfetto and M. Gibbert (Eds.), Creating and Managing Superior Customer Value. Bingley, UK: JAI/Emerald.

Henneberg, S.C., Naude, P., Mouzas, S. (2010). Sense-Making and Management in Business Networks - Some Observations, Considerations, and a Research Agenda. Industrial Marketing Management, 39(3), 355-360.

Herbert, I.P., Seal, W.B. (2012). Shared Services as a New Organisational Form: Some Implications for Management Accounting. The British Accounting Review, 44(2), 83-97.

Hevner, A.R., Chatterjee, S. (2010). Design Research in Information Systems: Theory and Practice. New York: Springer.

Hibbert, P., Huxham, C. (2010). The Past in Play: Tradition in the Structures of Collaboration. Organization Studies, 31(5), 525-554.

Higgins, C., Stubbs, W., Love T. (2014). Walking the Talk(s): Organisational Narratives of Integrated Reporting. Accounting, Auditing \& Accountability Journal, 27(7), 1090-1119.

Hillman, A.J., Keim, G.D. (2001). Shareholder Value, Stakeholder Management, and Social Issues: What's the Bottom Line? Strategic Management Journal, 22(2), 125-139.

Ho, C.H. (2007). Identifiying Stakeholders' Positions through Value Creation System. The Business Review, 7(1), 254-262.

Hobday, M. (2005). Firm-level Innovation Models: perspectives on Research in Developed and Developing Countries. Technology Analysis and Strategic Management, 17(2), 121-146.

Holmström, J., Stadler, F. (2001). Drifting Technologies and Multi-Purpose Networks: The Case of the Swedish Cash Card. Information and Organization, 11(3), 187-206.

Holttinen, H. (2014). Contextualizing Value Propositions: Examining how Consumers Experience Value Propositions in their Practices. Australasian Marketing Journal, 22(2), 103-110.

Hookway, C. (2013). Pragmatism. Stanford Encyclopedia of Philosophy, https://plato.stanford.edu/entries/pragmatism/index.html. 
Hospers, G.-J., Desrochers, P., Sautet, F. (2009). The Next Silicon Valley? On the Relationship between Geographical Clustering and Public Policy. International Entrepreneurship and Management Journal, 5(3), 285-299.

Howcroft, D., Richardson, H. (2012). The Back Office Goes Global: Exploring Connections and Contradictions in Shared Service Centres. Work, Employment and Society, 26(1), 111 127.

Hsiao, R.L., Tsai, S.D.H., Lee, C.F. (2006). The Problem of Embeddedness: Knowledge Transfer, Coordination and Reuse in Information Systems. Organization Studies, 27(9), 1289-1317.

Hsu, M.-H., Chang, C.-M. (2014). Examining Interpersonal Trust as a Facilitator and Uncertainty as an Inhibitor of Intra-organisational Knowledge Sharing. Information Systems Journal, 24(2), 119-142.

Huggins, R. (2010). Forms of Network Resource: Knowledge Access and the Role of Inter-Firm Networks. International Journal of Management Reviews, 12(3), 335-352.

Humair, Salal, Willems, Sean P. (2006). Optimizing Strategic Safety Stock Placement in Supply Chains with Clusters of Commonality. Operations Research, 54(4), 725-742.

Humphries, A.S., Wilding, R. (2004). UK Defence Supply Chain Relationships. Management Decision, 42(2), 259-276.

Huxham, C. (1993). Collaborative Capacity: An Intra-organizational Perspective on Collaborative Advantage. Public Money \& Management, 13(3), 21-28.

Huxham, C. (1996). Creating Collaborative Advantage. London: Sage.

Huxham, C. (2000). The Challenge of Collaborative Governance. Public Management Review, 2(3), 337-357.

Ibarra, H., Barbulescu, R. (2010). Identity as Narrative: Prevalence, Effectiveness, and Consequences of Narrative Identity Work in Macro Work Role Transitions. Academy of Management Review, 35(1), 135-154.

IMP. (2013). B2B Value Chains - The Way We See Them. http://www.teollinenmarkkinointi.fi/en/imp-services/value-chains.

Imran, M.K., Rehman, C.A., Aslam, U., Bilal, A.R. (2016). What's Organization Knowledge Management Strategy for Successful Change Implementation? Journal of Organizational Change Management, 29(7), 1097-1117.

Inderfurth, K., Clemens, J. (2012). Supply Chain Coordination through Risk Sharing Contracts under Different Forms of Yield Uncertainty. Paper presented at the 17th International Symposium on Inventories, Budapest, Hungary.

Inkpen, A.C. (1996). Creating Knowledge through Collaboration. California Management Review, 39(1), 123-140.

Inkpen, A.C., Beamish, P.W. (1997). Knowledge, Bargaining Power, and the Instability of International Joint Ventures. Academy of Management Review, 22(1), 177-202.

Inkpen, A.C., Curall, S.C. (2004). The Coevolution of Trust, Control, and Learning in Joint Ventures. Organization Science, 15(5), 586-599.

Ireland, R.D., Hitt, M.A., Vaidyanath, D. (2002). Alliance Management as a Source of Competitive Advantage. Journal of Management, 28(3), 413-446.

Isbell, M.G. (2012). The Role of Boundary Spanners as the Interorganizational Link in Nonprofit Collaborating. Management Communication Quarterly, 26(2), 159-165.

Jackson, P.T. (2008). Foregrounding Ontology: Dualism, Monism, and IR Theory. Review of International Studies, 34(1), 129-153.

Jacobides, M.G., Winter, S.G. (2005). The Co-evolution of Capabilities and Transaction Costs: Explaining the Institutional Structure of Production. Strategic Management Journal, 26(5), 395-413.

Jamali, D., (2004). Success and Failure Mechanisms of Public Private Partnerships (PPPs) in Developing Countries. The International Journal of Public Sector Management, 17(5), 414430. 
James, E.A., Slater, T., Bucknam, A. (2011). Action Research for Business, Nonprofit, and Public Administration: A Tool for Complex Times. Thousand Oaks, CA: Sage.

James, W. (1907). Pragmatism: A New Name for some Old Ways of Thinking. Cambridge, MA: Harvard University Press.

Janssen, M., Joha, A. (2008). Emerging Shared Service Organizations and the Service-Oriented Enterprise: Critical Management Issues. Strategic Organization, 1(1), 35-49.

Janssen, M., Joha, A., Weerakkoday, V. (2007). Exploring Relationships of Shared Service Arrangements in Local Government. Transforming Government: People, Process and Policy, 1(3), 271-284.

Janssen, M., Joha, A., Zuurmond, A. (2009). Simulation and Animation for Adopting Shared Services: Evaluating and Comparing Alternative Arrangements. Government Information Quarterly, 26(1), 15-24.

Janssen, M., Lee, J., Bharosa, N., Cresswell, A. (2010). Advances in Multi-agency Disaster Management: Key Elements in Disaster Research. Information Systems Frontiers, 12(1), 1-7.

Janzen, D.E. (1980). When is it Coevolution? Evolution, 34(3), 611-612.

Jarvenpaa, S.L., Leidner, D.E. (1997). Do You Read Me? The Development and Maintenance of Trust in Global Virtual Teams. INSEAD Working Paper.

Jarvenpaa, S.L., Majchrzak, A. (2016). Interactive Self-Regulatory Theory for Sharing and Protecting in Interorganizational Collaborations. Academy of Management Review, 41(1), 9-27.

Jarzabkowski, P., Balogun, J., Seidl, D. (2007). Strategizing: The Challenges of a Practice Perspective. Human Relations, 60(1), 5-27.

Jarzabkowski, P., Fenton, E. (2006). Strategizing and Organizing in Pluralistic Contexts. Long Range Planning, 39, 631-648.

Jarzabkowski, P., Kaplan S, Seidl D, Whittington, R. (2015). On the Risk of Studying Practices in Isolation: Linking What, Who and How in Strategy Research. Strategic Organization, 14(3), 248-259.

Jarzabkowski, P., Lê, J.K., Feldman, M.S. (2011). Toward a Theory of Coordinating: Creating Coordinating Mechanisms in Practice. Organization Science, 23(4), 907-927.

Jarzabkowski, P., Lê, J.K., Van de Ven, A.H. (2013). Responding to Competing Strategic Demands: How Organizing, Belonging, and Performing Paradoxes Coevolve. Strategic Organization, 11(3), 245-280.

Jarzabkowski, P., Sillince, J. (2007). A Rhetoric-in-Context Approach to Building Commitment to Multiple Strategic Goals. Organization Studies, 28(11), 1639-1665.

Jayaram, J., Tan, K.-C., Nachiappan, S.P. (2010). Examining the Interrelationships between Supply Chain Integration Scope and Supply Chain Management Efforts. International Journal of Production Research, 48(22), 6837-6857.

Jelinek, M., Romme, A.G.L., Boland, R.J. (2008). Introduction to the Special Issue "Organization Studies as a Science for Design": Creating Collaborative Artifacts and Research. Organization Studies, 29(2), 317-329.

Jensen, M.C. (2010). Value Maximization, Stakeholder Theory, and the Corporate Objective Function. Journal of Applied Corporate Finance, 22(1), 32-42.

Jensen, M.C., Meckling, W.H. (1986). Theory of the Firm: Managerial Behavior, Agency Costs, and Ownership Structure. In J. B. Barney and W. G. Ouchi (Eds.), Organizational Economics. San Francisco: Jossey-Bass.

Jiang L. (2007) Strategic Alliance: Case Study of Lenovo and IBM. University of Nottingham Business School.

Jiang, X., Li, M., Gao, S., Bao, Y., Jiang, F. (2013). Managing Knowledge Leakage in Strategic Alliances: The Effects of Trust and Formal Contracts. Industrial Marketing Management, 42(6), 983-991. 
Jing, R., and Benner, M. (2016). Institutional Regime, Opportunity Space and Organizational Path Constitution: Case Studies of the Conversion of Military Firms in China. Journal of Management Studies, 53(4), 552-579.

Joha, A., Janssen, M. (2010). Public-Private Partnerships, Outsourcing or Shared Service Centres? Motives and Intents for Selecting Sourcing Configurations. Transforming Government: People, Process and Policy, 4(3), 232-248.

Johansson, P. (2008). Implementing Stakeholder Management: A Case Study at a MicroEnterprise. Measuring Business Excellence, 12(3), 33-41.

Johnson, G., Melin, L., Whittington, R. (2003). Micro Strategy and Strategizing: Towards an Activity-based View - Guest Editors' Introduction. Journal of Management Studies, 40(1), 3-22.

Johnston, R., Lawrence, P.R. (1991). Beyond Vertical Integration - The Rise of Value-Adding Partnerships. In G. Thompson, J. Frances, R. Levacic and J. Mitchell (Eds.), Markets, Hierarchies, and Networks: The Coordination of Social Life. London: Sage.

Joncas, H., Kelly, M.J., Schaan, J.L. (2002). Managing Alliance Relationships: Key Challenges in the Early Stages of Collaboration. R\&D Management, 32(1), 11-22.

Jones, C., Hesterly, W.S., Borgatti, S.P. (1997). A General Theory of Network Governance: Exchange Conditions and Social Mechanisms. Academy of Management Review, 22(4), 911-945.

Jones, C., Lichtenstein, B.B. (2008). Temporary Inter-Organizational Projects: How Temporal and Social Embeddedness Enhance Coordination and Manage Uncertainty. In S. Cropper, M. Ebers, C. Huxham and P. Smith Ring (Eds.), The Oxford Handbook of InterOrganizational Relations (231-255). Oxford: Oxford University Press.

Jones, C.A., Galison, P. (1998). Introduction. In C.A. Jones and P. Galison (Eds.), Picturing Science, Producing Art. Oxon, UK: Routledge.

Joutsenvirta, M. (2011). Setting Boundaries for Corporate Social Responsibility: Firm-NGO Relationship as Discursive Legitimation Struggle. Journal of Business Ethics, 102(1), 5775.

Judge, W., Douglas, T. (2009). Organizational Change Capacity: The Systematic Development of a Scale. Journal of Organizational Change Management, 22(6), 635-649.

Julkunen S. (2016). Meanings of Shared Resources in Interorganizational Relationships: A Narrative Study in Retailing. Journal of Relationship Marketing, 15(1-2), 17-34.

Jüttner, U., Godsell, J., Christopher, M.G. (2006). Demand Chain Alignment Competence Delivering Value through Product Life Cycle Management. Industrial Marketing Management, 35(8), 989-1001.

Kaisler, S., Armour, F., Espinosa, J.A., Money, W. (2013). Big Data: Issues and Challenges Moving Forward. Paper presented at the Hawaii International Conference on System Sciences, Hawaii.Kale, P. , Dyer, J. , Singh, H. (2002). Alliance Capability, Stock Market Response and Long-term Alliance Succes: The Role of the Alliance Function. Strategic Management Journal, 28(8), 747-767.

Kalakota, R., Robinson, M. (2003). Services Blueprint: Roadmap for Execution. Reading, MA: Addison-Wesley Professional.

Kale, P., Dyer, J.H., Perlmutter, H. (2000). Learning and Protection of Proprietary Assets in Strategic Alliances: Building Relational Capital. Strategic Management Journal, 21(2), 217237.

Kale, P., Dyer, J.H., Singh, H. (2002). Alliance Capability, Stock Market Response, and LongTerm Alliance Success: The Role of the Alliance Function. Strategic Management Journal, 23(8), 747-767.

Kale, P., Puranam, P. (2013). The Design of Equity Ownership in Inter-Firm Relationships: Do Managers Choose According to Theory? Journal of Organization Design, 2(2), 15-30.

Kale, P., Singh, H. (2007). Building Firm Capabilities through Learning: the role of the Alliance Learning Process in Alliance Capability and Firm-Level Alliance Succes, Strategic Management Journal, 28(10), 981-1000. 
Kale, P., Singh, H. (2009). Managing Strategic Alliances: What Do We Know Now, and Where Do We Go From Here? Academy of Management Perspectives, 23(3), 45-62.

Kamal, M.M. (2012). Shared Services: Lessons from Private Sector for Public Sector Domain. Journal of Enterprise Information Management, 25(5), 431-440.

Kang, S.-C., Morris, S.S., Snell, S.A. (2007). Relational Archetypes, Organizational Learning, and Value Creation: Extending the Human Resource Architecture. Academy of Management Review, 32(1), 236-256.

Kannan, V.R., Tan, K.C. (2005). Just in Time, Total Quality Management, and Supply Chain Management: Understanding their Linkages and Impact on Business Performance Omega, 33(2), 153-162.

Kaplan, S. (2008). Framing Contests: Strategy Making under Uncertainty. Organization Science, 19(5), 729-752.

Kaplan, S. (2011a) Research in Cognition and Strategy: Reflections on Two Decades of Progress and a Look to the Future. Journal of Management Studies, 48(3), 665-695.

Kaplan, S. (2011b). Strategy and PowerPoint: An Inquiry into the Epistemic Culture and Machinery of Strategy Making. Organization Science, 22(2), 320-346.

Kaplan, R.S., Norton, D.P. (1996). Using the Balanced Scorecard as a Strategic Management System. Harvard Business Review(January-February), 3-13.

Kaplan, R.S., Norton, D.P. (2004). Strategy Maps: Converting Intangible Assets Into Tangible Outcomes. Boston: Harvard Business Press.

Kaplan, R.S., Norton, D.P., Rugelsjoen, B. (2010). Managing Alliances with the Balanced Scorecard. Harvard Business Review(January-February), 114-120.

Kapoor, R (2013). Collaborative Innovation Holds Key to Semiconductor Industry Growth. 'Future of Industries' series white paper produced by Knowledge@Wharton, Wharton University, Aviable from http://knowledge.wharton.upenn.edu.

Kapucu, N., Garayev, V. (2012). Designing, Managing, and Sustaining Functionally Collaborative Emergency Management Networks. The American Review of Public Administration, 43(3), 312-330.

Karsten, F., Basten, R.J.I. (2014). Pooling of Spare Parts between Multiple Users: How to Share the Benefits? European Journal of Operational Research, 233(1), 94-104.

Katzy, B.R., Crowston, K. (2007). Competency Rallying Processes in Virtual Organizations. In IFIP (Ed.), Virtuality and Virtualization. Heidelberg: Springer.

Keebler, J.S., Plank, R.E. (2009). Logistics Performance Measurement in the Supply Chain: A Benchmark. Benchmarking: An International Journal, 16(6), 785-798.

Keen, P., Williams, R. (2013). Value Architectures for Digital Business: Beyond the Business Model. MIS Quarterly Executive, 37(2), 643-647.

Keers, B.B.M., Van Fenema, P.C. (2015). Alliance Performance Management in Service Logistics. Journal of Organization Design 4(1), 12-28.

Kehler, N. (Producer). (2004, 2016, February 25). Interorganizational Relationships and Learning.

Keller, A., Ludwig, H. (2003). The WSLA Framework: Specifying and Monitoring Service Level Agreements forWeb Services. Journal of Network and Systems Management, 11(1), 5781.

Kerkhof, R.M., Akkermans, H.A., Noorderhaven, N.G. (2016). Knowledge Lost in Data: Organizational Impediments to Condition-Based Maintenance in the Process Industry, in H. Zijm, M. Klumpp, U. Clausen and M. ten Hompel (eds.), Logistics and Supply Chain Innovation: Bridging the Gap between Theory and Practice (223-237). Cham: Springer International Publishing.

Ketchen Jr, D.J., Hult, G.T.M. (2007). Bridging Organization Theory and Supply Chain Management: The Case of Best Value Supply Chains. Journal of Operations Management, 25(2), 573-580. 
Ketchen Jr, D.J., Thomas, J.B., McDaniel Jr, R.B. (1996). Process, Content and Context: Synergistic Effects on Organizational Performance. Journal of Management, 22(2), 231257.

Khatri, V., Brown, C.V. (2010). Designing Data Governance. Communications of the ACM, 53(1), 148-152.

Kijkuit, B., Van den Ende, J.E. (2010). With a Little Help from Our Colleagues: A Longitudinal Study of Social Networks for Innovation. Organization Studies, 31(4), 451-479.

King, A. (2004). The Structure of Social Theory. London: Routledge.

Kinney, G.F., Wiruth, A.D. (1976). Practical Risk Analysis for Safety Management. California: NWC TP 5865.

Kirk, J., Miller, M.L. (1986). Reliability and Validity in Qualitative Research. Beverly Hills: Sage.

Kivleniece, I., Quelin, B.V. (2012). Creating and Capturing Value in Public-Private Ties: A Private Actor's Perspective. Academy of Management Review, 37(2), 272-299.

Kleemann, F.C., Essig, M. (2013). A Providers' Perspective on Supplier Relationships in Performance-Based Contracting. Journal of Purchasing \& Supply Management, 19(3), 185-198.

Klievink, B., Bharosa, N., Tan, Y.-H. (2016). The Collaborative Realization of Public Values and Business Goals: Governance and Infrastructure of Public-Private Information Platforms. Government Information Quarterly, 33(1), 67-79.

Klijn, E. H. (2010). Public Private Partnerships: Deciphering Meaning, Message and Phenomenon. In G. Hogde and C. Greve (Eds.), International Handbook of PPP. Cheltenham: Edgar Elgar.

Klijn, E.H., Koppenjan, J.F.M. (2012). Governance Network Theory: Past, Present and Future. Policy \& Politics, 40(4), 187-206.

Knight, L. (2002). Network Learning: Exploring Learning by Interorganizational Networks. Human Relations, 55(4), 427-454.

Kogut, B., and Zander, U. (1992). Knowledge of the Firm, Combinative Capabilities and the Replication of Technology. Organization Science, 3(3), 383-397.

Kogut, B., Zander, U. (1996). What Firms Do? Coordination, Identity, and Learning. Organization Science, 7(5), 502-518.

Kohl, H., Cap, J.-P., Blaich, E., von Raesfeld, A. (2015). The Innovation Network Scoreboard: Towards Key Performance Indicators for the Assessment of Innovation Networks. Paper presented at the 10th European Conference on Innovation and Entrepreneurship, Genoa, Italy.

Kohlbacher, M. (2013). The Impact of Dynamic Capabilities through Continuous Improvement on Innovation: The Role of Business Process Orientation. Knowledge and Process Management, 20(2), 71-76.

Koppenjan, J.F.M. (2005). The Formation of Public-Private Partnerships: Lessons from Nine Transport Infrastructure Projects in The Netherlands. Public Administration, 83(1), 135157.

Kor, Y.Y., Mahoney, J.T. Michael, S.C. (2007). Resources, Capabilities and Entrepreneurial Perceptions. Journal of Management Studies, 44(7), 1187-1212.

Koschmann, M.A., Kuhn, T.R. Pfarrer, M.D. (2012). A Communicative Framework of Value in Cross-Sector Partnerships. Academy of Management Review, 37(3), 332-354.

Kothandaraman, P., Wilson, D.T. (2001). The Future of Competition: Value-Creating Networks. Industrial Marketing Management, 30(4), 379-389.

Kourti I. (2015). Achieving Collaborative Aims through Multiple Identity Construction: Managing a Public Inter-Organizational Collaboration. Border Crossing 5: http://www.tplondon.com/journal/index.php/bc/article/viewFile/477/367.

Kovács, G., Spens, K.M. (2005). Abductive Reasoning in Logistics Research. International Journal of Physical Distribution and Logistics Management, 35(2), 132-144.

Koza, M.P., Lewin, A.Y. (1998). The Co-evolution of Strategic Alliances. Organization Science, $9(3), 255-264$. 
Kraimer, M.L. (1997). Organizational Goals and Values: A Socialization Model. Human Resource Management Review 7(4), 425-447.

Krane, H.P., Olsson, N.O.E., Rolstadas, A. (2012). How Project Manager-Project Owner Interaction Can Work within and Influence Project Management. Project Management Journal, 43(2), 54-67.

Kuijken, B., Gemser, G., Wijnberg, N.M. (2017). Effective Product-Service Systems: A Valuebased Framework. Industrial Marketing Management, 60(SI), 33-41.

Kumar, K., Van Dissel, H., G. (1996). Sustainable Collaboration: Managing Conflict and Cooperation in Inter-Organizational Systems. MIS Quarterly, 20(3).

Kumar, K., Van Fenema, P.C., Von Glinow, M.A. (2009). Offshoring and the Global Distribution of Work: Implications for Task Interdependence Theory and Practice. Journal of International Business Studies, 40(4), 642-667.

Kumar, K., Van Hillegersberg, J. (2008). Bank-in-a-Box: An ICT Architecture for Enabling Agile Transformation of Financial Services. Managerial Finance, 34(6), 413-422.

Ladley, J. (2012). Data Governance: How to Design, Deploy, and Sustain an Effective Data Governance Program. Waltham, MA: Morgan Kaufmann Publishers.

Lai, F., Zhang, M., Lee, D.M.S., Zhao, X. (2012). The Impact of Supply Chain Integration on Mass Customization Capability: An Extended Resource-Based View. IEEE Transactions on Engineering Management, 59(3), 443-456.

Laine, P.-M., Vaara, E. (2007). Struggling over Subjectivity: A Discursive Analysis of Strategic Development in a Group. Human Relations, 60(1), 29-58.

Lambe, C.J., Spekman, R.E., Hunt, S.D. (2002). Alliance Competence, Resources, and Alliance Success: Conceptualization, Measurement, and Initial Test. Journal of the Academy of Marketing Science, 30(2), 141-158.

Landrum, N.E. (2008). A Narrative Analysis Revealing Strategic Intent and Purpose. Qualitative Research in Organizations and Management: An International Journal, 3(2), 127-146.

Lane, P.J., Koka, B.R., Pathak, S. (2006). The Reification of Absorptive Capacity: A Critical Review and Rejuvenation of the Construct. Academy of Management Review, 31(4), 833863.

Lane, P.J., Lubatkin M. (1998). Relative Absorptive Capacity and Interorganizational Learning. Strategic Management Journal, 19(5), 461-477.

Langefield-Smith. (2008). The Relations Between Transactional Characteristics, Trust and Risk in the Strat-up Phase of a Collaborative Alliance. Management Accounting Research, 19, 344-364.

Langley, A. (1999). Strategies for Theorizing from Process Data. Academy of Management Review, 24(4), 691-710.

Langley, A., Smallman, C., Tsoukas, H., Van de Ven, A. H. (2013). Process Studies of Change in Organization and Management: Unveiling Temporality, Activity, and Flow. Academy of Management Journal, 56(1), 1-13.

Laplume, A.O., Sonpar, K., Litz, R.A. (2008). Stakeholder Theory: Reviewing a Theory that Moves Us. Journal of Management, 34(6), 1152-1189.

Larsen, C., Nielsen, L.R., Wong, H. (2012). Spare Parts Sharing with Joint Optimization of Maintenance and Inventory Policies. Paper presented at the 17th International Symposium on Inventories, Budapest, Hungary.

Laszczuk, A., Garreau, L., De Montmorillon, B. (2017). Emergence in Business Model Development: Interaction with Stakeholders to Deal with Ambiguity. Paper presented at the Annual Meeting of the Academy of Management, Atlanta, GA.

Lawlor, M.S. (2006). William James's Psychological Pragmatism: Habit, Belief and Purposive Human Behaviour. Cambridge Journal of Economics, 30(3), 321-345.

Lawrence, P.R., Lorsch, J.W. (1967). Organization and Environment: Managing Differentiation and Integration. Boston, MA: Harvard University Press. 
Lawrence, T.B., Phillips, N., Hardy. C. (1999). Watching Whale Watching: Exploring the Discursive Foundations of Collaborative Relationships. Journal of Applied Behavioral Science, 35(4), 479-502.

Lazonick, W., Mazzucato, M. (2013). The Risk-reward Nexus in the Innovation-Inequality Relationship: Who Takes the Risks? Who Gets the Rewards? Industrial and Corporate Change, 22(4), 1093-1128.

LBS. (2012). Opportunities for Greater Lincolnshire Supply Chains.

http://www.greaterlincolnshirelep.co.uk/assets/downloads/Supply_Chains_FINAL_report_f ull.pdf: Lincoln Business School, ADA.

Le, J.K., Jarzabkowski, P. (2014). The Role of Task and Process Conflict in Strategizing. British Journal of Management, 26(3), 439-462.

Lee, A.S. (1991). Integrating Positivist and Interpretive Approaches to Organizational Research. Organization Science, 2(4), 342-365.

Leonard, D. (1988). Implementation as Mutual Adaptation of Technology and Organization. Research Policy, 17(5), 251-267.

Leonardi, P.M. (2013a). The Emergence of Materiality within Formal Organizations. In P. R. Carlile, D. Nicolini, A. Langley and H. Tsoukas (Eds.), How Matter Matters: Objects, Artifacts and Materiality in Organization Studies (pp. 142-170). Oxford: Oxford University Press.

Leonardi, P.M. (2013b). Theoretical Foundations for the Study of Sociomateriality. Information and Organization, 23, 59-76.

Leonardi, P.M. (2017). Methodological Guidelines for the Study of Materiality and Affordances. In M. Raza, S. Jain (Eds.), Routledge Companion to Qualitative Research in Organization Studies (pp. 142-170). New York: Routledge.

Lepak, D.P., Smith, K.G., Taylor, M.S. (2007). Value Creation and Value Capture: A Multilevel Perspective. Academy of Management Review, 32(1), 180-194.

Levering, R., Ligthart, R., Noorderhaven, N.G., Oerlemans, L.A.G. (2013). Continuity and Change in Interorganizational Project Practices: The Dutch Shipbuilding Industry, 19502010. International Journal of Project Management, 31(5), 735-747.

Levina, N., Ross, J.W. (2003). From the Vendor's Perspective: Exploring the Value Proposition in Information Technology Outsourcing. MIS Quarterly, 27(3), 331-364.

Levina, N., Su, N. (2008). Global Multisourcing Strategy: The Emergence of a Supplier Portfolio in Services Offshoring. Decision Sciences, 39(3), 541-570.

Levina, N., Vaast, E. (2005). The Emergence of Boundary Spanning Competence in Practice: Implications for Implementation and Use of Information Systems. MIS Quarterly, 29(2), 335-363.

Levine, S.S., Prietula, M.J. (2014). Open Collaboration for Innovation: Principles and Performance. Organization Science, 25(5), 1414-1433.

Lewin, A.Y., Massini, S., Peeters, C. (2011). Microfoundations of Internal and External Absorptive Capacity Routines. Organization Science, 22(1), 81-98.

Lewis, M.W., Dehler, G.E. (2012). Learning through Paradox: A Pedagogical Strategy for Exploring Contradictions and Complexity. Journal of Management Education, 24(6), 708725.

Leydesdorff, L., Ivanova, I. (2016). "Open Innovation" and "Triple Helix" Models of Innovation: Can Synergy in Innovation Systems be Measured? Journal of Open Innovation: Technology, Market, and Complexity, 2(1), 1-12.

Li, P.-F. (2014). Global Temporary Networks of Clusters: Structures and Dynamics of Trade Fairs in Asian Economies. Journal of Economic Geography, 14(5), 995-1021.

Lia, J., Sikorab, R., Shawa, M.J., Tan, G.W. (2006). A Strategic Analysis of Interorganizational Information Sharing. Decision Support Systems, 42(1), 251-266.

Lichtenthaler, U. (2011). Open Innovation: Past Research, Current Debates, and Future Directions. Academy of Management Perspectives, 25(1), 75-93. 
Lijphart, A. (1975). The Comparable-Cases Strategy in Comparative Research. Comparative Political Studies, 8(2), 158-177.

Lin N. (2008) A Network Theory of Social Capital. In: Osborne SP (ed) The Handbook of Social Capital. New York, NY: Taylor \& Frances.

Liu, C.H., Matthews, R. (2005). Vygotsky's Philosophy: Constructivism and its Criticisms Examined. International Education Journal, 6(3), 386-399.

Loebbecke, C., Van Fenema, P.C., Powell, P. (2000). Towards A Theory of IS-Supported InterOrganisational Knowledge Exchange. In C. Murphy and P. Finnegan (Eds.), Information Systems at the Core: European Perspectives on Deploying and Managing Information Systems in Business (pp. 88-99). Dublin: Blackhall.

Loebbecke, C., Van Fenema, P.C., Powell, P. (2016). Managing Interorganizational Knowledge Sharing. Journal of Strategic Information Systems, 25(1), 4-14.

Loebbecke, C., Picot, A. (2015). Reflections on Societal and Business Model Transformation Arising from Digitization and Big Data Analytics: A Research Agenda. Journal of Strategic Information Systems, 24(3), 149-157.

Lofland J and Lofland LH. (1995) Analyzing Social Settings: A Guide to Qualitative Observation and Analysis, Belmont, CA: Wadsworth.

London, N., Pogue, G., Spinuzzi, C. (2015). Understanding the Value Proposition as a Cocreated Claim. IEEE Professional Communication Society International Professional Communication Conference.

Long, Y. Zhai, S. (2010). Risk Control in Business Alliances of SMEs: A Case Study of SMEs in Zhejiang Province. Retrieved from hhrp://http://www.divaportal.org/smash/get/diva2:352524/FULLTEXT01 website:

Loock, M., Hacklin F. (2015). Business Modelling as Configuring Heuristics. In: Baden-Fuller C and Mangematin V (eds) Business Models and Modelling Bingley, United Kingdom: Emerald.

Lorand, R. (2000) Aesthetic Order, London: Routledge.

Lorell, M.A. (1980). Multinational Development of Large Aircraft: The European Experience. Santa Monica, CA: RAND Corporation.

Lorenzen, M. (2005). Editorial : Why do Clusters Change? European Urban and Regional Studies, 12(3), 203-208.

Lowe, S., Rod, M., Hwang, K.-S. (2016). Understanding Structures and Practices of MeaningMaking in Industrial Networks. Journal of Business \& Industrial Marketing, 31(4), 531-542.

Lumineau, F., Frechet, M., Puthod, D. (2011). An Organizational Learning Perspective on the Contracting Process. Strategic Organization, 9(1), 8-32.

Lunnan, R., Haugland, S.A. (2008). Predicting and Measuring Alliance Performance: A Multidimensional Analysis. Strategic Management Journal, 29(5), 545-556.

Luo, Y., Shenkar, O., Gurnani, H. (2008). Control-Cooperation Interfaces in Global Strategic Alliances: A Situational Typology and Strategic Responses. Journal of International Business Studies, 39(3), 428-453.

Lusch, R.F., Vargo, S.L. (2006). Service-Dominant Logic: Reactions, Reflections and Refinements. Marketing Theory, 6(3), 281-288.

Lusch, R.F., Vargo, S.L., Tanniru, M. (2010). Service, Value Networks and Learning. Journal of the Academy of Marketing Science, 38(1), 19-31.

Maas, J.B., Van Fenema, P.C., Schakel, J.K. (2014). Business Analytics as a Method for Military Organizations. In P. Shields, J.M.M.L. Soeters and S.J.H. Rietjens (Eds.), Routledge Handbook on Research Methods in Military Studies. London: Routledge.

Maas, J.B., Van Fenema, P.C., Soeters, J.M.M.L. (2016). ERP as an Organizational Innovation: Key Users and Cross-boundary Knowledge Management. Journal of Knowledge Management, 20(3), 557-577.

Maclntosh, E., Spence, K. (2012). An Exploration of Stakeholder Values: In Search of Common Ground within an International Sport and Development Initiative. Sport Management Review, 15(4), 404-415. 
Madhok, A., Keyhani, M., Bossink, B. (2015). Understanding Alliance Evolution and Termination: Adjustment Costs and the Economics of Resource Value. Strategic Organization, 13(2), 91-116.

Magala, S. (2009). The Management of Meaning in Organizations. Hampshire, UK: Palgrave Macmillan.

Maguire, S., Hardy, C. (2005). Identity and Collaborative Strategy in the Canadian HIVIAIDS Treatment Domain. Strategic Organization, 3(1), 11-46.

Mahon, D. (2007). Performance-Based Logistics: Transforming Sustainment. Journal of Contract Management, 5(1), 53-71.

Maines, D. (1982). In Search of Mesostructure: Studies in the Negotiated Order. Urban Life, 11(3), 267-279.

Mair, A. (1999). Learning from Honda. Journal of Management Studies, 36(1), 25-44.

Maitlis, S., Christianson, M. (2014). Sensemaking in Organizations: Taking Stock and Moving Forward. The Academy of Management Annals, 8(1) 57-125.

Maitlis, S., Sonenshein, S. (2010). Sensemaking in Crisis and Change: Inspiration and Insights From Weick (1988). Journal of Management Studies, 47(3), 551-580.

Majchrzak, A., Jarvenpaa, S.L., Bagherzadeh, M. (2015). A Review of Interorganizational Collaboration Dynamics. Journal of Management, 41(5), 1338-1360.

Majchrzak, A., Jarvenpaa, S.L., Hollingshead, A.B. (2007). Coordinating Expertise Among Emergent Groups Responding to Disasters. Organization Science, 18(1), 147-161.

Majchrzak, A., Rice, R.E., Malhotra, A., King, N, Ba, S. (2000). Technology Adaptation: The Case of a Computer-Supported Inter-Organizational Virtual Team. MIS Quarterly, 24(4), 569-600.

Makadok, R., Coff, R. (2009). Both Market and Hierarchy: An Incentive-System Theory of Hybrid Governance Forms. Academy of Management Review, 34(2), 297-319.

Mäläskä, M., Saraniemi, S., Tähtinen, J. (2011). Network Actors' Participation in B2B SME Branding. Industrial Marketing Management, 40(7), 1144-1152.

Malgonde, O., Bhattacherjee, A. (2014). Innovating Using Big Data: A Social Capital Perspective. Paper presented at the Twentieth Americas Conference on Information Systems, Savannah, GA.

Malhotra, A., Majchrzak, A., Carman, R., Lott, V. (2001). Radical Innovation without Collocation: A Case Study at Boeing-Rocketdyne. MIS Quarterly, 25(2), 229-249.

Mamavi, O., Meier, O., Zerbib, R. (2015). Alliance Management Capability: The Roles of Alliance Control and Strength of Ties. Management Decision, 53(10), 2250-2267.

Mandal, P., Love, P.E.D., Irani, Z. (2003). Pre-Alliance Planning: Development of an Information System Infrastructure to Support Strategic Alliance Activities. Management Decision, 41(2), 132-140.

Mandell, M.P., Keast, R. (2008). Evaluating the Effectiveness of Interorganizational Relations through Networks: Developing a Framework for Revised Performance Measures. Public Management Review, 10(6), 715-731.

Mantere, S., Vaara, E. (2008). On the Problem of Participation in Strategy: A Critical Discursive Perspective. Organization Science, 19(2), 341-358.

Marcum, C.S., Bevc, C.A., Butts, C.T. (2012). Mechanisms of Control in Emergent Interorganizational Networks. The Policy Studies Journal, 40(3), 516-546.

Markand, J., Truffer, B. (2008). Technological Innovation Systems and the Multi-level Perspective: Towards an Integrated Framework. Research Policy, 37(4), 596-615.

Martinez, V., Bititci, U. (2006). Aligning Value Propositions in Supply Chains. International Journal of Value Chain Management 1(1), 6-8.

Martins, L.L., Rindova, V., Greenbaum, B.E. (2015). Unlocking the Hidden Value of Concepts: A Cognitive Approach to Business Model Innovation. Strategic Entrepreneurship Journal, 9(1), 99-117. 
Mason, R., Lalwani, C., Boughton, R. (2007). Combining Vertical and Horizontal Collaboration for Transport Optimisation. Supply Chain Management: An International Journal, 12(3), 187-199.

Matinheikki, J., Rajala, R., Peltokorpi, A. (2016). From the Profit of one toward Benefitting Many - Crafting a Vision of Shared Value Creation. Journal of Cleaner Production, In Press.

Matlay, H. (2011). The Influence of Stakeholders on Developing Enterprising Graduates in UK HEls. International Journal of Entrepreneurial Behaviour \& Research, 17(2), 166-182.

Matthyssens, P., Vandenbempt, K., Berghman, L. (2006). Value Innovation in Business Markets: Breaking the Industry Recipe. Industrial Marketing Management, 35(6), 751-761.

Mattsson, L.G., Corsaro, D., Ramos, C. (2015). Sense-Making in Business Markets - The Interplay between Cognition, Action and Outcomes. Industrial Marketing Management, 48(Special Issue), 4-11.

Maull, R., Geraldi, J., Johnston, R. (2012). Service Supply Chains: A Customer Perspective. Journal of Supply Chain Management, 48(4), 72-86.

Mayring, P. (2000). Qualitative Content Analysis. Retrieved 10 March, 2016, from http://www.qualitative-research.net/index.php/fqs/article/view/1089/2385

McAfee, A., Brynjolfsson, E. (2012). Big Data: The Management Revolution. Harvard Business Review, 1, 3-9.

McDermot, C.L. (2011). Trust, Legitimacy and Power in Forest Certification: A Case Study of the FSC in British Columbia. Geoforum, 43(3), 634-644.

Mclvor, R., McCracken, M., McHugh, M. (2011). Creating Outsourced Shared Services Arrangements: Lessons from the Public Sector. European Management Journal, 29(6), 448-461.

McKelvey, B. (2004). Toward a Complexity Science of Entrepreneurship. Journal of Business Venturing, 19(3), 313-341.

McNiff, J. (2003). Action Research: Principles and Practice (2nd ed.). New York: Routledge Falmer.

Meier, H., Roy, R., Seliger, G. (2010). Industrial Product-Service Systems-IPS2. CIRP Annals Manufacturing Technology, 59(2), 607-627.

Meijerink, J.G. , Bondarouk, T.V. (2013). Exploring the Central Characteristics of HR Shared Services: Evidence from a Critical Case Study in The Netherlands. International Journal of Human Resource Management, 24(3), 487-513.

Mena, C., Humphries, A., Choi, T.Y. (2013). Toward a Theory of Multi-Tier Supply Chain Management. Journal of Supply Chain Management, 49(2), 58-77.

Merli, G. (2013). The Transformation of the Business Model: Business Modelling. In L. Cinquini, A. Di Minin, R. Varaldo (Eds.), New Business Models and Value Creation: A Service Science Perspective. Milan: Springer.

Messinger, P.R. (2013). Municipal Service Delivery: A Multi-Stakeholder Framework. Human Factors and Ergonomics in Manufacturing \& Service Industries, 23(1), 37-46.

Metcalfe, M. (2014). How Concepts Solve Management Problems. Cheltenham, UK: Edward Elgar.

Michailova, S., Ang, S.H. (2008). Institutional Explanations of Cross-border Alliance Modes: The Case of Emerging Economies Firms. Management International Review, 48(5), 551-576.

Miles, M.B., Huberman AM. (1994) Qualitative Data Analysis: An Expanded Sourcebook, Thousand Oaks, CA: Sage.

Miller, D., Droge, C., Toulouse, J.-M. (1988). Strategic Process and Content as Mediators Between Organizational Context and Structure. Academy of Management Journal, 31(3), 544-569.

Minkiewicz, J., Bridson, K., Evans, J. (2016). Co-Production of Service Experiences: Insights from the Cultural Sector. Journal of Services Marketing, 30(7).

Mitroff, I.I., Kilmann, R.H. (1975). Stories Managers Tell: A New Tool for Organizational Problem Solving. Management Review, 64(7), 18-28. 
Mitsuhashi, H. (2002). Uncertainty in Selecting Alliance Partners: The Three reduction Mechanisms and Alliance Formation Processes. The International Journal of Organizational Analysis, 10(2), 109-133.

Mitsuhashi, H., Greve, H.R. (2009). A Matching Theory of Alliance Formation and Organizational Success: Complementarity and Compatibility. Academy of Management Journal, 52(5), 975-995.

Moelker, R. (2014). The Genesis of the "Dutch Approach" to Asymmetric Conflicts: Operations in Uruzgan and the "Softly, Softly" Manner of Approaching the Taleban. Armed Forces \& Society, 40(1), 96-117.

Mohammed, I.R., Shankar, R., Banwet, D.K. (2008). Creating Flex-Lean-Agile Value Chain by Outsourcing: An ISM-based Interventional Roadmap. Business Process Management Journal, 14(3), 338-389.

Mohr, J., Spekman, R. (1994). Characteristics of Partnership Succes: Partnership Attributes, Communication Behavior, and Conflict Resolution Techniques. Strategic Management Journal, 15(2), 135-152.

Mohr, L.B. (1982). Explaining Organizational Behavior: The Limits and Possibilities of Theory and Research (Vol. 16). San Francisco, CA: Jossey-Bass.

Möller, K., Rajala, A. (2007). Rise of Strategic Nets - New Modes of Value Creation. Industrial Marketing Management, 36(7), 895-908.

Möller, K., Svahn, S. (2003). Managing Strategic Nets A Capability Perspective. Marketing Theory, 3(2), 201-226.

Moller, K.K., Wilson, D.T. (2006). Business Marketing: An Interaction and Network Perspective. Boston: Kluwer.

Montfort, N. (2007). Ordering Events in Interactive Fiction Narratives. Intelligent Narrative Technologies AAAI Fall Symposium, November 9-11, 2007, Washington, DC, http://nickm.com/if/FS06MontfortN.pdf.

Moore, M.H. (1995). Creating Public Value: Strategic Management in Government. London: Harvard University Press.

Morabito, M.S. (2010). Understanding Community Policing as an Innovation: Patterns of Adoption. Criminology \& Penology, 56(4), 564-587.

Moran, M., Rein, M., Goodin, R.E. (2008). The Oxford Handbook of Public Policy, Oxford: Oxford University Press.

Moretti, A., Zirpoli F. (2016). A Dynamic Theory of Network Failure: The Case of the Venice Film Festival and the Local Hospitality System. Organization Studies, 37(5), 607-633.

Morgan, D.L. (2007). Paradigms Lost and Pragmatism Regained: Methodological Implications of Combining Qualitative and Quantitative Methods. Journal of Mixed Methods Research, 1(1), 48-76.

Morris, M., Schindehutte, M., Allen, J. (2005). The Entrepreneur's Business Model: Toward a Unified Perspective. Journal of Business Research, 58(6), 726-735.

Mosley, M. (2008). DAMA-DMBOK Functional Framework, Ver. 3.02. Middletown, DE: Data Management Association (DAMA International).

Mowery, D.C. (1996). Strategic Alliances and Interfirm Knowledge Transfer. Strategic Management Journal, 17(Winter), 77-91.

Mukherjee, D., Gaur, A.S., Gaur, S.S., Schmid, F. (2013). External and Internal Influences on R\&D Alliance Formation: Evidence from German SMEs. Journal of Business Research, 66(11), 2178-2185.

Murray, D.J., Rentell, P.G. (2008). Procurement as a Shared Service in English Local Government. International Journal of Public Sector Management, 21(5), 540-555.

Murray, F. (2002). Innovation as Co-evolution of Scientific and Technological Networks: Exploring Tissue Engineering. Research Policy, 31(8), 1389-1403.

Muzellec, L., Ronteau, S., Lambkin, M. (2015). Two-sided Internet Platforms: A Business Model Lifecycle Perspective. Industrial Marketing Management, 45(2), 139-150. 
Myers, M.D., Klein, H.K. (2011). A Set of Principles for Conducting Critical Research in Information Systems. MIS Quarterly, 35(1), 17-36.

Mylan, J. (2015). Understanding the Diffusion of Sustainable Product-Service Systems: Insights from the Sociology of Consumption and Practice theory. Journal of Cleaner Production, 97(15), 13-20.

Nag, R., Corley, K.G., Gioia, D.A. (2007). The Intersection of Organizational Identity, Knowledge, and Practice: Attempting Strategic Change via Knowledge Grafting. Academy of Management Journal, 50(4), 821-847.

Nag, R., Hambrick, D.C., C, M.-J. (2007). What is Strategic Management, Really? Inductive Derivation of a Consensus Definition of the Field. Strategic Management Journal, 28(9), 935-955.

NASCIO. (2009). Data Governance Part II: Maturity Models - A Path to Progress. Lexington, KY: Nascio.org.

Neely, A. (2008). Exploring the Financial Consequences of the Servitizaton of Manufacturing. Operations Management Research, 1(2), 13-18.

Neely, A. (2013). What is Servitization? http://andyneely.blogspot.nl/2013/11/what-isservitization.html. Retrieved February 16, 2016.

Neely, A., Adams, C. (2003). The Performance PRISM in Action. Control(February), 14-17.

Neely, A., Adams, C., Crowe, P. (2001). The Performance PRISM in Practice. Management Business Excellence, 5(2), 6-11.

Neely, A., Adams, C., Kennerley, M. (2002). The Performance Prism: The Scorecard for Measuring and Managing Business Success. Upper Saddle River, NJ: Pearson.

Nelson, J.C., Rashid, H., Galvin, V.G., Essien, J.D.K., Levine, L.M. (1999). Public/Private Partners: Key Factors in Creating a Strategic Alliance for Community Health. American Journal of Preventive Medicine, 16(3 Suppl.), 94-102.

Nenonen, S., Storbacka, K. (2010). Business Model Design: Conceptualizing Networked Value Co-creation. International Journal of Quality and Service Sciences, 2(1), 43-59.

Ng, I.C.L., Nudurupati, S.S., Tasker, P. (2010) Value Co-creation in the Delivery of Outcomebased Contracts for Business-to-business Service. AIM Reserach Working Paper Series May: 1-48.

Ng, I., Parry, G., Smith, L., Maull, R., Briscoe, G. (2012). Transitioning from a Goods-Dominant to a Service-Dominant Logic: Visualising the Value Proposition of Rolls-Royce. Journal of Service Management, 23(3), 416-439.

Ngo, L.V., O'Cass, A. (2010). Value Creation Architecture and Engineering: A Business Model Encompassing the Firm-customer Dyad. European Business Review, 22(5), 496-514.

Niehaves, B., Krause, A. (2010). Shared Service Strategies in Local Government - A Multiple Case Study Exploration. Transforming Government: People, Process and Policy, 4(3), 266-279.

Nijkamp, P., Van der Burch, M., Vindigni, G. (2002) A Comparative Institutional Evaluation of Public-Private Partnerships in Dutch Urban Land-use and Revitalisation Projects. Urban Studies, 39(10), 1865-1880.

Nonaka, I. (1994). A Dynamic Theory of Organizational Knowledge Creation. Organization Science, 5(1), 14-37.

Nonaka, I., G. von Krogh, Nishiguchi, T. (2000). Knowledge Creation: A Source of Value. New York: St. Martin's Press Inc.

Nooteboom, B. (1996). Trust, Opportunism and Governance: A Process and Control Model. Organization Studies, 17(6), 985-1010.

Nooteboom, B. (1999). Inter-Firm Alliances. London: Routledge.

Nooteboom, B. (2008). Learning and Innovation in Interorganizational Relationships. In C. e. al. (Ed.), The Oxford Handbook of Interorganizational Relationships. New York: Oxford University Press.

Nooteboom, B., Berger, H., Noorderhaven, N.G. (1997). Effects of Trust and Governance on Relational Risk. Academy of Management Journal, 40(2), 308-338. 
Nylén, D., Holmström, J. (2015). Digital Innovation Strategy: A Framework for Diagnosing and Improving Digital Product and Service Innovation. Business Horizons, 58(1), 57-67.

O'Mahony, S., Bechky, B.A. (2008). Boundary Organizations: Enabling Collaboration among Unexpected Allies. Administrative Science Quartely, 53(3), 422-459.

Öberg, C. (2016). Let's Talk about Innovation: Is there a Hidden Potential of Knowledge Exchange between Open Innovation and IMP? IMP Journal, 10(3), 540-560.

Oke, A. (2012). An Investigation of the Relationship between Supply Chain Integration, Flexibility, and Business Performance in Manufacturing Firms. Paper presented at the 17th International Symposium on Inventories, Budapest, Hungary.

Oliver, C. (1990). Determinants of Interorganizational Relationship: Integration and Future Directions. Academy of Management Review, 15(2), 241-265.

Oliver, C. (1991). Strategic Responses to Institutional Processes. Academy of Management Review, 16(1), 145-179.

Oliveros, M.E.G., Halliday, S.V., Posada, M.M.B. (2010). Contradictions and Power Play in Service Encounters: An Activity Theory Approach. Cadernos EBAPE http://www.scielo.br/pdf/cebape/v8n2/v8n2a11.pdf, 8(2), 353-369.

Olsen, P.I., Håkansson, H. (2017). The Roles of Deals and Business Networks in Innovation Processes. IMP Journal, 11(1), 25-50.

Orlikowski, W.J. (2000). Using Technology and Constituting Structures: A Practical Lens for Studying Technology in Organizations. Organization Science, 11(4), 404-428.

Orlikowski, W.J. (2005). Material Works: Exploring the Situated Entanglement of Technological Performativity and Human Agency. Scandinavian Journal of Information Systems, 17(1), 183-186.

Orlikowski, W.J. (2010). The Sociomateriality of Organisational Life: Considering Technology in Management Research. Cambridge Journal of Economics, 34(1), 125-141.

Orlikowski, W.J., Baroudi, J.J. (1991). Studying Information Technology in Organizations: Research Approaches and Assumptions. Information Systems Research, 2(1), 1-28.

Orlikowski, W.J.,Iacono, C.S. (2001). Research Commentary: Desperately Seeking the "IT" in IT Research - A Call to Theorizing the Artifact. Information Systems Research, 12(2), 121 134.

Orlikowski, W.J., Robey, D. (1991). Information Technology and the Structuring of Organizations. Information Systems Research, 2(2), 143-169.

Orlikowski, W., Scott, S.V. (2015). The Algorithm and the Crowd: Considering the Materiality of Service Innovation. MIS Quarterly, 39(1), 201-216.

Oshri, I., Kotlarsky, J.P., Willcocks L., Van Fenema, P.C. (2007). Managing Expertise in IT Outsourcing Relationships. Paper presented at the Information Systems Workshop on Global Sourcing: Services, Knowledge and Innovation, Val d'Isere, France.

Osterwald, A., Pigneur, Y. (2010). Business Model Generation: A Handbook for Visionaries, Game Changers, and Challengers, Hoboken, NJ: Wiley.

Otto, B., Lee, Y.W., Caballero, I. (2011). Information and Data Quality in Networked Business. Electronic Markets, 21(2), 79-81.

Ouchi, W.G. (1980). Markets, Bureaucracies, and Clans. Administrative Science Quarterly, 25(March), 129-141.

Pache, A-C., Santos, FM. (2010). When Worlds Collide: The Internal Dynamics of Organizational Responses to Conflicting Institutional Demands. Academy of Management Review, 35(3), 455-476.

Pagani, M. (2013). Digital Business Strategy and Value Creation: Framing the Dynamic Cycle of Control Points. MIS Quarterly, 37(2), 617-632.

Palm, J., Ramsell, E. (2007). Developing Local Emergency Management by Co-Ordination Between Municipalities in Policy Networks: Experiences from Sweden. Journal of Contingencies and Crisis Management, 15(4), 173-182. 
Panico, C. (2011). On the Contractual Governance of Research Collaborations: Allocating Control and Intellectual Property Rights in the Shadow of Potential Termination. Research Policy, 40(10), 1403-1411.

Parasuraman, A., Zeithaml, V.A., Berry, L. L. (1985). A Conceptual Model of Service Quality and its Implications for Future Research. Journal of Marketing, 49(Fall), 41-50.

Parker, G.G., Van Alstyne, M.W. (2005). Two-Sided Network Effects: A Theory of Information Product Design. Management Science, 51(10), 1494-1504.

Parkhe, A. (1993). Strategic Alliance Structuring: A Game Theoretic and Transaction Cost Examination of Interfirm Cooperation. Academy of Management Journal, 36(4), 794-829.

Parmigiani, A., Rivera-Santos, M. (2011). Clearing a Path Through the Forest: A Meta-Review of Interorganizational Relationships. Journal of Management, 37(4), 1108-1136.

Patel, N.V. (2002). Emergent Forms of IT Governance to Support Global E-Business Models. JITTA: Journal of Information Technology Theory and Application, 4(2), 33.

Pateli, A. (2009). Decision Making on Governance of Strategic Technology Alliances. Management Decisions, 47(2), 246-270.

Paton, R.A., McLaughlin, S. (2008). Services Innovation: Knowledge Transfer and the Supply Chain. European Management Journal, 26(2), 77-83.

Patton, M.Q. (2002). Qualitative Research and Evaluation Methods (3rd ed.). Thousand Oaks, CA: Sage.

Peeters, C., Thienpont, I., Van Hese, C., Djohan, S., Webers, H. (2012). De Nederlandse Maritieme Cluster Monitor 2012. Rotterdam: Stichting Nederland Maritiem Land.

Penrose, E. (1959). The Theory of the Growth of the Firm. Oxford: Oxford University Press.

Pentland, B.T. (1992). Organizing Moves in Software Support Hot Lines. Administrative Science Quarterly, 37(4), 527-548.

Pentland, B.T. (1999). Building Process Theory with Narrative: From Description to Explanation. Academy of Management Review, 24(4), 711-724.

Pentland, B.T. (2007). Narrative Networks: Patterns of Technology and Organization. Organization Science, 18(5), 781-795.

Pentland, B.T. (2015) What Happens Next? An Affordance Network Perspective on Innovation in Routines. EGOS 2015 Conference.

Pentland, B.T., Feldman, D.C., Becker, M.C., Liu, P. (2012). Dynamics of Organizational Routines: A Generative Model. Journal of Management Studies, 49(8), 1484-1508.

Pentland, B.T., Feldman, M.S. (2005). Organizational Routines as a Unit of Analysis. Industrial and Corporate Change, 14(5), 793-815.

Pentland, B.T., Feldman, M.S. (2007). Narrative Networks: Patterns of Technology and Organization. Organization Science, 18(5), 781-795.

Pentland, B.T., Feldman, M.S. (2008). Designing Routines: On the Folly of Designing Artifacts, While Hoping for Pattern of Action. Information and Organization, 18(4), 235-250.

Pentland, B.T., Hærem, T., Hillison, D. (2011). The (N) ever-Changing World: Stability and Change in Organizational Routines. Organization Science, 22(6), 1369-1383.

Perkmann, M., Neely, A., Walsh, K. (2011). How Should Firms Evaluate Success in UniversityIndustry Alliances? A Performance Measurement System. R\&D Management, 41(2), 202216.

Perlow, L.A., Gittell, J.H., Katz, N. (2004). Contextualizing Patterns of Work Group Interaction: Toward a Nested Theory of Structuration. Organization Science, 15(5), 520-536.

Peronard, J.-P. (2014). Managing Inter-Organisational Networks for Customer Value. Paper presented at the PMA Conferenc on Performance Management: Designing the HighPerformance Organization, Aarhus, Denmark.

Pestana, G., Rebelo, I., Duarte, N., Couronné, S. (2012). Adressing Stakeholders Coordination for Airport Efficiency and Decision-Support Requirements. Journal of Aerospace Operations, 1(3), 267-280.

Peterson, H.C. (2013). Fundamental Principles of Managing Multi-Stakeholder Engagement International Food and Agribusiness Management Review, 16(A), 11-22. 
Pettigrew, A.M. (1985). Contextualist Research and the Study of Organizational Change Processes. In E. Lawler (Ed.), Doing Research that is Useful for Theory and Practice. San Francisco: Jossey-Bass.

Pettigrew, A.M. (1987). Context and Action in the Transformation of the Firm. Journal of Management Studies, 24(6), 649-670.

Pettigrew, A.M. (1992). The Character and Significance of Strategy Process Research. Strategic Management Journal, 13(S2), 5-16.

Pfeffer, J., Salancik, G.R. (1978). The External Control of Organizations: A Resource Dependence Perspective. New York: Harper \& Row.

Pieri, N. (2012). Supply Chain Control Towers Offer a Bird's-Eye View. Available from http://www.inboundlogistics.com/cms/article/supply-chain-control-towers-offer-a-birds-eyeview/.

Pilbeam, C., Alvarez, G., Wilson, H. (2012). The Governance of Supply Networks: A Systematic Literature Review. Supply Chain Management: An International Journal, 17(4), 358-376.

Pintelon, L., Pinjala, S.K., Vereecke, A. (2006). Evaluating the Effectiveness of Maintenance Strategies. Journal of Quality in Maintenance Engineering, 12(1), 7-20.

Pishchulov, G., Richter, K., Golesorkhi, S. (2012). A Single Supplier - Single Buyer Bargaining Model with Asymmetric Information and Partial Vertical Integration. Paper presented at the 17th International Symposium on Inventories, Budapest, Hungary.

Pitsis, T.S., Kornberger, M., Clegg, S.R. (2004). The Art of Managing Relationships in Interorganizational Collaboration.M@n@gement (http://www.management-aims.com), 7(3), 47-67.

Pittaway, L., Robertson, M., Munir, K., Denyer, D., Neely, A. (2004). Networking and Innovation: A Systematic Review of the Evidence. International Journal of Management Reviews, 5/ 6 (3\&4), 137-167.

Pollitt, C., Bouckaert, G. (2004). Public Management Reform: A Comparative Analysis (2nd ed.). Oxford: Oxford University Press.

Pongsiri, N. (2002). Regulation and Public-Private Partnerships. International Journal of Public Sector Management, 15(6), 487-495.

Porac, J.F., Ventresca, M.J., Mishina, Y. (2002). Interorganizational Cognition and Interpretation. In: Baum J (ed) The Blackwell Companion to Organizations. Oxford: Blackwell Publishers, 579-598.

Porter, M.E. (1980). Competitive Strategy: techniques for Analyzing Industries and Competition. New York: Free Press.

Porter, M.E. (1985). Competitive Advantage: Creating and Sustaining Superior Performance. New York: Free Press.

Porter, M.E. (1998). Competitive Strategy: Techniques for Analyzing Industries and Competitors. New York: Free Press.

Porter, M.E., Kramer, M.R. (2011). Creating Shared Value. Harvard Business Review (JanuaryFebruary), http://hbr.org/2011/2001/the-big-idea-creating-shared-value.

Powell, W.W. (1996). Trust-Based Forms of Governance. In R. M. Kramer and T.R. Tyler (Eds.), Trust in Organizations: Frontiers of Theory and Research. Thousand Oaks, CA: Sage.

Powell, W.W., Koput, K.W., Smith-Doerr, L. (1996). Interorganizational Collaboration and the Locus of Innovation: Networks and Learning in Biotechnology. Administrative Sceince Quarterly, 41(1), 116-145.

Prahalad, C.K., Hamel, G. (1990). The Core Competence of the Corporation. Harvard Business Review, 68(3), 79-91.

Prahalad, C.K., Ramaswamy, V. (2000). Co-opting Customer Competence. Harvard Business Review, 78(1), 79-88.

Prahalad, C.K., Ramaswamy, V. (2004). The Future of Competition: Co-creating Unique Value with Customers. Boston, MA: Harvard Business School Press. 
Premkumar, G., Ramamurthy, K., Saunders, C.S. (2005). Information Processing View of Organizations: An Exploratory Examination of Fit in the Context of Interorganizational. Relationships. Journal of Management Information Systems, 22(1), 257-294

Priem, R.L. (2007). A Consumer Perspective on Value Creation. Academy of Management Review, 32(1), 219-235.

Priem, R.L., Swink, M. (2007). A Demand-Side Perspective on Supply Chain Management. Journal of Supply Chain Management(April), 7-13.

Provan, K.G. (1984). Interorganizational Cooperation and Decision Making Autonomy in a Consortium Multihospital System. Academy of Management Review, 9(3), 494-504.

Provan, K.G., Fish, A., Sydow, J. (2007). Interorganizational Networks at the Network Level: A Review of the Empirical Literature on Whole Networks. Journal of Management, 33(3), 479-516.

Provan, K.G., Kenis, P.N. (2008). Modes of Network Governance: Structure, Management, and Effectiveness. Journal of Public Administration Research and Theory, 18(2), 229-252.

Provan, K.G., Lemaire, R.H. (2012). Core Concepts and Key Ideas for Understanding Public Sector Organizational Networks: Using Research to Inform Scholarship and Practice. Public Administration Review, 72(5), 638-648.

Provan, K.G., Milward, H.B. (1995). A Preliminary Theory of Interorganizational Network Effectiveness: A Comparative Study of Four Community Mental Health Systems. Administrative Science Quarterly, 40(1), 1-33.

Provan, K.G., Sydow, J. (2008). Evaluating Inter-Organizational Relationships. In: Cropper, S., Ebers, M., Huxham, C., Smith Ring, P. (eds.) The Oxford Handbook of InterOrganizational Relations. Oxford: Oxford University Press.

Pyrko, I., Dörfler, V., Eden, C. (2017). Thinking Together: What Makes Communities of Practice Work? Human Relations, 70(4), 389-409.

Quarantelli, E.L. (2007). Disaster Crisis Management: A Summary of Research Findings. Journal of Management Studies, 25(4), 373-385.

Qureshi, A.M.A., Evans, N. (2015). Deterrents to Knowledge-Sharing in the Pharmaceutical Industry: A Case Study. Journal of Knowledge Management, 19(2), 296-314.

Radaelli, G., Sitton-Kent, L. (2016). Middle Managers and the Translation of New Ideas in Organizations: A Review of Micro-practices and Contingencies. International Journal of Management Reviews, 18(3), 311-332.

Raes, A.M.L., Heijltjes, M.G., Glunk, U., Roe, R.A. (2011). The Interface of the Top Management Team and Middle Managers: A Process Model. Academy of Management Review, 36(1), 102-126.

Rai, A., Tang, X. (2014). Research Commentary. Information Technology-Enabled Business Models: A Conceptual Framework and a Coevolution Perspective for Future Research. Information Systems Research, 25(1), 1-14.

Raisch, S., Birkinshaw, J.n, Probst, G., Tushman, M.L. (2009). Organizational Ambidexterity: Balancing Exploitation and Exploration for Sustained Performance. Organization Science, 20(4), 685-695.

Ranga, M., Etzkowitz, H. (2013). Triple Helix Systems: An Analytical Framework for Innovation Policy and Practice in the Knowledge Society. Industry \& Higher Education, 27(3), 237262.

Ransbotham, S., Kiron, D., Prentice, P.K. (2016). Why Competitive Advantage from Analytics is Declining and What to Do About It. Sloan Management Review, March 8.

Rasmussen, A.F. (2011). "Smart Defence Can Help Nations to Build Greater Security with Fewer Resources but more Coordination and Coherence". European Security and Defence (http://www.europeansecurityanddefence.info/Ausgaben/2011/01_2011/01_Rasmussen/R asmussen.pdf).

Rau, K. (2004). Effective Governance of IT: Design Objectives, Roles, and Relationships. Information Systems Management, 21(4), 35-42. 
Rausser, G., Simon, L., Ameden, H. (2000). Public-Private Alliances in Biotechnology: Can they Narrow the Knowledge Gaps between Rich and Poor? Food Policy, 25(4), 499-513.

Reid, D., Bussiere, D., Greenaway, K. (2001). Alliance Formation Issues for Knowledge-based Enterprises. International Journal of Management Reviews, 3(1), 79-100.

Reuer, J.J. (2004). Strategic Alliances: Theory and Evidence. Oxford: Oxford University Press.

Reuer, J.J., Miller, K.D. (1997). Agency Costs and the Performance Implications of International Joint Venture Internalization. Strategic Management Journal, 18(6), 425-438.

Reypens, C., Lievens, A., Blazevic, V. (2016). Leveraging Value in Multi-stakeholder Innovation Networks: A Process Framework for Value Co-creation and Capture. Industrial Marketing Management, 56(SI), 40-50.

Richardson, H.L. (1998). Pooling with Competitors. Transportation \& Distribution, 39(11), 105110.

Rietjens, S.J.H., Van Fenema, P.C., Essens, P. (2013). 'Train as you Fight' Revisited: Preparing for a Comprehensive Approach. PRISM, http://www.ndu.edu/press/prism.html, 4(2), 17-29.

Rindova, V., Fombrun, C.J. (1999). Constructing Competitive Advantage: The Role of FirmConstituent Interactions. Strategic Management Journal, 20(8), 691-710.

Rindova, V., Petkova, A.P. (2007). When Is a New Thing a Good Thing? Technological Change, Product Form Design, and Perceptions of Value for Product Innovations. Organization Science, 18(2), 217-232.

Ring, P.S., Van de Ven, A.H. (1992). Structuring Cooperative Relationships between Organizations. Strategic Management Journal, 13(7), 483-498.

Ring, P.S., Van de Ven, A.H. (1994). Developmental Processes of Cooperative Interorganizational Relationships. Academy of Management Review, 19(1), 90-118.

Rivera-Santos. (2011). Clearing a Path Through the Forest: A Meta-Review of Interorganizational Relationships. Journal of Management, 37(4), 1108-1136.

Robinson, H. (2016). Dualism. Stanford Encyclopedia of Philosophy, https://stanford.library.sydney.edu.au/entries/dualism/.

Roehrich, J.K., Barlow, H., Wright, S. (2014). Delivering European Health Care Through PublicPrivate Partnerships: The theory and Practice of Contracting and Bundling. In T.K. Das, Managing Public-Private Strategic Alliances. New York: Information Age Publishing Inc.

Rod, F., Spinler, S. (2011). Shared Warehouses - Sharing Risks and Increasing Eco-efficiency. International Commerce Review, 10(1), 22-31.

Roijakkers, N., Bell, J., Fok, J., Vanhaverbeke, W. (2014). Open Innovation through R\&D Partnerships: Implementation Challenges and Routes to Succes. In R. Culpan (Ed.), Open Innovation through Strategic Alliances. New York: Palgrave.

Rokeach, M. (1973). The Nature of Human Values. New York: Free Press.

Rollins, M., Pekkarinen, S., Mehtälä, M. (2011). Inter-firm Customer Knowledge Sharing in Logistics Services: An Empirical Study. International Journal of Physical Distribution \& Logistics Management, 41(10), 956-971.

Romero, D., Galeano, N., Molina, A. (2009). Mechanisms for Assessing and Enhancing Organisations' Readiness for Collaboration in Collaborative Networks. International Journal of Production Research, 47(17), 4691-4710.

Romme, A.G.L., Endenburg, G. (2006). Construction Principles and Design Rules in the Case of Circular Design. Organization Science, 17(2), 287-229.

Rosa, J.A., Porac, J.F., Spanjol, J. (1999). Product Markets as Socio-Cognitive Systems: Theoretical Foundations and Research Propositions. University of Illinois, Office of Research Working Paper No. 99-0121.

Roselle, L. (2010). Strategic Narratives of War: Fear of Entrapment and Abandonment During Protracted Conflict. Paper presented at the American Political Science Associstion 2010.

Ross, J., Weill, P., Robertson, D.C. (2006). Enterprise Architecture as Strategy: Creating a Foundation for Business Execution. Boston, MA: Harvard Business Press.

Rossignoli, C., Ricciardi, F. (2014). Emerging Business Models in B2B Research: Virtual Organization and e-Intermediaries. In C. Rossignoli and F. Ricciardi (Eds.), Inter- 
Organizational Relationships: Towards a Dynamic Model for Understanding Business

Network Performance. Cham, Switzerland: Springer.

Rothenberg, S. (2003). Knowledge Content and Worker Participation in Environmental

Management at NUMMI. Journal of Management Studies, 40(7), 1783-1802.

Rouleau, L. (2005). Micro-practices of Strategic Sensemaking and Sensegiving: How Middle Managers Interpret and Sell Change Every Day. Journal of Management Studies, 42(7), 1413-1441.

Rowley, J. (2007). The Wisdom Hierarchy: Representations of the DIKW Hierarchy. Journal of Information Science, 33(2), 163-180.

Rumelt, R.P., Schendel, D.E., Teece, D. J. (1994). Fundamental Issues in Strategy: A Research Agenda. Boston, MA: Harvard Business School Press.

Russell, J.L., Meredith, J., Childs, J., Stein, M.K., Prine, D.W. (2015). Designing InterOrganizational Networks to Implement Education Reform: An Analysis of State Race to the Top Applications. Educational Evaluation and Policy Analysis, 37(1), 92-112.

Ruuska, I., Ahola, T., Artto, K., Localetti, G., Mancini, M. (2011). A New Governance Approach for Multi-Firm Projects: Lessons from Olkiluoto. International Journal of Project Management, 29(6), 647-660.

Rysman, M. (2009). The Economics of Two-Sided Markets. Journal of Economic Perspectives, 23(3), 125-143.

Saji, B.S., Ellingstad, P. (2016). Social Innovation Model for Business Performance and Innovation. International Journal of Productivity and Performance Management, 65(2), 256-274.

Sako, M. (1992). Prices, Quality and Trust: Inter-firm Relationships in Britain and japan. Cambridge: Cambridge University Press.

Samaddar, S., Nargundkar, S., Daley, M. (2006). Inter-Organizational Information Sharing: The Role of Supply Network Configuration and Partner Goal Congruence. European Journal of Operational Research, 174(2), 744-765.

Sandin, J. (2015). Procuring Industrial Service Solutions: Exploring Enablers for Co-creating Value Procedia CIRP, 30(1), 7-12.

Sarkar, M.B., Aulakh, P.S., Madhok, A. (2009). Process Capabilities and Value Generation in Alliance Portfolios. Organization Science, 20(3), 583-600.

SAS. (2008). Five Steps to Evolving into an Intelligent, High-Performing Enterprise; Where does Your Organization Stand in the Information Evolution Model, and How Do You Get Where You Need to Be? Cary, NC: SAS Institute Inc.

Schäffer, T., Leyh, C. (2016). Master Data Quality in the Era of Digitization - Toward InterOrganizational Master Data Quality in Value Networks: A Problem Identification. In International Conference on Enterprise Resource Planning Systems (99-113). Springer, Cham.

Schakel, J.K., Van Fenema, P.C., Faraj, S. (2016). Shots Fired! Switching Between Practices in Police Work. Organization Science, 27(2), 391-410.

Schaub Jr, G.J., Breitenbauch, H.O. (2012). Connected Forces Military Education : A NATO Market for Staff Courses. Euro-Atlantic Quarterly, 9-10.

Schein, E.H. (1985). Organizational Culture and Leadership (Vol. 2). San Francisco: JosseyBass Publishers.

Schein, E.H. (1990). Organizational Culture. American Psychologist, 45(2), 109-119.

Schemm, J., Legner, C. (2008). Toward the Inter-Organizational Product Information Supply Chain - Evidence from the Retail and Consumer Goods Industries. Journal of the Association for Information Systems, 9(4), 120-152.

Schifrin, M. (2001). Partner or Perish. Forbes(May 21), 26-28.

Schilke, O., Goerzen, A. (2010). Alliance Management Capability: An Investigation of the Construct and Its Measurement. Journal of Management, 36(5), 1192-1219.

Schreier, M. (2015). Qualitative Content Analysis. In U. Flick (Ed.), The SAGE Handbook of Qualitative Data Analysis. Thousand Oaks, CA: Sage. 
Sedláček, T. (2011). Economics of Good and Evil: The Quest for Economic Meaning from Gilgamesh to Wall Street. New York, NY: Oxford University Press.

Segers, J.-P. (2015). The Interplay between New Technology Based Firms, Strategic Alliances and Open Innovation, within a Regional Systems of Innovation Context. The Case of the Biotechnology Cluster in Belgium. Journal of Global Entrepreneurship Research, 5(16).

Shapiro, C. (1989). The Theory of Business Strategy. The RAND Journal of Economics, 22(1), 125-137

Sherbrooke, C.C. (2004). Optimal Inventory Modeling of Systems: Multi-echelon Techniques. New York: Springer.

Shinn, T. (2002). The Triple Helix and New Production of Knowledge: Prepackaged Thinking on Science and Technology Social Studies of Science, 32(4), 599-614.

Shipilov, A. (2012). Strategic Multiplexity. Strategic Organization, 10(3), 215-222.

Shirodkar, S., Kempf, K. (2006). Supply Chain Collaboration Through Shared Capacity Models. Interfaces, 36(5), 420-432.

Shostack, G.L. (1984). Designing Services That Deliver. Harvard Business Review (JanuaryFebruary), 133-139.

Shotter, J. (2006). Understanding Process from Within: An Argument for 'Withness' - Thinking. Organization Studies, 27(4), 585-604.

Sierra, J.J., Heiser, R.S., McQuitty, S. (2009). Exploring Determinants and Effects of Shared Responsibility in Service Exchanges. Journal of Marketing Theory and Practice, 17(2), 111-128.

Sillince, J. (2005). A Contingency Theory of Rhetorical Congruence. Academy of Management Review, 30(3), 608-621.

Sillince, J. (2006). Resources and Organizational Identities: The Role of Rhetoric in the Creation of Competitive Advantage. Management Communication Quarterly, 20(2), 186-212.

Sillince, J., Jarzabkowski, P., Shaw, D. (2012). Shaping Strategic Action Through the Rhetorical Construction and Exploitation of Ambiguity. Organization Science, 23(3), 630-650.

Simmons, G., Palmer, M., Truong, Y. (2013). Inscribing Value on Business Model Innovations: Insights from Industrial Projects Commercializing Disruptive Digital Innovations. Industrial Marketing Management, 42(5), 744-754.

Simon, H.A. (1996). The Sciences of the Artificial (3rd ed.). Cambridge, MA: MIT Press.

Simonin, B.L. (1997). The Importance of Developping Collaborative Know-How: An Empirical Test of the Learning Organization. Academy of Management Journal, 40(5), 1150-1174.

Singleton, R.A. Straits, B.C. (2005). Approaches to Social Research, New York: Oxford University Press.

Sinkovics, R.R., Ghauri, P.N. (2008). Enhancing the Trustworthiness of Qualitative Research in International Business. Management International Review, 48(6), 689-714.

Sirmon, D.G., Hitt, M.A., Ireland, R.D. (2007). Managing Firm Resources in Dynamic Environments to Create Value: Looking Inside the Black Box. Academy of Management Review, 32(1), 273-292.

Sluyts, K, Matthussens, P., Martens, R., Streukers, S. (2012). How to Build Alliance Capability: A Life Cycle Approach. Advances in Applied Business Strategy (173-200). Bingley: Emerald Group Published Limited.

Sminia, H. (2003). The Failure of the Sport7 TV-channel: Controversies in a Business Network. Journal of Management Studies, 40(7), 1621-1649.

Sminia, H. (2015). The Strategic Manager. London: Routledge.

Sminia, H., DeRond, M. (2003). Context and Action in the Transformation of Strategy Scholarship. Journal of Management Studies, 49(7), 1329-1349.

Smith, J.E. (1978). Purpose and Thought. Chicago: University of Chicago Press.

Smith, K.G., Carroll, S.J., Ashford, S. J. (1995). Intra- and Interorganizational Cooperation: Toward a Research Agenda. Academy of Management Journal, 38(1), 7-23.

Smith, K.G., Carroll, S.J., Ashford, S.J. (1995). Intra- and Interorganizational Cooperation: Toward a Research Agenda. Academy of Management Journal, 38(1), 7-23. 
Smith, W.K., Lewis, M. (2011). Toward a Theory of Paradox: A Dynamic Equilibrium Model of Organizing. Academy of Management Review, 36(2), 381-403.

Sobrero, M., Schrader, S. (1998). Structuring Inter-firm Relationships: A Meta-analytic Approach. Organization Studies, 19(4), 585-615.

Soekijad, M., Andriessen, E. (2003). Conditions for Knowledge Sharing in Competative Alliances. European Management Journal, 21(5), 578-587.

Soeters, J.M.M.L., Tresch, T.S. (2010). Towards Cultural Integration in Multinational Peace Operations. Defence Studies, 10(1-2), 272-287.

Solaimani, S., Bouwman, H. (2012). A Framework for the Alignment of Business Model and Business Processes: A Generic Model for Trans-sector Innovation. Business Process Management Journal, 18(4), 655-679.

Sols, A., Romero, J., Cloutier, R. (2012). Performance-Based Logistics and Technology Refreshment Programs: Bridging the Operational-Life Performance Capability Gap in the Spanish F-100 Frigates. Systems Engineering, 15(4), 422-432.

Sonenshein, S. (2010). We're Changing - or Are We? Untangling the Role of Progressive, Regressive, and Stability Narratives Academy of Management Journal, 53(3), 477-512.

Spender, J.C. (1989). Industry Recipes. Oxford: Blackwell.

Spender, J.C. (1996). Making Knowledge the Basis of a Dynamic Theory of the Firm. Strategic Management Journal, 17(Winter), 77-91.

Spender, J.C. (1998). Pluralist Epistemology and the Knowledge-based Theory of the Firm. Organization, 5(2), 233-256.

Spira, L., Page, M. (2003). Risk Management: The Reinvention of Internal Control and the Changing Role of Internal Audit. Accounting, Auditing \& Accountability Journal, 16(4), 640661.

Stabell, C.B., Fjeldstad, O.D. (1998). Configuring Value for Competitive Advantage: On Chains, Shops, and Networks. Strategic Management Journal, 19(5), 413-437.

Stake, R.E. (1995). The Art of Case Study Research. Thousand Oaks, CA: Sage.

Starkey, K., Crane, A. (2003). Toward Green Narrative: Management and the Evolutionary Epic. Academy of Management Review, 28(2), 220-237.

Stemler, S. (2001). An Overview of Content Analysis. Practical Assessment, Research \& Evaluation, 7(17), (http://PAREonline.net/getvn.asp?v=7\&n=17).

Storbacka, K., Brodie, R.J., Bohmann, T., Maglio, P.P., Nenonen, S. (2016). Actor Engagement as a Microfoundation for Value Co-creation. Journal of Business Research, 69(8), 30083017.

Storbacka, K., Nenonen, S. (2011). Scripting Markets: From Value Propositions to Market Propositions Industrial Marketing Management, 40(2), 255-266.

Stuart, T.E. (1998). Network Positions and Propensities to Collaborate: An Investigation of Strategic Alliance Formation in a High-Technology Industry. Administrative Sceince Quarterly, 43, 668-698.

Susini, J.P. (2004). The Determinants of Alliance Performance : Case Study of Renault \& Nissan Alliance. Econ. J. of Hokkaido Univ., 33, 233-262.

Sydow, J., Schmidt, T., Braun, T. (2015). Business Model Change and Network Creation: Evidence from Berlin Start-ups. Academy of Management Annual Meeting. Vancouver, BC.

Tallon, P.P. (2012). Value Chain Linkages and the Spillover Effects of Strategic Information Technology Alignment. Journal of Management Information Systems, 28(3), 9-44.

Tang, L., Shen, Q. (2013). Factors Affecting Effectiveness and Efficiency of Analyzing Stakeholders' Needs at the Briefing Stage of Public Private Partnership Projects. International Journal of Project Management, 31(4), 513-521.

Tantalo, C., Priem, R.L. (2016). Value Creation through Stakeholder Synergy. Strategic Management Journal, 37(2), 314-329.

Taplin, R. (2007). Innovation and Business Partnering in Japan, Europe and the United States. Abington: Routledge. 
Tatham, P. (2013). An Exploration of Trust and Shared Values in UK Defence Supply Networks. International Journal of Physical Distribution \& Logistics Management, 43(2), 148-166.

Tatikonda, M.V., Brown, C.V., Vessey, I. (2005). ERP as a Platform for Vendor Managed Inventory. In E. Bendoly and F. R. Jacobs (Eds.), Strategic ERP Extension and Use. Stanford: Stanford University Press.

Tax, S.S. (2013). The Service Delivery Network (SDN): A Customer-Centric Perspective of the Customer Journey. Journal of Service Research, 16(4), 454-470.

Teece, D.J. (2007). Explicating Dynamic Capabilities: The Nature and Microfoundations of (Sustainable) Enterprise Performance. Strategic Management Journal, 28(13), 1319-1350.

Teece, D.J., Pisano, G., Shuen, A. (1997). Dynamic Capabilities and Strategic Management. Strategic Management Journal, 18(7), 509-533.

Teng, B., Das, T.K. (2008). Governance Structure Choice in Strategic Alliances: The Roles of Alliance Objectives, Alliance Management Experience, and International Partners. Management Decision, 46(5), 725-742.

Ter Wiel, A.A. (2012). Learning to Collaborate: A Qualitative Study of Interorganizational Relationship Management. PhD Dissertation, Free University, Amsterdam.

Thomson, A.M., Perry, J.L. (2006). Collaboration Processes: Inside the Black Box. Public Administration Review, 66(S1), 20-32.

Thornton, R. (1970). Organizational Involvement and Commitment to Organization and Profession. Adminstrative Science Quartely, 26(2), 187-206.

Tikkanen, H., Lamberg, J.-A., Parvinen, P., Kallunki, J.-P. (2005) Managerial Cognition, Action and the Business Model of the Firm. Management Decision, 43(6), 789-809.

Tiwana, A., Konsynski, B., Bush, A.A. (2010). Platform Evolution: Coevolution of Platform Architecture, Governance, and Environmental Dynamics. Information Systems Research, 21(4), 675-687.

Tjemkes, B., Vos, P., Burgers, K. (2012). Strategic Alliance Management. Oxon, UK: Routledge.

Toor, S.R., Ogunlana, S.O. (2010). Beyond the 'Iron Triangle': Stakeholder Perception of Key Performance Indicators (KPI) for Large-Scale Public Sector Development Projects. International Journal of Project Management, 28, 228-236.

Törmälä, M., Gyrd-Jones, R.I. (2017). Development of New B2B Venture Corporate Brand Identity: A Narrative Performance Approach. Industrial Marketing Management Forthcoming.

Trkman, P., McCormack, K., Valadares de Oliveira, M.P., Ladeira, M.B. (2010). The Impact of Business Analytics on Supply Chain Performance. Decision Support Systems, 49(3), 318327.

Tsadikovich, D., Levner, E., Tell, H., Werner, F. (2016). Integrated Demand-Responsive Scheduling of Maintenance and Transportation Operations in Military Supply Chains. International Journal of Production Research, 54(19), 5798-5810.

Tsang, A.H.C. (2002). Strategic Dimensions of Maintenance Management. Journal of Quality in Maintenance Engineering, 8(1), 7-39.

Tsoukas, H. (2005). Complex Knowledge: Studies in Organizational Epistemology. Oxford: Oxford University Press.

Tsoukas, H. (2009). A Dialogical Approach to the Creation of New Knowledge in Organizations. Organization Science, 20(6), 941-957.

Turle, M. (2010). Shared Services: An Outline of Key Contractual Issues. Computer Law \& Security Review, 26(2), 178-184.

Turner, S.F., Rindova, V. (2012). A Balancing Act: How Organizations Pursue Consistency in Routine Functioning in the Face of Ongoing Change. Organization Science, 23(1), 24-46.

Uiterwijk, D.J.W.B., Soeters, J.M.M.L., Van Fenema, P.C. (2013). Aligning National 'Logics' in a European Military Helicopter Program. Defense \& Security Analysis, 29(1), 54-67.

Ukko, J., Pekkola, S., Saunila, M., Rantala, T. (2015). Performance Measurement Approach to Show the Value for the Customer in an Industrial Service Network. International Journal of Business Performance Management, 16(2/3), 214-229. 
Ulbrich, F. (2010). Adopting Shared Services in a Public-sector Organization. Transforming Government: People, Process and Policy, 4(3), 249-265.

USArmy. (2013). Army Materiel Command and Marine Corps Logistics Command Collaborate to Support Joint Warfighter.

http://www.army.mil/article/111869/Army_Materiel_Command_and_Marine_Corps_Logisti cs Command_collaborate to support_joint warfighter/.

Vaara, E. (2003). Post-acquisition Integration as Sensemaking: Glimpses of Ambiguity, Confusion, Hypocrisy, and Politicization. Journal of Management Studies, 40(4), 859-894.

Vaara, E., Kleymann, B., Seristo, H. (2004). Strategies as Discursive Constructions: The Case of Airline Alliances. Journal of Management Studies, 41(1), 1-35.

Vaara, E., Tienari, J., Laurila, J. (2006). Pulp and Paper Fiction: On the Discursive Legitimation of Global Industrial Restructuring. Organization Studies, 27(6), 789-813.

Vaara, E., Whittington, R. (2012). Strategy-as-Practice: Taking Social Practices Seriously. Academy of Management Annals, 6(1), 285-336.

Van Aken, J.E. (2004). Management Research on the Basis of the Design Paradigm: the Quest for Field-tested and Grounded Technological Rules. Journal of Management Studies, 41(2), 219-246.

Van Aken, J.E. (2005). Management Research as a Design Science: Articulating the Research Products of Mode 2 Knowledge Production. British Journal of Management, 16(1), 19-36.

Van Aken, J.E., Chandrasekaran, A., Halman, J.I.M. (2016). Conducting and Publishing Design Science Research: Inaugural Essay of the Design Science Department of the Journal of Operations Management. Journal of Operations Management, 47-48, 1-8.

Van Baalen, P.B., Van Fenema, P.C. (2009). Instantiating Global Crisis Networks: The Case of SARS. Decision Support Systems, 47(4), 277-286.

Van Broek, T., Van Veenstra, A.F. (2015). Modes of Goverance in Inter-Organizational Data Collaborations. ECIS 2015 Completed Research Papers. Paper 188.

Van Bortel, G. (2009). Network Governance in Action: The Case of Groningen Complex Decision-making in Urban Regeneration. Journal of Housing and the Built Environment, 24(2), 167-183.

Vandaie, R. Zaheer, A. (2014). Alliance Partners and Firm Capability: Evidence from the Motion Picture Industry. Organization Science, 26(1), 22-36.

Van den Hoonaard, W.C. (1997). Working with Sensitizing Concepts: Analytical Field Research. Thousand Oaks, CA: Sage.

Van de Ven, A.H. (2005). Running in Packs to Develop Knowledge-Intensive Technologies. MIS Quarterly, 29(2), 365-377.

Van de Ven, A.H., Delbecq, A.L. (1974). A Task Contingent Model of Work-Unit Structure. Administrative Science Quarterly, 183-197.

Van de Ven, A.H., Delbecq, A.L., Koenig Jr, R. (1976). Determinants of Coordination Modes within Organizations. American Sociological Review, 41(April), 322-338.

Van de Ven, A.H., Walker, G. (1984). The Dynamics of Interorganizational Coordination. Administrative Science Quarterly, 29(4), 598-621.

Van der Aalst, W. (2012). Process Mining. Communications of the ACM, 55(8), 76-83.

Van der Lei, T., Herder, P., Wijnia, Y. (2012). Asset Management: The State of the Art in Europe from a Life Cycle Perspective. Dordrecht, Netherlands: Springer.

Van der Vlist, P. (2004). Supply Chain Synchronization: Retailing Beyond ECR. Amsterdam: Deloitte Consumer Business and Retail.

Van Dijk, S., Berends, J.J., Jelinek, M., Romme, A.G.L., Weggeman, M. (2011). MicroInstitutional Affordances and Strategies of Radical Innovation. Organization Studies, 32(11), 1485-1513.

Van Fenema, P.C., Beeres, R. (2010). (Re-)Drawing the Boundaries: Sourcing Operational and Supportive Services in Military Organizations. In J. M. M. L. Soeters, P. C. Van Fenema and R. Beeres (Eds.), Managing Military Organizations: Theory and Practice. London: Routledge. 
Van Fenema, P.C., Keers, B.B.M., Zijm, W.H.M. (2014). Interorganizational Shared Services: Creating Value across Organizational Boundaries. In T. Bondarouk (Ed.), Shared Services as a New Organizational Form. Bingley, UK Emerald.

Van Fenema, P.C., Koeiman, I. (2003). Implementing the 'Supply Chain Synchronization' Concept in the Dutch Retail: Pointers for Successful Inter-Organizational Innovation. Rotterdam: Erasmus University Rotterdam.

Van Fenema, P.C., Loebbecke, C. (2014). Towards a Framework for Managing Strategic Tensions in Dyadic Interorganizational Relationships. Scandinavian Journal of Management, 30(4), 516-524.

Van Fenema, P.C., Soeters, J.M.M.L. (2012). Addressing Cyber Threats: Will Strategic Network Management Do the Job? In F.P.B. Osinga, P. Ducheine and J.M.M.L. Soeters (Eds.), Cyber Warfare: Critical Perspectives. The Hague: TMC Asser/ Springer

Van Ham, H., Koppenjan, J. (2001). Building Public-Private Partnerships: Assessing and Managing Risks in Port Development. Public Management Review, 3(4), 593-616.

Van Heck, E., Vervest, P.H.M. (2007). Smart Business Networks: How the Network Wins. Communications of the ACM, 50(6), 29-37.

Van Horenbeek, A., Buré, J., Cattrysse, D., Pintelon, L., Vansteenwegen, P. (2013). Joint Maintenance and Inventory Optimization Systems: A Review. International Journal of Production Economics, 143(2), 499-508.

Van Horenbeek, A., Van Ostaeyen, J., Pintelon, L. (2012). Maintenance Service Contracts and Business Models: A Review. Paper presented at the Seventeenth International Working Seminar on Production Economics, Innsbruck, Austria.

Van Liere, D.W., Koppius, O.R. (2007). Network Horizon and Obtaining a Favorable Network Position. Communications of the ACM, 50(6), 35-36.

Van Marrewijk, A., Clegg, S.R., Pitsis, T.S., Veenswijk, M. (2008). Managing Public-Private Megaprojects: Paradoxes, Complexity and Project Design. International Journal of Project Management, 26(6), 591-600.

Van Opdorp, H. (2005). The Joint Interagency Coordination Group. Small Wars Journal, 2, 1-12.

Vandaele, D., Rangarajan, D., Gemmel, P., Lievens, A. (2007). How to Govern Business Services Exchanges: Contractual and Relational Issues. International Journal of Management Reviews, 9(3), 237-258.

Vanhaverbeke, W., Cloodt, M. (2006). Open Innovation in Value Networks. In H. Chesbrough, W. Vanhaverbeke and J. West (Eds.), Open Innovation: Researching a New Paradigm. Oxford: Oxford University Press.

Vargo, S.L., Lusch, R.F. (2008). Service Dominant Logic: Continuing the Evolution. Journal of the Academy of Marketing Science, 36(1), 1-10.

Vauterin, J.J., Linnanen, L., Marttila, E. (2012). Value Creation in International Higher Education: The Role of Boundary Spanning in University-Industry Collaboration. International Journal of Quality and Service Sciences, 4(3), 283-298.

Vendrell-Herrero, F., Bustinza, O.F., Parry, G., Georgantzis, N. (2016). Servitization, Digitization and Supply Chain Interdependency. Industrial Marketing Management, 60(SI), 6981.Venkitachalam, K., Willmott, H. (2015). Factors Shaping Organizational Dynamics in Strategic Knowledge Management. Knowledge Management Research and Practice, 13(3), 344-359.

Verdecho, M.-J., Alfaro-Saiz, J.-J., Rodriguez-Rodriguez, R. (2012). Prioritization and Management of Inter-Enterprise Collaborative Performance. Decision Support Systems, 53(1), 142-153.

Vesalainen, J., Hakala, H. (2014). Strategic Capability Architecture: The Role of Network Capability. Industrial Marketing Management, 43(6), 938-950.

Vlaar, P.W.L. (2006). Making Sense of Formalization in Interorganizational Relationships. (PhD), Erasmus Universiteit Rotterdam, Rotterdam. (ISBN-13: 978-90-5892-103-1) 
Vlaar, P.W.L., Van den Bosch, F.A.J., Volberda, H.W. (2006a). Coping with Problems of Understanding in Interorganizational Relationships: Using Formalization as a Means to Make Sense. Organization Studies, 27(11), 1617-1638.

Vlaar, P.W.L., Van den Bosch, F.A.J., Volberda, H.W. (2006b). Towards a Dialectic Perspective on Formalization in Interorganizational Relationships: How Alliance Managers Capitalize on the Duality Inherent in Contracts, Rules and Procedures. Organization Studies, 28(4), 437-466.

Vlaar, P.W.L., Van Fenema, P.C., Tiwari, V. (2008). Cocreating Understanding and Value in Distributed Work: How Members of Onsite and Offshore ISD Vendor Teams Give, Make, Demand and Break Sense. MIS Quarterly, 32(2), 227-255.

Voinov, A., Bousquet, F. (1010). Modelling with Stakeholders. Environmental Modelling \& Software, 25(11), 1267-1488.

Volberda, H.W., Lewin, A.Y. (2003). Co-evolutionary Dynamics within and between Firms: from Evolution to Co-evolution. Journal of Management Studies, 40(8), 2111-2136.

Von Deimling, C., Glas, A., Ekström, T., Essig, M. (2013). Cooperative Purchasing in Defence: Analysis of NATO and EU Initiatives. Paper presented at the IPSERA, Nantes, France.

Von Hippel, E. (1994). "Sticky Information" and the Locus of Problem Solving: Implications for Innovation. Management Science, 40(4), 429-439.

Von Krogh, G., Ichijo, K., Nonaka, I. (2000). Enabling Knowledge Creation : How to Unlock the Mystery of Tacit Knowledge and Release the Power of Innovation: How to Unlock the Mystery of Tacit Knowledge and Release the Power of Innovation. New York: Oxford University Press.

Von Krogh, G., Nonaka, I., Rechtsteiner, L. (2012). Leadership in Organizational Knowledge Creation: A Review and Framework. Journal of Management Studies, 49(1), 240-277.

Vom Brocke, J., Rosemann, M. (2015). Handbook on Business Process Management 1: Introduction, Methods and Information Systems. Heidelberg: Springer.

Voorhoeve, J.J.C. (2010). From War to the Rule of Law: Peacebuilding after Violent Conflicts. Amsterdam: Amsterdam University Press.

Walker, H., Chicksand, D., Radnor, Z., Watson, G. (2015). Theoretical Perspectives in Operations Management: An Analysis of the Literature. International Journal of Operations \& Production Management, 35(8), 1182-1206.

Walker, R.M., Damanpour, F., Devece, C.A. (2011). Management Innovation and Organizational Performance: The Mediating Effect of Performance Management. Journal of Public Administration Research and Theory, 21(2), 367-386.

Waluszewski, A., Håkansson, H. (2007). Economic Use of Knowledge. In A. Waluszewski, H. Håkansson (Eds.), Knowledge and Innovation in Business and Industry: The Importance of Using Others. Abingdon, Oxon: Routledge.

Wang, E.T.G., Wei, H.L. (2007). Interorganizational Governance Value Creation: Coordinating for Information Visibility and Flexibility in Supply Chains. Decision Sciences, 38(4), 647674.

Wareham, J., Fox, P.B., Cano Giner, J.L. (2014). Technology Ecosystem Governance. Organization Science, 25(4), 1195-1215.

Weick, K.E. (1979). The Social Psychology of Organizing, Reading, MA: Addison-Wesley.

Weick, K.E. (1982). Enactment Processes in Organizations. In B.M. Staw, G.R. Salancik (Eds.), New Directions in Organizational Behavior. Malabar, Florida: Robert E. Krieger.

Weick, K.E. (1995). Sensemaking in Organizations. Thousand Oaks, CA: Sage Publications.

Weick, K.E., Sutcliffe, K.M., Obstfeld, D. (2005). Organizing and the Process of Sensemaking. Organization Science, 16(4), 409-421.

Weick, K.E., Westley, F. (1996). Organizational Learning. In: Clegg SR, Hardy C and Nord WR (eds) Handbook of Organization Studies. London: Sage.

Weiller, C., Neely, A. (2013). Business Model Design in an Ecosystem Context. Working paper Cambridge Service Alliance, http://www.cambridgeservicealliance.org(June). 
Wende, K. (2007). Data Governance - Defining Accountabilities for Data Quality Management. Paper presented at the Swiss - Italian Workshop on Information Systems (SIWIS) 2007, St. Gallen, Switzerland.

Weller, S. (2012). Achieving Curriculum Coherence: Curriculum Design and Delivery as Social Practice. In P. Blackmore and C. Kandiko (Eds.), Strategic Curriculum Change in Universities: Global Trends in Universities (Society for Research into Higher Education) (pp. 21-33). Abingdon, Oxon: Routledge.

Werner, M.D., Cornelissen, J.P. (2014). Framing the Change: Switching and Blending Frames and their Role in Instigating Institutional Change. Organization Studies, 35(10), 1449-1472.

Wernerfelt, B. (1984). A Resource-Based Theory of the Firm. Strategic Management Journal, $5(2), 171-180$.

Westley, F.R. (1990). Middle Managers and Strategy: Microdynamics of Inclusion. Strategic Management Journal, 11(5), 337-351.

Whiteman, G., Cooper, W.H. (2011). Ecological Sensemaking. Academy of Management Journal, 54(5), 889-911.

Whitford, J., Zirpoli, F. (2014). Pragmatism, Practice, and the Boundaries of Organization Organization Science, 25(6), 1823-1839.

Whittington, R. (2006). Completing a Practice Turn in Strategy Research. Organization Studies, 27(5), 613-634.

Wikstrom, S., Normann, R. (1994). Knowledge \& Value: A New Perspective on Corporate Transformation, London: Routledge.

Wilding, R. (2012). The Governance of Supply Networks: A Systematic Literature Review. Supply Chain Management: An International Journal, 17(4), 358-376.

Wilkinson, I. F., Young, L.C. . (2002). On Cooperating: Firms, Relations and Networks. Journal of Business Research, 55(2), 123-132.

Williams, P. (2010). Special Agents: The Nature and Role of Boundary Spanners. Paper to the ESRC Research Seminar Series - 'Collaborative Futures: New Insights from Intra and Inter-Sectoral Collaborations', University of Birmingham, Available from http://www.download.bham.ac.uk/govsoc/pdfs/special-agents-paper.pdf.

Williamson, O.E. (1991). Comparative Economic Organization: The Analysis of Discrete Structural Alternatives. Administrative Science Quarterly, 36(2), 269-296.

Williamson, O.E. (1996). The Mechanisms of Governance. Oxford: Oxford University Press.

Williamson, O.E., Ouchi, W.G. (1981). The Markets and Hierarchies Program of Research: Origins, Implications, Prospects. In A.H. Van de Ven and W. F. Joyce (Eds.), Perspectives on Organization Design and Behavior. New York: John Wiley.

Wilson, C. (2007). Network Centric Operations: Background and Oversight Issues for Congress. CRS Report for Congress, Order Code RL32411.

Wolf, J. (2011). Sustainable Supply Chain Management Integration: A Qualitative Analysis of the German Manufacturing Industry. Journal of Business Ethics, 102(2), 221-235.

Wolfswinkel, J.F., Furtmueller, E., Wilderom, C.P.M. (2011). Using Grounded Theory as a Method for Rigorously Reviewing Literature. European Journal of Information Systems, 22(1), 45-55.

Wong, H., Van Oudheusden, D., Cattrysse, D. (2007). Cost Allocation in Spare Parts Inventory Pooling. Transportation Research Part E: Logistics and Transportation Review, 43(4), 370386.

Woywood, M. (2002). Global Management Concepts and Local Adaptations: Working Groups in the French and German Car Manufacturing Industry. Organization Studies, 23(4), 497524.

Wycisk, C., McKelvey, B., Hülsmann, M. (2008). "Smart Parts" Supply Networks as Complex Adaptive Systems: Analysis and Implications. International Journal of Physical Distribution \& Logistics Management, 38(2), 108 - 125.

Wynn, D., Williams, C.K. (2012). Principles for Conducting Critical Realist Case Study Research in Information Systems. MIS Quarterly, 36(3), 787-810. 
Wynstra, F., Spring, M., Schoenherr, T. (2015). Service Triads: A Research Agenda for BuyerSupplier-Customer Triads in Business Services. Journal of Operations Management, 35, 1-20.

Xu, L., Beamon, B.M. (2006). Supply Chain Coordination and Cooperation Mechanisms: An Attribute-Based Approach. Journal of Supply Chain Management, 42(1), 4-12.

Yadav, P., Miller, D.M., Schmidt, C.P. (2003). McGriff Treading Company Implements Service Contracts with Shared Savings. Interfaces, 33(6), 18-29.

Yang, T., Maxwell, T.A. (2011). Information-sharing in Public Organizations: A Literature Review of Interpersonal, Intra-organizational and Inter-Organizational Success Factors. Government Information Quarterly, 28(2), 164-175.

Yao, Y., Evers, P.T., Dresner, M.E. (2007). Supply Chain Integration in Vendor-managed Inventory. Decision Support Systems, 43(2), 663-674.

Yaziji, M., Doh, J. (2009). NGOs and Corporations: Conflict and Collaboration. Cambridge: Cambridge University Press.

Ye, G., Priem, R.L., Alshwer, A.A. (2012). Achieving Demand-Side Synergy from Strategic Diversification: How Combining Mundane Assets Can Leverage Consumer Utilities. Organization Science, 23(1), 207-224.

Yin, R.K. (1989). Research Design Issues in Using the Case Study Method to Study Management Information Systems. In J. I. Cash and P. R. Lawrence (Eds.), The Information Systems Research Challenge: Qualitative Research Methods (Vol. 1). Boston, MA: Harvard Business School.

Yin, R.K. (2003). Case Study Research: Design and Methods. Newbury Park, CA: Sage.

Yin, R.K. (2013). Case Study Research: Design and Methods $\left(5^{\text {th }}\right.$ ed). Newburry Park, CA: Sage Publications.

Yoo, Y., Boland Jr, R.J., Lyytinen, K., Majchrzak, A. (2012). Organizing for Innovation in the Digitized World. Organization Science, 23(5), 1398-1408.

Yoo, Y., Henfridsson, O., Lyytinen, K. (2010). Research Commentary - The New Organizing Logic of Digital Innovation: An Agenda for Information Systems Research. Information Systems Research, 21(4), 724-735.

Zajac, E. J., and Olsen, C. P. (1993). From Transaction Cost to Transactional Value Analysis: Implications for the Study of Inter-Organizational Strategies. Journal of Management Studies, 30(1), 131-145.

Zeng, M., Chen, X. (2003). Achieving Cooperation in Multiparty Alliances: A Social Dilemma Approach to PArtnership Management. Academy of Management Review, 28(4), 587-605.

Zerrillo, P., Raina, R. (1996). A Vertical View of Marketing Networks: A New Entrants Approach. New York: Russell Sage.

Zhang, J., Dawes, S.S. (2006). Expectations and Perceptions of Benefits, Barriers, and Success in Public Sector Knowledge Networks. Public Performance and Management Review, 29(4), 433-466.

Zhang, C., Canning, L., Dubois, L., Vipham, M. (2011). Multi-Stakeholder Engagement for Sustainable Bridge Delivery. Engineering Sustainability, 163(ES3), 197-211.

Zirpoli, F., Errichiello, L., and Whitford, J. (2013). Behavioral Decision-Making and Network Dynamics: A Political Perspective. In I. Giannoccaro (Ed.), Behavioral Issues in Operations Management. London: Springer-Verlag.

Zollo, M., Reuer, J.J., Singh, H. (2002). Interorganizational Routines and Performance in Strategic Alliances. Organization Science, 13(6), 701-713.

Zollo, M., Winter, S.G. (2002). Deliberate Learning and the Evolution of Dynamic Capabilities. Organization Science, 13(3), 339-352.

Zott, C., Amit, R. (2010). Business Model Design: Activity System Perspective. Long Range Planning, 43(2-3), 216-226. 
292 


\section{OBJECTIVE}

This thesis examines the context, process and requirements for developing an alliance strategy to improve company performance. The research is part of a broader research project called MaSeLMA (Maintenance and Service Logistics for Maritime Assets) that seeks to innovate service logistics within the capital-intensive Dutch maritime sector by means of forming strategic alliances.

Earlier studies have shown that the success rate of alliances is low (only $30-50 \%$ ). In literature, alliance performances are, on one hand, explained by means of the structural characteristics of the inter-organisational relationship. For example, alliance success is related to the strategic or cultural synergy between participating organisations, the level of trust and communication, and the balance between power and control. On the other hand, research focuses on the individual organisations to explain differences between successful and unsuccessful organisations in alliance formation. Results indicate the importance of alliance experience and the ability to incorporate alliance knowledge within business management.

Although we recognise the importance of above factors, this thesis assumes that alliance success depends on the extent to which participating organisations are able to develop their capabilities in preparation for the joint effort. The objective of this thesis is to identify principles for organisational development in the sense of improving alliance capability, as well as to gain insight in the close interaction between intra-organisational and inter-organisational performance management. A diverse yet coherent set of theories was explored and integrated as a starting point for empirical research.

\section{METHOD}

Qualitative business research aimed at gaining insight is combined with action research aimed at joint development. Research has been carried out at seven organisations, with an in-depth study of two of these organisations. Discussions were conducted with senior managers and subsequently in-depth interviews were held with various employees experienced in and responsible for the alliance formation process. A collaborative experiment was also used to validate the results. 


\section{RESULTS}

\subsection{CONTEXT}

The first (literature) study, presented in chapter three, examines the circumstances under which a service-oriented alliance strategy can be considered. The conceptual results show that organisations often initiate service alliances (instead of other forms of collaboration) as a costeffective means to gain long-term access to complementary knowledge and skills, with the aim of improving customer value and reducing operating costs. A distinction can be made between vertical, horizontal and hybrid alliances. Because of beneficial synergy, performance improvement can take place that cannot be realized individually. However, the development of formal and relational governance mechanisms is essential to make an alliance successful.

\subsection{PROCESS}

The next four studies described in this thesis are aimed at analysing the process by which a strategic alliance can be realized in an effective manner.

The first two studies are theoretical in nature. Analysis of literature in the area of interorganisational innovation shows that this research domain mainly focuses on understanding and developing interaction processes for the development of a new product or service. The consideration of the strategic content, in other words the strategic motives of the parties involved, has in our view remained underexposed. This thesis reflects on the importance of applying a strong process approach with a focus on strategic content; this enables a better understanding of such content and its development based on pragmatism.

The third study analyses the process by which inter-organisational value creation develops. On the basis of five paradigms, a conceptual model has been designed to describe the dynamic management of inter-organisational value creation involving value architecture and process coordination. On one hand, value architecture consists of value management processes (the strategic logic), governance processes (mechanisms for the control of value creation and distribution), and capacity processes (the operational capacity). On the other hand, process coordination depends on a combination of differentiation and integration efforts.

The other two studies are empirical in nature. The fourth study analyses the influence of stakeholder values on alliance performance at six (public and private) chain organisations, and it provides an instrument for assessing inter-organisational value processes. By means of an alliance success map, it becomes clear that potential partners, despite corresponding objectives, can be in conflict with their 'terminal' (end) and instrumental values that form their motives. An early sign of conflicting values (e.g. transparency / openness in government versus intellectual 
property rights) can be a warning for future tensions that require management attention and action because they affect joint performance.

In the fifth, qualitative case study, the relationship between an organisation and one of its alliances was analysed. On the basis of the employees' strategic narratives regarding the perception of the future of their business, both the organisation and the alliance are investigated on the basis of the process of value creation, required capabilities, and organisational identity. Successively, the relationship between the organisation and the alliance has been clarified on the basis of these three dimensions. The results show that both are of added strategic value to each other, but at the same time also pose a risk to each other. Tensions between the organisation and the alliance may rise in terms of production factors and by differences in social cohesion. The results highlight the relationship between intra- and inter-organisational performance management.

\subsection{REQUIREMENTS}

The sixth study examines the competences and resources that determine the alliance capability of an organisation, and applies thereby a perspective focused on organisational change. The results of the case study indicate that this capability is determined by four interactive skills, namely the ability of an organisation to develop alliance management skills, the presence of an effective information structure, adequate strategic decision-making, and the organisational learning ability. Two methods to be used simultaneously are discussed that can enable development of these skills (a top-down directive, and a bottom-up growth approach). The seventh study examined empirically why an organisation is in some alliance projects more successful than in others. Firstly, on the basis of risk analysis, common alliance formation risks were identified and task areas were mapped. Subsequently, the strategic risk management process was analysed and compared between two alliance projects. The results suggest a difference in risk awareness and control measures taken. In the less successful case, risks were not recognized at an early stage, nor proactively addressed in a structured manner. Timely and structural risk analysis and constant attention by (top) management can help in general to enhance the feasibility of a cooperation plan and improve strategic decision-making in this regard.

Finally, to anticipate on operational collaboration, a better understanding was needed of 'what it takes' to organize data exchange between organisations. The eighth study examines from a process perspective the ability of organisations to implement inter-organisational data governance. The content and process of implementation (challenges) was examined on the basis of two cooperation projects. The study results have led to a conceptual management 
framework showing important management activities for the phase of design and planning, the rollout, and the application and monitoring of inter-organisational data governance.

\section{CONCLUSION}

This thesis has contributed to

- a more integrated understanding of the theories on alliance formation;

- a glance at the scope of alliance performance management by describing the interfaces with supply chain management, innovation management, strategic narratives, organisation change management, risk management, and data governance;

- principles for organisational development aimed at successful alliance management. 


\section{DOELSTELLING}

Dit proefschrift onderzoekt de context, het verloop en de voorwaarden voor het ontwikkelen van een alliantiestrategie om bedrijfsprestaties te verbeteren. Het onderzoek is onderdeel van een breder onderzoeksproject genaamd MaSeLMA (Maintenance and Service Logistics for Maritime Assets), gefinancierd door het TKI Dinalog. Dit project beoogt middels het formeren van allianties service logistieke innovatie te realiseren in de kapitaal en kennisintensieve Nederlandse maritieme sector.

Eerdere studies hebben aangetoond dat de succesgraad van allianties laag ligt (slecht 30-50\%). In de literatuur worden alliantieprestaties enerzijds verklaard aan de hand van de structurele kenmerken van de inter-organisatorische relatie (de relatie tussen organisaties). Zo wordt alliantiesucces in verband gebracht met de strategische of culturele synergie tussen de deelnemende organisaties, de mate van vertrouwen en communicatie, en de balans tussen macht en controle. Anderzijds richt onderzoek zich op de individuele organisaties om het verschil tussen succesvolle en niet succesvolle organisaties te verklaren. Resultaten daarvan tonen het belang aan van alliantie-ervaring en het vermogen om kennis over alliantiemanagement te integreren in de bedrijfsvoering (de alliantiefunctie). Hoewel we het belang van bovenstaande factoren erkennen, gaat dit proefschrift ervan uit dat alliantiesucces afhangt van de vraag in welke mate de deelnemende organisaties in staat zijn zich te ontwikkelen ter voorbereiding op de gezamenlijke inspanning, de alliantiestrategie. Dit onderzoek beoogt principes te identificeren voor organisatorische ontwikkeling ten behoeve van de verbetering van het alliantievermogen, alsmede inzicht te krijgen in de verwevenheid tussen intra-organisatorisch en inter-organisatorisch prestatiemanagement.

\section{METHODE}

Kwalitatief bedrijfskundig onderzoek gericht op inzicht verwerving is gecombineerd met action research gericht op gezamenlijke ontwikkeling. Er is bij zeven organisaties onderzoek uitgevoerd, met een verdiepingsslag bij twee van deze organisaties. Voor dit onderzoek zijn gesprekken gevoerd met senior managers en daarop voortbordurend zijn diepte-interviews gehouden met verschillende werknemers met ervaring en verantwoordelijkheden in het proces van alliantieformatie. Tevens werd gebruik gemaakt van een samenwerkingsexperiment om de resultaten te valideren. Doordat er met name onderzoek is gedaan waarbij bestaande theorie als 
startpunt voor de empirie is gebruikt, kon er binnen verscheidene managementgebieden steeds een gerichte onderzoekfocus worden gehanteerd.

\section{RESULTATEN}

\subsection{CONTEXT}

De eerste (literatuur) studie, gepresenteerd in hoofdstuk drie, onderzoekt de omstandigheden waaronder een op service gerichte alliantie strategie kan worden overwogen. De resultaten tonen aan dat organisaties vaak service-allianties (in plaats van andere samenwerkingsvormen) aangaan als een kosteneffectieve manier om langdurig toegang te krijgen tot complementaire kennis en vaardigheden, met als doel het verhogen van de waarde voor de klant en het reduceren van de bedrijfskosten. Er kan onderscheid worden gemaakt tussen verticale, horizontale, en hybride allianties. Vanwege synergievoordelen kan prestatieverbetering plaatsvinden die niet door de individuele organisaties kunnen worden gerealiseerd. Echter, de ontwikkeling van formele en relationele stuurmechanismen is essentieel om een alliantie succesvol te maken.

\subsection{VERLOOP}

De daarop volgende vier studies die in dit proefschrift worden beschreven, zijn gericht op een analyse van het proces waarmee op een verantwoorde wijze een strategische alliantie kan worden gerealiseerd.

De eerste twee studies zijn theoretisch van aard. Analyse van de literatuur op het gebied van inter-organisatorische innovatie toont aan dat dat onderzoeksdomein met name gericht is op het begrijpen en ontwikkelen van het interactieproces ten behoeve van de ontwikkeling van een nieuw product of nieuwe dienst. De beschouwing van de strategische inhoud, m.a.w. de strategische drijfveren van de betrokkenen, is naar onze mening onderbelicht gebleven. In dit proefschrift wordt gerefelcteerd op het belang van een procesbenadering gericht op inzicht in en het pragmatisch ontwikkelen van de strategische inhoud.

De derde studie analyseert het proces waarlangs inter-organisatorische waarde creatie zich ontwikkelt. Aan de hand van vijf paradigma's is een conceptueel model ontworpen om het dynamisch management van inter-organisatorische waardecreatie te beschrijven. De management architectuur bestaat uit waarde management processen (de strategische logica), bestuurlijke processen (mechanismen voor de besturing van waarde-creatie en -distributie), en capaciteitsprocessen (het operationele vermogen). De procescoördinatie is afhankelijk van een combinatie van differentiatie- en integratie-inspanningen. 
De overige twee studies zijn empirisch van aard. De vierde studie analyseert bij zes (publieke en private) ketenorganisaties de invloed van stakeholderwaarden op alliantie prestaties, en biedt een instrument voor de beoordeling van het inter-organisatorische waardeproces. Door het instrument van een alliantie succesmap wordt duidelijk dat potentiele partners, ondanks overeenstemmende doelstellingen, in conflict kunnen raken met de 'terminale' (eind-) en instrumentele waarden die hun drijfveren vormen. Een vroeg teken van conflicterende waarden (bijvoorbeeld transparantie/ openbaarheid van bestuur versus intellectuele eigendomsrechten) kan een waarschuwing zijn voor aanstaande spanningen die management aandacht en actie vereisen omdat ze de gezamenlijke prestaties beïnvloeden.

In de vijfde, kwalitatieve case studie is de relatie tussen een organisatie en één van haar allianties geanalyseerd. Aan de hand van uitgesproken percepties van werknemers inzake hun visie op de toekomst van de onderneming is in zowel de organisatie als de alliantie onderzoek gedaan naar het proces van waardecreatie, het vermogen van de onderneming dat te realiseren, en de sociale identiteit in de onderneming. Achtereenvolgens is de relatie tussen de organisatie en de alliantie aan de hand van deze drie dimensies verduidelijkt. De resultaten tonen aan dat beiden voor elkaar van toegevoegde strategische waarde zijn maar tegelijkertijd ook een afbreukrisico vormen. Tussen organisatie en alliantie kunnen spanningen optreden op het gebied van productiefactoren en door verschil in sociale cohesie. De resultaten belichten de verwevenheid tussen intra- en inter-organisatorisch prestatiemanagement.

\subsection{VOORWAARDEN}

In de laatste drie studies die in dit proefschrift worden beschreven staat de organisatie als systeem centraal. De zesde studie onderzoekt de competenties en middelen die het alliantievermogen van een organisatie bepalen, en hanteert daarbij een perspectief gericht op de benodigde organisatorische verandering. De resultaten van de case studie vormen een indicatie dat dit vermogen wordt bepaald door vier interactieve bekwaamheden, te weten het vermogen om als organisatie alliantiemanagement vaardigheden te ontwikkelen, de aanwezigheid van een effectieve informatiestructuur, adequate strategische besluitvorming, en het organisatorisch leervermogen. Twee simultaan te hanteren methoden (een top-down directieve en bottom-up groeibenadering) worden besproken waarmee deze bekwaamheden kunnen worden ontwikkeld.

In de zevende studie is empirisch onderzocht waarom een organisatie in sommige alliantie projecten succesvoller is dan in andere. Eerst zijn aan de hand van een risicoanalyse veel voorkomende alliantieformatie risico's benoemd en taakgebieden in kaart gebracht. Vervolgens is in twee alliantieprojecten het strategisch risicomanagement proces geanalyseerd en 
vergeleken. De resultaten suggereren een verschil in risicobewustzijn en genomen beheersmaatregelen. In het minder succesvolle geval werd ogenschijnlijk niet in een vroeg stadium op een gestructureerde wijze bewust en proactief om gegaan met risico's bij alliantiestrategievorming. In plaats daarvan werden risico's en beheersmaatregelen op een enigszins willekeurige wijze geïnventariseerd en toegepast. Tijdige en structurele risicoanalyse en voortdurende aandacht voor de beheersing ervan bij het (top)management kan helpen om de haalbaarheid van het samenwerkingsplan aan te tonen en de strategische besluitvorming te verbeteren.

Tot slot was er als anticipatie op operationele samenwering behoefte aan een beter begrip van wat er nodig is om gegevensuitwisseling tussen organisaties te regelen. De achtste studie onderzoekt vanuit een procesperspectief het vermogen van organisaties om interorganisatorisch gegevensbeheer te implementeren. Aan de hand van twee samenwerkingsprojecten wordt de inhoud en het proces van implementatie onderzocht. De studieresultaten hebben geleid tot een conceptueel management kader met daarin weergegeven belangrijke management activiteiten tijdens de fase van ontwerp en planning, de uitrol en de toepassing en monitoring van het inter-organisatorisch gegevensbeheer.

\section{CONCLUSIE}

Dit proefschrift heeft bijgedragen aan:

- een integraal begrip van de theorieën op het gebied van alliantie vorming;

- een blik op de reikwijdte van alliantie prestatiemanagement door de interfaces te beschrijven met supply chain management, innovatie management, strategische percepties, organisatie verandermanagement in organisaties, risico management, en data governance;

- principes voor organisatieontwikkeling gericht op succesvol alliantie management. 


\section{ACKNOWLEDGEMENTS}

This dissertation would not have been possible without the opportunity given to me by the Royal Netherlands Navy in cooperation with Gordian, in addition to the time, insights, and ideas of many people who where involved in the MaSeLMa project and the numerous respondents with who I had been in contact over the past four years. A special thanks goes out to the delegates from KVSA (i.e. Dhr. F. Vreeburg), Thales Netherlands (i.e. Dhr. E. Dontje), the Royal Netherlands Navy DMI (i.e. Dhr P.F.W. Oerlemans), and SeaMar (i.e. Balkema Sr. and Jr.) for our discussions.

I have very much appreciated the guidance and support of my academic supervisor Professor Paul C. van Fenema. Without his curiosity and encouraging intellectual support to explore the research field, this dissertation would not have developed as smoothly as it did. I hope that we continue to work together in the future. I also want to express my sincere gratitude to Professor W. Henk M. Zijm. You have always critically commented my work and reminded me of the importance to develop academic skills. Next to this, I would like to thank you for the honourable opportunity to defend this dissertation at the University of Twente.

Also, I want to thank Commodore L.H.I. Brummelaar, Commander B.A.M. Pollmann and H.J. Stoelinga for the invaluable trust and room I was given to work as a graduate student. I am grateful for the cooperation with the students, especially Nick van Ommen, Sander Dito, and Lisa van Leeuwen. Dhr. F. Mosk, the dedicated librarian at the Royal Netherlands Academy also deserves a sincere 'thank you!' for his dedication.

Last but not least, I would like to thank my parents who taught me to learn and be ambitious, and to my dearest: "Thank you for your support, interest and scepticism, helping me throughout this PhD-journey!" 
Bianca Keers has been an Officer in the Royal Dutch Navy for seventeen years. Bianca finished the Navy Academy and achieved the degree of Master in Business Administration, Transport, Distribution and Logistics at Free University Amsterdam in 2005 with her thesis on increasing the efficiency of the operational logistics supply chain.

From 2005 untill 2009 she gained extensive operational experiences being deployed to International Stabilization Force Afghanistan (2007, 2011 and 2012) and Eufor/Chad (2009). As a CIMIC-officer she experienced under extreme circumstances first hand what it takes to collaborate with other organizations. Next to this, several deployments as a Logistic PlatoonCommander contributed to her drive and enthusiasm with regards to joint logistic operations. In 2009 she achieved the position of Deputy Chief of Logistics at the Royal Naval Headquarter. She gained responsibility for efficient multi-national and private-public cooperation in operational supply chains for large scale international operations or (amphibious) exercises. Here she proved her forecasting and leadership skills.

Over the last seventeen years, Bianca has shown a consequent strong work ethic and motivation to improve supply chain integration and collaboration between various armed forces regarding transport and distribution of goods. She also became an expert in public-military and public-private cooperation concerning service logistics. In a relatively short period of time she has obtained much theoretical knowledge and practical experience in managing a wide diversity of logistic processes. Combing military professionalism and critical strategic thinking, her ambition, skills and experience made the Navy to invite her to attain a PhD, and work on the Integrated Maintenance and Service Logistics Concepts for the Maritime Assets (MaSeLMa) research project. 
304 
"In every end, there is also a beginning"

(Libba Bray) 


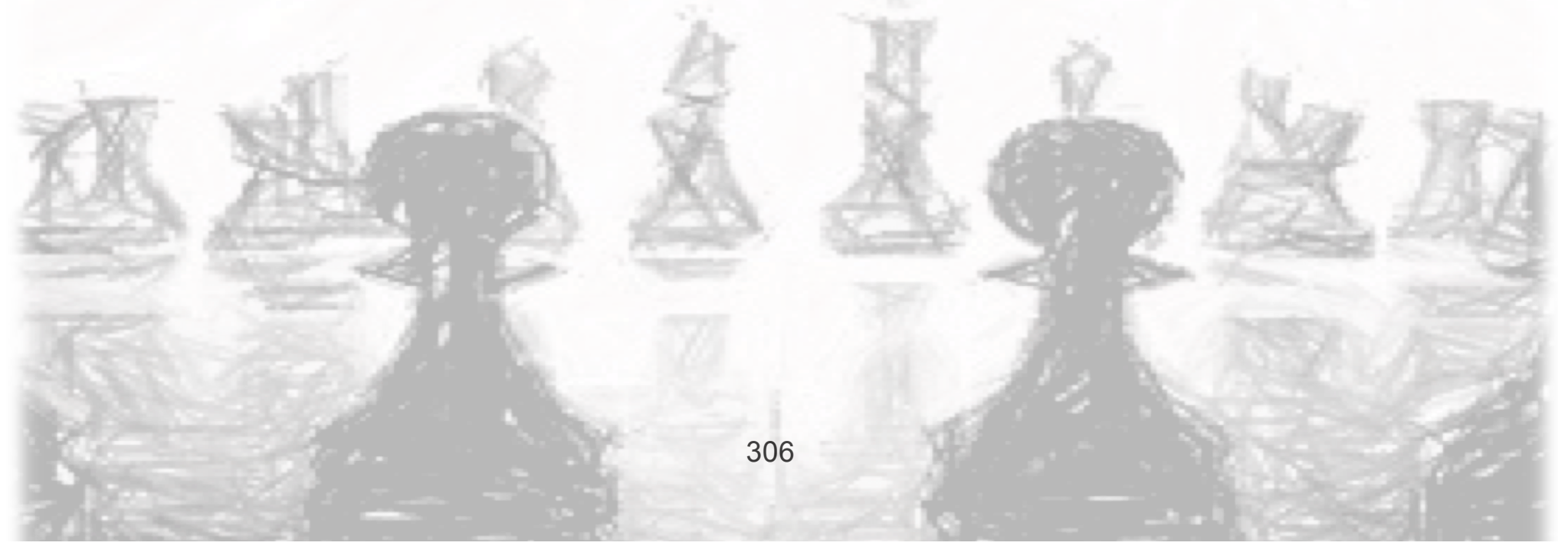




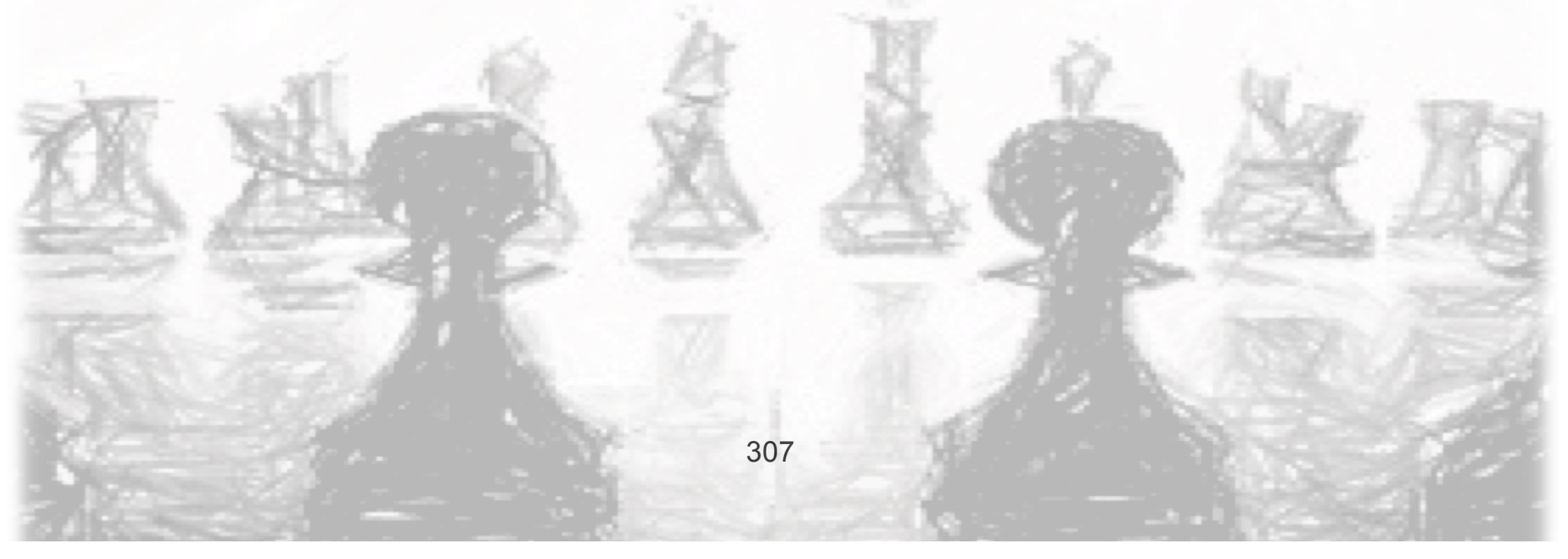

